UNIVERSIDAD POLITÉCNICA DE CARTAGENA

DEPARTAMENTO DE ARQUITECTURA Y TECNOLOGÍAS DE LA EDIFICACIÓN

\title{
CARACTERIZACIÓN Y OPTIMIZACIÓN ELECTROQUÍMICA DE DISPOSITIVOS ELECTROCRÓMICOS DUALES BASADOS EN POLÍMEROS CONDUCTORES
}

D. JAVIER PADILLA MARTÍNEZ 

D. Toribio Fernández Otero, Profesor Doctor del Área de Química-Física en el Departamento de Arquitectura y tecnologías de la Edificación

\section{A U T O R I Z A:}

La presentación de la Tesis Doctoral titulada "CARACTERIZACIÓN Y OPTIMIZACIÓN ELECTROQUÍMICA DE DISPOSITIVOS ELECTROCRÓMICOS DUALES BASADOS EN POLÍMEROS CONDUCTORES", realizada por D. Javier Padilla Martínez, bajo mi dirección y supervisión, en el Departamento de Arquitectura y tecnologías de la Edificación, y que presenta para la obtención del grado de Doctor por la Universidad Politécnica de Cartagena.

En Cartagena, a de de

Fdo.: 

UNIVERSIDAD POLITÉCNICA DE CARTAGENA

Comisión de Doctorado

\section{AUTORIZACIÓN DE LA PRESENTACIÓN DE LA TESIS DOCTORAL} POR EL DEPARTAMENTO RESPONSABLE

D.Vicente Ferrándiz Araujo, Director del Departamento de Arquitectura y Tecnologías de la Edificación

\section{N F O R M A:}

Que la Tesis Doctoral titulada “CARACTERIZACIÓN Y OPTIMIZACIÓN ELECTROQUÍMICA DE DISPOSITIVOS ELECTROCRÓMICOS DUALES BASADOS EN POLÍMEROS CONDUCTORES", ha sido realizada por D. Javier Padilla Martínez, bajo la dirección y supervisión de D.Toribio Fernández Otero y que el Departamento ha dado su conformidad para que sea presentada ante la Comisión de Doctorado.

En Cartagena, a de de

EL/LA DIRECTOR/A DEL DEPARTAMENTO

Fdo.: 

Es de bien nacidos el ser agradecido.

Todas las personas a las que por uno u otro motivo debo mi agradecimiento por su ayuda, paciencia o apoyo de cualquier otra índole, lo han recibido a lo largo de estos años de trabajo.

Va por ustedes! 



\title{
ELECTROCHEMICAL CHARACTERIZATION AND OPTIMIZATION OF DUAL CONDUCTING POLYMER ELECTROCHROMIC DEVICES
}

\begin{abstract}
Variable transmission electrochromic devices are able to modulate, by means of electrical current, light passing through them. Applications such as smart windows in architecture, antireflective rearview mirrors or adaptable vision systems for sport, professional or military use are being developed.

These devices are electrochemical cells, constituted by materials for which oxidation or reduction processes promote reversible colour changes. Among electrochromic materials, organic conducting polymers appear as excellent candidates for the construction of devices, compared with inorganic transition metal oxides, because of their larger versatility of attainable colours, or their easier processing and low cost. A cell configuration in which both electrodes are active and complementary from an electrochromic point of view appears as a good option to improve the devices performance.

The aim of this thesis is to emphasize the existing relations between electrochemical processes, or electrochemical magnitudes, and colour changes. The work is focused on two aspects: individual spectroelectrochemical characterization of the constituent materials followed by an electrochemical and optical study of the performance of the dual system constructed with those materials. The objective is the optimization of both electrochemical and optical processes in dual conducting polymer systems, obtaining
\end{abstract}


experimental methodologies able to characterize, predict, and finally design optimal dual electrochromic devices.

The first part of the study is focused on the development of the proper methodology to obtain an optical characterization of any electrochromic material as a function of its electrochemical properties. Materials used were poly((3,4-ethylenedioxy)thiophene) (PEDOT) and poly-(3,6-bis(2-(3,4-ethylenedioxy)thienyl)-N-methylcarbazole) (PBEDOT-NMCz). PEDOT films are coloured under reduction, while PBEDOT$\mathrm{NMCz}$ are coloured under oxidation, showing complementary colouration, and so they can be used to construct a dual electrochromic device.

Based on the obtained experimental results, a theoretical study was undertaken to establish the optical responses of a system comprising several electrochromic layers. The theoretically obtained relations were experimentally proved. Relations obtained allow the prediction of the maximum contrast configuration for a dual system, as a function of the individual electrochemical properties of each constituent material. The system studied was PEDOT/PBEDOT-NMCz.

The third chapter deals with the proposal and development of a new experimental methodology able to register the individual oxidation states of each electrode during operation of a dual device, obtaining then direct information about device performance. This methodology allows the study of the influence of different physical and chemical variables, like ratio of redox charge between both constituent films, applied potential to the device and initial oxidation state of the constituent polymer films, on the device performance.

The final objective of this work is the construction of electrochromic devices that can be use in real applications out of research or academic contexts. It is necessary then, for 
safety purposes, to use solid electrolytes in the cell. For final applications it is also required to construct devices of appropriate dimensions.

In the fourth chapter, the construction and study of large dimensions and solid state devices for the system PEDOT/ PBEDOT-NMCz was carried out. The information obtained in previous sections was used to determine maximum contrast combinations. Problems related to electrodeposition of conducting polymers on large surfaces (around $30 \mathrm{~cm}^{2}$ ) are discussed, together with the optimization of switching speeds when a solid electrolyte is used. Finally the ability to tune colour states and retain them in the absence of an external potential applied was studied and discussed.

A fast and straightforward assembling method is proposed, consisting of the UV crosslinking of the gel electrolyte.

Finally, an easy and fast electrochemical technique is proposed to evaluate possible defective devices.

As a result of the above mentioned studies, solid state electrochromic devices with an active area of $30 \mathrm{~cm}^{2}$, with $30 \%$ contrast and switching speeds lower than 1 second were constructed.

The last section deals with the study of two new cathodically colouring polymers, poly(3-(Biphenyl-4-ylmethoxymethyl)-3,4-dihydro-2H-thieno(3,4-b)-(1,2)dioxepine)

(BPMOM-ProDOT) and poly-dibenzylProDOT (PDiBz-ProDOT), which have been reported to show larger contrasts than PEDOT. For this reason, dual cells were constructed and checked by combination of these two polymers with PBEDOT-NMCz.

The methodology previously developed and used to characterize PEDOT and PBEDOT-NMCz was applied to these polymers. The developed theoretical equations were used to determine the maximum contrast for both systems. The obtained information was used to construct solid state devices, and it was shown that both 
PDiBz-ProDOT/PBEDOT-NMCz and PBPMOM-ProDOT/PBEDOT-NMCz systems achieve larger contrasts than PEDOT/PBEDOT-NMCz system. The values obtained were $46 \%$ and $52 \%$ for PBPMOM-ProDOT/PBEDOT-NMCz and PDiBz-ProDOT/ PBEDOT-NMCz systems, respectively.

Finally, the use of standard optical magnitudes as photopic values is emphasized. Photopic values are standardized by the Commission Internationale de l'Eclairage (CIE), and correspond to real sensations perceived by the human eye, whose sensitivity is different for each wavelength. In this sense the use of photopic values, instead of values corresponding to a single wavelength, is encouraged. 


\title{
CARACTERIZACIÓN Y OPTIMIZACIÓN ELECTROQUÍMICA DE DISPOSITIVOS ELECTROCRÓMICOS DUALES BASADOS EN POLÍMEROS CONDUCTORES
}

\author{
RESUMEN
}

Los dispositivos electrocrómicos de transmisión variable son capaces de modular la luz que pasa a través suyo, por medio del paso de una corriente eléctrica. Sus aplicaciones más importantes pasan por el diseño de ventanas inteligentes en arquitectura, espejos retrovisores antirreflectantes en automoción o sistemas de visión adaptables para uso deportivo, profesional o militar.

Estos dispositivos son celdas electroquímicas compuestas por materiales para los que los procesos de reducción u oxidación provocan cambios de color: materiales electrocrómicos. Dentro de los materiales con estas características, los polímeros conductores orgánicos se presentan como excelentes candidatos frente a los metales de transición inorgánicos, debido a su gran versatilidad en cuanto a colores alcanzables, facilidad de procesado, y bajo coste. Una configuración de celda en la que los dos electrodos sean activos electrocrómicamente, configuración dual, se presenta como una buena opción de cara a mejorar el rendimiento del dispositivo.

El trabajo desarrollado en esta tesis pretende hacer hincapié en las relaciones existentes entre procesos electroquímicos y cambios de color, sobre la base de dos aspectos: estudio individual de los materiales constituyentes, y estudio del sistema dual. El objetivo es la optimización, tanto de los procesos electroquímicos como ópticos, de sistemas duales de polímeros conductores, obteniendo metodologías experimentales 
capaces de caracterizar, predecir teóricamente, y finalmente diseñar dispositivos electrocrómicos duales óptimos.

La primera parte del estudio se centra en el desarrollo de la metodología precisa para obtener la caracterización óptica de un material electrocrómico en función de sus características electroquímicas, como son la carga redox total consumida durante sus procesos de oxidación o reducción, y la ventana de potencial donde ocurren estos procesos. Los materiales empleados son los polímeros conductores poli-3,4etilendioxitiofeno (PEDOT) y poli-3,6-bis(2-(3,4-etilendioxi)tienil)-N-metilcarbazol (PBEDOT-NMCz). El primero de ellos se colorea mediante la reducción, mientras que el segundo lo hace durante la oxidación, además presentando coloraciones complementarias, por lo que pueden ser utilizados en un dispositivo electrocrómico dual.

En base a los resultados obtenidos, durante la segunda parte se realiza un estudio teórico, junto con su comprobación experimental, sobre las respuestas ópticas resultantes en un sistema que incluya varias capas electrocrómicas. Las relaciones obtenidas permiten predecir la configuración de máximo contraste para un sistema dual, en función de las características electroquímicas de cada componente individual. El sistema dual estudiado es PEDOT / PBEDOT-NMCz.

En una tercera sección, se propone y desarrolla una metodología experimental capaz de registrar los estados de oxidación individuales en cada electrodo durante el funcionamiento de un dispositivo dual, obteniendo una información directa sobre el rendimiento del dispositivo. Esto permite el estudio de la influencia que varias variables, como son el ratio de carga redox entre las dos películas constituyentes, el potencial aplicado al dispositivo, y el estado de oxidación inicial de los polímeros, tienen sobre el rendimiento del dispositivo. 
El objetivo final es la construcción de dispositivos electrocrómicos que puedan ser empleados fuera del ámbito académico. Para ello, y por motivos de seguridad para el usuario final, es necesario utilizar medios electrolíticos sólidos en la celda. Asimismo, es necesario fabricar dispositivos de unas dimensiones adecuadas.

En la siguiente sección, se estudia la construcción de este tipo de dispositivos para el sistema PEDOT/PBEDOT-NMCz. La información obtenida en las secciones anteriores se utiliza para determinar las combinaciones con el máximo contraste posible. Se discuten problemas relativos a la deposición de polímeros en grandes superficies (alrededor de $30 \mathrm{~cm}^{2}$ ), la optimización de la velocidad de cambio de color cuando se utiliza un medio sólido, así como la capacidad de ajuste y retención del color en ausencia de potencial aplicado.

Se propone un método de ensamblado fácil y rápido consistente en la solidificación del gel por curado ultravioleta.

Por último, se propone una técnica electroquímica sencilla y rápida para detectar posibles dispositivos defectuosos.

Los dispositivos electrocrómicos construidos presentan una superficie activa de $30 \mathrm{~cm}^{2}$, con un contraste de $30 \%$ y con una velocidad de cambio de color menor de $1 \mathrm{~s}$.

La última sección incorpora el estudio de dos nuevos polímeros, poli-dibencil-ProDOT (PDiBz-ProDOT) y poli-bifenilmetiloximetil-ProDOT (PBPMOM-ProDOT), coloreables catódicamente y que individualmente presentan mayores contrastes que el PEDOT. Por esta razón, se estudia el efecto de la sustitución de éste por los dos nuevos polímeros en sistemas duales con el PBEDOT-NMCz.

Para ello se repiten las caracterizaciones individuales con la metodología utilizada para el sistema PEDOT/PBEDOT-NMCz. Asimismo, se realiza el estudio teórico para calcular el máximo contraste de cada sistema. Con la información obtenida se 
construyen dispositivos en estado sólido, y se comprueba que los dos sistemas PDiBzProDOT/ PBEDOT-NMCz y PBPMOM-ProDOT/PBEDOT-NMCz presentan mayores contrastes que el sistema PEDOT/PBEDOT-NMCz. Los valores obtenidos son 46 y 52 $\%$ para los sistemas PBPMOM-ProDOT/PBEDOT-NMCz y PDiBz-ProDOT/ PBEDOT-NMCz, respectivamente.

Por último, durante todo el estudio se propone la utilización de magnitudes ópticas comparables para cualquier estudio electrocrómico. Para ello, se propone la utilización de valores fotópicos, en sustitución a los valores descritos en una sola longitud de onda. Las medidas fotópicas están estandarizadas por la Commission Internationale de l'Eclairage (CIE), y se corresponden con las sensaciones reales que percibe el ojo humano, cuya sensibilidad es diferente para cada longitud de onda. 


\section{Tabla de contenidos}





\section{Tabla de contenidos}

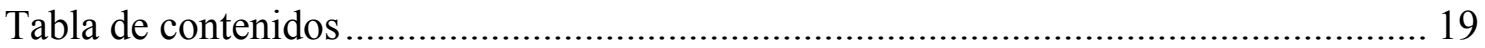

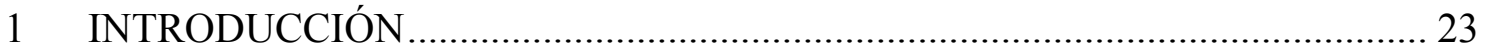

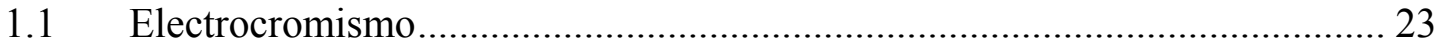

1.2 Dispositivos electrocrómicos como celdas electroquímicas. Sistemas duales y

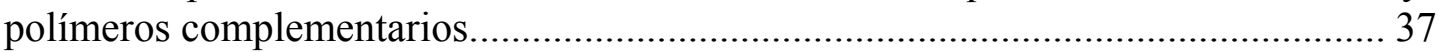

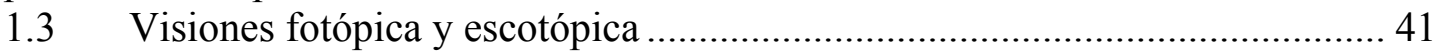

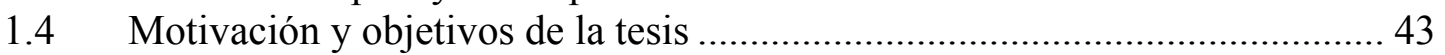

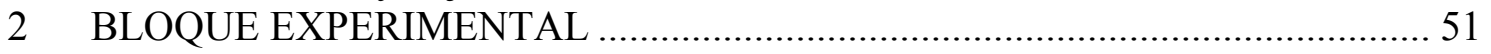

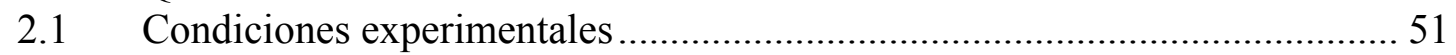

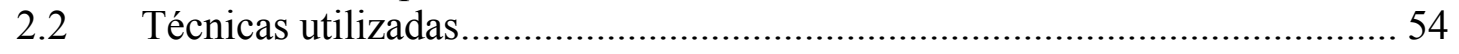

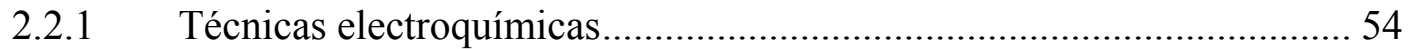

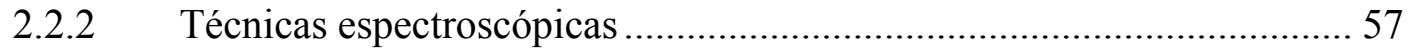

2.3 Construcción de dispositivos electrocrómicos en estado sólido..................... 59

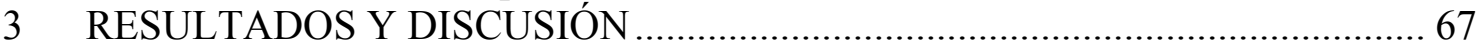

3.1 ESTUDIO ESPECTROELECTROQUIMICO DE POLÍMEROS

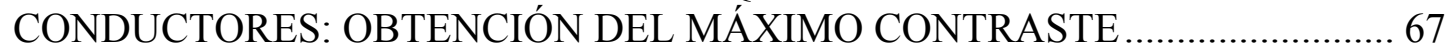

3.1.1 Estudio espectroelectroquímico de los polímeros usados ......................69 69

3.1.2 Consideraciones preliminares en electropolimerización de polímeros

conductores. Efecto del potencial de polimerización.............................................. 74

3.1.2.1 Electropolimerización sobre ITO. Consideraciones generales........... 81

3.1.2.2 Efecto de la desoxigenación en la eficiencia culómbica ................... 83

3.1.3 Variación de la transmitancia en función de la carga redox. Obtención

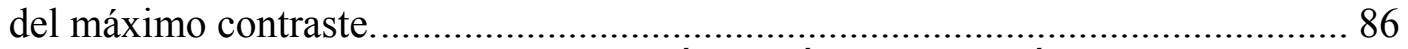

3.2 SISTEMAS DUALES. OBTENCIÓN TEÓRICA Y PRÁCTICA DEL

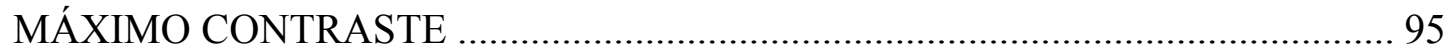

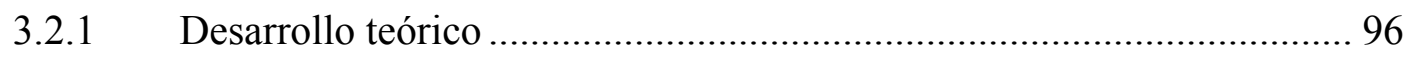

3.2.1.1 Efecto de la inclusión de capas absorbentes en el contraste de

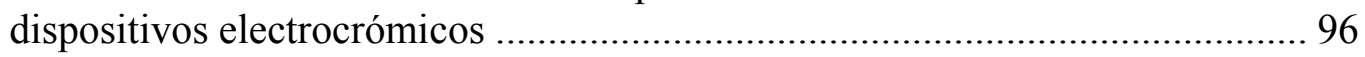

3.2.1.1.1 Efecto de la inclusión de una capa de absorbancia constante en el contraste de un sistema electrocrómico .................................................... 100

3.2.1.1.2 Efecto de la inclusión de una capa de absorbancia variable adicional en el contraste de un sistema electrocrómico.............................. 104

3.2.1.1.3 Sistemas electrocrómicos duales. Contribución de dos capas electrocrómicas al contraste del sistema................................................ 107

3.2.1.2 Obtención teórica del máximo contraste en sistemas duales............ 108

3.2.1.2.1 Criterio electroquímico.......................................................... 108

3.2.1.2.2 Criterio óptico................................................................. 110

3.2.2 Obtención experimental del máximo contraste en sistemas duales

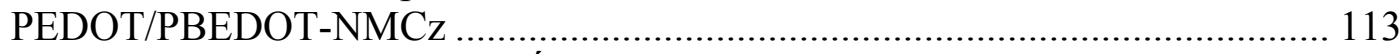

3.3 ESTUDIO ELECTROQUÍMICO DE SISTEMAS DUALES. FACTORES

INVOLUCRADOS EN UN FUNCIONAMIENTO CORRECTO ......................... 119

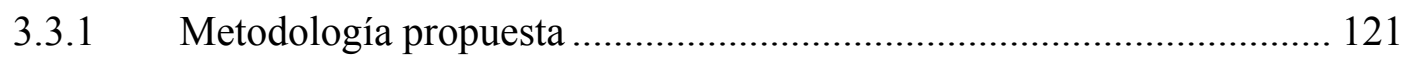

3.3.1.1 Caracterización individual de los materiales. Ventana de potencial

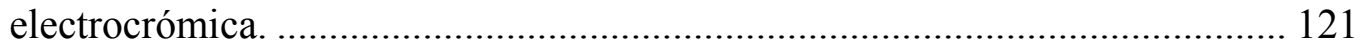

3.3.1.2 Caracterización de sistemas duales. Carga consumida útil y no útil. 121 
3.3.2 Aplicación de la metodología propuesta .............................................. 124

3.3.2.1 Distribución de potenciales en sistemas de un solo polímero .......... 124

3.3.2.2 Estudio de las variables de funcionamiento de dispositivos poliméricos duales 126

3.3.2.2.1 Efecto de los límites de potencial aplicados ............................. 126

3.3.2.2.2 Influencia de la relación de carga electrocrómica entre los electrodos consituyentes ...................................................................... 128

3.3.2.2.3 Influencia del estado de oxidación inicial ................................ 131

3.4 DISPOSITIVOS EN ESTADO SÓLIDO. VENTANAS INTELIGENTES.

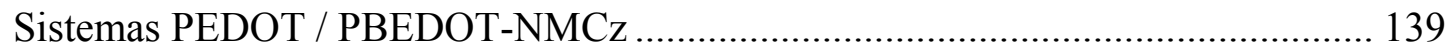

3.4.1 Procesos de electropolimerización en superficies grandes de ITO ...... 140

3.4.2 Contraste fotópico en los dispositivos EC ensamblados ...................... 141

3.4.3 Potenciales de funcionamiento de los dispositivos en estado sólido.... 144

3.4.4 Optimización de la velocidad de respuesta............................................ 148

3.4.5 Corrientes de pérdida y memoria de los dispositivos ........................... 152

3.5 SISTEMAS DUALES DE CONTRASTE AUMENTADO. Sistemas

PBPMOM-ProDOT//PBEDOT-NMCz y PDiBz-PRODOT//PBEDOT-NMCz ...... 157

3.5.1 Caracterización optoelectroquímica individual de PBPMOM-ProDOT y

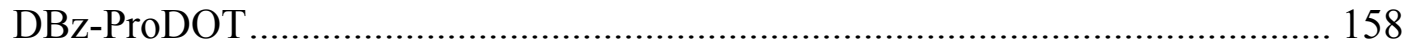

3.5.2 Combinaciones duales. Valores teóricos de contraste........................... 163

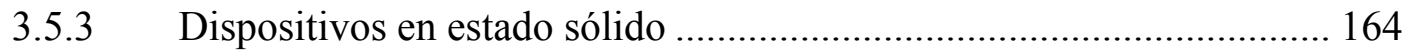

3.5.4 Contraste en los dispositivos .......................................................... 164

3.5.5 Potenciales de funcionamiento de los dispositivos ............................. 166

3.5.6 Velocidad de respuesta y memoria en circuito abierto.......................... 169

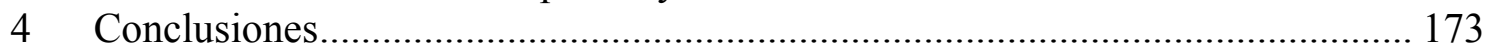

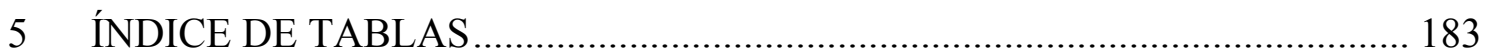

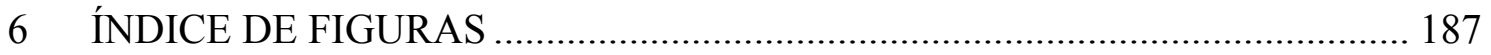

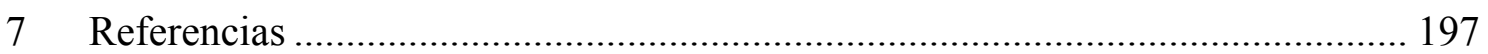




\section{Introducción}





\section{INTRODUCCIÓN}

\subsection{Electrocromismo}

El color, como la Real Academia de la Lengua define en dos de sus acepciones, es la "sensación producida por los rayos luminosos que impresionan los órganos visuales y que depende de la longitud de onda" y la "propiedad de la luz transmitida, reflejada o emitida por un objeto, que depende de su longitud de onda". Es, por lo tanto, una percepción subjetiva de un fenómeno físico objetivo. Dentro del espectro de radiación electromagnética, el ojo humano es sensible al rango de longitudes de onda entre 350 y $850 \mathrm{~nm}$., lo que llamamos espectro visible. Cuando un haz de luz incide sobre un material, ciertas longitudes de onda son absorbidas y otras reflejadas; si ninguna de las longitudes de onda absorbidas está dentro del rango del visible, no percibimos ningún cambio y el material nos resulta transparente, mientras que si se producen absorciones dentro del rango visible, se genera la sensación de color. La absorción está determinada por la configuración electrónica del material, concepto que será tratado con más profundidad más adelante. El color que de una determinada sustancia química percibimos es el resultado de las longitudes de onda que no son absorbidas.

El electrocromismo está definido como la capacidad de un material para cambiar reversiblemente su color mediante una reacción electroquímica de oxidación o reducción provocada por la aplicación de un potencial [1]. La aplicación de un determinado potencial eléctrico produce la extracción ó inserción de electrones (oxidación ó reducción del material), modificando la estructura electrónica del material, generando nuevos niveles electrónicos ocupados y desocupados, lo que permite que 
aquellas longitudes de onda cuya energía coincide con la diferencia entre un nivel electrónico ocupado y uno desocupado sean absorbidas, provocando las correspondientes transiciones electrónicas, y por lo tanto, modificando el color del material.

Las posibles aplicaciones para materiales con estas características comprenden cualquier dispositivo de creación de imágenes, dinámicas o estáticas, y la modulación del color en sistemas de visión. En el campo de la creación de imagen existen tecnologías maduras, como pueden ser la generación en tubo de rayos catódicos, el empleo de cristales líquidos y plasma, o incluso la más reciente utilización de diodos emisores de luz, inorgánicos, u orgánicos (con desarrollo de pantallas flexibles) frente a las cuales la tecnología electrocrómica aún no es capaz de competir. Sin embargo, las aportaciones del electrocromismo en el campo de la modulación de color en dispositivos ópticos, hasta ahora controlados por sistemas lentos o con poca capacidad de control por parte del usuario final, como pueden ser el termocromismo ó fotocromismo, son muy significativas.

Es en este campo, y concretamente en los denominados dispositivos de transmisión variable, donde se han venido realizando mayores esfuerzos de investigación pública y privada [2-7]. Ventanas capaces de modular la intensidad de luz que los atraviesa, permitiendo la creación de espacios habitables de iluminación controlada (ventanas inteligentes), espejos retrovisores capaces de modificar la absorción de destellos provenientes de otros vehículos, o lentes capaces de modular su color permitiendo en todo momento el confort visual del usuario, tanto en actividades deportivas, como laborales o militares, vienen siendo desarrollados con éxito basándose en este concepto $[6,8,9]$. 


\section{Electrocromismo de transmisión variable}

La definición más amplia de un dispositivo electrocrómico es la de un dispositivo capaz de controlar mediante una o varias reacciones electroquímicas reversibles la cantidad de luz que pasa a su través en diferentes rangos de longitudes de onda. La carga consumida en las reacciones electroquímicas modifica los estados electrónicos, y por lo tanto la probabilidad de absorción (o transmisión) a lo largo del espectro electromagnético. Habitualmente se denomina dispositivo electrocrómico al que presenta cambios de absorción perceptibles por el ojo humano [1]. Esta concepción, incorrecta en términos estrictos, deberá ampliarse en un futuro próximo, puesto que se están desarrollando dispositivos capaces de modular su absorción en el rango infrarrojo o ultravioleta [10-13]. La extensión de la absorción a nuevas longitudes de onda permitirá desarrollar aplicaciones en el campo de la protección antirradar o escudos frente a radiación electromagnética (ondas de radio y de telecomunicaciones).

Los dispositivos de transmisión variable se encuentran en un punto intermedio entre estos dos grupos. Son dispositivos concebidos para permitir la variación controlada de la absorción entre un estado, generalmente lo mas transparente posible, y diversos estados de absorción creciente. Los requerimientos en cuanto a variación óptica del dispositivo dependerán de la aplicación deseada; visores, gafas o espejos retrovisores antirreflectantes necesitarán una disminución de la transmisión hasta el nivel deseado, pero permitiendo en todo momento la visión a través de ellos, mientras que para ventanas inteligentes integradas en edificios, automóviles o invernaderos, puede ser deseable un estado completamente absorbente, por razones de privacidad o de ahorro energético. 
a)

b)
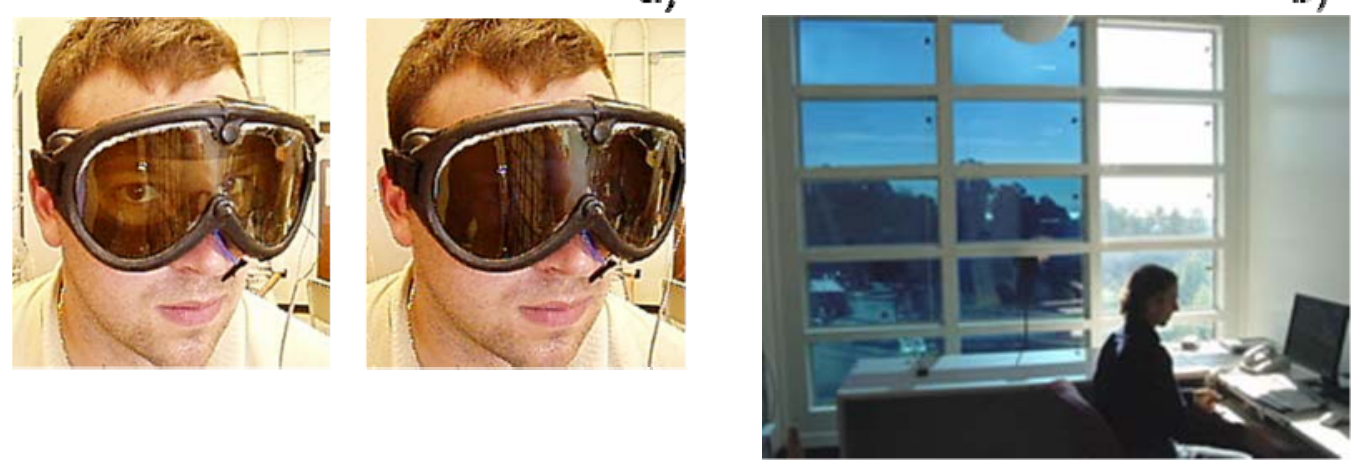

Figura 1.1.1 a) Dispositivo electrocrómico de transmisión variable integrado en un sistema de visión desarrollado por los grupos del Pr. G.A. Sotzing (Institute of Materials Science, UCONN) y Pr. T.F. Otero (Centro de Electroquímica y Materiales Inteligentes, UPCT) b) Ventana inteligente desarrollada por la compañía Smartglass.

El interés generado por este tipo de dispositivos en el campo de la domótica y la arquitectura ecológica proviene de la capacidad de control del estado de iluminación de los habitáculos así como de su mejora en el rendimiento energético de la construcción. Algunos estudios estiman que el uso de ventanas electrocrómicas en edificios podría representar un ahorro energético de entre el 30-40 \% en refrigeración [14].

La capacidad de absorción de un material se cuantifica a través de la absorbancia, magnitud definida para una determinada longitud de onda como

$\mathrm{A}=-\log \left(\mathrm{I}_{\mathrm{f}} / \mathrm{I}_{\mathrm{i}}\right)$

Siendo $\mathrm{I}_{\mathrm{i}}$ la intensidad de la radiación electromagnética con la longitud de onda considerada, que incide sobre el material, $\mathrm{y}_{\mathrm{f}}$ la intensidad de esa radiación después de atravesarlo, como se muestra en el esquema siguiente. 


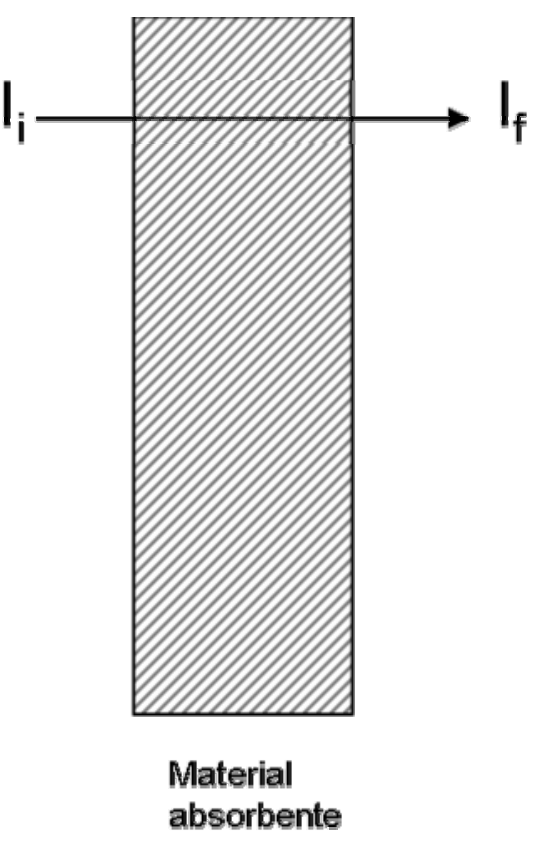

Figura 1.1.2 Esquema utilizado para la definición de absorbancia de un material. Una radiación electromagnética de intensidad inicial $\mathrm{I}_{\mathrm{i}}$ incide sobre el material. Una vez atravesado, la intensidad resultante disminuye hasta un valor de $I_{\mathrm{f}}$. La absorbancia del material, $A$, se define como $A=-\log \left(I_{f} / I_{i}\right)$.

Por lo tanto los materiales que sean candidatos para su utilización en dispositivos de transmisión variable deberán tener la capacidad de variar desde un estado de absorbancia significativa (bien sea en estado oxidado o reducido) dentro del rango del visible, hasta otro cuya absorbancia dentro de este rango sea lo mínima posible.

\section{Materiales electrocrómicos}

Dos tipos de materiales han sido utilizados mayoritariamente en aplicaciones electrocrómicas: los óxidos de metales de transición (inorgánicos) y los polímeros conductores (orgánicos). Entre los primeros destacan por su uso mayoritario el trióxido de Wolframio $\left(\mathrm{WO}_{3}\right)[3,9,15,16]$ ó el pentóxido de Vanadio $\left(\mathrm{V}_{2} \mathrm{O}_{5}\right)$ [17-20]. Las limitaciones de estos sistemas vienen motivadas por las velocidades de cambio de color, 
los altos potenciales necesarios para completar el proceso de cambio de color, y las dificultades en el procesamiento y deposición de los materiales. Las ventajas que presentan los polímeros conductores frente a estos materiales inorgánicos son una amplia capacidad de ajuste del color, facilidad de procesado y deposición, funcionamiento a bajos potenciales y una extraordinaria capacidad de modificación de las estructuras químicas [2], generando un abanico de posibilidades en el cambio de color ajustable a cada necesidad concreta y en constante actualización.

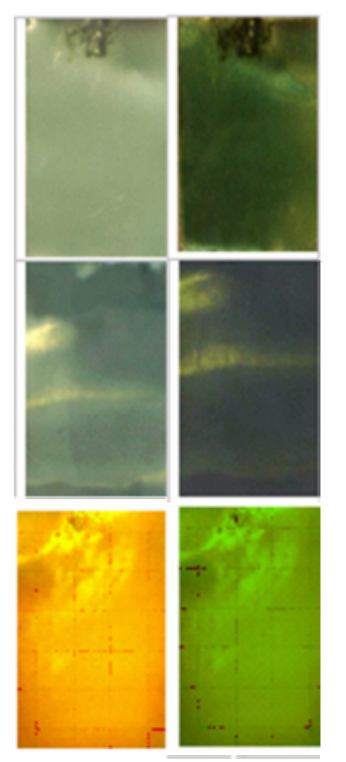

\section{a) polianilina}

b) polimetilanilina

c) polipirrol
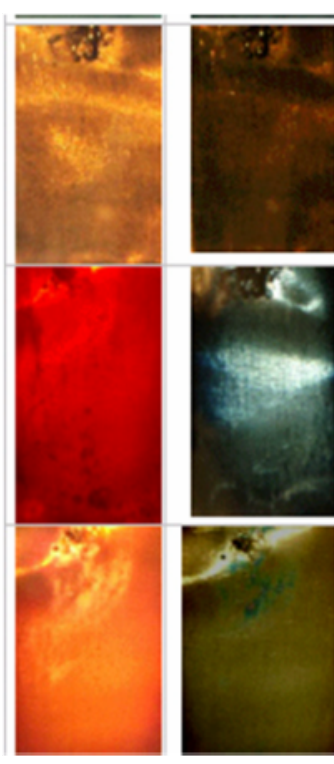

d) poli3-metilpirrol

e) poli3-metilitiofeno

f) politiofeno

Figura 1.1.3 Estados electrocrómicos de distintos tipos de polímeros conductores: a) polianilina b) polimetilanilina c) polipirrol d) poli-3-metilpirrol e) poli-3-metiltiofeno y f) politiofeno. Para cada polímero, la figura izquierda representa el estado neutro, y la derecha el oxidado [21].

Asimismo, las propiedades mecánicas de los polímeros pueden permitir la creación de nuevas generaciones de dispositivos flexibles. Recientemente, Reynolds et al. describieron la construcción del primer dispositivo electrocrómico completamente plástico, constituyendo una primera prueba de su posible aplicación [22].

\section{Polímeros conductores}


La característica principal de los polímeros conductores es la existencia de enlaces de carbono-carbono simples y dobles alternados a lo largo de las cadenas poliméricas. La figura siguiente muestra la estructura química de algunos de los polímeros conductores más conocidos.

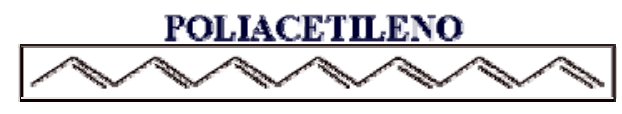

POLIANILINA

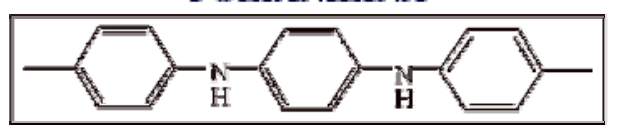

POLIPIRROL

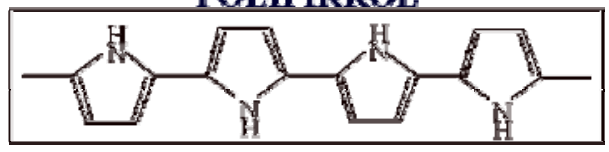

POLITIOFENO

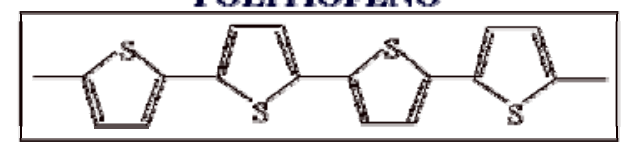

Figura 1.1.4 Estructura química de varios polímeros conductores: poliacetileno, polianilina, polipirrol y politiofeno

La configuración de los enlaces moleculares carbono-carbono dobles a lo largo de las cadenas está formada por enlaces tipo sigma, enlaces muy estables, energéticamente hablando, en los que los electrones están muy localizados y enlaces de tipo pi, menos fuertes que los sigma. La cadena polimérica, formada por $\mathrm{n}$ átomos de carbono, puede ser tratada, desde un punto de vista teórico, mediante la teoría de bandas propia de los metales. Los electrones de la cadena neutra quedan localizados en la banda de valencia, que está separada de la de conducción, vacía de electrones; la energía que necesitaría un electrón para moverse libremente se sitúa en torno a los $3 \mathrm{eV}$. En términos de conducción eléctrica, los materiales se dividen en conductores, semiconductores y aislantes. Considerando que para los metales esta diferencia de energía entre la banda de valencia y de conducción es cero, para los semiconductores se sitúa alrededor de 1-1.5 $\mathrm{eV}$, y para los aislantes sería superior a $5 \mathrm{eV}$, el comportamiento eléctrico de los 
polímeros conductores en estado neutro tiene cierta similitud con las características de los semiconductores, del que han asimilado gran parte de la terminología [23]. A pesar de no contar con una estructura cristalina, los niveles energéticos que son accesibles para los electrones en una cadena polimérica pueden ser representados mediante diagramas de bandas, análogos al caso de semiconductores inorgánicos tradicionales, definiendo de esta manera un gap energético entre la banda de valencia y de conducción. El proceso de "dopado" se genera por la inserción de átomos ajenos en la estructura cristalina en el caso de semiconductores inorgánicos. En las cadenas poliméricas conductoras, es la oxidación o reducción del material lo que permite la creación de niveles energéticos intermedios dentro del gap de energía, que modifican las propiedades del material, permitiendo la conducción eléctrica. Centrándonos exclusivamente en las propiedades ópticas, el rango de radiación que es absorbida por el material en estado neutro viene determinado por el valor de dicho gap energético. El efecto del dopado (oxidación electroquímica en el caso de polímeros conductores) es el de crear estados intermedios de energía accesibles, reduciendo la energía necesaria (o lo que es lo mismo aumentando la longitud de onda, en el caso de radiación electromagnética, recordemos que $\mathrm{E}=\mathrm{hc} / \lambda^{1}$ ) para que una determinada radiación pueda ser absorbida, es decir, desplazando el rango de absorción hacia longitudes de onda mayores.

La creación de estos nuevos niveles energéticos viene motivada por el proceso de oxidación, lo que en términos energéticos significa que los electrones han sido extraídos de la banda de valencia hacia un nivel energético mayor. Cada vez que un electrón es extraído de la banda de valencia, se crea una vacante (en términos físicos), o radical catión (en términos químicos), pero no se deslocaliza completamente. Se produce una

\footnotetext{
. ${ }^{1} \mathrm{E}=$ Energía, $\mathrm{h}=$ Constante de Planck,c=Velocidad de la luz, $\lambda=$ Longitud de onda
} 
deslocalización parcial a lo largo de varias unidades monoméricas, y éstas se deforman estructuralmente. Los niveles energéticos asociados con el radical catión representan orbitales de enlace desestabilizados, y por lo tanto su energía es mayor que la de la banda de valencia, es decir, se sitúan dentro del gap energético. Un catión radical que está parcialmente deslocalizado a lo largo de un segmento polimérico se llama polarón, y tiene un spin $1 / 2$. A su vez, un mayor nivel de oxidación del material puede crear dicationes, y los consiguientes bipolarones los cuales tienen dos cargas asociadas y spin 0 [24]. Tanto polarones como bipolarones tienen asociados dos niveles energéticos dentro del gap, uno enlazante (de menor energía) y un segundo, antienlazante (de mayor energía). La figura siguiente muestra las estructuras químicas del polipirrol en el proceso de oxidación, junto con la creación de los niveles energéticos asociados. Las diferentes transiciones energéticas permitidas entre estos nuevos niveles, en todo caso menores a las iniciales, determinadas por el ancho del gap energético, corresponden a longitudes de onda diferentes a las iniciales, por lo tanto modificando el espectro de absorción que presenta el material.

El material en estado neutro presenta un pico de absorción centrado en la longitud de onda correspondiente a $E_{g}$, diferencia entre la energía de la banda de conducción y de valencia. La oxidación del material provoca la creación de sucesivos niveles energéticos polarónicos, que al estar energéticamente muy próximos crean bandas energéticas cuyo número de niveles energéticos crece al mismo ritmo que el estado de oxidación del material. 

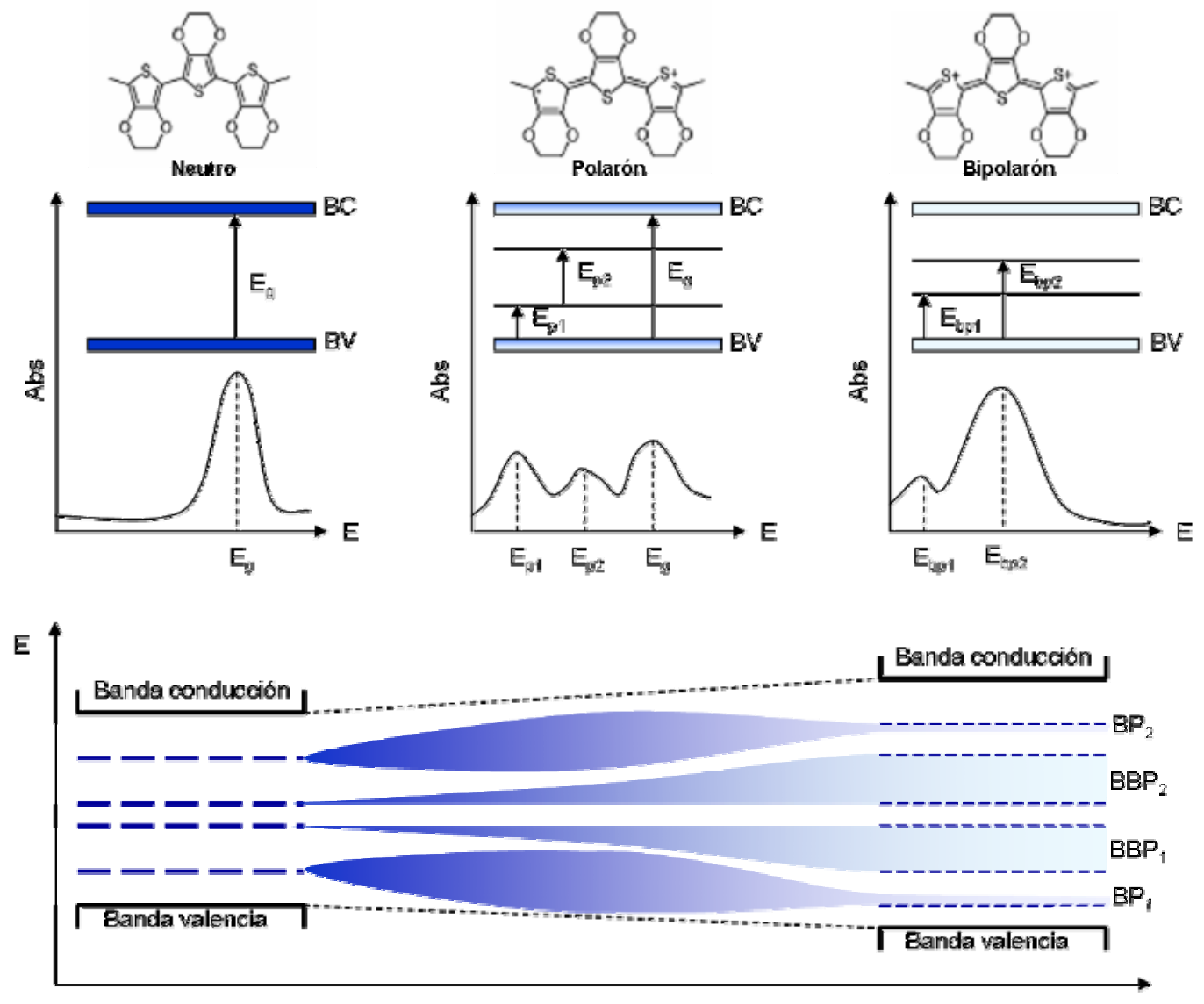

Estado de oxidación

Figura 1.1.5 Estructuras químicas y niveles energéticos en el proceso de oxidación-reducción del polietilendioxitiofeno (PEDOT). La figura muestra el proceso de creación-eliminación de niveles energéticos en el intervalo entre banda de valencia y banda de conducción, asociados a polarones y bipolarones, junto con las transiciones energéticas permitidas entre estos nuevos niveles y la modificación del espectro de absorbancia correspondiente. Notación utilizada: Eg: gap energético, diferencia de energía entre banda de valencia y banda de conducción. $\mathrm{E}_{\mathrm{p} 1}$ : nivel energético polarónico enlazante. $\mathrm{E}_{\mathrm{p} 2}$ : nivel energético polarónico antienlazante. $\mathrm{E}_{\mathrm{bp} 1}$ : nivel energético bipolarónico enlazante. $\mathrm{E}_{\mathrm{bp} 2}$ : nivel energético bipolarónico antienlazante. $\mathrm{BP}_{\mathrm{i}}$ : banda energética polarónica. $\mathrm{BBP}_{\mathrm{i}}$ : banda energética bipolarónica

La probabilidad de existencia de transiciones entre estos nuevos niveles aumenta, disminuyendo la probabilidad de transiciones de energía $\mathrm{E}_{\mathrm{g}}$, siendo esto reflejado en una disminución del pico de absorción centrado en la longitud de onda asociada, y la formación de nuevos picos de absorción crecientes, asociados a las transiciones de 
niveles polarónicos. Una mayor oxidación del material, junto con una población creciente de polarones asociada, aumenta la probabilidad de la combinación de dos polarones en un bipolaron, así como la creación de bipolarones por medio de la formación de dicationes, apareciendo por lo tanto un número creciente de niveles bipolarónicos. La magnitud de las bandas asociadas a cada especie, polarón y bipolarón, viene determinada por la propia estructura energética del material. Varios estudios confirman la existencia de un gran número de estados polarónicos incluso en niveles altos de oxidación para el polipirrol $[25,26]$, mientras que para el polietilendioxitiofeno, existe una mayor proporción de estados bipolarónicos desde los primeros estados de oxidación $[27,28]$.

Como hemos visto, el efecto de la oxidación es la creación de bandas energéticas intermedias dentro del gap, por lo tanto disminuyendo la energía a la que la radiación electromagnética incidente puede ser absorbida. Teniendo en cuenta estas observaciones, se concluye que dos tipos de materiales podrían poseer las características ópticas que antes mencionábamos para poder ser incluidos en dispositivos de transmisión variable, es decir, que uno de sus estados fuera transparente. Puesto que el espectro de luz visible comprende las longitudes de onda entre $350 \mathrm{~nm}$ y $850 \mathrm{~nm}(3.55$ eV y $1.46 \mathrm{eV}$ ), materiales que en alguno de sus estados de oxidación tengan tanto un gap energético mayor que $3.55 \mathrm{eV}$, como inferior a $1.46 \mathrm{eV}$, tendrían sus espectros de absorción fuera del visible, resultando transparentes al ojo humano. Polímeros con características próximas a éstas han sido desarrollados [8]; a los primeros, con gaps energéticos en sus estados neutros alrededor de $3 \mathrm{eV}$, se les denomina polímeros de alto gap de energía (high-bandgap) y a los segundos, con gaps cercanos a $1 \mathrm{eV}$, polímeros de bajo gap de energía (low-bandgap). Puesto que el efecto de la oxidación de un polímero es la de desplazar el espectro de absorción a longitudes de onda mayores, y el 
efecto de la reducción es el contrario, los polímeros de alto gap de energía absorberán en el visible en su estado oxidado, mientras que los de bajo gap energético lo harán en su estado reducido.

Los primeros estudios de electrocromismo de polímeros conductores se centraron en el polipirrol [29-31] y polianilina [32-34]. El punto de inflexión histórica fue marcado por el desarrollo del PEDOT (polietilendioxitiofeno) [35], polímero de bajo gap energético que presenta unas superiores características de conductividad, llegando a presentar valores iguales o mayores de $10^{3} \mathrm{Scm}^{-1}[36,37]$, frente a los valores en el rango de $10^{2}$ encontrados habitualmente para polímeros conductores como el polipirrol o la polianilina[38], empleado en multitud de aplicaciones [36] y que ópticamente tiene la ventaja de presentar una transparencia muy alta en su estado oxidado, frente a un azul intenso fuertemente absorbente en su estado reducido [39]. Estas características, junto con su gran estabilidad, han permitido que sea el polímero mayoritariamente utilizado en dispositivos de transmisión variable [36]. Su estructura química se muestra en la figura siguiente.

\section{PEDOT}

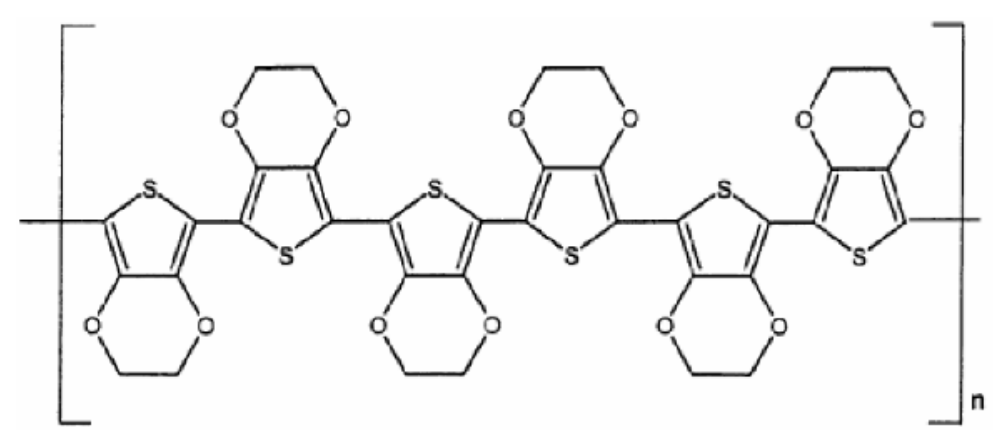

Figura 1.1.6 Estructura química del PEDOT

Sin embargo, en los últimos años, el diseño de nuevos monómeros específicamente diseñados para aplicaciones electrocrómicas ha perseguido la mejora de las propiedades ópticas respecto al PEDOT. Es destacable la labor del grupo del profesor Reynolds en el 
estudio sistemático de las propiedades de monómeros derivados del EDOT [40, 41] o las recientes contribuciones del grupo del profesor Toppare [42-46]. A su vez, ha habido un considerable esfuerzo en el estudio de las relaciones entre estructura y propiedades ópticas de polímeros conductores basados en el alquilendioxitiofeno, y a través de estos esfuerzos se han conseguido significativas mejoras en el comportamiento óptico respecto del PEDOT. Una de las mejoras proviene de la introducción de grupos alquil para disminuir el rango de absorción que se extiende desde el IR y se introduce en el visible, obteniendo polímeros más transparentes en su estado transmisivo, y con un color mas intenso en su estado absorbente [47]. Dietrich et al fueron los primeros en confirmar que los polímeros conjugados basados en el 3, 4-propilendioxitiofeno (ProDOT) exhiben mayores contrastes en comparación con polímeros conjugados basados en EDOT [48].

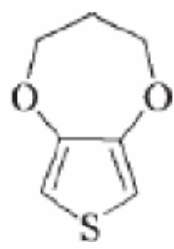

a)

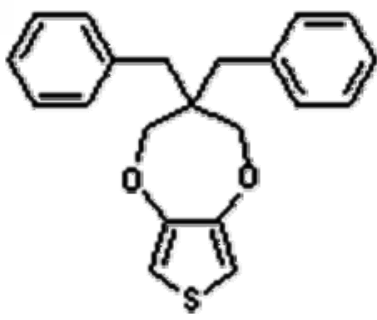

b)

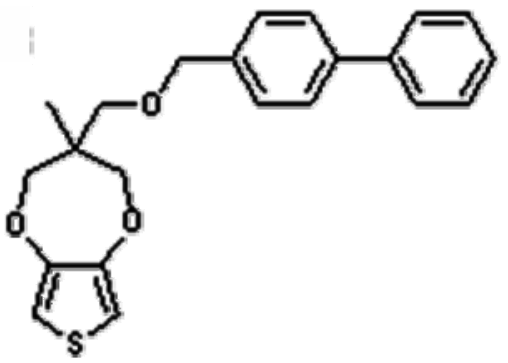

c)

Figura 1.1.7 Estructuras químicas del 3,4-propilendioxitiofeno (ProDOT) (a) y dos monómeros derivados de el, mediante la introducción de grupos sustituyentes, dibencil-ProDOT (b) y bifenilmetiloximetil-ProDOT (c).

La diferencia entre ProDOT y EDOT es un grupo metileno extra en la estructura cíclica del dioxano. Basándose en estos descubrimientos, Reynolds y Kumar introdujeron sistemáticamente grupos sustituyentes en la estructura cíclica del anillo de dioxano del EDOT y ProDOT, y demostraron que los polímeros conjugados creados a 
partir de estos monómeros pueden exhibir grandes contrastes en sus $\lambda_{\max }(>60 \%)$ [4952]. Los polímeros creados a partir de EDOT y ProDOT cambian entre un azul oscuro intenso en su estado neutro coloreado a un estado prácticamente transparente azul cielo en su estado oxidado. 


\subsection{Dispositivos \\ electrocrómicos \\ como \\ celdas \\ electroquímicas. Sistemas duales y polímeros complementarios.}

La capacidad de los polímeros conductores para modificar electroquímicamante no solo sus propiedades ópticas, sino el volumen, carga almacenada, porosidad, etc. ha sido utilizada para desarrollar diferentes dispositivos electroquímicos, como músculos artificiales [53-57], displays electrocrómicos [7, 9, 58-61], membranas inteligentes [6266], baterías poliméricas [67] o supercondensadores [68] . Las distintas arquitecturas de los dispositivos varían dependiendo de la funcionalidad deseada, pero independientemente de su configuración, todos estos dispositivos no son más que celdas electroquímicas. Un flujo externo de electrones provoca procesos de oxidación (o reducción) en uno de los electrodos, junto con el transporte simultáneo de carga iónica a través del electrolito.

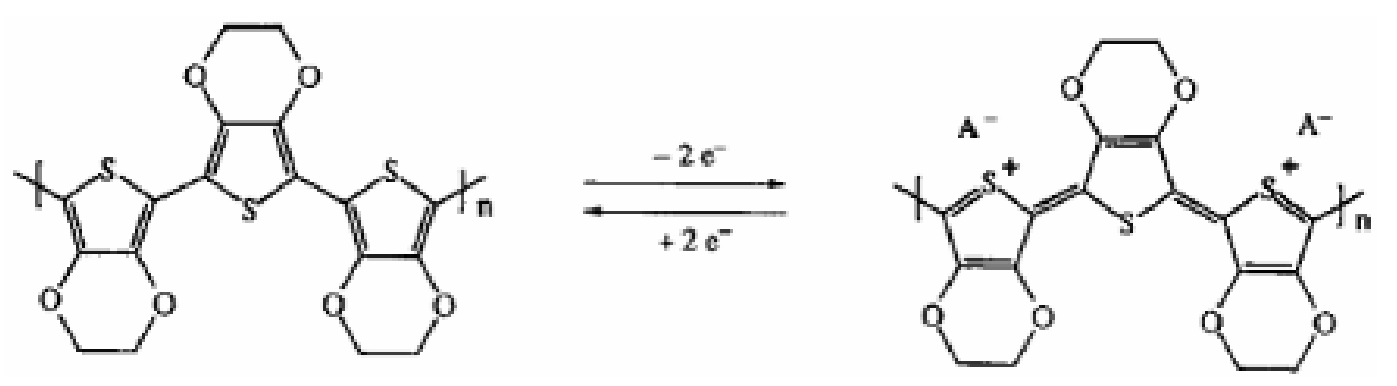

Figura 1.2.1 Proceso de oxidación-reducción del PEDOT. La extracción o inserción de electrones (oxidación o reducción), está acompañada por un transporte simultáneo de carga iónica. Estos iones se introducen en (o son expulsados de) la estructura del polímero para mantener la electroneutralidad.

Los procesos de reacción ( $\mathrm{u}$ oxidación) ocurren en el electrodo opuesto completando la reacción de la celda. Desde esta perspectiva, el uso de configuraciones 
consistentes en dos electrodos poliméricos con características ópticas complementarias (la absorbancia aumenta con la oxidación para uno de ellos, mientras que disminuye para el segundo) se muestra como una manera eficiente para mejorar las características de los dispositivos, puesto que ambos electrodos modifican simultáneamente sus propiedades, contribuyendo a un mayor rendimiento de la energía eléctrica consumida.

Este tipo de configuraciones han sido especialmente útiles en el diseño de músculos artificiales [54, 69-71] o dispositivos electrocrómicos duales [59, 60]. La figura 1.2.2 muestra la configuración de un dispositivo electrocrómico de estas características.

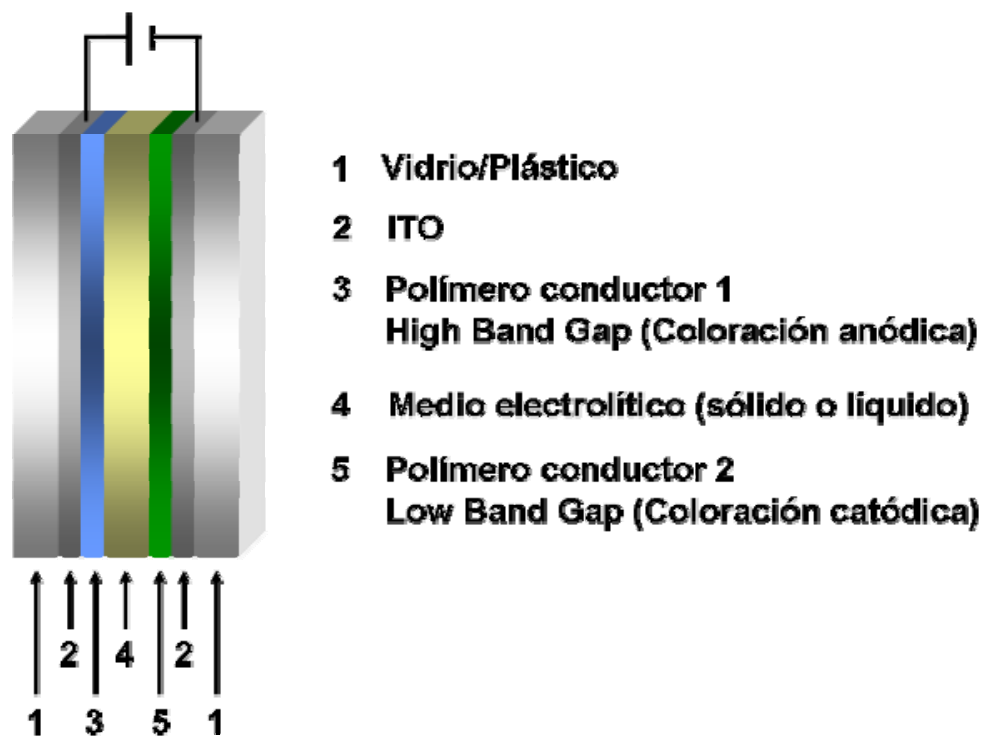

Figura 1.2.2 Esquema de un dispositivo electrocrómico dual. El dispositivo está formado por siete capas. Dos de ellas sirven de substrato para los dos electrodos conductores transparentes (ITO: oxido de indio y estaño). Sobre uno de los electrodos se deposita un material electrocrómico (polímero 1), y sobre el opuesto se deposita otro material (polímero 2) con comportamiento óptico complementario al primero. El dispositivo se completa mediante un medio electrolítico (sólido ó líquido) capaz de proporcionar contacto íonico entre los dos electrodos.

Este concepto, utilizando únicamente polímeros conductores en ambos electrodos, fue aplicado por primera vez en dispositivos electrocrómicos por el grupo del profesor Reynolds [59], mediante la síntesis de monómeros derivados del carbazol con 
características complementarias al PEDOT [72]. Su contribución a la hora de diseñar nuevas parejas de polímeros complementarios ha sido fundamental $[2,13,40,50,58-$ 60, 72-78]. Cabe destacar, igualmente, las aportaciones que en el desarrollo de los sistemas complementarios ha tenido el grupo del profesor De Paoli [79, 80], que había utilizado con anterioridad el concepto de sistema dual combinando polímeros conductores con óxidos de metales de transición. El concepto de sistema complementario polimérico está generalmente aceptado en dispositivos electrocrómicos y ha sido utilizado por varios grupos [81-86].

Aunque se han realizado algunos prototipos con superficies suficientemente grandes como para ser aplicados en dispositivos reales $[87,88]$, como ventanas o techos solares, la mayoría de los estudios siguen confinados a las escalas de laboratorio, en el rango de los $2-3 \mathrm{~cm}^{2}$.

\section{Dispositivos en estado sólido}

Los potenciales usos de los dispositivos electrocrómicos se desarrollan en relativa proximidad al ojo del usuario, y pueden ser expuestos a temperaturas considerablemente altas. Por lo tanto, por razones de seguridad, se desaconseja el uso de electrolitos líquidos dentro del dispositivo. En esta dirección, el uso de distintos geles conductores iónicos compuestos de polimetilmetacrilato (PMMA) con plastificantes de baja presión de vapor [89-94] y electrolitos poliméricos basados en óxido de polietileno (PEO) ha sido descrito $[95,96]$. Los polímeros basados en PEO son conocidos por su excelente capacidad de disolución de sales de litio, evitando su cristalización incluso a temperaturas considerablemente bajas [97]. Aparte de las consideraciones de seguridad, los electrolitos poliméricos sólidos en forma de gel aumentan el tiempo de 
funcionamiento de los dispositivos, evitando la evaporación del disolvente desde el medio conductor iónico, problema que se presenta cuando electrolitos líquidos basados en solventes orgánicos son utilizados.

Una práctica común en la fabricación de los dispositivos es la de formar la capa de electrolito polimérico por medio de la técnica de casting, consistente en la aplicación del electrolito disuelto en solventes orgánicos, y la posterior formación de la membrana conductora iónica sólida por medio de la evaporación del solvente. Una aproximación más práctica de cara a la construcción de dispositivos de gran superficie es la de fotopolimerizar un oxido de polietileno de bajo peso molecular funcionalizado con unidades de acrilato, en presencia de un fotoiniciador [98, 99]. Para su utilización en ventanas electrocrómicas, el electrolito polimérico debe ser una película muy delgada, buen conductor iónico, excelente aislante electrónico y ser suficientemente transparente. 


\subsection{Visiones fotópica y escotópica}

La consideración de las características propias del ojo humano es un factor clave en el desarrollo de dispositivos electrocrómicos, puesto que hay diferencias sustanciales en la manera en que el ojo percibe la luz visible en diferentes condiciones. Existen dos tipos de receptores de luz dentro del ojo humano: conos y bastones. Los primeros son sensibles a muy pequeñas cantidades de radiación, y por lo tanto son usados en condiciones de baja iluminación, pero no pueden percibir los diferentes colores. Los segundos son capaces de percibir los colores, pero requieren de una mayor intensidad de radiación para ser activados, por lo que son usados predominantemente en situaciones de adecuada iluminación.

La visión escotópica se refiere a las situaciones en las que los conos actúan como perceptores, mientras que la visión fotópica se refiere a las situaciones en las que la participación de los bastones es más relevante. Para cada una de las situaciones, el ojo es más sensible a ciertas longitudes de onda. Para visión fotópica, el ojo es más sensible hacia la luz de $555 \mathrm{~nm}$. Cada longitud de onda en el espectro visible tiene un peso relativo en términos de cómo es percibida por el ojo. Estos valores relativos para cada longitud de onda han sido estandarizados por la Commission Internationale de l'Eclairage (CIE) [92, 94].

Generalmente, en el área de los dispositivos $\mathrm{EC}$, los valores ópticos son normalmente descritos en función de la $\lambda_{\text {máx }}$ o en función de los valores a $555 \mathrm{~nm}$, longitud de onda a la cual el ojo es más sensible. La utilización de datos referidos al comportamiento fotópico sería más realista respecto a la verdadera percepción por parte 
del usuario. La ecuación usada para convertir para convertir un espectro visible convencional a un espectro fotópico ponderado es:

$T_{\text {fotópica }}=\frac{\int_{380}^{720} T\left(\lambda_{0}\right) \cdot S(\lambda) \cdot P(\lambda) \mathrm{d} \lambda}{\int_{380}^{720} \mathrm{~S}\left(\lambda_{2}\right) \cdot \mathrm{P}(\lambda) \mathrm{d} \lambda}$

$\mathbf{T}(\lambda)$ es la transmitancia espectral del dispositivo bajo estudio,

$\mathbf{S}(\lambda)$ es la emitancia espectral normalizada de un cuerpo negro a $6000^{\circ} \mathrm{K}$

$\mathbf{P}(\lambda)$ es la respuesta espectral normalizada del ojo.

Tanto $\mathbf{S}(\lambda)$ como $\mathbf{P}(\lambda)$ se encuentran tabulados para los valores de longitudes de onda dentro del visible [94], mientras que $\mathbf{T}(\lambda)$ es una medida experimental. 


\subsection{Motivación y objetivos de la tesis}

Como hemos visto, el proceso de oxidación o reducción electroquímica de un polímero conductor provoca cambios en los niveles electrónicos del material, modificando la respuesta de éste ante la absorción de luz, y generando por lo tanto un cambio de color. Esto es equivalente a decir que proceso electroquímico y proceso electrocrómico (cambio de absorción y color), están directamente relacionados. La importancia de esta aseveración, que estrictamente hablando llegaría a ser redundante, puesto que la definición de electrocromismo es la de cambio de color provocado por un proceso de oxidación-reducción, habitualmente no es explícitamente considerada en la literatura científica, en la que frecuentemente se encuentran estudios sobre las propiedades ópticas de los materiales electrocrómicos sin establecer ninguna relación cuantitativa con los procesos electroquímicos relacionados.

Una determinada película de polímero conductor puede ser caracterizada electroquímicamente por la cantidad de procesos redox reversibles que puede sufrir. Estos procesos de oxidación y reducción electroquímica reversible de cada polímero conductor se producen en un intervalo determinado de potencial para unas condiciones experimentales concretas. Someter al polímero a potenciales mas allá de su correspondiente rango es totalmente ineficiente en términos de cambio en las propiedades deseadas en el dispositivo. Es más, esto puede provocar procesos de sobreoxidación y degradación del polímero. Este tema ha sido ampliamente estudiado [100-103], y los mecanismos de degradación propuestos incluyen ataques nucleofílicos, entrecruzado de las cadenas [104] o ataque químico por parte del medio electrolítico [105]. Puesto que procesos electroquímicos y ópticos están directamente relacionados, 
la cuestión que se plantea es si existe la posibilidad de establecer esa relación y caracterizar las películas de polímero conductor por el cambio de color que pueden ofrecer.

Durante los últimos años ha habido un considerable esfuerzo desde el campo de la química orgánica para sintetizar nuevos monómeros con propiedades ópticas mejoradas, con contribuciones realmente significativas $[35,38,41,51,52,72,76,106-108]$. La trascendencia del propio proceso de síntesis de un nuevo monómero es tal que frecuentemente la caracterización de las propiedades del nuevo material, aunque presente, se mantiene en un segundo plano. En este sentido, es especialmente significativa la ausencia de estudios sistemáticos para la obtención del máximo contraste posible para un determinado material. El único estudio en esa dirección corresponde a Lim et al [109]. En él se propone la obtención del valor máximo de contraste posible para el PEDOT en función del número de ciclos de polimerización. Este parámetro, sin embargo, es difícilmente generalizable a cualquier polímero conductor, y no es el más adecuado para caracterizar electroquímicamente una película electroactiva, puesto que existen diferentes métodos de electropolimerización como pueden ser la cronoamperometría o cronoculometría. La siguiente pregunta por lo tanto sería si existe la posibilidad de definir un método sistemático para la obtención del máximo contraste que se puede conseguir para un material, en función de variables electroquímicas generalizables a cualquier polímero.

Estas debilidades respecto a la falta de información respecto a la caracterización de cada material individualmente, así como la ausencia de una metodología electroquímica generalizable, se multiplican a la hora de diseñar y fabricar dispositivos electrocrómicos duales. Estos dispositivos, como se ha comentado anteriormente, son celdas electroquímicas, en este caso con materiales distintos en cada electrodo, cada uno con 
unas propiedades electroquímicas y ópticas diferentes, cuyos procesos de oxidación y reducción deben complementarse para obtener un comportamiento óptimo. Generalmente el único criterio explícitamente descrito en la literatura a la hora de configurar el dispositivo y emparejar los dos electrodos es el de utilizar dos películas con la misma carga redox, aunque no existe un criterio que defina cual es esa carga redox para cada material. En otros casos, aunque minoritariamente, no se especifica ningún criterio óptico o electroquímico para la construcción de los dispositivos, asumiendo por lo tanto que un proceso de ensayo y error es el utilizado para optimizar el sistema en cuestión. Aún cuando el criterio de emparejar películas con la misma carga redox, o lo que es lo mismo, con un ratio 1 para esos valores, es el más razonable desde el punto de vista electroquímico, y es generalmente aceptado, es llamativo el hecho de que apenas existan estudios sobre el efecto que este ratio pueda tener en el funcionamiento del dispositivo. Únicamente los estudios realizados por Ho et al [86, 110-113], realizados para dispositivos basados en óxidos de metales de transición abordan este tema. Asimismo, respecto a la predicción del máximo contraste posible para una determinada combinación dual de materiales en función de las características individuales de cada material, únicamente encontramos la contribución realizada por Rauh [114] para el sistema inorgánico $\mathrm{WO}_{3} / \mathrm{IrO}_{2}$.

La ausencia de un mayor número de estudios podría provenir de la dificultad en la obtención de información sobre los procesos electroquímicos individuales de cada electrodo en sistemas duales. Las técnicas electroquímicas capaces de obtener esta información, como la voltamperometría cíclica o la cronoamperometría, se utilizan normalmente en una configuración de celda de tres electrodos, aplicando un potencial conocido a uno de los electrodos (electrodo de trabajo, WE) respecto a un segundo (electrodo de referencia, RE). El electrodo restante (contraelectrodo, CE) permite el 
paso de corriente para completar la reacción en la celda, adoptando para ello el potencial necesario.

Estas técnicas son útiles para la obtención de información sobre la ventana de potencial redox del material, o la carga consumida en el proceso. Cuando se aplica a configuraciones duales, sin embargo, éstas presentan algunas debilidades: la información sobre el estado de oxidación está limitada al electrodo de trabajo, y el potencial al que está sometido el contraelectrodo no se controla.

Una aproximación diferente es el uso de celdas de dos electrodos, en las cuales se aplica una diferencia de potencial entre los dos electrodos. Esta configuración se aproxima más a las condiciones reales de funcionamiento de cualquier dispositivo. Sin embargo, en este caso ninguno de los estados de oxidación de los materiales constituyentes es conocido.

En base al conjunto de circunstancias enumeradas, sería necesario el desarrollo de herramientas experimentales capaces de aportar información relativa a los procesos electródicos individuales de un sistema dual. El objetivo último sería no sólo la obtención de las condiciones óptimas de funcionamiento electroquímico, sino el establecimiento de una metodología y un criterio generalizable para la obtención de esas condiciones.

En este contexto, el objetivo de esta tesis será el de intentar responder a las preguntas planteadas, enfatizando en todo momento la relación directa entre procesos electroquímicos y ópticos. Es decir, asumiendo que habiendo establecido esta relación, cualquier caracterización u optimización electroquímica es implícitamente una caracterización u optimización óptica y viceversa. Para conseguir estos objetivos, planteamos un estudio individual de los materiales previo a su inclusión en un sistema 
dual. Posteriormente el sistema dual será estudiado y caracterizado en sus propiedades ópticas y electroquímicas.

Por último, se estudiarán los problemas que la construcción de estos dispositivos plantea cuando se pretenden desarrollar a una escala suficientemente grande como para ser utilizados realmente en aplicaciones prácticas, así como la construcción de dispositivos en estado sólido. 



\section{$\underline{\text { Experimental }}$}





\section{BLOQUE EXPERIMENTAL}

\subsection{Condiciones experimentales}

\section{Materiales}

Trifluorometanosulfanato $\left(\mathrm{LiCF}_{3} \mathrm{SO}_{3}\right) 96 \%$, de Aldrich, fue usado sin ninguna modificación. El acetonitrilo utilizado (ACROS), adquirido a Fisher Scientific, fue destilado a través de hidruro de calcio antes de su uso.

Respecto a los monómeros utilizados, el 3,4-etilendioxitiofeno (EDOT), de Aldrich, fue destilado en vacío antes de su uso. 3,6-bis(2-(3,4-etilendioxi)tienil)-N-metilcarbazol (BEDOT-NMCz) fue sintetizado por el método descrito previamente [72]. DibencilProDOT (DiBz-ProDOT) y Bifenilmetiloximetil-ProDOT (BPMOM-ProDOT) fueron preparados por los procedimientos descritos en la literatura [49, 51, 52].

\section{Celdas electroquímicas}

Las experiencias sobre el estudio de la eficiencia de polimerización (Sección 3.1.2) fueron llevadas a cabo en una celda electroquímica convencional (Metrohm) de un solo compartimento. Para el estudio del efecto del potencial de polimerización, como electrodo de trabajo se utilizó un electrodo cilíndrico de platino recubierto de teflón, con una superficie descubierta de $0.0314 \mathrm{~cm}^{2}$, ó cristales recubiertos de ITO (oxido de indio $y$ estaño), de resistencia nominal superficial $R_{s}=15-25$ ohmios y superficie $S=3.5 \mathrm{~cm}^{2}$, de Delta Technologies (Sección 3.1.2.1). El contraelectrodo fue una lámina de platino de $5 \mathrm{~cm}^{2}$ de superficie en ambos casos. Se usó un electrodo de referencia orgánico 
$\mathrm{Ag} / \mathrm{Ag}^{+}(10 \mathrm{mM} \mathrm{AgNO} 3,0.1 \mathrm{M}$ perclorato de tetrabutilamonio (TBAP) en acetonitrilo, calibrado a $0.456 \mathrm{~V}$ vs. NHE).

Para los estudios espectroelectroquímicos, una cubeta de cuarzo de dimensiones 12x12x45 mm, fue convenientemente modificada para la inclusión de electrodos y sistema de desoxigenación. La figura siguiente muestra las dimensiones de los componentes y la configuración experimental de la celda. Una tapa de teflón fue mecanizada para permitir la inserción de los distintos componentes. El contraelectrodo fue diseñado para permitir el paso del haz de luz incidente en todo momento; para ello, se utilizó una lámina de acero AISI 304 de dimensiones 9x3×55 mm. Un pseudoelectrodo de referencia consistente en un hilo de plata (calibrado a $0.1 \mathrm{~V}$ vs. NHE) fue introducido en un tubo capilar de $1.4 \mathrm{~mm}$ de diámetro para evitar el contacto eléctrico con el electrodo de trabajo o contraelectrodo.

Para las medidas espectroelectroquímicas individuales de cada polímero, se utilizó la configuración de celda tal y como está descrita en la figura siguiente. Para los experimentos con sistemas duales, se utilizó la tapa indicada en la figura 2.1.1.b, y el contraelectrodo metálico se sustituyó por una segunda lámina de vidrio+ITO con el polímero correspondiente.

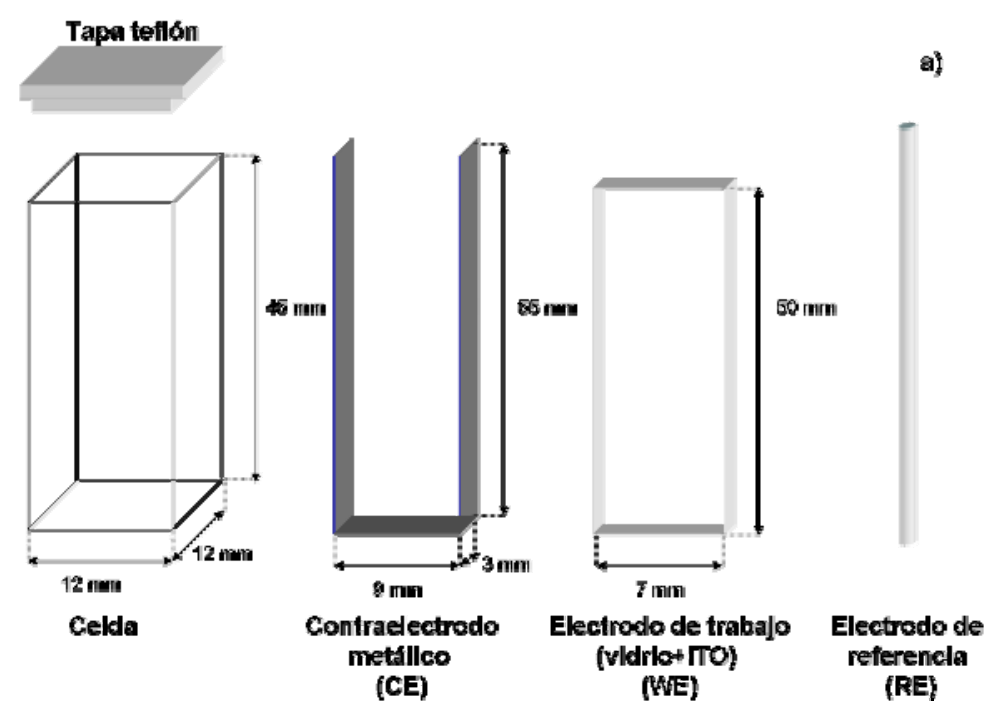




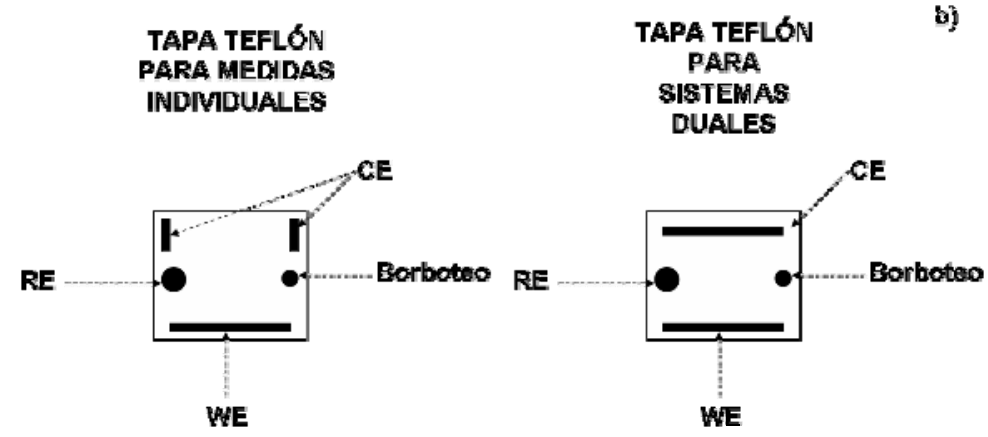

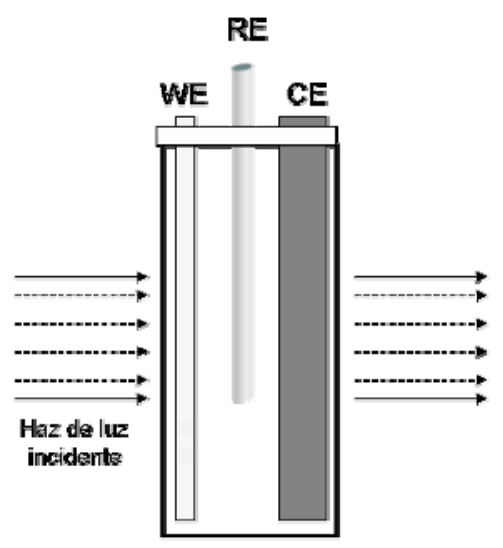

VISTA LATERAL
RE

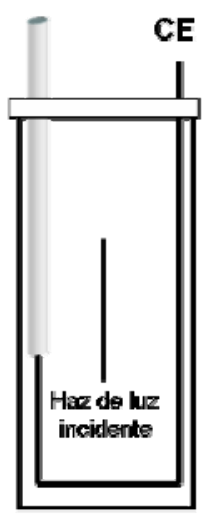

VISTA FRONTAL

Figura 2.1.1 a) Componentes de la celda electroquímica utilizada para medidas espectro electroquímicas individuales b) Mecanizado de la tapa de teflón para la inserción de los electrodos y borboteo de nitrógeno para desoxigenación c) Vistas lateral y frontal de la celda. El contraelectrodo fue diseñado para no interferir en las medidas espectroscopicas.

Condiciones de polimerización.

Todas las polimerizaciones electroquímicas fueron llevadas a cabo a potencial constante en disolución $0.1 \mathrm{M} \mathrm{LiCF}_{3} \mathrm{SO}_{3}$ en acetonitrilo. Las películas de PEDOT se electrogeneraron a $1.3 \mathrm{~V}$ vs. $\mathrm{Ag} / \mathrm{Ag}^{+}$en disoluciones monoméricas de $20 \mathrm{mM}$. Las películas de PBEDOT-NMCz se obtuvieron a $0.65 \mathrm{~V}$, en disoluciones monoméricas de 1 mM. Los monómeros BPMOM-ProDOT y DiBz-ProDOT fueron polimerizados electroquímicamente mediante la aplicación de un potencial de $1.3 \mathrm{~V}$ (vs. $\mathrm{Ag} / \mathrm{Ag}^{+}$), en disoluciones monoméricas 5mM. 
Instrumentación.

La caracterización electrocrómica se llevó a cabo usando indistintamente los espectrofotómetros de doble haz UV-Vis 8500 (Dinko Instruments) ó UV lambda 900 (Perkin-Elmer).

Se usaron ambos modelos de potenciostatos, $\mathrm{CHI} 400$ (CH Instruments) y AUTOLAB PGSTAT100 (Ecochemie) para la electropolimerización y estudio de los materiales y dispositivos electrocrómicos.

Una cámara de curado ultravioleta UVP CL-1000 con fuente de luz de $365 \mathrm{~nm}$ fue usada para el curado del gel electrolítico.

\subsection{Técnicas utilizadas}

\subsubsection{Técnicas electroquímicas}

\section{Voltamperometría cíclica}

La voltamperometría cíclica es una técnica electroquímica que consiste en aplicar al electrodo de trabajo una variación lineal del potencial eléctrico, de forma cíclica, entre dos potenciales límite $\mathrm{E}_{1} \mathrm{y} \mathrm{E}_{2}$, a una velocidad constante $v\left(\mathrm{Vs}^{-1}\right)$, registrándose la evolución de la corriente que pasa por el sistema en función del potencial aplicado. La evolución del potencial aplicado frente al tiempo para esta técnica, junto con la evolución de intensidad frente a potencial habitualmente obtenida para polímeros conductores, se muestran en la figura siguiente. 

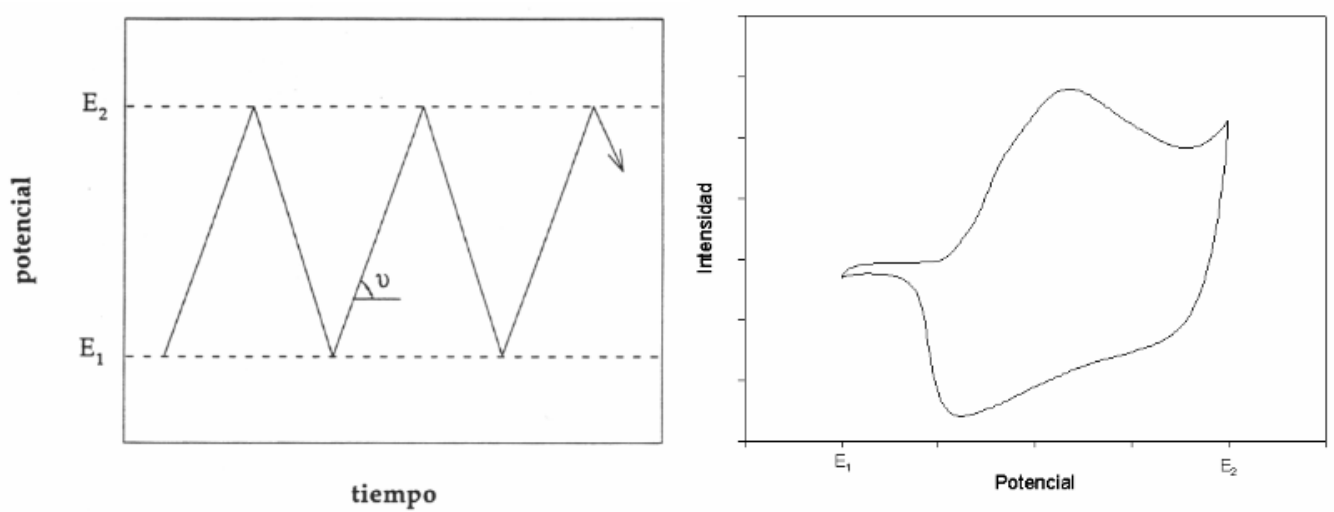

Figura 2.2.1 Evolución del potencial aplicado frente al tiempo para la técnica de voltamperometría cíclica, junto con la respuesta registrada (intensidad frente a potencial)

\section{Cronoamperometria}

La cronoamperometría consiste en la aplicación al electrodo de trabajo de un salto de potencial instantáneo, desde un potencial inicial $\left(E_{1}\right)$ a un potencial final $\left(E_{2}\right)$, durante un tiempo determinado, registrándose la evolución de la intensidad frente al tiempo. El perfil del potencial aplicado frente al tiempo para esta técnica se muestra en la figura siguiente.
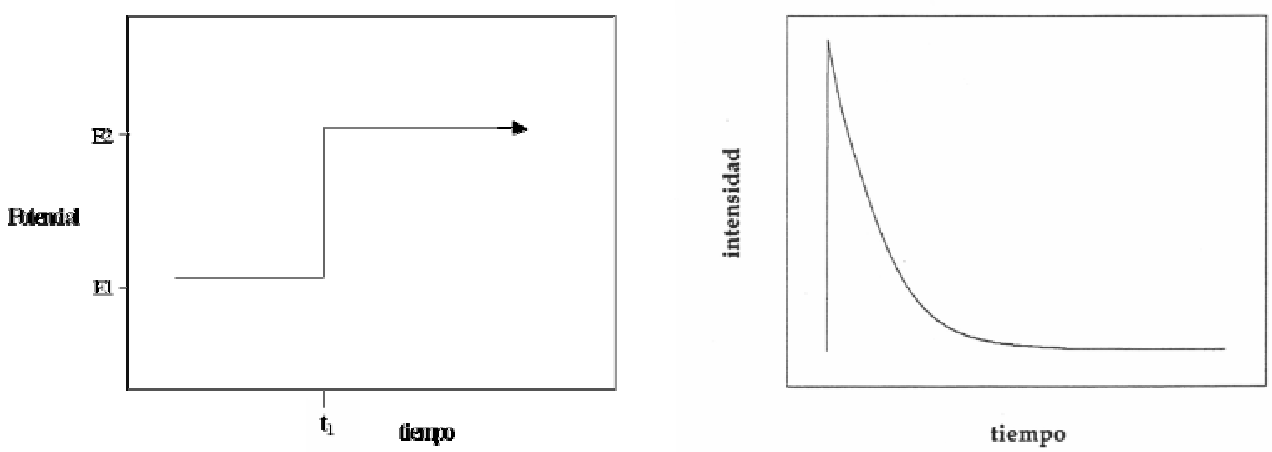

Figura 2.2.2 Evolución del potencial aplicado frente al tiempo para la técnica de cronoamperometría, junto con la respuesta registrada (intensidad frente a tiempo) 
Dispositivo experimental para el estudio electroquímico de sistemas duales

El esquema del dispositivo experimental se muestra en la figura 2.2.3

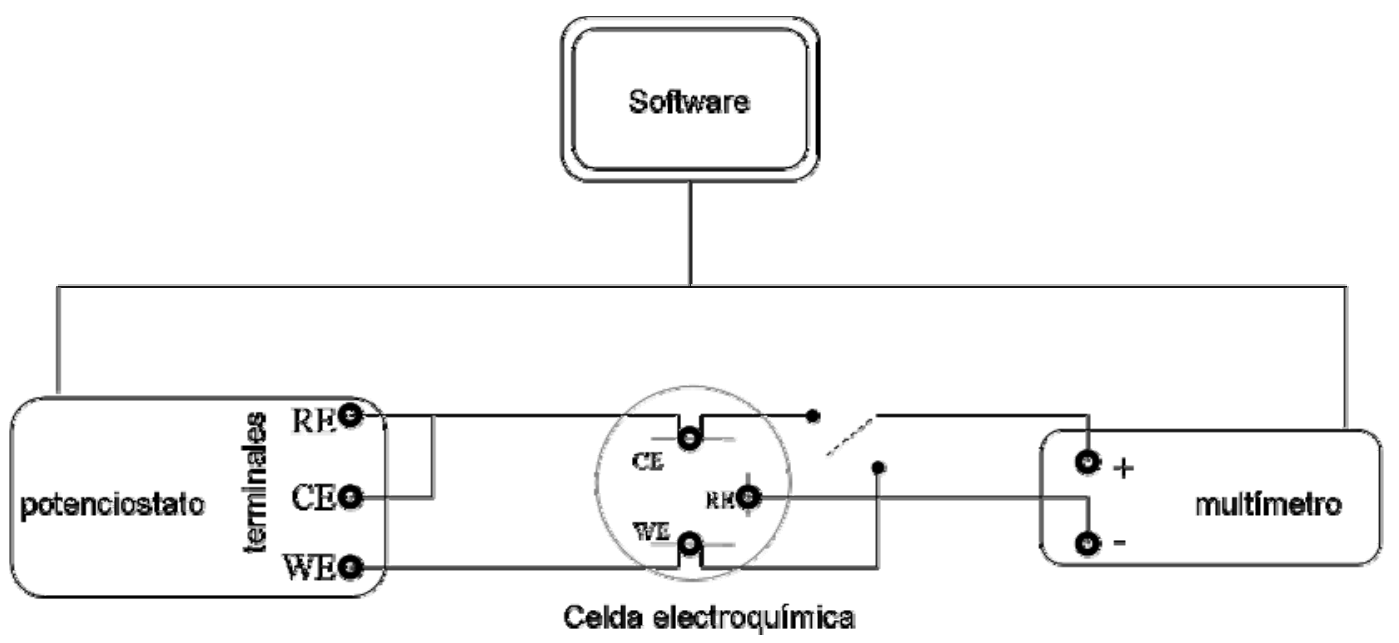

Figura 2.2.3 Esquema del dispositivo experimental. El potenciostato fue usado como fuente de potencial. Ambos terminales de contraelectrodo y electrodo de referencia del potenciostato fueron conectados al contraelectrodo en la celda. El terminal negativo del multímetro se conectó al electrodo de referencia, y el terminal positivo alternativamente al electrodo de trabajo o al contraelectrodo.

El equipamiento necesario incluye una fuente de potencial, con adquisición simultánea de la corriente, para hacer funcionar el dispositivo, y un multímetro capaz de registrar simultáneamente el potencial entre un electrodo de referencia y los electrodos del dispositivo electroquímico. Se usó un potenciostato CHI 400 para aplicar los potenciales necesarios, mientras que un multímetro Keithley 9000 fue usado para la medición del potencial de uno de los electrodos respecto al electrodo de referencia. Los datos del multímetro fueron adquiridos a través del software Labview (National Instruments).

Para llevar a cabo los experimentos, los terminales CE (contraelectrodo) y RE (electrodo de referencia) del potenciostato se conectaron, cortocircuitados, a uno de los electrodos, mientras que el terminal WE (electrodo de trabajo) se conectaba al opuesto. 
El multímetro era conectado al electrodo de referencia y al electrodo elegido en cada caso (CE ó WE), de tal manera que el potencial respecto al electrodo de referencia (estado de oxidación) de dicho electrodo era conocido en todo momento. Puesto que el potencial aplicado entre WE y $\mathrm{CE}$ era conocido, el potencial respecto al RE del electrodo restante era obtenido por simple diferencia.

\subsubsection{Técnicas espectroscópicas}

Espectrofotometría de doble haz UV-Vis

Un espectrofotómetro es un fotómetro (dispositivo para la medición de intensidad de luz) capaz de medir la intensidad de luz en función de la longitud de onda. Los espectrofotómetros se clasifican según el rango de longitudes de onda en el que trabajan. Habitualmente, este rango se sitúa entre 180-1100 nm para un equipo UVVisible.

Los dos tipos más comunes son los espectrofotómetros de haz simple y de doble haz. Los equipos de doble haz miden la diferencia entre las intensidades de dos haces de luz al mismo tiempo, muestra y referencia, mientras que los de haz simple miden la intensidad absoluta de un solo haz cada vez, y posteriormente se comparan entre sí. Este tipo de sistemas tiene el problema de que en ocasiones la lámpara no es muy estable, y no funciona igual durante la toma de los dos espectros (además de la lentitud, o la posibilidad de que accidentalmente puede variar la posición de algún elemento entre la medida los dos espectros).

El funcionamiento de un equipo de doble haz es el siguiente. Se utiliza como fuente de luz una lámpara que tenga una emisión intensa en todo el intervalo de longitudes de 
onda que se quiere analizar. La emisión de la lámpara pasa a través de un monocromador que selecciona la luz de una determinada longitud de onda. Esta luz monocromada se divide mediante un divisor de haz que la separa en dos haces de luz con una intensidad de luz aproximadamente igual. Uno de los haces pasa directamente al detector, mientras que el otro atraviesa la muestra antes de llegar al mismo. Posteriormente el detector compara la luz que le llega en los dos sensores y calcula la cantidad de luz que ha transmitido (o absorbido) la muestra. La operación se repite variando la longitud de onda de la luz que sale del monocromador con lo que se obtiene el espectro de absorción. El esquema de un equipo de estas características se muestra en la figura siguiente.

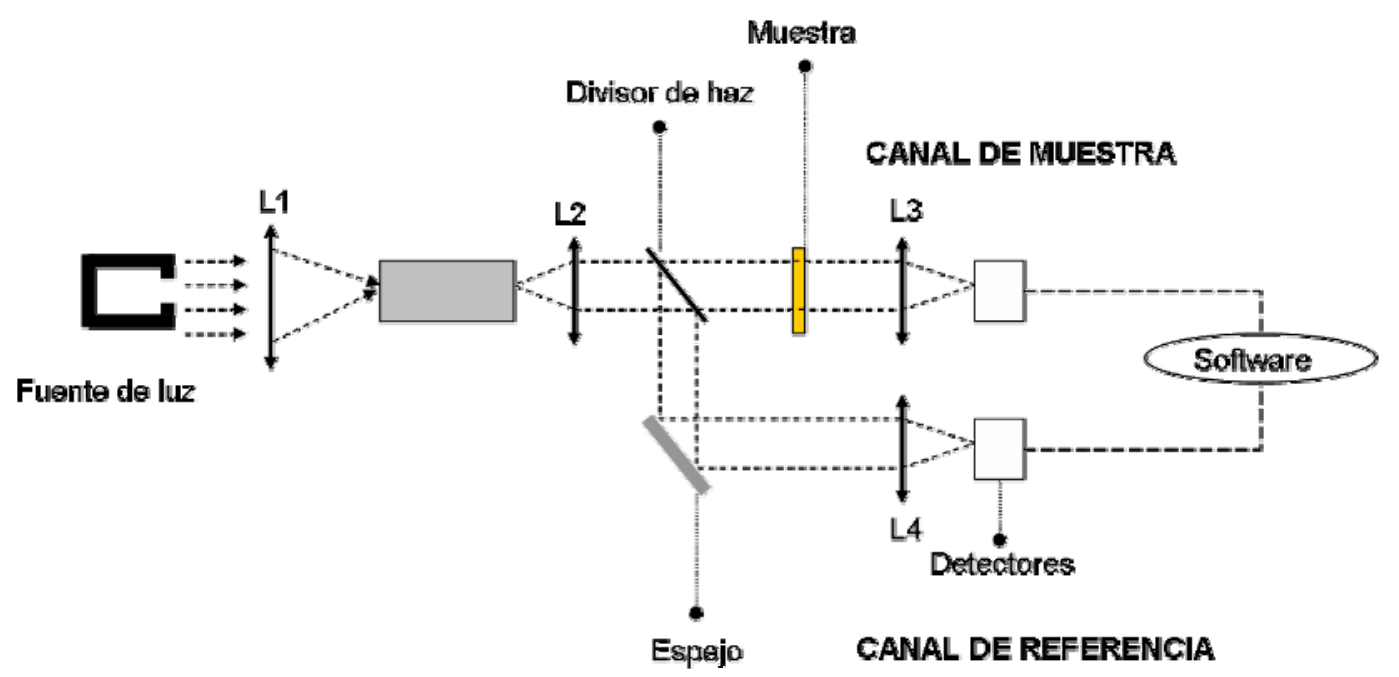

Figura 2.2.4 Esquema de funcionamiento de un espectrofotómetro de doble haz. La luz emitida por la fuente de luz es recogida en un monocromador que selecciona la longitud de onda deseada. El haz de luz es dividido en dos; uno atraviesa la sustancia que se define como referencia, y el segundo atraviesa la muestra en estudio. Los dos haces son detectados por los sensores, comparando las intensidades resultantes. Los datos son tratados por el correspondiente software. $\mathrm{L}_{\mathrm{i}}$ con $\mathrm{i}=1,4$, hace referencia a las lentes presentes en el aparato.

Se utilizaron dos técnicas para las medidas espectroelectroquímicas; una dinámica y otra estática, asociadas a las técnicas electroquímicas descritas en el anterior apartado. 
Para el seguimiento del cambio óptico durante una voltamperometría cíclica, se obtuvo el cambio de absorbancia en función del tiempo para una determinada longitud de onda. Para la caracterización del espectro de cada película, se mantuvo un potencial constante, mediante la utilización de la cronoamperometría, y se obtuvieron los valores de absorbancia para las longitudes de onda comprendidas entre 350 y $850 \mathrm{~nm}$.

\subsection{Construcción de dispositivos electrocrómicos en estado sólido}

\section{Materiales}

Polietilenglicoletileter metacrilato (MA), polietilenglicol diacrilato (DA) y 2,2dimetoxi-2-fenil-acetofenona 99\% (DMPAP) de Aldrich, fueron usados sin ninguna modificación. Las cuentas de cristal (diámetro 50-100 $\mu \mathrm{m}$ ) fueron adquiridas a través de Polysciences Inc. Se usaron láminas de vidrio recubierto de ITO, de dimensiones 58 $\mathrm{cm}^{2}(7.6 \times 7.6 \mathrm{~cm})$ de área y $0.7 \mathrm{~cm}$. de grosor, con una resistencia superficial nominal de 15-25 $\Omega$, y rollos de tereftalato de polietileno, PET (aprox. $0.2 \mathrm{~mm}$ de grosor), recubierto de ITO con una resistencia de 40-60 $\Omega$, de Delta Technologies. UVS-91, un pegamento fotocurable de Norland Products Inc. fue usado sin ninguna modificación.

Generación electroquímica de los polímeros conductores

Una celda electroquímica especial fue diseñada para la electropolimerización sobre láminas de ITO de aprox. $58 \mathrm{~cm}^{2}$. El área final recubierta de polímero se situó en torno a los $30 \mathrm{~cm}^{2}$ usando esta configuración (figura 2.3.1) 

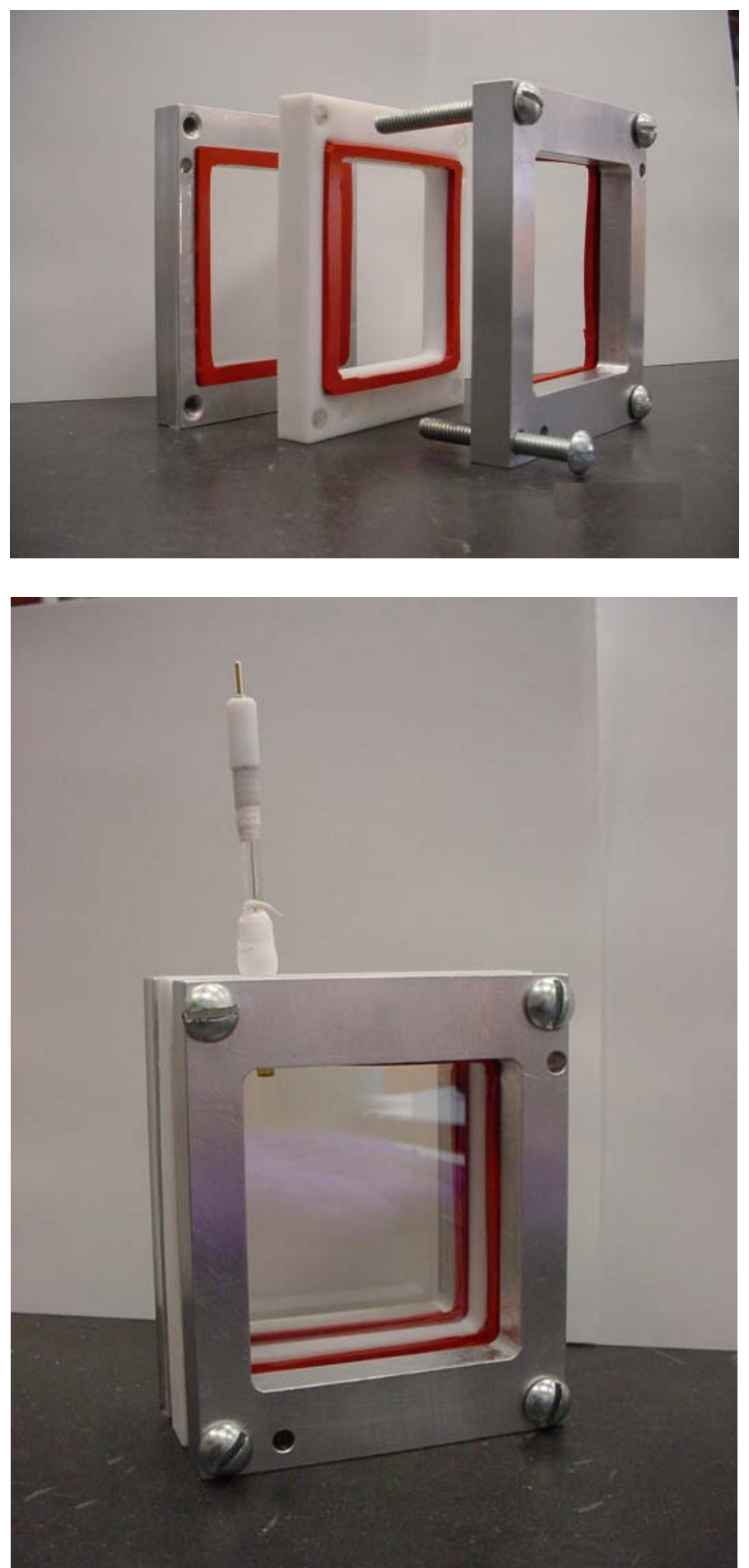

Figura 2.3.1 Celda electroquímica usada para la polimerización de los polímeros conductores sobre electrodos de $58 \mathrm{~cm}^{2}$. Las juntas estancas (naranjas) son de silicona, la pieza central (blanca) es de teflón, y las dos piezas restantes son de aluminio. En la figura inferior se observa la celda ensamblada, con el electrodo de referencia. 
Las películas de PEDOT fueron electrogeneradas, en las condiciones indicadas anteriormente en la sección 2.1, sobre vidrio recubierto de ITO, mientras que las películas de PBEDOT-NMCz fueron electrogeneradas sobre PET recubierto de ITO. Ambas películas fueron lavadas concienzudamente con acetonitrilo después de la polimerización, secadas y almacenadas en un desecador hasta su uso en la construcción de los dispositivos.

\section{Construcción de los dispositivos}

El gel electrolítico estaba compuesto de uno de los polímeros basados en polietilenglicol y acrilato (Polietilenglicoletileter metacrilato (MA) ó polietilenglicol diacrilato (DA)), fotoiniciador, cuentas de cristal y la sal $\left(\mathrm{LiCF}_{3} \mathrm{SO}_{3}\right)$ capaz de proporcionar la conductividad iónica para permitir el movimiento de cargas en el proceso electroquímico. Ha sido descrito que la máxima conductividad iónica de las disoluciones Litio-PEO se obtiene para un ratio $\mathrm{Li} / \mathrm{O}$ de 0.04 [115] y por lo tanto la composición del gel sin plastificante fue preparada manteniendo aproximadamente este ratio. Se utilizaron un MA de peso molecular medio $258 \mathrm{grmol}^{-1} \mathrm{y}$ un DA de peso molecular medio 246 grmol $^{-1}$. Observando la figura 2.3.2, donde se muestran las estructuras de los dos compuestos, se observa que para $n=1$, el MA cuenta con 3 oxígenos en su estructura, y el DA con 4. En una disolución de MA ó DA con $\mathrm{LiCF}_{3} \mathrm{SO}_{3}$, un ratio de 0.04 entre moles de $\mathrm{Li}$ y $\mathrm{O}$ correspondería a 0.12 moles de $\mathrm{LiCF}_{3} \mathrm{SO}_{3}$ por mol de MA y 0.16 por mol de DA. Comparando los pesos moleculares $\left(\mathrm{LiCF}_{3} \mathrm{SO}_{3}=156.01 \mathrm{gr} / \mathrm{mol}\right)$ esto resulta en una proporción aproximada de $1 \mathrm{gr}$ de $\mathrm{LiCF}_{3} \mathrm{SO}_{3}$ por cada 10 de MA ó DA. 


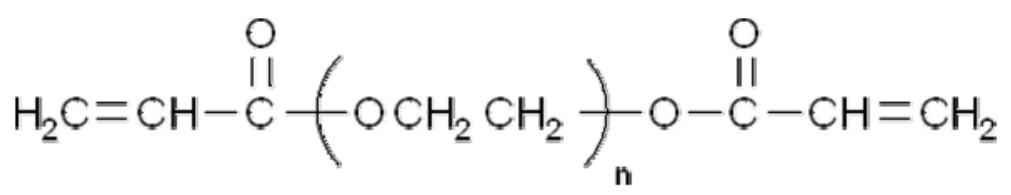

Polietilenglicol diacrilato $\mathrm{Mw} \sim 258$

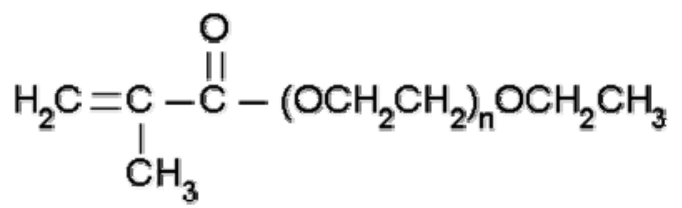

\section{Polietilenglicoletiletermetacrilato $\mathrm{Mw} \sim 246$}

Figura 2.3.2 Estructura de los polímeros usados en la composición del gel electrolítico

Puesto que nuestra intención era la de estudiar el efecto del plastificante, esta proporción de sal se mantuvo constante para todas las composiciones de gel estudiadas. Las distintas composiciones de gel estudiadas se muestran en la tabla 2.3.1.

Aproximadamente $0.5 \mathrm{ml}$ del gel electrolítico se aplicaban sobre el vidrio cubierto de PEDOT, y la lámina de PET recubierta de PBEDOT-NMCz se situaba encima de ella, con las caras conductoras enfrentadas. Las cuentas de cristal dispersadas en el gel electrolítico evitaban un posible contacto eléctrico entre las dos caras. Los dos electrodos se apretaban para eliminar cualquier burbuja que hubiese quedado atrapada y para eliminar el exceso de gel electrolítico.

La solidificación del polímero, MA ó DA, por entrecruzado de sus cadenas, en presencia del fotoiniciador DMPAP, se obtenía por medio de luz UV [365 nm, 5.8 $\mathrm{mW} / \mathrm{cm}^{2}$ ] durante 15 minutos. 


\begin{tabular}{|c|c|c|c|}
\hline $\begin{array}{c}\text { MA } \\
\text { (g) }\end{array}$ & $\begin{array}{l}\text { DA } \\
(\mathbf{g})\end{array}$ & $\begin{array}{c}\text { Carbonato } \\
\text { de } \\
\text { propileno } \\
\text { (g) }\end{array}$ & $\begin{array}{c}\text { DMPAP } \\
\text { (mg) }\end{array}$ \\
\hline 10.0 & 0.0 & 0.0 & 25.0 \\
\hline 9.0 & 0.0 & 1.0 & 22.5 \\
\hline 8.0 & 0.0 & 2.0 & 20.0 \\
\hline 7.0 & 0.0 & 3.0 & 17.5 \\
\hline 6.0 & 0.0 & 4.0 & 15.0 \\
\hline 5.0 & 0.0 & 5.0 & 12.5 \\
\hline 0.0 & 10.0 & 0.0 & 25.0 \\
\hline 0.0 & 9.0 & 1.0 & 22.5 \\
\hline 0.0 & 8.0 & 2.0 & 20.0 \\
\hline 0.0 & 7.0 & 3.0 & 17.5 \\
\hline 0.0 & 6.0 & 4.0 & 15.0 \\
\hline 0.0 & 5.0 & 5.0 & 12.5 \\
\hline
\end{tabular}

* Se usaron $1.0 \mathrm{~g} \mathrm{LiCF}_{3} \mathrm{SO}_{3}$ y $5 \mathrm{mg}$ de cuentas de cristal 50-100 $\mu \mathrm{m}$ para todas las composiciones

Tabla 2.3.1 Diferentes composiciones de los geles electrolíticos empleados en la construcción de dispositivos electrocrómicos. Las sustancias referidas son polietilenglicoletileter metacrilato (MA), polietilenglicol diacrilato (DA), 2,2-dimetoxi-2-fenil-acetofenona (DMPAP) y trifluorometanosulfonato de litio $\left(\mathrm{LiCF}_{3} \mathrm{SO}_{3}\right)$.

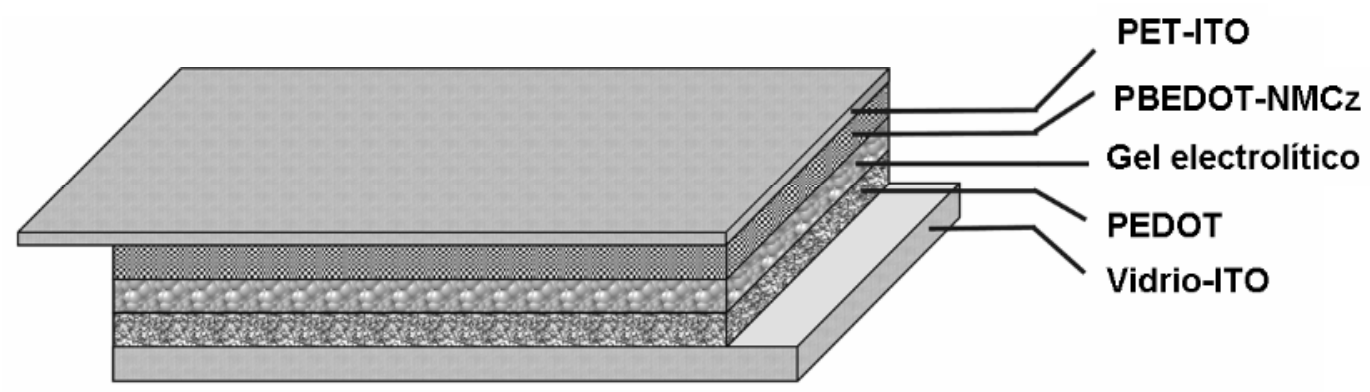

Figura 2.3.3 Corte transversal de un dispositivo electrocrómico dual PEDOT/PBEDOT-NMCz en estado sólido 
Los laterales de los dispositivos eran entonces sellados usando el pegamento UVS91 que era fotocurado durante tres minutos usando la misma fuente de luz ultravioleta. La figura 2.3.3 muestra un corte de los dispositivos en estado sólido construidos.

La calidad del sellado se comprobó por medio de la inmersión de los dispositivos en una disolución acuosa ligeramente acidificada de un complejo de tiocianato de hierro (III). Los dispositivos que no fueron sellados, o presentaban sellados deficientes se delaminaban completamente en un par de minutos. El gel electrolítico se agrietaba completamente por la absorción de agua, y quedaba completamente coloreado por la acción del tinte. No se observó ningún cambio en la velocidad de respuesta o en el contraste para dispositivos convenientemente sellados, después de someterlos a un vacío de 0.1 torr a $75^{\circ} \mathrm{C}$. 


\section{$\underline{\text { Resultados y discusión }}$}





\section{RESULTADOS Y DISCUSIÓN}

\subsection{ESTUDIO ESPECTROELECTROQUÍMICO DE POLÍMEROS CONDUCTORES: OBTENCIÓN DEL MÁXIMO CONTRASTE}

Polímeros utilizados en este estudio. Características ópticas de PEDOT y PBEDOT$N M C z$

El poli-3,4-etilendioxitiofeno (PEDOT) es un polímero conductor de bajo gap energético $(1.7 \mathrm{eV})[50,108]$, y por lo tanto, coloreable catódicamente, ampliamente conocido y utilizado en distintas aplicaciones de dispositivos electrocrómicos $[8,59,60$, 84, 85, 98, 116]. El PEDOT cambia desde un color azul cielo transparente en su estado oxidado a un azul oscuro en su estado reducido, con un máximo de absorción centrado en $620 \mathrm{~nm}$. El poli-3,6-bis(2-(3,4-etilendioxi)tienil)-N-metilcarbazol (PBEDOT$\mathrm{NMCz})$, polímero de alto gap energético $(2.4 \mathrm{eV})$, fue sintetizado por Sotzing et al. [72] y sus estados ópticos fueron descritos como un amarillo pálido en su estado reducido y un azul oscuro en su estado oxidado $\left(\lambda_{\max }\right.$ en estado oxidado $\left.=580 \mathrm{~nm}\right)$, pudiendo alcanzar un tercer color intermedio, verde lima, entre estos dos estados. Por lo tanto, el PBEDOT-NMCz se colorea anódicamente, y su comportamiento es complementario al del PEDOT cuando funcionan como electrodo de trabajo y contraelectrodo. Las estructuras químicas de los dos monómeros se muestran en la figura 3.1.1. Los espectros individuales de cada polímero fueron adquiridos en sus estados reducido y oxidado, utilizando la celda descrita en la figura 2.1.1, correspondiendo a -0.75 y $0.75 \mathrm{~V}$ vs. $\mathrm{Ag} / \mathrm{Ag}^{+}$para el PBEDOT-NMCz y -1.15 y $0.05 \mathrm{~V}$ vs. $\mathrm{Ag} / \mathrm{Ag}^{+}$para el PEDOT, en 
disolución $0.1 \mathrm{M} \mathrm{LiCF}_{3} \mathrm{SO}_{3}(\mathrm{ACN})$. Los espectros resultantes se muestran en la figura

\subsection{2.}

BEDOT-NMCZ

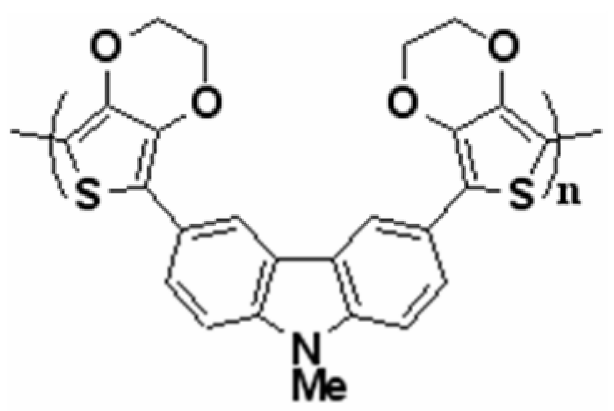

EDOT

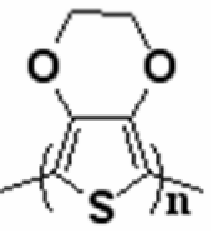

Figura 3.1.1 Estructuras químicas del 3,6-bis(2-(3,4-etilendioxi)tienil)-N-metilcarbazol (BEDOT$\mathrm{NMCz}$ ) y 3,4-etilendioxitiofeno (EDOT).

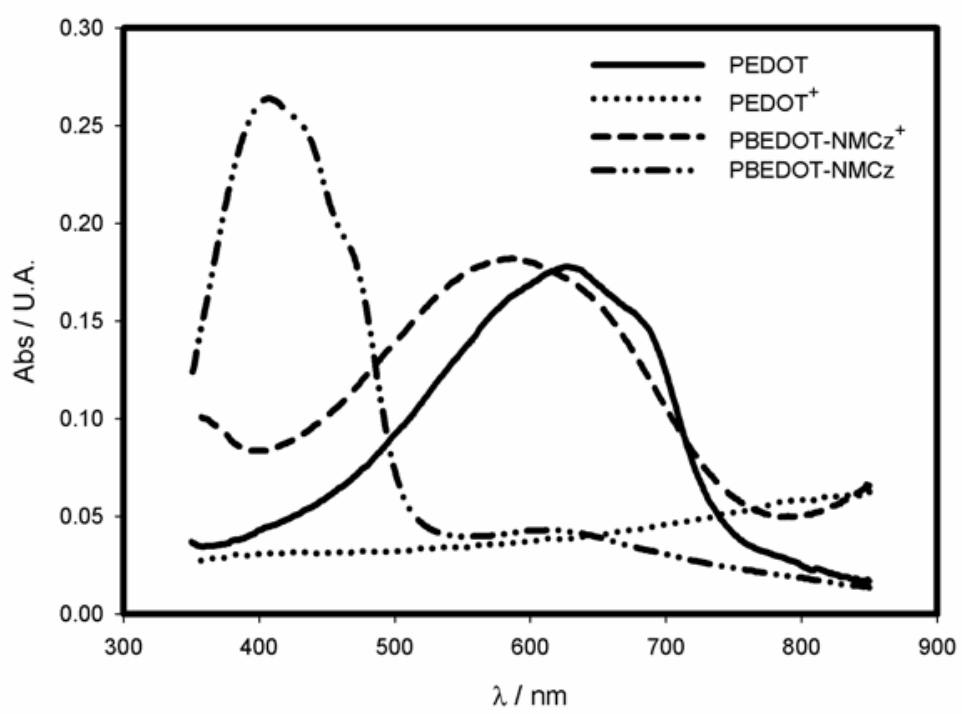

Figura 3.1.2 Espectros de absorbancia del PEDOT y PBEDOT-NMCz en la región visible. Los espectros de PBEDOT-NMCz corresponden a un estado de oxidación de $-0.75 \mathrm{~V}$ (estado neutro) y $0.75 \mathrm{~V}$ (estado oxidado) vs. $\mathrm{Ag} / \mathrm{Ag}^{+}$, mientras que los espectros de PEDOT corresponden a -1.15 (estado neutro) y 0.05 $\mathrm{V}$ (estado oxidado) vs. $\mathrm{Ag} / \mathrm{Ag}^{+}$. Experiencias realizadas en disolución $0.1 \mathrm{M} \mathrm{LiCF}_{3} \mathrm{SO}_{3}(\mathrm{ACN})$. 


\subsubsection{Estudio espectroelectroquímico de los polímeros usados}

Se obtuvieron los rangos de operación voltamperométrica y espectroelectroquímica individual, es decir, la ventana de potencial en la que se producen los procesos de oxidación y reducción, junto con el cambio en la absorbancia asociado independientemente para cada uno de los polímeros utilizados. Todos los experimentos fueron realizados en disolución de acetonitrilo $0.1 \mathrm{M} \mathrm{LiCF}_{3} \mathrm{SO}_{3}$, utilizando la cubeta modificada como se muestra en la figura 2.1.1.

De cara a determinar la ventana de potencial en la que ocurren cambios en el espectro del material, lo que definiremos como ventana de potencial electrocrómica, se obtuvieron los espectros de absorción a diferentes potenciales, en intervalos de $0.2 \mathrm{~V}$, entre -1.55 y $0.45 \mathrm{~V}$ vs. $\mathrm{Ag} / \mathrm{Ag}^{+}$para el PEDOT y entre -1.15 y 1.05 para el PBEDOT$\mathrm{NMCz}$ (figura 3.1.3). Durante la aplicación de 0.45 y $0.25 \mathrm{~V}$ no se observó ningún cambio en el espectro del PEDOT, mostrándose los espectros superpuestos. A partir de $0.05 \mathrm{~V}$ comienzan a observarse cambios en el espectro, produciéndose un pico de absorción en $620 \mathrm{~nm}$, como era esperado, creciente hasta llegar a $-1.15 \mathrm{~V}$; los espectros a -1.35 y -1.55 se superponen al de $-1.15 \mathrm{~V}$. Por lo tanto el rango de potenciales en los que ocurren cambios de color para el PEDOT es $-1.15 \mathrm{~V}$ a $0.05 \mathrm{~V}$ vs. $\mathrm{Ag} / \mathrm{Ag}^{+}$. En el caso del PBEDOT-NMCz, el espectro para $-1.15 \mathrm{~V}$ presenta el pico de absorción característico alrededor de $400 \mathrm{~nm}$, lo que le confiere la tonalidad amarillenta descrita anteriormente; no se aprecian cambios en el espectro desde -1.15 a $-0.75 \mathrm{~V}$, a partir de los cuales comienza a aparecer un pico de absorción en $580 \mathrm{~nm}$ creciente con el potencial anódico, mientras que el pico de absorción a $400 \mathrm{~nm}$ va desapareciendo. La aparición de este pico centrado alrededor de $580 \mathrm{~nm}$ es lo que permitirá su uso como 
polímero complementario al PEDOT. A partir de $0.45 \mathrm{~V}$, este pico comienza a disminuir hasta que prácticamente desaparece alrededor de $0.85 \mathrm{~V}$. Este comportamiento se ha descrito previamente [72], y está relacionado con el hecho de que este polímero presenta tres colores distintos. Puesto que nuestro interés se centra en su uso como polímero complementario al PEDOT, la ventana de potencial se determinó considerando el criterio de que el pico a $580 \mathrm{~nm}$ fuese apreciable. Esta ventanas de potencial es $-0.75 \mathrm{~V}$ a $0.75 \mathrm{~V}$ vs. $\mathrm{Ag} / \mathrm{Ag}^{+}$para PBEDOT-NMCz.
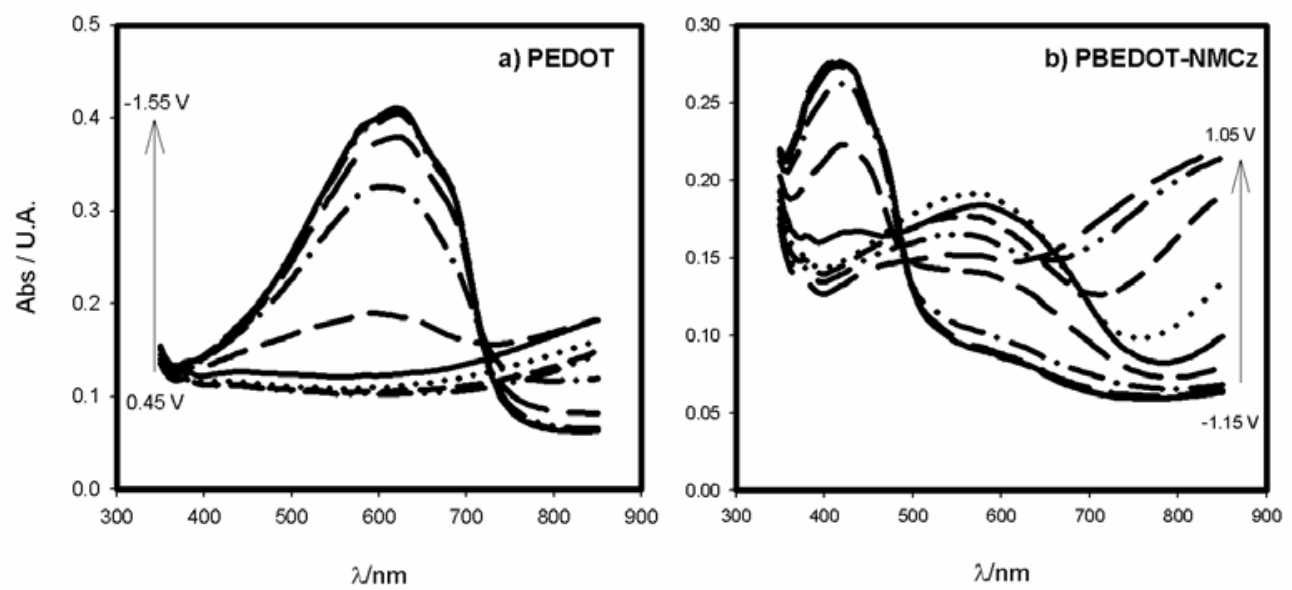

Figura 3.1.3 Espectros de absorbancia en función del estado de oxidación para los polímeros usados, a) PEDOT y b) PBEDOT-NMCz. Los espectros fueron obtenidos a intervalos de potencial de $0.2 \mathrm{~V}$ entre 1.55 y $0.45 \mathrm{~V}$ para el PEDOT y -1.15 a $1.05 \mathrm{~V}$ para el PBEDOT-NMCz (potenciales referidos a $\mathrm{Ag} / \mathrm{Ag}^{+}$), en disolución $0.1 \mathrm{M} \mathrm{LiCF}_{3} \mathrm{SO}_{3}$ en acetonitrilo.

Incursiones a potenciales más allá de estas ventanas, realizados experimentalmente por medio de voltamperometrías cíclicas, para cualquiera de estos polímeros, provocaron una disminución en los valores de transmitancia correspondientes al estado reducido del PEDOT, y en ambos estados, oxidado y reducido, para el PBEDOT- 
$\mathrm{NMCz}$, junto con la electroactividad de las películas, hecho posiblemente atribuible a procesos de degradación irreversibles.
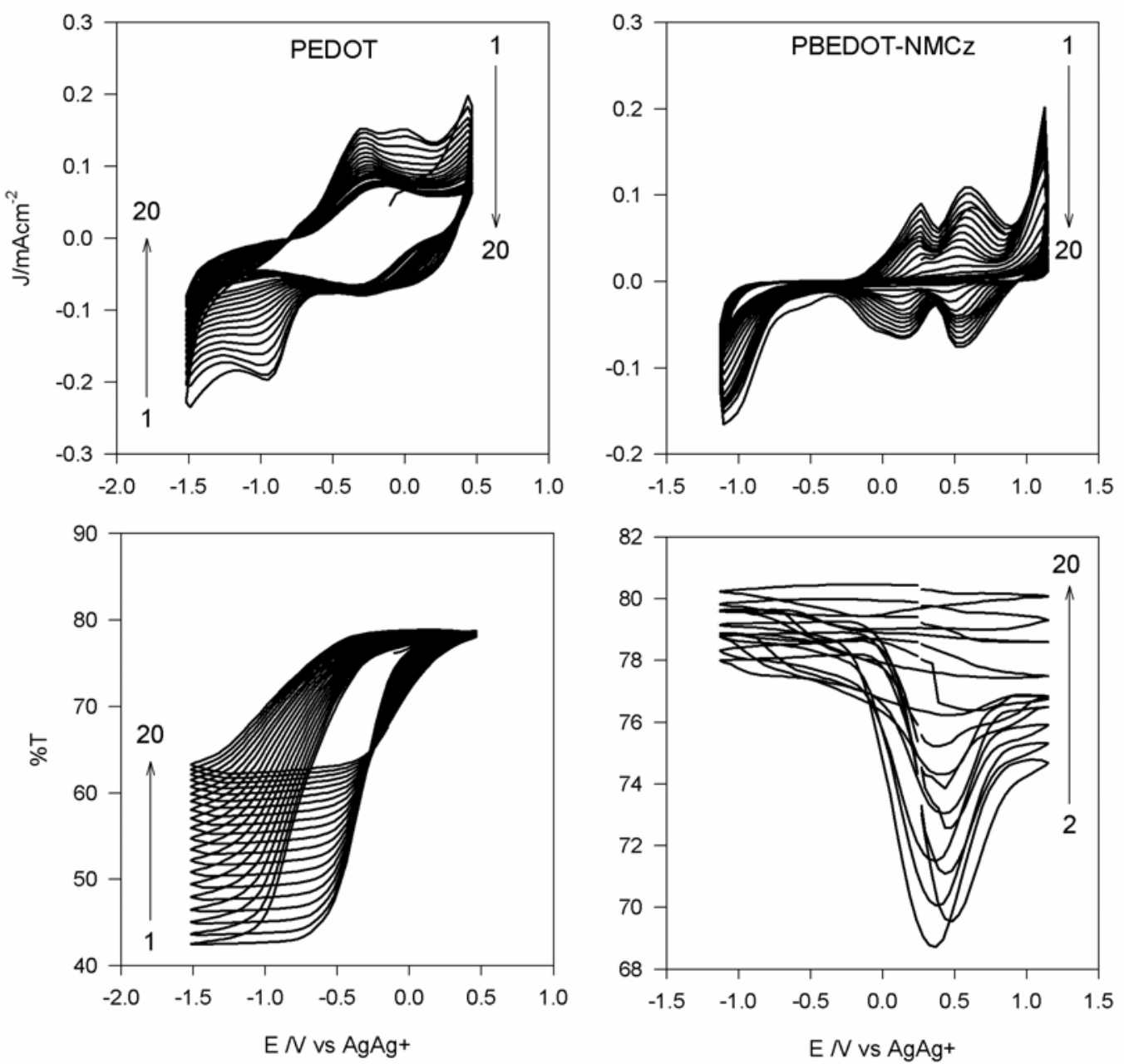

Figura 3.1.4 Voltamperogramas y sus correspondientes respuestas en absorbancia para PEDOT (registrado en $\left.\lambda_{\max }=620 \mathrm{~nm}\right)$, PBEDOT-NMCz $\left(\lambda_{\max }=580 \mathrm{~nm}\right)$ ciclados en $0.1 \mathrm{M} \mathrm{LiCF} \mathrm{SO}_{3}(\mathrm{ACN})$, velocidad de barrido $100 \mathrm{mVs}^{-1}$, durante 20 ciclos, entre: -1.55 y $0.45 \mathrm{~V}$ vs. $\mathrm{Ag} / \mathrm{Ag}^{+}$(PEDOT), -1.15 y 1.15 (PBEDOT-NMCz). Como contraelectrodo se usó un electrodo de ITO. Por claridad en las gráficas de transmitancia del PBEDOT-NMCz, sólo se representan los ciclos pares.

En la figura 3.1 .4 se muestran los valores de transmitancia en $\lambda_{\max }$ para cada polímero (620 nm para PEDOT y $580 \mathrm{~nm}$ para PBEDOT-NMCz), durante voltamperometrías cíclicas realizadas en rangos de potencial que excedían a los citados 
anteriormente en $0.4 \mathrm{~V}$ tanto en el límite anódico como el catódico, concretamente $1.55 \mathrm{~V}$ a $0.45 \mathrm{~V}$ para PEDOT y $-1.15 \mathrm{~V}$ a $1.15 \mathrm{~V}$ para PBEDOT-NMCz. Se produjeron pérdidas de 71 y $92 \%$ de los valores iniciales, respectivamente, en 20 ciclos.

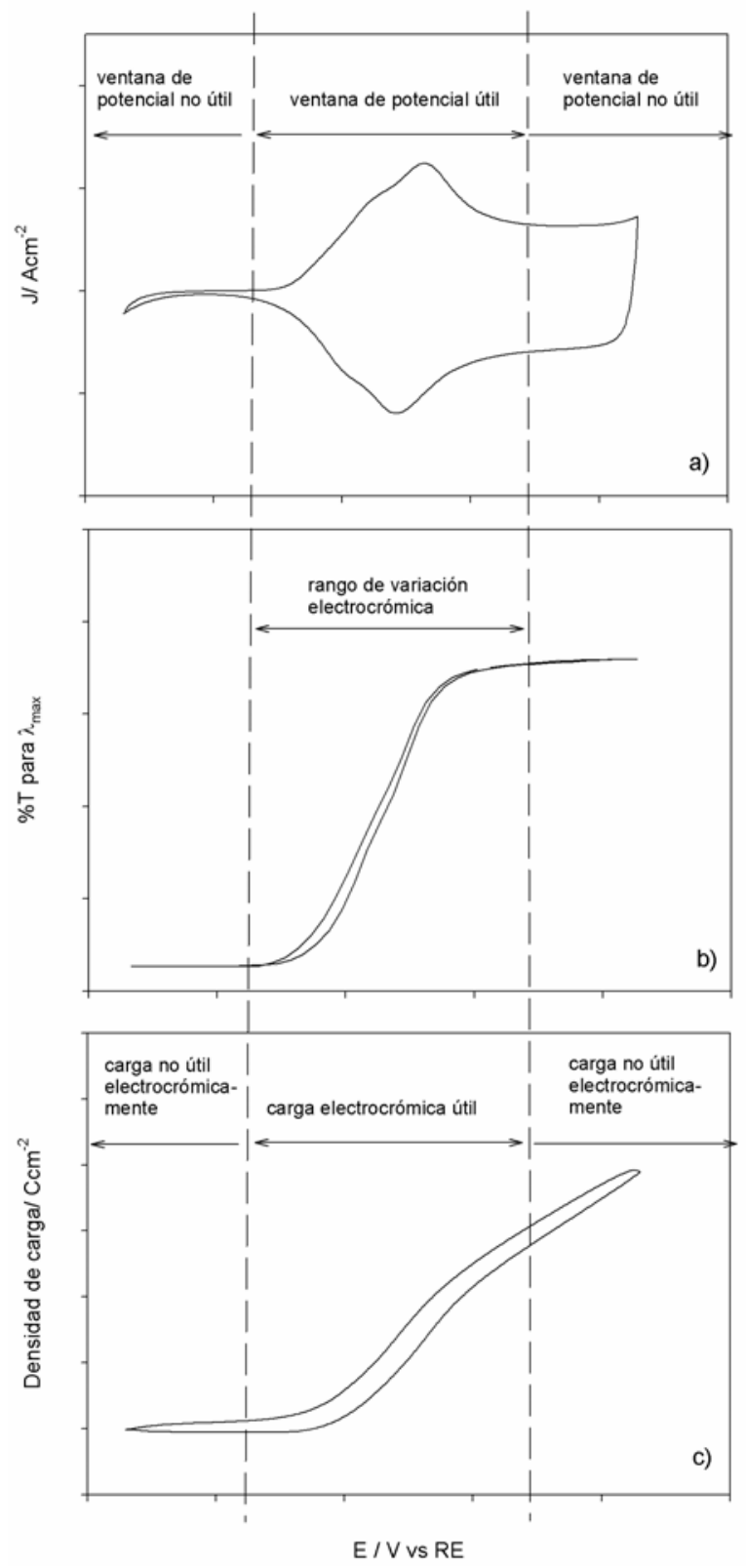

Figura 3.1.5 a) Voltamperograma genérico de un polímero conductor, junto con b) su respuesta en transmitancia registrada en $\lambda_{\max }(580 \mathrm{~nm})$ y c) la densidad de carga consumida, para una película de PBPMOM-ProDOT ciclada en disolución $0.1 \mathrm{M} \mathrm{LiCF}_{3} \mathrm{SO}_{3}$ de acetonitrilo (velocidad de barrido 100 $\mathrm{mVs}^{-1}$ ) Se definen las magnitudes de carga y potencial electrocrómicos útiles y no útiles, en función del rango de potencial en el que se producen cambios de color. 
En la figura anterior se ilustran algunos de los conceptos y definiciones que serán usados a lo largo del trabajo. En ella se muestran un voltamperograma genérico, junto con las evoluciones correspondientes a la carga consumida durante la oxidaciónreducción y transmitancia para una longitud de onda determinada.

La carga consumida dentro de la zona delimitada por rayas verticales está asociada con la creación (oxidación) o eliminación (reducción) de cromóforos (polarones y bipolarones) y la producción de cambios electrocrómicos y por lo tanto evolución en el color. La carga consumida en este rango de potenciales es la carga electrocrómica total para esa película, y el correspondiente rango de potenciales representa su ventana de potencial electrocrómica. Las cargas consumidas fuera de ese rango no son útiles para producir cambios electrocrómicos, y eventualmente pueden producir procesos degradativos, directa o indirectamente. Usaremos los términos carga y potencial inútil para referirnos a carga consumida y evoluciones de potencial fuera de la ventana electrocrómica. 


\subsubsection{Consideraciones preliminares en electropolimerización de polímeros conductores. Efecto del potencial de polimerización.}

Los procesos de polimerización electroquímica, mediante la aplicación de un potencial anódico suficiente como para provocar la oxidación de los monómeros presentes, seguido de posteriores reacciones de acoplamiento, oligomerización, y finalmente, deposición de la película polimérica, ampliamente descritos en la literatura $[35,106,107,117-120]$, pueden estar acompañados de reacciones paralelas o parásitas [103, 121-128]. Los dos tipos de reacciones paralelas más importantes son los procesos de sobreoxidación del polímero creado y las reacciones de descarga del solvente o electrolito empleados. Las reacciones de sobreoxidación afectan directamente a la electroactividad del material depositado, destruyendo la conjugación de la cadena polimérica. El efecto directo de las reacciones de descarga del electrolito o solvente, es el de un consumo ineficiente de carga, pues ésta no se emplea en la obtención de película polimérica. Indirectamente, los reactivos creados durante estos procesos pueden atacar las cadenas poliméricas, provocando también una degradación del polímero y disminuyendo su electroactividad.

La aparición de reacciones paralelas está directamente relacionada con el potencial al que se produce la polimerización.

Cualquier aplicación electroquímica de estos materiales está relacionada con el cambio provocado por los procesos de oxidación y reducción, por lo que la definición de unas condiciones de síntesis que aseguren una electroactividad suficiente es necesaria. 
Como norma general se emplea el potencial más bajo posible, pero suficiente para producir la polimerización. Es un criterio fiable para reducir posibles reacciones parásitas. Sin embargo, el aumento del potencial aplicado produce un aumento de la velocidad de polimerización. Si bien a escala de laboratorio, la diferencia de tiempos para películas delgadas puede ser insignificante, la posible aplicación de estos procesos a escala industrial necesitará optimizar el tiempo de fabricación, asegurando a su vez unos mínimos de calidad en las películas resultantes. Teniendo en cuenta estas consideraciones, se realizó un estudio del efecto del potencial de polimerización sobre la electroactividad de las películas resultantes, de cara a definir un intervalo de potenciales correctos para realizar la electropolimerización.

Las condiciones de trabajo fueron las siguientes: se escogieron 4 potenciales por encima del de inicio de la polimerización para cada uno de los monómeros, (1 V vs. Ag/Ag+ para el PEDOT [40] y $0.28 \mathrm{~V}$ vs. Ag/Ag+ para el PBEDOT-NMCz [72]), realizándose series de polimerizaciones a distintos tiempos.

Los potenciales aplicados en el caso del PEDOT fueron 1, 1.3, 1.6 y $1.9 \mathrm{~V}$ vs. $\mathrm{Ag} / \mathrm{Ag}^{+}$, mientras que en el caso del PBEDOT-NMCz, los potenciales fueron $0.4,0.8$, 1.2 y $1.6 \mathrm{~V}$ vs. $\mathrm{Ag} / \mathrm{Ag}^{+}$. La celda de trabajo fue una celda electroquímica convencional. El electrodo de trabajo fue un electrodo de platino cilíndrico recubierto de teflón, con una superficie descubierta de $0.0314 \mathrm{~cm}^{2}$, siendo el contraelectrodo una lámina de platino de $5 \mathrm{~cm}^{2}$.

La figura 3.1.6 muestra el consumo de carga para los distintos potenciales y tiempos aplicados. La densidad de carga de polimerización se define como la carga consumida por unidad de superficie electródica. 

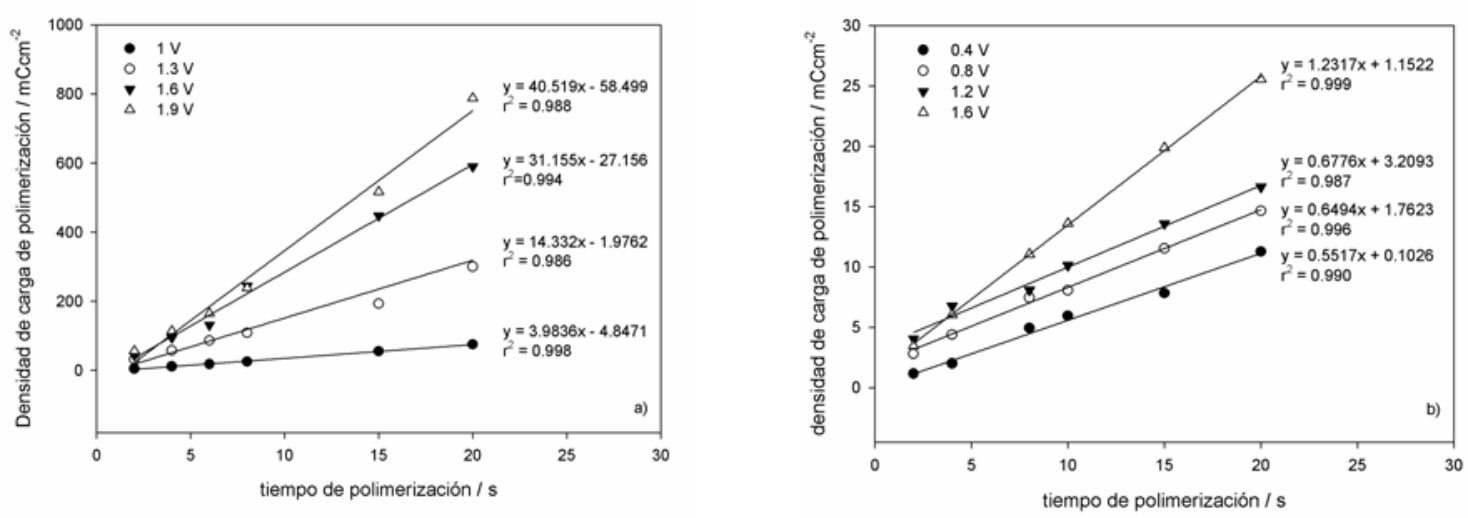

Figura 3.1.6 Densidad de carga de polimerización consumida en función del tiempo de polimerización, para distintos potenciales. a) PEDOT, potenciales de polimerización 1, 1.3, 1.6 y $1.9 \mathrm{~V}$ vs. $\mathrm{Ag} / \mathrm{Ag}^{+}$b) PBEDOT-NMCz, potenciales de polimerización 0.4, 0.8, 1.2 y $1.6 \mathrm{~V}$ vs. $\mathrm{Ag} / \mathrm{Ag}^{+}$. En ambos casos las polimerizaciones fueron llevadas a cabo sobre electrodo de platino como electrodo de trabajo (con contraelectrodo de platino), en disolución de acetonitrilo $0.1 \mathrm{M} \mathrm{LiCF}_{3} \mathrm{SO}_{3}(20 \mathrm{mM}$ EDOT ó $1 \mathrm{mM}$ BEDOT-NMCz).

Podemos observar como un aumento en el potencial aplicado implica un aumento en la carga consumida. Se producen, por tanto, un mayor número de reacciones de oxidación en la disolución, y a una velocidad mayor. La posterior determinación de la cantidad de sitios electroactivos creados para cada película, por medio de la técnica voltamperométrica, nos aportará información sobre cuanta de esa carga ha sido finalmente utilizada en la creación de sitios con capacidad de oxidación y reducción, dentro de la película. Por lo tanto las películas fueron caracterizadas electroquímicamente por medio de voltamperometrías cíclicas realizadas en la misma disolución de polimerización en ausencia de monómero, entre -1.15 y $0.05 \mathrm{~V}$ vs. $\mathrm{Ag} / \mathrm{Ag}^{+}$, para el caso del PEDOT y -0.75 y $0.75 \mathrm{~V}$ para el PBEDOT-NMCz, a $100 \mathrm{mVs}{ }^{-}$ 1. Los voltamperogramas obtenidos para cada serie se muestran en la figuras 3.1.7 y 3.1.8. 

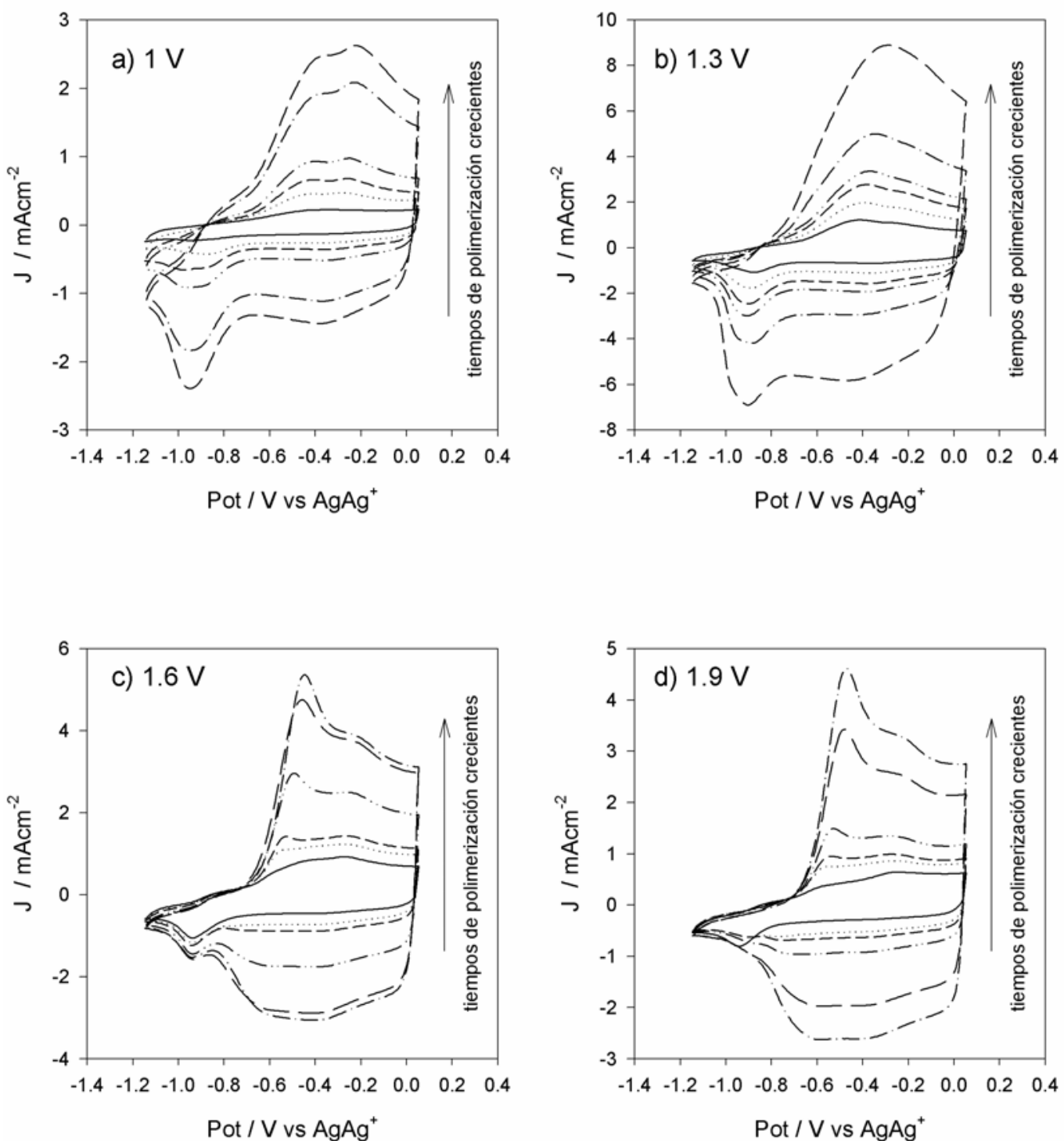

Figura 3.1.7 Voltamperogramas de cuatro series de películas de PEDOT depositadas a distintos tiempos de polimerización ( $\mathrm{t}=2,4,6,8,15$ y $20 \mathrm{~s}$ ). Los potenciales de polimerización fueron a) $1 \mathrm{~V}$, b) $1.3 \mathrm{~V}$, c) $1.6 \mathrm{~V}$ y d) $1.9 \mathrm{~V}$ vs. $\mathrm{Ag} / \mathrm{Ag}^{+}$. Las polimerizaciones fueron llevadas a cabo sobre electrodo de platino como electrodo de trabajo (con contraelectrodo de platino), en disolución de acetonitrilo $0.1 \mathrm{M}$ $\mathrm{LiCF}_{3} \mathrm{SO}_{3}(20 \mathrm{mM}$ EDOT), y las voltamperometrías se llevaron a cabo en la misma disolución en ausencia de monómero, entre -1.15 y $0.05 \mathrm{~V}$ vs. $\mathrm{Ag} / \mathrm{Ag}^{+}$a $100 \mathrm{mVs}^{-1}$. 

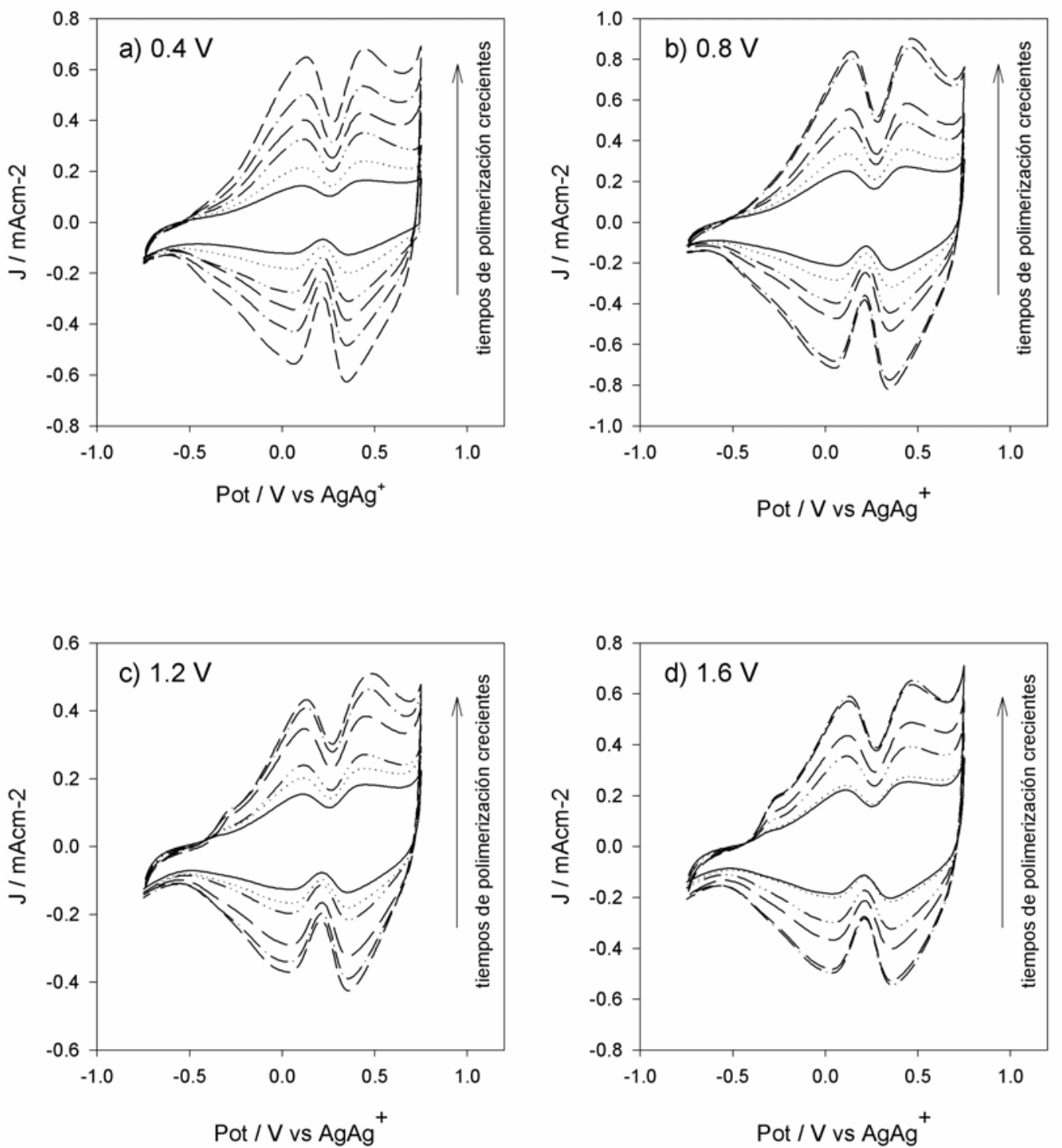

Figura 3.1.8 Voltamperogramas de cuatro series de películas de PBEDOT-NMCz depositadas a distintos tiempos de polimerización ( $\mathrm{t}=2,4,8,10,15$ y $20 \mathrm{~s}$ ). Los potenciales de polimerización fueron a) $0.4 \mathrm{~V}, \mathrm{~b}) 0.8 \mathrm{~V}, \mathrm{c}) 1.2 \mathrm{~V}$ y d) $1.6 \mathrm{~V}$ vs. $\mathrm{Ag} / \mathrm{Ag}^{+}$. Las polimerizaciones fueron llevadas a cabo sobre electrodo de platino como electrodo de trabajo (con contraelectrodo de platino), en disolución de acetonitrilo $0.1 \mathrm{M} \mathrm{LiCF}_{3} \mathrm{SO}_{3}(1 \mathrm{mM}$ BEDOT-NMCz), y las voltamperometrías se llevaron a cabo en la misma disolución en ausencia de monómero, entre $-0.75 \mathrm{~V}$ y $0.75 \mathrm{~V}$ vs. $\mathrm{Ag} / \mathrm{Ag}^{+}$a $100 \mathrm{mVs}^{-1}$. 
De los voltamperogramas correspondientes, se calculó la carga anódica, Qox, (oxidación del polímero) y catódica, $\mathrm{Q}_{\text {red }}$ (reducción del polímero) consumida para cada película. La densidad de carga redox se definió como la media de estos dos valores, dividido por la superficie de electrodo polimerizada, que fue $0.0314 \mathrm{~cm}^{2}$ en todos los casos.
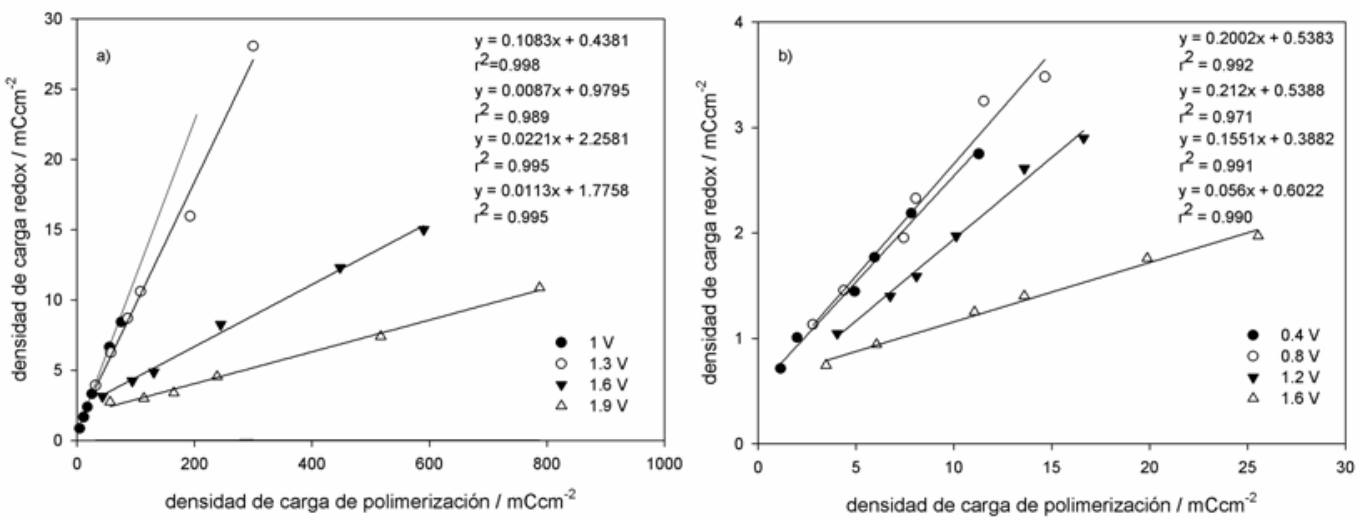

Figura 3.1.9 Relación entre la densidad de carga de polimerización consumida y la densidad de carga redox, para distintos potenciales de polimerización. a) PEDOT, potenciales de polimerización 1, 1.3, 1.6 y $1.9 \mathrm{~V}$ vs. $\mathrm{Ag} / \mathrm{Ag}^{+}$b) PBEDOT-NMCz, potenciales de polimerización 0.4, 0.8, 1.2 y $1.6 \mathrm{~V} \mathrm{vs.} \mathrm{Ag} / \mathrm{Ag}^{+}$. En ambos casos las polimerizaciones fueron llevadas a cabo sobre electrodo de platino como electrodo de trabajo (con contraelectrodo de platino), en disolución de acetonitrilo $0.1 \mathrm{M} \mathrm{LiCF}_{3} \mathrm{SO}_{3}(20 \mathrm{mM}$ EDOT ó 1mM BEDOT-NMCz)

Con esta información adicional, podremos obtener conclusiones acerca de cual de las condiciones de polimerización es más productiva en términos de electroactividad en las películas producidas. Relacionando los datos experimentales para las cargas redox consumidas durante la caracterización voltamperométrica y las cargas de polimerización consumidas en la polimerización de la película, definimos la eficiencia de polimerización como el cociente entre estas dos magnitudes. Los distintos datos experimentales para cada serie fueron representados en la figura 3.1.9. 
Analizando las pendientes de los datos obtenidos para distintos potenciales de polimerización (tabla 3.1.1), se observa una disminución de la eficiencia de polimerización con el aumento del potencial aplicado para los dos polímeros. Para el caso del PEDOT, hay una disminución progresiva de la eficiencia de polimerización al aumentar el potencial de polimerización aplicado, obteniendo a $1.3,1.6$ y $1.9 \mathrm{~V}$, unas eficiencias que representan el 80,20 y $10 \%$ del valor obtenido para $1 \mathrm{~V}$, respectivamente. Sin embargo en el caso del PBEDOT-NMCz no existe tal disminución hasta llegar a $1.2 \mathrm{~V}$, manteniendo un valor aproximadamente constante para 0.4 y $0.8 \mathrm{~V}$. Los valores de eficiencia correspondientes a 1.2 y $1.6 \mathrm{~V}$ representan el 65 y $25 \%$ del valor obtenido para $0.4 \mathrm{~V}$, respectivamente.

\begin{tabular}{cccc}
\hline \multicolumn{2}{c}{ PEDOT } & \multicolumn{2}{c}{ PBEDOT-NMCz } \\
\hline $\begin{array}{c}\text { Potencial de } \\
\text { polimerización/v v } \\
\text { vs AgAg+ }\end{array}$ & $\begin{array}{c}\text { Eficiencia de } \\
\text { polimerización }\end{array}$ & $\begin{array}{c}\text { Potencial de } \\
\text { polimerización/V } \\
\text { vs AgAg+ }\end{array}$ & $\begin{array}{c}\text { Eficiencia de } \\
\text { polimerización }\end{array}$ \\
\hline 1 & 0.11 & 0.4 & 0.20 \\
1.3 & 0.09 & 0.8 & 0.21 \\
1.6 & 0.02 & 1.2 & 0.16 \\
1.9 & 0.01 & 1.6 & 0.06
\end{tabular}

Tabla 3.1.1 Eficiencia de polimerización, definida como cociente entre la carga consumida durante la polimerización respecto a la carga redox consumida por cada película durante su caracterización voltamperométrica, en función del potencial de polimerización para PEDOT y PBEDOT-NMCz

Los valores de eficiencia en el caso de PBEDOT-NMCz son más altos que los correspondientes al PEDOT. La utilización de potenciales mas anódicos en este último caso, sobrepasando el potencial de descarga del solvente utilizado, acetonitrilo, que se sitúa en torno a $1 \mathrm{~V}$ vs. $\mathrm{Ag} / \mathrm{Ag}^{+}$[129], plantea la posibilidad de que la reacción de 
descarga esté tomando protagonismo frente a la de polimerización, resultando en procesos de menor eficiencia en la generación de sitios electroactivos.

De los datos obtenidos, se desprende que un rango aceptable de potenciales de polimerización para el EDOT estaría situado entre 1 y $1.3 \mathrm{~V}$ vs. $\mathrm{Ag} / \mathrm{Ag}^{+}$, mientras que valores entre 0.4 y $0.8 \mathrm{~V}$ serían los óptimos para la electropolimerización del BEDOT$\mathrm{NMCz}$

\subsubsection{Electropolimerización sobre ITO. Consideraciones generales}

La posible aplicación de este tipo de películas poliméricas en dispositivos electrocrómicos de transmisión variable, o ventanas inteligentes, implica su deposición sobre substratos transparentes, por lo que, una vez conocidos los potenciales adecuados para la polimerización sobre electrodo de platino, en base al anterior estudio, se procedió a estudiar la electrodeposición sobre electrodos de ITO, óxido de indio y estaño, material transparente y conductor eléctrico, depositado sobre vidrio convencional.

Películas de los polímeros utilizados en el anterior estudio, PEDOT y PBEDOT$\mathrm{NMCz}$, con distintos tiempos de polimerización $(2,4,5,10,12,15$ y $20 \mathrm{~s}$ para el PEDOT; 2,4,6,10,12 y 16 para el PBEDOT-NMCz) fueron depositadas sobre este material, en las mismas condiciones experimentales de concentración de electrolito y monómero, así como solvente utilizado. Los potenciales empleados para la polimerización fueron 0.65 $\mathrm{V}$ vs. $\mathrm{Ag} / \mathrm{Ag}^{+}$para el PBEDOT-NMCz y $1.3 \mathrm{~V}$ vs. $\mathrm{Ag} / \mathrm{Ag}^{+}$para el PEDOT. La superficie polimerizada fue $2.1 \mathrm{~cm}^{2}$ en todos los casos. Se calcularon las mismas 
magnitudes que en el anterior estudio. La figura 3.1.10 muestra la evolución de la carga consumida durante el proceso de polimerización en función del tiempo de polimerización para los dos polímeros.
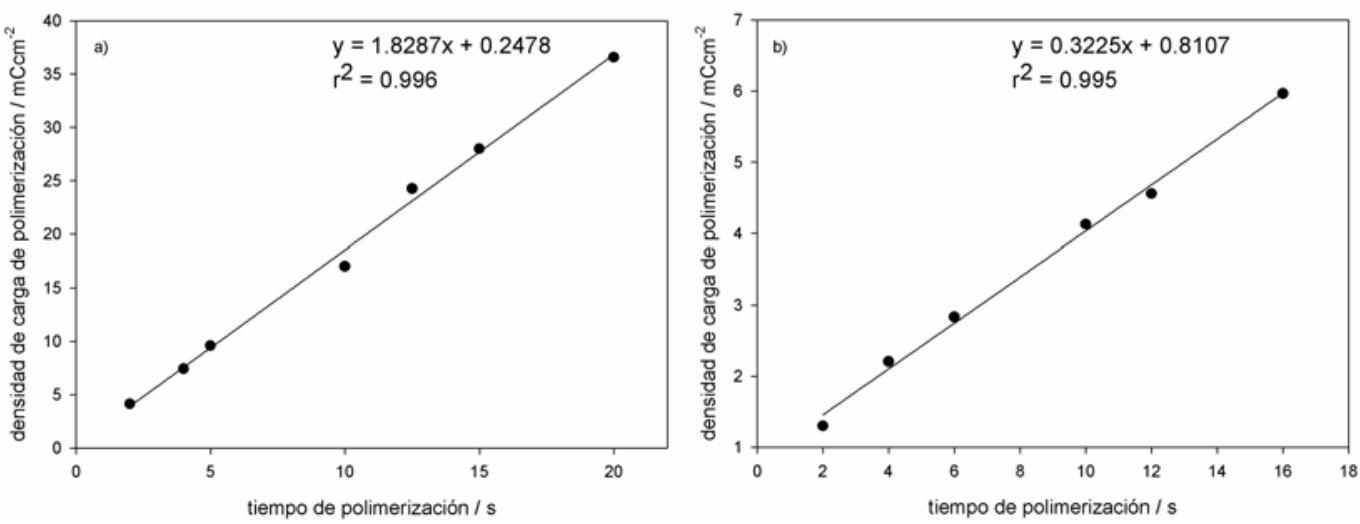

Figura 3.1.10 Densidad de carga de polimerización consumida en función del tiempo de polimerización a) PEDOT, potencial de polimerización $1.3 \mathrm{~V}$ vs. $\mathrm{Ag} / \mathrm{Ag}^{+} \quad$ b) PBEDOT-NMCz, potencial de polimerización $0.65 \mathrm{~V}$ vs. $\mathrm{Ag} / \mathrm{Ag}+$. En ambos casos las polimerizaciones fueron llevadas a cabo sobre ITO como electrodo de trabajo (con contraelectrodo de platino), en disolución de acetonitrilo 0.1 $\mathrm{M} \mathrm{LiCF}_{3} \mathrm{SO}_{3}$ (20 mM EDOT ó 1mM BEDOT-NMCz).

Comparándolos con los resultados de electropolimerización sobre platino, se observa que el consumo de carga de polimerización frente a tiempo es menor en el caso de deposición sobre ITO para los dos polímeros. La menor conductividad del ITO respecto a un metal como el platino impondría un límite al paso de corriente eléctrica a través del electrodo, traduciéndose en una disminución en el consumo de carga.

Sin embargo, una vez obtenidos los valores de las densidades de carga redox de las películas, por medio de voltamperometrías cíclicas, los valores de eficiencia en la polimerización resultantes son similares, aunque ligeramente menores, a los valores obtenidos sobre platino (figura 3.1.11). 

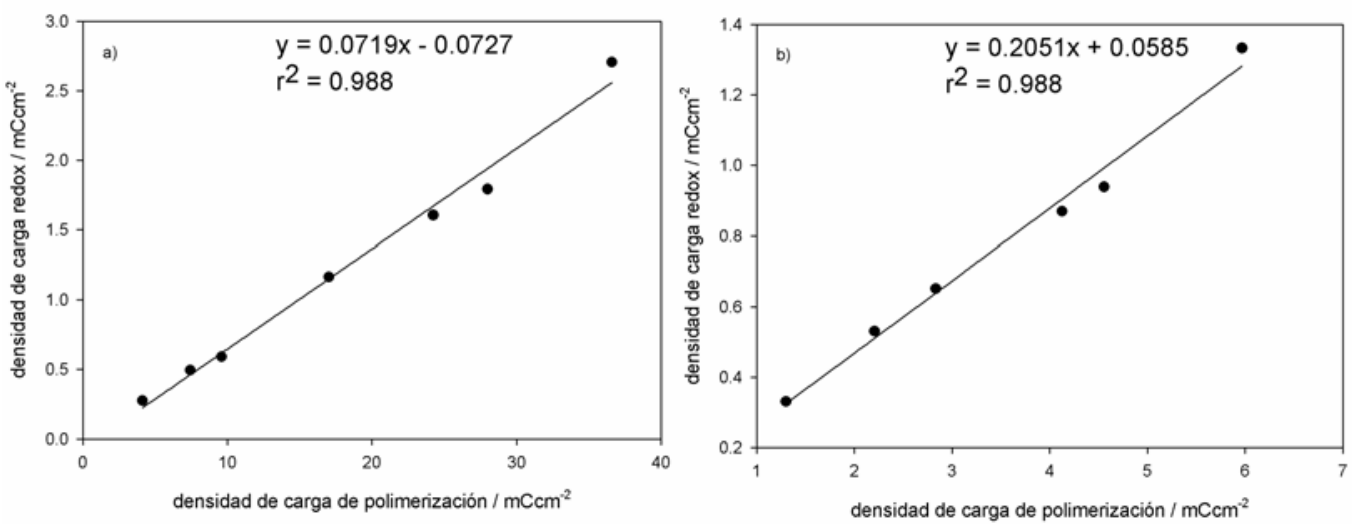

Figura 3.1.11 Relación entre la densidad de carga de polimerización consumida y la densidad de carga redox de películas de a) PEDOT, potencial de polimerización $1.3 \mathrm{~V}$ vs. $\mathrm{Ag} \mathrm{Ag}^{+}$b) PBEDOT-NMCz, potencial de polimerización $0.65 \mathrm{~V}$ vs. $\mathrm{Ag} / \mathrm{Ag}^{+}$. En ambos casos las polimerizaciones fueron llevadas a cabo sobre ITO como electrodo de trabajo (con contraelectrodo de platino), en disolución de acetonitrilo $0.1 \mathrm{M} \mathrm{LiCF}_{3} \mathrm{SO}_{3}(20 \mathrm{mM}$ EDOT ó $1 \mathrm{mM}$ BEDOT-NMCz).

\subsubsection{Efecto de la desoxigenación en la eficiencia culómbica}

La eficiencia culómbica se define como el cociente porcentual entre carga anódica y catódica consumida durante el proceso cíclico de oxidación-reducción (realizada mediante voltamperometría cíclica, en nuestro caso). Idealmente, esta eficiencia debería ser del $100 \%$. Valores distintos, indican que, o bien toda la carga de oxidación (o reducción) consumida durante el barrido en la dirección anódica (catódica) no se está recuperando durante el barrido en la dirección opuesta, o bien existe algún tipo de proceso de oxidación o reducción irreversible adicional al de la película polimérica.

Series de películas de los dos polímeros utilizados, PEDOT y PBEDOT-NMCz polimerizadas a distintos tiempos $(2,4,8,10,12.5,15,17.5$ y 20 s para PEDOT; $2,4,6$ , $8,10,12,14$ y 16 para PBEDOT-NMcz) en las mismas condiciones que el estudio anterior, fueron caracterizadas voltamperométricamente, obteniendo los valores de 
carga anódica y catódica, así como su eficiencia culómbica. La superficie polimerizada fue $2.1 \mathrm{~cm}^{2}$ para todos los casos. Los resultados se muestran en la figura 3.1.12.

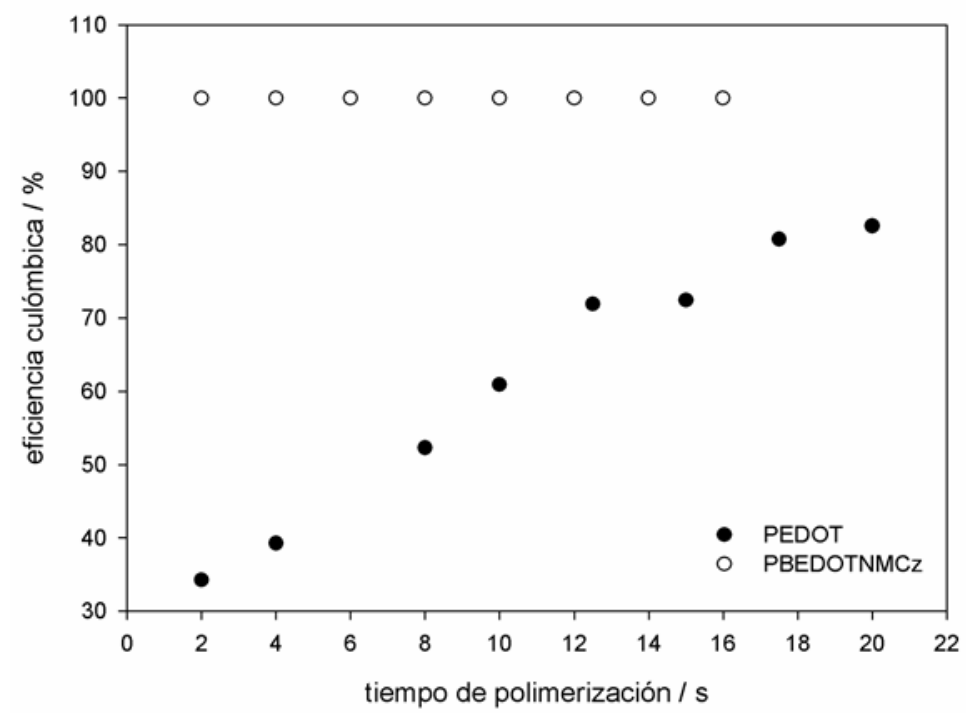

Figura 3.1.12 Eficiencia culómbica, definida como el cociente porcentual entre la carga redox anódica y catódica, obtenida a partir de las correspondientes voltamperometrías cíclicas, para películas de PEDOT y PBEDOT-NMCz, polimerizadas a tiempos crecientes. (PEDOT, potencial de polimerización $1.3 \mathrm{~V}$ vs. $\mathrm{Ag} / \mathrm{Ag}^{+}$y PBEDOT-NMCz, potencial de polimerización $0.65 \mathrm{~V}$ vs. $\mathrm{Ag} / \mathrm{Ag}^{+}$) En ambos casos las polimerizaciones fueron llevadas a cabo sobre ITO como electrodo de trabajo (con contraelectrodo de platino), en disolución de acetonitrilo $0.1 \mathrm{M} \mathrm{LiCF}_{3} \mathrm{SO}_{3}(20 \mathrm{mM}$ EDOT ó $1 \mathrm{mM}$ BEDOT-NMCz) y las voltamperometrías se llevaron a cabo en la misma disolución en ausencia de monómero.

Mientras que para el caso de PBEDOT-NMCz, este valor se mantiene constante y próximo al $100 \%$, en el caso del PEDOT este valor varia desde el 34 al $80 \%$ aproximadamente. Estos valores en el PEDOT reflejan la existencia de un proceso de consumo de carga paralelo al de oxidación y reducción de la película, e independiente de ésta. La independencia de los dos procesos se pone claramente de manifiesto al obtener la diferencia entre carga anódica y carga catódica consumida, para todas las películas utilizadas en la serie. Esta operación da un valor constante e igual a 0.61 $\mathrm{mC} / \mathrm{cm}^{2}$ (desviación standard $\sigma=0.05$ ) para ese proceso paralelo y no correspondiente a 
reducción u oxidación del polímero, independientemente de la carga redox de la película polimérica (figura 3.1.13).

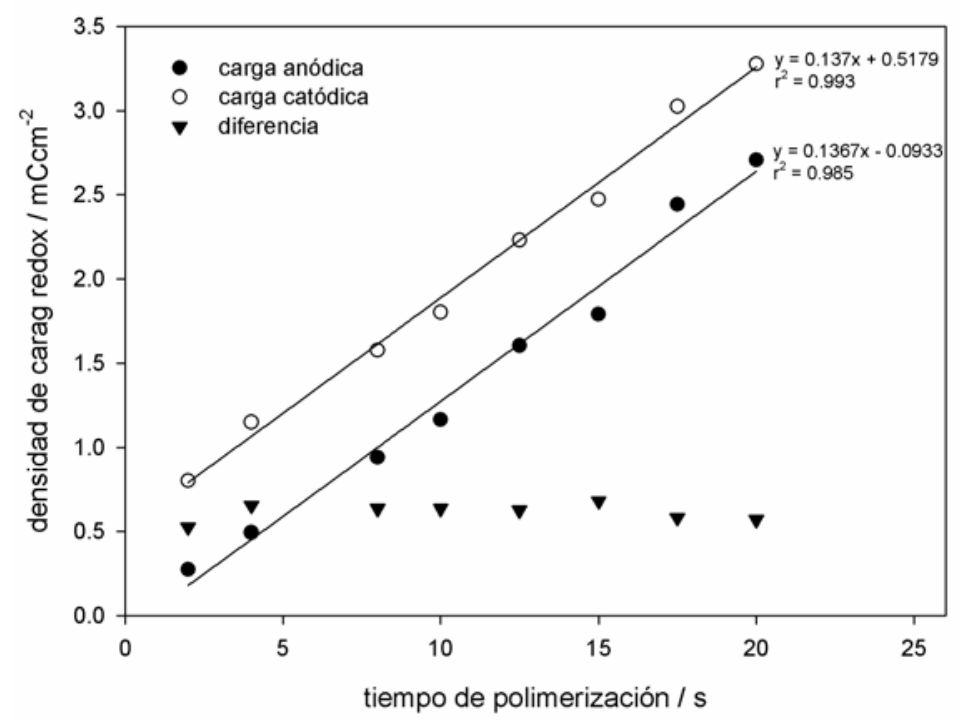

Figura 3.1.13 Densidades de carga anódicas y catódicas, junto con la diferencia entre ambos valores, obtenidas a partir de las voltamperometrías cíclicas (entre -1.15 y $0.05 \mathrm{~V}$ vs. $\mathrm{Ag} / \mathrm{Ag}^{+}$) de películas de PEDOT polimerizadas a distintos tiempos. Las polimerizaciones fueron llevadas a cabo sobre ITO como electrodo de trabajo (con contraelectrodo de platino), en disolución de acetonitrilo $0.1 \mathrm{M} \mathrm{LiCF}_{3} \mathrm{SO}_{3}(20$ $\mathrm{mM}$ EDOT) y las voltamperometrías se llevaron a cabo en la misma disolución en ausencia de monómero.

Estos procesos pueden ser fácilmente reducidos por medio del borboteo de nitrógeno a través de la disolución durante unos minutos. La realización de esta acción disminuye estos procesos indeseados, aumentando los valores de eficiencia culómbica hasta más de un $80 \%$, permaneciendo aproximadamente constantes para todas las películas estudiadas. 


\subsubsection{Variación de la transmitancia en función de la carga redox. Obtención del máximo contraste.}

La transmitancia de un material está definida por la expresión:

$$
\mathrm{T}=\exp (-\alpha c \mathrm{c})
$$

Siendo $\alpha$ el coeficiente de absorción lineal, c la concentración de especies absorbentes, y 1 el grosor del material absorbente.

Para una película electrocrómica, la concentración de especies absorbentes está directamente relacionada con los procesos de oxidación-reducción y la creación de bandas intermedias de energía, es decir, con la densidad de carga redox asociada a la película.

Habitualmente nos referimos al contraste alcanzado por una película, como la diferencia de transmitancia entre dos estados a y b, siendo b el más absorbente de los dos, como convención para obtener valores de contraste positivos,

$\Delta \mathrm{T}=\exp \left(-\alpha_{\mathrm{b}} \mathrm{c}_{\mathrm{b}} \mathrm{l}\right)-\exp \left(-\alpha_{\mathrm{a}} \mathrm{c}_{\mathrm{a}} \mathrm{l}\right)$

Es una observación frecuente en el trabajo con polímeros conductores, que películas suficientemente gruesas no presenten electrocromismo, puesto que tanto el estado oxidado como el reducido son tan absorbentes como para no distinguir ningún cambio de color. Asimismo, los estados oxidado y reducido de películas con muy poco material son prácticamente transparentes y apenas distinguibles. Es decir, tanto en una 
situación como otra, el contraste apreciado es nulo. Por lo tanto, debe existir un punto intermedio en el que el contraste sea máximo. Esta percepción concuerda con la expresión matemática para la $\Delta \mathrm{T}$, resta de dos decaimientos exponenciales, y que por lo tanto presenta un máximo para el valor $\mathrm{d} \Delta \mathrm{T}=0$. El cálculo del máximo para una expresión genérica $\mathrm{y}=\mathrm{a} \mathrm{e}^{(-\mathrm{bx})}-\mathrm{ce}^{(-\mathrm{dx})}$ es el siguiente:

$y=a e^{(-b x)}-c e^{(-d x)}$

$\mathrm{d} \Delta \mathrm{T} / \mathrm{dx}=-\mathrm{abe} \mathrm{e}^{(-\mathrm{bx})}+\mathrm{cde}^{(-\mathrm{dx})}$

igualando esta expresión a cero, obtenemos:

$-\mathrm{abe}^{(-\mathrm{bx})}+\mathrm{cde}^{(-\mathrm{dx})}=0$

$\mathrm{y}$ despejando la $\mathrm{x}$, obtenemos que $\mathrm{x}_{\max }$ es igual a

$\mathrm{x}_{\max }=\ln (\mathrm{cd} / \mathrm{ab}) /(\mathrm{d}-\mathrm{b})$

En nuestro caso, la variable x está directamente relacionada con la concentración de cromóforos, o lo que es lo mismo, puesto que la carga de oxidación o reducción se emplea en la creación o eliminación de éstos cromóforos, con la carga redox consumida.

La optimización de cualquier sistema electrocrómico pasa por la obtención del máximo contraste posible en cada uno de sus componentes, por lo que la finalidad del siguiente estudio es la de determinar las condiciones de contraste máximo para cada uno 
de los polímeros constituyentes de los dispositivos electrocrómicos que se pretenden construir.

Para ello se determinará la relación existente entre transmitancia y densidad de carga redox (directamente asociada con la concentración de especies absorbentes) para cada polímero a estudiar. El procedimiento a utilizar para la obtención de esta información sería el siguiente:

Polimerización de películas de los polímeros conductores a estudiar, en este caso PEDOT y PBEDOT-NMCz, con densidades de carga redox crecientes, seguido de la obtención de sus espectros de absorbancia en los estados transparente y coloreado; con esta información, pueden calcularse las respuestas fotópicas ponderadas para cada película, tal y como se especifica en la sección 1.3. Representación de los valores fotópicos en los estados transparente y coloreado, junto con el contraste correspondiente, para los polímeros estudiados, en función de su densidad de carga redox, obteniendo el punto de máximo contraste para cada uno de ellos.

Se polimerizaron películas de PEDOT con densidades de carga redox comprendidas entre 0 y $5 \mathrm{mCcm}^{-2}$. La densidad de carga redox para cada película se obtuvo mediante la integración de la carga consumida durante la caracterización voltamperométrica, llevada a cabo entre -1.15 y $0.05 \mathrm{~V}$ vs. $\mathrm{Ag} / \mathrm{Ag}^{+}$. Esta caracterización se llevó acabo en disoluciones $0.1 \mathrm{M}$ de $\mathrm{LiCF}_{3} \mathrm{SO}_{3}$ en acetonitrilo, a una velocidad de barrido de $100 \mathrm{mVs}^{-1}$. Se obtuvieron los espectros en sus estados neutro y oxidado, por medio de la aplicación de potenciales -1.15 y $0.05 \mathrm{~V}$ vs. $\mathrm{Ag} / \mathrm{Ag}^{+}$. Los valores experimentales obtenidos se muestran en la tabla 3.1.2. 


\begin{tabular}{ccccc}
\cline { 3 - 5 } & & \multicolumn{3}{c}{$\%$ T valores fotópicos } \\
\hline $\begin{array}{c}\text { Densidad de } \\
\text { carga de } \\
\text { polimerización } \\
\text { / mCcm-2 }\end{array}$ & $\begin{array}{c}\text { Densidad de } \\
\text { carga } \\
\text { redox } \\
\text { / mCcm-2 }\end{array}$ & $\begin{array}{c}\text { Transmitancia } \\
\text { estado } \\
\text { oscuro }\end{array}$ & $\begin{array}{c}\text { Transmitancia } \\
\text { estado } \\
\text { claro }\end{array}$ & Contraste \\
\hline & & & & \\
4.91 & 0.53 & 69.85 & 93.24 & 23.39 \\
5.11 & 0.56 & 64.48 & 88.69 & 24.21 \\
5.02 & 0.61 & 67.22 & 90.47 & 23.26 \\
5.45 & 0.62 & 70.23 & 93.14 & 22.91 \\
11.86 & 1.06 & 39.55 & 82.48 & 42.92 \\
11.65 & 1.25 & 42.99 & 85.13 & 42.14 \\
13.52 & 1.49 & 35.63 & 80.87 & 45.24 \\
22.90 & 2.01 & 21.90 & 72.87 & 50.96 \\
36.65 & 2.72 & 15.20 & 67.43 & 52.22 \\
70.13 & 4.78 & 3.36 & 41.89 & 38.53 \\
70.13 & 5.10 & 4.07 & 39.37 & 35.29 \\
*Experimentos llevados a cabo en disolución de acetonitrilo $0.1 \mathrm{M} \mathrm{LiCF}_{3} \mathrm{SO}_{3}$ &
\end{tabular}

Tabla 3.1.2 Valores de densidad de carga de polimerización, densidad de carga redox (obtenida de la integración de la carga consumida durante una voltamperometría cíclica entre -1.15 y $0.05 \mathrm{~V}$ vs. $\mathrm{Ag} / \mathrm{Ag}^{+}$, velocidad de barrido $100 \mathrm{mVs}^{-1}$ ) y valores fotópicos asociados (calculados en base a los espectros de transmisión obtenidos en $-1.15 \mathrm{~V}$ y $0.05 \mathrm{~V}$ vs. $\mathrm{Ag} / \mathrm{Ag}^{+}$), para una serie de películas de PEDOT depositadas sobre ITO.

Se representaron los valores de transmitancia en los estados claro y oscuro, junto con el contraste correspondiente, en función de la densidad de carga redox (figura 3.1.14), obteniéndose relaciones exponenciales con un excelente ajuste. Por medio de estas relaciones fue posible obtener el punto de máximo contraste posible, junto con la densidad de carga redox asociada. 


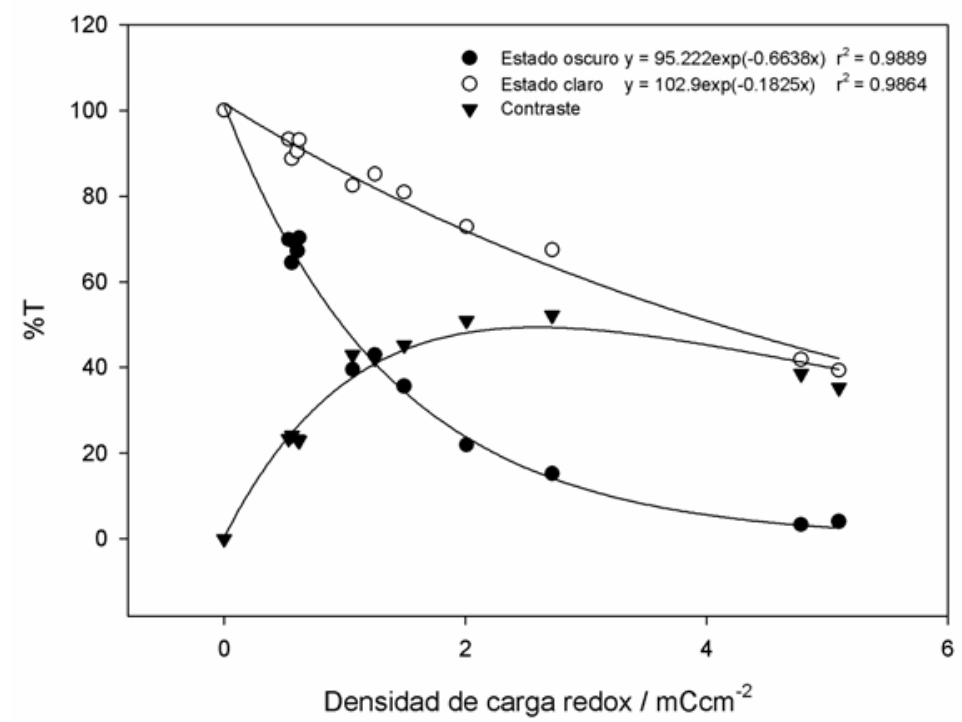

Figura 3.1.14 Relación entre densidad de carga redox y transmitancia fotópica para películas de PEDOT depositadas sobre ITO. Potencial de polimerización $1.3 \mathrm{~V}$ vs. $\mathrm{Ag} / \mathrm{Ag}^{+}$en disolución $20 \mathrm{mM}$ EDOT $0.1 \mathrm{M} \mathrm{LiCF}_{3} \mathrm{SO}_{3}$ (acetonitrilo). Obtención de valores de carga redox a través de voltamperometría cíclica entre -1.15 y $0.05 \mathrm{~V}$ vs. $\mathrm{Ag} / \mathrm{Ag}^{+}$en la misma disolución en ausencia de monómero, velocidad de barrido $100 \mathrm{mVs}^{-1}$. Valores ópticos obtenidos a través de espectros realizados en $-1.15 \mathrm{~V}$ y $0.05 \mathrm{~V}$ vs. $\mathrm{Ag} / \mathrm{Ag}^{+}$.

La serie experimental fue repetida, obteniendo los correspondientes valores (tabla 3.1.3), y hallando un valor para el máximo contraste de $43.4 \pm 3.01 \% \mathrm{~T}$ para una densidad de carga redox $2.23 \pm 0.28 \mathrm{mCcm}^{-2}$. Las expresiones generales, obtenidas de la media entre las cinco series, para los valores de transmitancia, absorbancia y contraste en función de la carga redox electrocrómica de una película de PEDOT serían, siendo x el valor de carga total electrocrómica, expresado en $\mathrm{mCcm}^{-2}$, calculado experimentalmente para la película:

$\mathrm{A}($ estados claros $)=0.09 \mathrm{x}-0.01$

$\mathrm{A}($ estados oscuros $)=0.31 \mathrm{x}+0.03$

$\% \mathrm{~T}($ estados claros $)=101.44 \exp ^{(-0.22 x)}$

$\% \mathrm{~T}($ estados oscuros $)=94.08 \exp ^{(-0.72 \mathrm{x})}$

$\Delta \mathrm{T}($ contraste $)=101.44 \exp ^{(-0.22 \mathrm{x})}-94.08 \exp ^{(-0.72 \mathrm{x})}$ 
Valores en el punto de máximo contraste

\begin{tabular}{ccccc}
\hline & $\begin{array}{c}\text { Densidad de } \\
\text { carga redox } \\
\text { / mCcm-2 }\end{array}$ & $\begin{array}{c}\text { \% fotópica } \\
\text { estado } \\
\text { claro }\end{array}$ & $\begin{array}{c}\text { \%T fotópica } \\
\text { estado } \\
\text { oscuro }\end{array}$ & Contraste \\
\hline serie 1 & 2.03 & 61.85 & 15.70 & 46.15 \\
serie 2 & 1.88 & 63.81 & 22.24 & 41.56 \\
serie 3 & 2.48 & 61.60 & 19.75 & 41.85 \\
serie 4 & 2.22 & 61.61 & 21.26 & 40.35 \\
serie 5 & 2.52 & 64.95 & 17.86 & 47.09 \\
\hline Valor medio & $\mathbf{2 . 2 3}$ & $\mathbf{6 2 . 7 6}$ & $\mathbf{1 9 . 3 6}$ & $\mathbf{4 3 . 4 0}$ \\
Desviación standard & 0.28 & 1.53 & 2.63 & 3.01 \\
\hline
\end{tabular}

Tabla 3.1.3 Valores de contraste máximo obtenible y densidad de carga redox asociada para el PEDOT

\begin{tabular}{ccccc}
\cline { 3 - 5 } & \multicolumn{3}{c}{ \%T valores fotópicos } \\
\hline $\begin{array}{c}\text { Densidad de } \\
\text { carga de } \\
\text { polimerización } \\
\text { / mCcm-2 }\end{array}$ & $\begin{array}{c}\text { Densidad de } \\
\text { carga } \\
\text { redox } \\
\text { / mCcm-2 }\end{array}$ & $\begin{array}{c}\text { Transmitancia } \\
\text { estado } \\
\text { oscuro }\end{array}$ & $\begin{array}{c}\text { Transmitancia } \\
\text { estado } \\
\text { claro }\end{array}$ & Contraste \\
\hline & & & & \\
0.73 & 0.60 & 87.66 & 97.83 & 10.18 \\
1.26 & 0.71 & 84.99 & 97.81 & 12.82 \\
1.42 & 0.85 & 81.11 & 91.08 & 9.97 \\
1.73 & 0.91 & 79.59 & 95.25 & 15.66 \\
1.56 & 0.91 & 79.28 & 95.86 & 16.58 \\
1.62 & 0.94 & 79.12 & 92.72 & 13.60 \\
1.72 & 1.13 & 80.15 & 95.51 & 15.37 \\
5.32 & 1.94 & 67.07 & 81.25 & 14.19 \\
4.17 & 2.23 & 61.75 & 83.81 & 22.06 \\
5.62 & 2.41 & 55.65 & 75.03 & 19.39 \\
12.32 & 3.85 & 32.51 & 60.47 & 27.96 \\
26.14 & 7.81 & 13.31 & 37.40 & 24.09 \\
\hline
\end{tabular}

*Experimentos llevados a cabo en disolución de acetonitrilo $0.1 \mathrm{MLiCF}_{3} \mathrm{SO}_{3}$

Tabla 3.1.4 Valores de densidad de carga de polimerización, densidad de carga redox (obtenida de la integración de la carga consumida durante una voltamperometría cíclica entre -0.75 y $0.75 \mathrm{~V}$ vs. $\mathrm{Ag} / \mathrm{Ag}^{+}$, velocidad de barrido $100 \mathrm{mVs}^{-1}$ ) y valores fotópicos asociados (calculados en base a los espectros de transmisión obtenidos en $-0.75 \mathrm{~V}$ y $0.75 \mathrm{~V}$ vs. $\mathrm{Ag} / \mathrm{Ag}^{+}$), para una serie de películas de PBEDOT-NMCz depositadas sobre ITO. 
Asimismo, se polimerizaron películas de PBEDOT-NMCz con densidades de carga redox comprendidas entre 0 y $8.5 \mathrm{mCcm}^{2}$. La densidad de carga redox para cada película se obtuvo mediante la integración de la carga consumida durante la caracterización voltamperométrica, llevada a cabo entre -0.75 y $0.75 \mathrm{~V}$ vs. $\mathrm{Ag} / \mathrm{Ag}^{+}$. Esta caracterización se llevó acabo en disoluciones $0.1 \mathrm{M}$ de $\mathrm{LiCF}_{3} \mathrm{SO}_{3}$ en acetonitrilo, a una velocidad de barrido de $100 \mathrm{mVs}^{-1}$. Se obtuvieron los espectros en sus estados neutro y oxidado, por medio de la aplicación de potenciales -0.75 y $0.75 \mathrm{~V}$ vs. $\mathrm{Ag} / \mathrm{Ag}^{+}$. $\mathrm{Los}$ valores experimentales se muestran en la tabla 3.1.4.

Los valores de transmitancia correspondientes en función de la densidad de carga redox se representan en la figura 3.1.15.

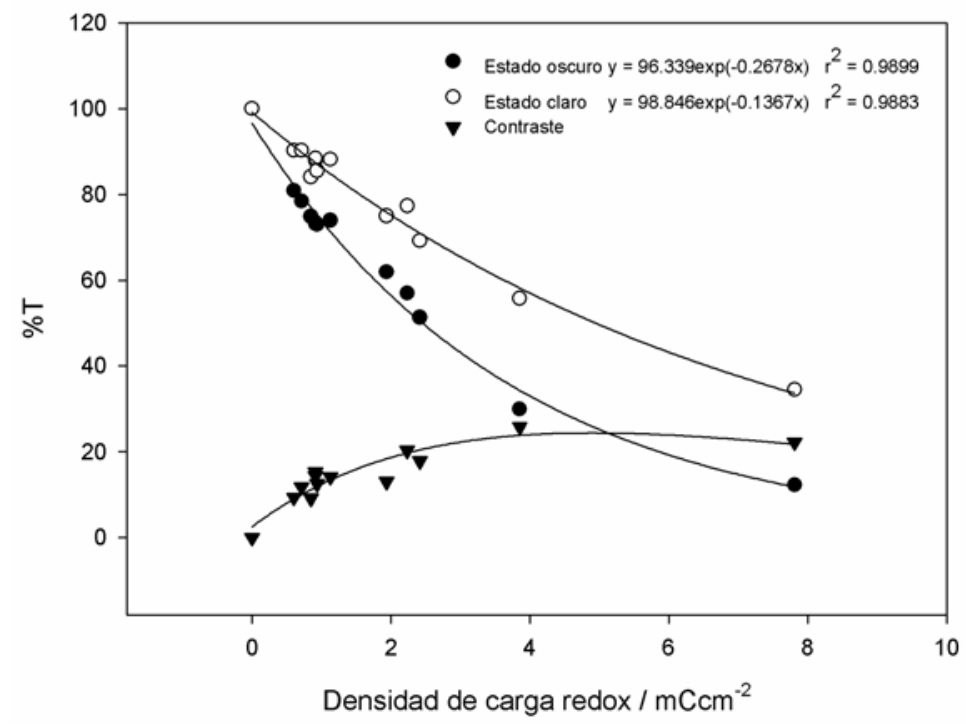

Figura 3.1.15 Relación entre densidad de carga redox y transmitancia fotópica para películas de PBEDOT-NMCz depositadas sobre ITO. Potencial de polimerización $0.65 \mathrm{~V}$ vs. $\mathrm{Ag} / \mathrm{Ag}^{+}$en disolución 1mM BEDOT-NMCz $0.1 \mathrm{M} \mathrm{LiCF}_{3} \mathrm{SO}_{3}$ (Acetonitrilo). Obtención de valores de carga redox a través de voltamperometría cíclica entre -0.75 y $0.75 \mathrm{~V}$ vs. $\mathrm{Ag} / \mathrm{Ag}^{+}$en la misma disolución en ausencia de monómero, velocidad de barrido $100 \mathrm{mVs}^{-1}$. Valores ópticos obtenidos a través de espectros realizados en $-0.75 \mathrm{~V}$ y $0.75 \mathrm{~V}$ vs. $\mathrm{Ag} / \mathrm{Ag}^{+}$. 
La serie experimental fue repetida, obteniendo los correspondientes valores (tabla 3.1.5), y hallando un valor para el máximo contraste de $23.36 \pm 6.86 \% \mathrm{~T}$, para una densidad de carga redox $4.77 \pm 0.31 \mathrm{mCcm}^{-2}$. Las expresiones generales, obtenidas de la media entre las cinco series, para los valores de transmitancia, absorbancia y contraste en función de la carga redox electrocrómica de una película de PBEDOT-NMCz serían,

$\mathrm{A}($ estados claros $)=0.06 \mathrm{x}-0.01$

$\mathrm{A}($ estados oscuros $)=0.11 \mathrm{x}+0.01$

$\% \mathrm{~T}($ estados claros $)=102.23 \exp ^{(-0.13 \mathrm{x})}$

$\% \mathrm{~T}($ estados oscuros $)=96.80 \exp ^{(-0.25 x)}$

$\Delta \mathrm{T}($ contraste $)=102.23 \exp ^{(-0.13 \mathrm{x})}-96.80 \exp ^{(-0.25 \mathrm{x})}$

siendo $\mathrm{x}$ el valor de carga total electrocrómica, expresado en $\mathrm{mCcm}^{-2}$, calculado experimentalmente para la película.

Valores en el punto de máximo contraste

\begin{tabular}{ccccc}
\hline & $\begin{array}{c}\text { Densidad de } \\
\text { carga redox } \\
\text { / mCcm-2 }\end{array}$ & $\begin{array}{c}\text { \% fotópica } \\
\text { estado } \\
\text { claro }\end{array}$ & $\begin{array}{c}\text { \%T fotópica } \\
\text { estado } \\
\text { oscuro }\end{array}$ & Contraste \\
\hline serie 1 & 5.14 & 55.02 & 29.72 & 25.30 \\
serie 2 & 4.42 & 54.01 & 22.30 & 31.72 \\
serie 3 & 4.52 & 51.81 & 33.23 & 18.58 \\
serie 4 & 4.74 & 55.95 & 41.54 & 14.41 \\
serie 5 & 5.02 & 54.13 & 27.33 & 26.80 \\
\hline Valor medio & $\mathbf{4 . 7 7}$ & $\mathbf{5 4 . 1 8}$ & $\mathbf{3 0 . 8 2}$ & $\mathbf{2 3 . 3 6}$ \\
Desviación standard & 0.31 & 1.54 & 7.19 & 6.86 \\
\hline
\end{tabular}

Tabla 3.1.5 Valores de contraste máximo obtenible y densidad de carga redox asociada para el PBEDOT$\mathrm{NMCz}$

La optimización del funcionamiento de un dispositivo electrocrómico pasa por obtener el mejor rendimiento electroquímico de las películas constituyentes, así como la 
optimización del contraste obtenible. El desarrollo experimental llevado a cabo en este estudio, centrado en dos puntos, optimización electroquímica y optimización óptica de los materiales, es un paso previo necesario para el estudio de cualquier material que pretenda ser utilizado en dispositivos electrocrómicos. 


\subsection{SISTEMAS DUALES. OBTENCIÓN TEÓRICA Y PRÁCTICA DEL MÁXIMO CONTRASTE}

La caracterización electroóptica individual de los polímeros conductores constituyentes de un sistema dual fue llevada a cabo en la sección 3.1.3. Cada polímero, en función de sus características individuales, presenta un punto de máximo contraste, con una carga redox asociada, puesto que los cambios de color son producidos por la oxidación o reducción del polímero. Tanto el contraste máximo obtenido, como la carga asociada son diferentes para cada polímero. A la hora de configurar un sistema dual, estas características individuales deben ser tenidas en cuenta.

Dos objetivos esenciales en la optimización de sistemas electrocrómicos son la obtención del máximo contraste posible, y la maximización de la vida media del dispositivo.

La disminución de la capacidad de reducción y oxidación del polímero, y por lo tanto de las características del dispositivo, acortando de esta manera su vida media, viene motivada por procesos de sobreoxidación y degradación, que generalmente ocurren cuando sometemos al material a potenciales mayores de los correspondientes a su ventana de oxidación-reducción, como se comprobó en la sección 3.1.1. En términos electroquímicos, el equilibrio óptimo entre los dos electrodos constituyentes se producirá cuando éstos tengan la misma capacidad de oxidación-reducción, es decir, cuando tengan la misma densidad de carga redox. En estas condiciones, toda la carga consumida por el dispositivo puede ser empleada única y exclusivamente en producir 
procesos de reducción y oxidación de las películas electrocrómicas, evitando la aparición de reacciones paralelas que pudiesen provocar la citada degradación.

Desde un punto de vista exclusivamente óptico, el mayor contraste se obtendría en principio emparejando en un mismo dispositivo las películas que individualmente presentan el máximo contraste para cada polímero.

Se llevó a cabo un estudio para determinar las condiciones para la obtención del máximo rendimiento óptico y electroquímico atendiendo a estos dos criterios.

\subsubsection{Desarrollo teórico}

\subsubsection{Efecto de la inclusión de capas absorbentes en el contraste de dispositivos electrocrómicos}

La ley de Lambert-Beer establece una relación proporcional entre concentración de la especie absorbente y absorbancia resultante. Esta relación puede ser extrapolada a la situación en la que varias especies absorbentes, sin interacción química entre ellas, están presentes en disolución. La ley de aditividad de las absorbancias expone que la absorbancia total de un sistema con varias especies absorbentes en disolución, sin interacción química entre ellas, es la suma de las contribuciones individuales [130].

Para un sistema consistente en la superposición de varias capas con propiedades de absorción diferentes, esta ley también se cumple. Esto puede demostrarse matemáticamente.

La expresión matemática de la absorbancia es el logaritmo negativo del cociente de intensidades de luz antes y después de atravesar la muestra, 
$\mathrm{A}=-\log \left(\mathrm{I}_{\mathrm{f}} / \mathrm{I}_{\mathrm{i}}\right)=\varepsilon \mathrm{Cd}$

siendo $\mathrm{I}_{\mathrm{i}}$ la intensidad antes de atravesar la muestra, $\mathrm{I}_{\mathrm{f}}$ la resultante al atravesarla, $\varepsilon$ el coeficiente de absortividad molar, propio de cada material, C la concentración de especies absorbentes, y d la distancia recorrida por la luz incidente.

Consideremos dos capas de materiales distintos, como se muestra en la figura siguiente, (figura 3.2.1)

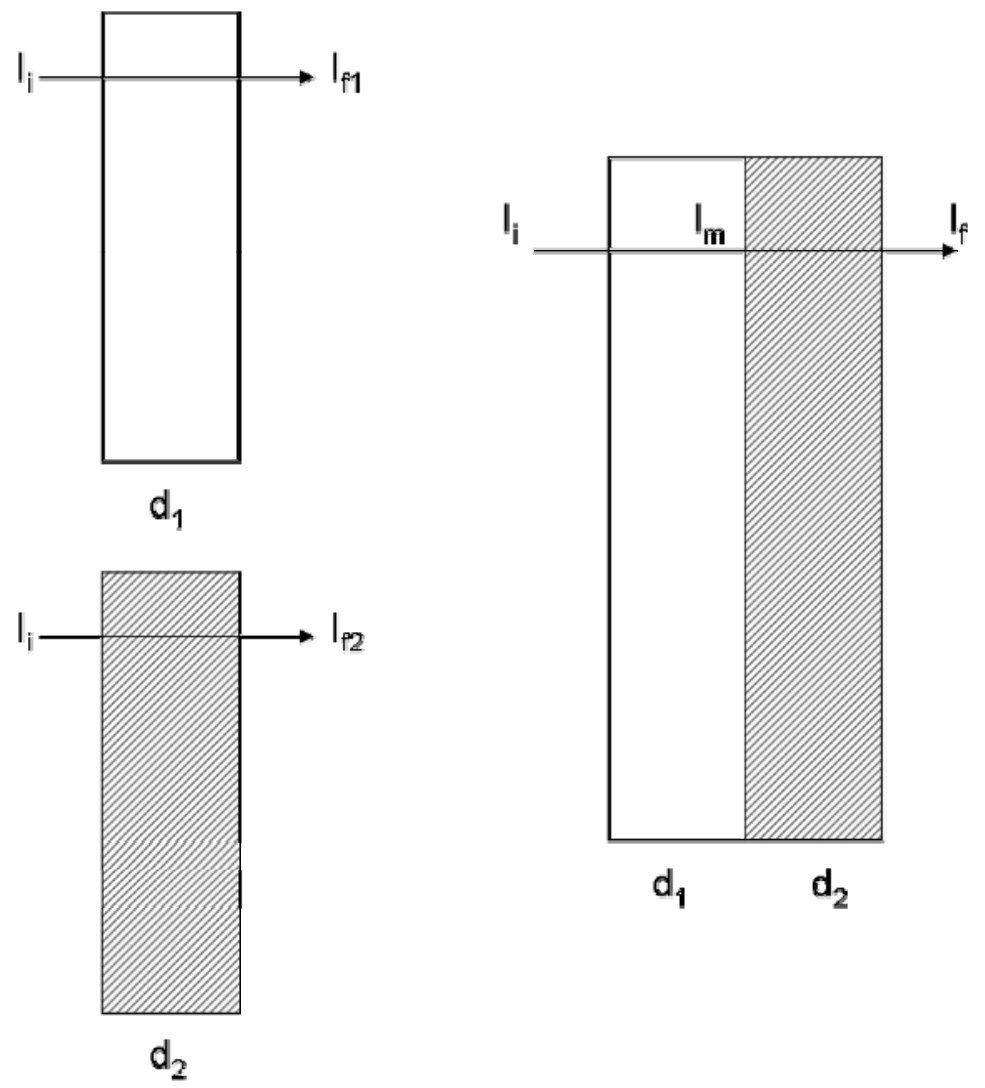

Figura 3.2.1 Esquema teórico de intensidades inicial y final para sistemas de capas individuales y sistemas bicapa.

con espesores, $\mathrm{d}_{1} \mathrm{y} \mathrm{d}_{2}$, absortividades molares, $\varepsilon_{1}$ y $\varepsilon_{2}$, y concentraciones de especies absorbentes $\mathrm{C}_{1}$ y $\mathrm{C}_{2}$ respectivamente. La absorbancia resultante para una luz 
incidente de intensidad $\mathrm{I}_{\mathrm{i}}$, para cada uno de ellos, tendrá la siguiente expresión matemática,

$\mathrm{A}_{1}=-\log \left(\mathrm{I}_{\mathrm{fl}} / \mathrm{I}_{\mathrm{i}}\right)=\varepsilon_{1} \mathrm{C}_{1} \mathrm{~d}_{1}$

$\mathrm{A}_{2}=-\log \left(\mathrm{I}_{\mathrm{f} 2} / \mathrm{I}_{\mathrm{i}}\right)=\varepsilon_{2} \mathrm{C}_{2} \mathrm{~d}_{2}$

En la situación en que tengamos una luz incidente atravesando los dos materiales consecutivamente, la absorbancia tomará en este caso la expresión

$A=-\log \left(I_{f} / I_{i}\right)$

Y puesto que

$-\log \left(\mathrm{I}_{\mathrm{f}} / \mathrm{I}_{\mathrm{i}}\right)=-\log \left(\mathrm{I}_{\mathrm{f}} / \mathrm{I}_{\mathrm{m}}\right)-\log \left(\mathrm{I}_{\mathrm{m}} / \mathrm{I}_{\mathrm{i}}\right)=\varepsilon_{1} \mathrm{C}_{1} \mathrm{~d}_{1}+\varepsilon_{2} \mathrm{C}_{2} \mathrm{~d}_{2}=\mathrm{A}_{1}+\mathrm{A}_{2}$

esto implica que:

$\mathrm{A}=\mathrm{A}_{1}+\mathrm{A}_{2}$

Por lo tanto, y mientras la ley de Lambert-Beer se cumpla para cada uno de los materiales individualmente, un sistema polimérico electrocrómico dual podrá ser tratado de esta manera matemáticamente (ec. 3.2.7). La absorbancia total del sistema será la suma de las contribuciones individuales de cada polímero, 
$\mathrm{A}_{\text {dual }}=\Sigma \mathrm{A}_{\mathrm{i}}=\mathrm{A}_{1}+\mathrm{A}_{2} \quad \mathrm{i}=1,2$

siendo $\mathrm{A}_{1}$ y $\mathrm{A}_{2}$ las absorbancias de cada polímero en el estado correspondiente.

Los dispositivos electrocrómicos de transmisión variable se caracterizan por el contraste que presentan entre sus estados transmisivo o claro $\left(\mathrm{T}_{\mathrm{c}}\right)$ y no transmisivo $\mathrm{u}$ oscuro $\left(\mathrm{T}_{\mathrm{o}}\right)$. El contraste viene definido por la diferencia entre los valores de transmitancia en uno y otro estado.

$\Delta \mathrm{T}=\mathrm{T}_{\mathrm{c}}-\mathrm{T}_{\mathrm{o}}$

La absorbancia y transmitancia de un material electrocrómico están relacionadas por medio de una relación exponencial,

$\mathrm{T}=10^{-\mathrm{A}}$

por lo que la aditividad no se cumple en el caso de las transmitancias. La transmitancia de un sistema dual en un determinado estado vendrá dada por la exponencial decimal negativa de la absorbancia del sistema; esta absorbancia es la resultante aditiva de las absorbancias individuales, por lo que su expresión matemática será la siguiente,

$\mathrm{T}_{\text {dual }}=10^{- \text {Adual }}=10^{-\left(\mathrm{A}_{1}+\mathrm{A}_{2}\right)}$ 
siendo $\mathrm{A}_{1}$ y $\mathrm{A}_{2}$ las absorbancias individuales de cada polímero en el estado correspondiente. La suma de las transmitancias individuales tiene como expresión matemática en función de las absorbancias la siguiente ecuación,

$\mathrm{T}_{1}+\mathrm{T}_{2}=10^{-\mathrm{A}}{ }_{1}+10^{-\mathrm{A}}$

por lo que se comprueba inmediatamente que la transmitancia del sistema dual no es la suma de las transmitancias individuales.

$\mathrm{T}_{\text {dual }} \neq \mathrm{T}_{1}+\mathrm{T}_{2}$

Estas relaciones matemáticas tienen implicaciones en los contrastes obtenibles en sistemas formados por varias capas absorbentes independientes.

\subsection{Efecto de la inclusión de una capa de absorbancia constante en el contraste de un sistema electrocrómico}

Una película de polímero conductor electrocrómica puede ser caracterizada electroquímicamente por medio del valor de la carga de oxidación o reducción consumida en el rango de potenciales para los que se observan cambios en la respuesta espectral.

Asimismo, la película se caracteriza electrocrómicamente por medio de los valores de absorbancia (o transmitancia) en dos estados límites (aunque existen determinadas familias de polímeros conductores que presentan varios colores intermedios, como la polianilina [32]. Para los denominados polímeros conductores de transmisión variable, 
la caracterización se realiza entre un estado transparente y otro coloreado. El contraste de cada película se obtiene de la resta de los valores de transmitancia entre los dos estados límite alcanzables, en este caso el más transparente y el más oscuro de los disponibles para la película concreta.
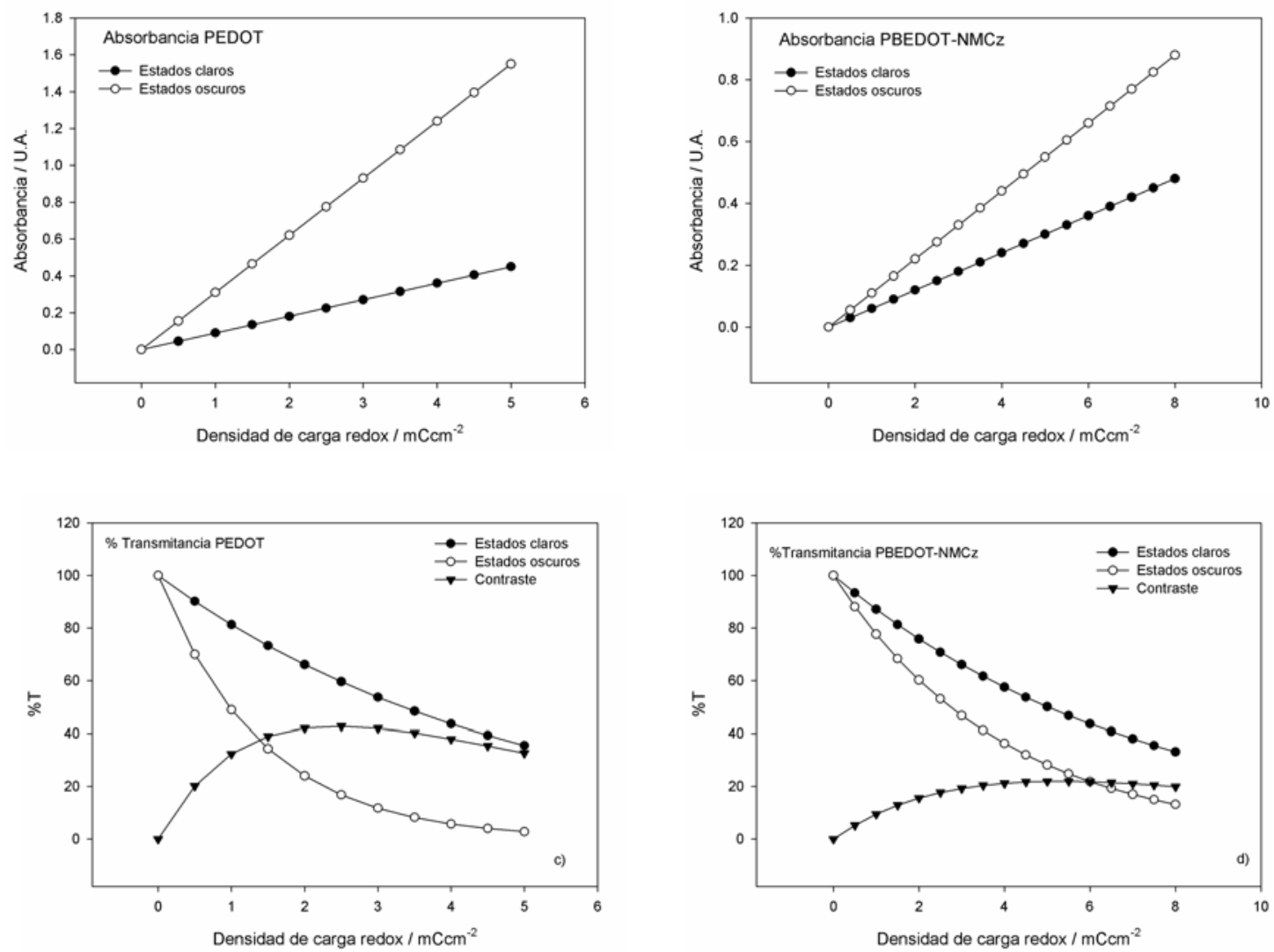

Figura 3.2.2 Relaciones lineales entre absorbancia en los estados transmisivos (claros) y no transmisivos (oscuros) para películas de a) PEDOT y b) PBEDOT-NMCz, en función de la carga redox electrocrómica de la película. Conversión de los valores a transmitancias, para c) PEDOT y d) PBEDOTNMCz. Los valores de contraste son obtenidos por diferencia entre valores de transmitancia en el estado claro y oscuro.

Experimentalmente ha sido comprobado (Sección 3.1.3) que la evolución de la relación entre los valores de carga redox y absorbancia de distintas películas, para cada uno de los estados límite, es líneal. Los valores experimentales obtenidos demostraron 
las siguientes relaciones para el PEDOT: A (estados claros) $=0.09 x$, A (estados oscuros $)=0.31 \mathrm{x}$, y para el PBEDOT-NMCz: A (estados claros)=0.06x, A (estados oscuros $)=0.11 \mathrm{x}$, respectivamente (figuras 3.2.2.a y 3.2.2.b). Esto permite el cálculo, mediante el paso previo de conversión a transmitancias, del máximo contraste alcanzable para un determinado material, y la carga redox asociada a ese valor (figuras 3.2.2.c y 3.2.2.d)

El efecto de la inclusión de una capa no electrocrómica (y por lo tanto, de absorbancia definida y constante), puede ser calculado matemáticamente por medio de la aditividad de las absorbancias. Físicamente, esta situación representa la adición de nuevas capas absorbentes como pueden ser los substratos donde se deposita el polímero ó el medio electrolítico. Este efecto debe ser tenido en cuenta a la hora del diseño y fabricación de dispositivos electrocrómicos, puesto que la percepción final por parte del usuario incluye la contribución de todos los elementos del dispositivo, y no solamente de los materiales electrocrómicos.

Incluyendo la contribución de una capa de estas caracteristicas, la evolución de los valores ópticos para películas con distinta carga redox se verá modificada. El efecto de está inclusión en los valores de absorbancia será un desplazamiento positivo y constante en los valores obtenidos previamente para el polímero, como se muestra en la figura siguiente (figura 3.2.3.a) 

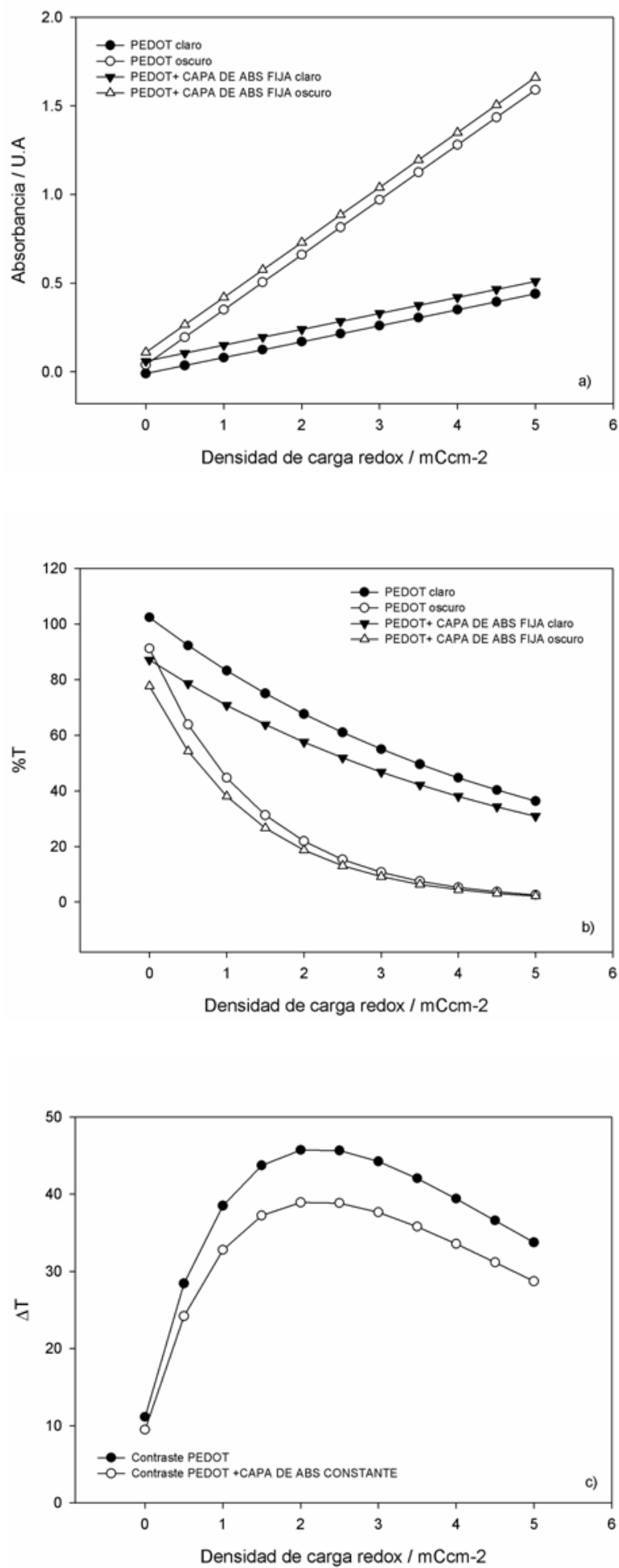

Figura 3.2.3 Contribución de una capa de absorbancia fija (absorbancia fotópica 0.07) a los valores ópticos fotópicos del PEDOT en función de la densidad de carga redox. a) Efecto en los valores de absorbancia. b) Efecto en los valores de transmitancia. c) Efecto en los valores de contraste. 
La contribución de esta capa adicional resulta en una disminución de los valores de transmitancia. Sin embargo, y debido a la relación exponencial entre absorbancia y transmitancia, el efecto de la adición de esta capa en dichos valores no es constante. La disminución es mucho más significativa para los valores de los estados más transparentes (figura 3.2.3.b).

El resultado final (figura 3.2.3.c) es el de una disminución en los valores de contraste. Puesto que la capa adicional no es activa ni electroquímica ni electrocrómicamente, su inclusión no modifica los valores de carga redox para los cuales se obtiene el máximo contraste.

\subsection{Efecto de la inclusión de una capa de absorbancia variable adicional en el contraste de un sistema electrocrómico}

El efecto de la inclusión de capas adicionales de absorbancia variable al sistema en la respuesta óptica representa una situación más compleja. Supongamos la adición de una capa que presenta dos estados de color, claro y oscuro, que durante el funcionamiento del dispositivo se superponen al de la capa electrocrómica inicial, es decir, cuando ésta alcanza su estado transparente, se suma la contribución del estado transparente de la capa adicional, e igual para los estados oscuros. En una primera aproximación, consideraremos únicamente las propiedades ópticas de esta capa adicional, sin tener en cuenta el origen de los cambios crómicos (eléctrico, térmico, etc.). 

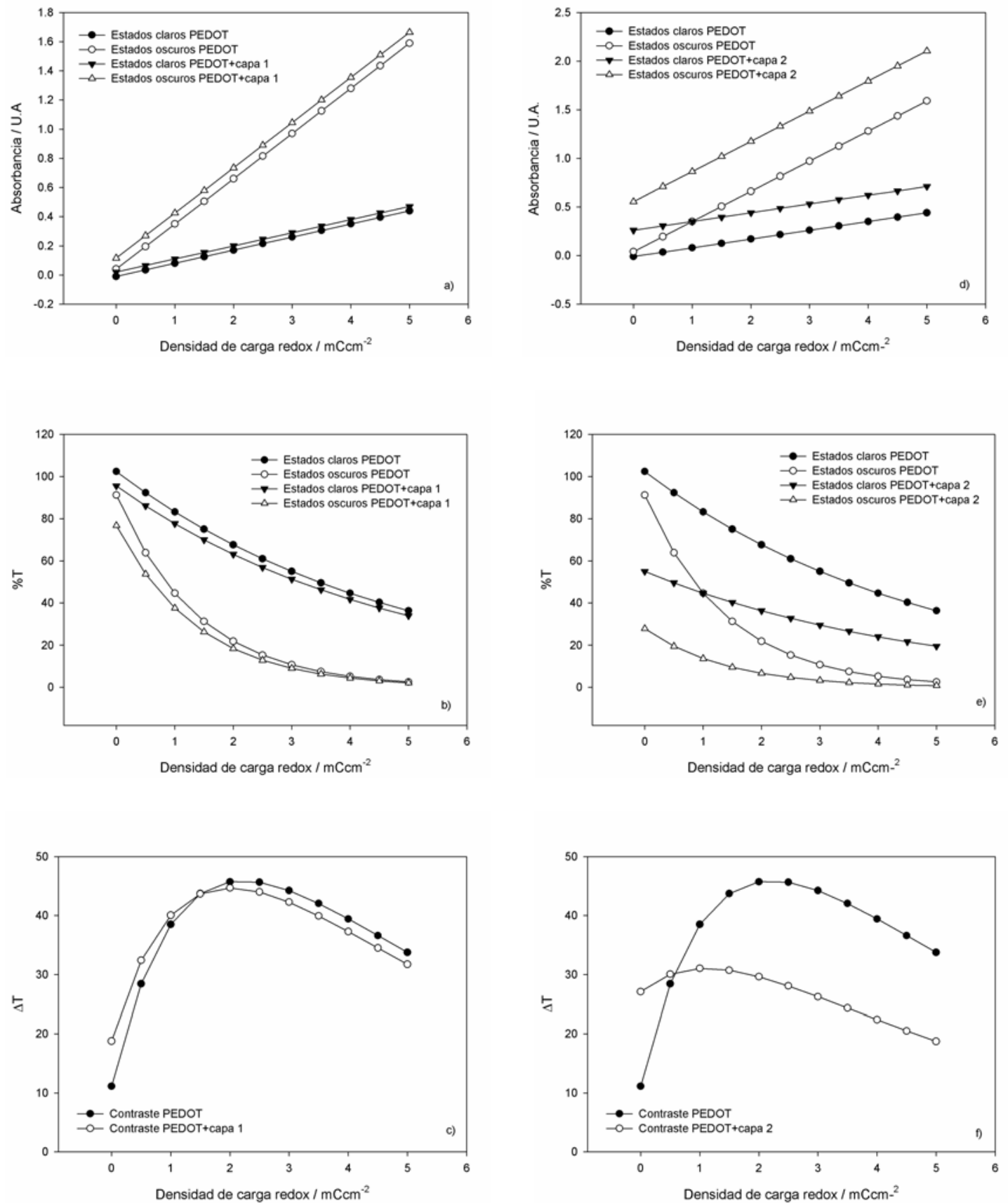

Figura 3.2.4 Contribución de capas de absorbancia variable a los valores ópticos fotópicos del PEDOT en función de la densidad de carga redox para dos supuestos con diferentes valores. Capa 1: Absorbancia en el estado claro 0.03, oscuro 0.075 a) Efecto en los valores de absorbancia. b) Efecto en los valores de transmitancia. c) Efecto en los valores de contraste. Capa 2: Absorbancia en el estado claro 0.27, oscuro 0.515 d) Efecto en los valores de absorbancia. e) Efecto en los valores de transmitancia. f) Efecto en los valores de contraste. 
Las figuras anteriores muestran el efecto de la inclusión de capas en estas condiciones en dos casos supuestos. En el primer supuesto, incluiremos una capa adicional cuya absorbancia en su estado transparente es 0.03 , y en su estado oscuro 0.075 (estos valores coinciden con los obtenidos para una película de PBEDOT-NMCz de $0.5 \mathrm{mCcm}^{-2}$ de densidad de carga redox); las relaciones de absorbancia, transmitancia y contraste del sistema formado por películas de PEDOT más una capa de este tipo, frente a sistemas únicamente de PEDOT se representan en las figuras 3.2.4.a, 3.2.4.b y 3.2.4.c, respectivamente. En un segundo supuesto, se incluirá una capa adicional con valores de absorbancia 0.27 y 0.515 en sus estados claro y oscuro, respectivamente (estos valores coinciden con los obtenidos para una película de PBEDOT-NMCz de 4.5 $\mathrm{mCcm}^{-2}$ de densidad de carga redox). Las relaciones de absorbancia, transmitancia y contraste para este sistema comparado con la contribución únicamente del PEDOT, se muestran en las figuras 3.2.4.d, 3.2.4.e y 3.2.4.f

Se observa como el efecto de está inclusión en los valores de absorbancia es, en cualquiera de los dos casos supuestos, un desplazamiento positivo y constante en los valores obtenidos previamente para el polímero, pero el desplazamiento no es idéntico para las evoluciones de los estados claros y oscuros, puesto que la contribución de la capa adicional es distinta en cada caso.

Esto transforma las evoluciones de las gráficas de transmitancia, obteniendo, por lo tanto, evoluciones del contraste totalmente distintas a las del polímero individualmente. El punto de mayor contraste se ha desplazado, y su valor disminuido en ambos casos. Una observación significativa es la existencia de rangos en los que la combinación de estas dos capas aumenta el contraste respecto al obtenido individualmente por el polímero. 


\subsection{Sistemas electrocrómicos duales. Contribución de dos capas electrocrómicas al contraste del sistema}

La situación real de los dispositivos electrocrómicos duales presenta una mayor complejidad. En ella se suman las contribuciones de todos los componentes del dispositivo: substratos, polímeros y electrolito. Como hemos visto, la contribución de los substratos y electrolito (sea sólido ó líquido), capas no electrocrómicas y de propiedades ópticas constantes, es la de una reducción en el contraste final, sin modificación de las condiciones electroquímicas en las que se produce el máximo contraste para los polímeros dados. Sin embargo, el contraste obtenido durante el funcionamiento simultáneo de dos capas electrocrómicas (dos capas de absorción variable) difiere totalmente del obtenido previamente para cada película individual.

Varias consideraciones deben ser tenidas en cuenta a la hora de determinar la situación óptima en la que podemos obtener el máximo contraste para dos materiales determinados:

Mediante la caracterización previa de cada material, es posible obtener las condiciones electroquímicas y ópticas de máximo contraste. Estas condiciones son diferentes para cada material.

Asimismo, dentro del rango en el que el material es electrocrómico (es decir, que sus estados ópticos no sean tan absorbentes como para no distinguir los cambios de color), y caracterizando a las películas por la densidad de carga redox que consumen en sus procesos de oxidación-reducción, pueden existir tantas combinaciones duales como películas diferentes existan en ese rango. Teniendo en cuenta que la unidad de densidad de carga redox estaría cuantizada por el valor de la carga de un electrón $\left(1.6 \times 10^{-19} \mathrm{C}\right), \mathrm{y}$ 
los rangos de caracterización que se han obtenido previamente (entre 0 y $5 \mathrm{mCcm}^{-2}$ ), el número de combinaciones posibles se eleva considerablemente.

Por último, la configuración de un dispositivo electrocrómico es la de una celda electroquímica, siendo los polímeros conductores los electrodos de dicha celda. La reacción global de la celda, con la reducción de uno de los electrodos y la oxidación del opuesto es única e implica a los dos polímeros simultáneamente.

La determinación de las condiciones óptimas de funcionamiento para una combinación dual, tanto desde un punto de vista electroquímico como óptico, es el objeto de estudio del siguiente punto.

\subsubsection{Obtención teórica del máximo contraste en sistemas duales}

\subsection{Criterio electroquímico}

Se ha visto anteriormente como una película electrocrómica puede ser caracterizada por la carga de reducción u oxidación que está asociada a cambios efectivos de color (Sección 3.1.1), lo que se denominó carga electrocrómica. Se ha comprobado, a su vez, que el consumo de carga adicional no produce ningún cambio asociado en el color, $\mathrm{y}$ que, por el contrario, puede estar asociado a procesos de degradación directa o indirecta de la película electrocrómica.

Asimismo, el funcionamiento de un dispositivo electrocrómico dual, consistiendo en una celda electroquímica, implica que la carga consumida para la oxidación (ó reducción) en un electrodo forzosamente debe ser la misma consumida en el opuesto para la reducción (u oxidación). 
Por lo tanto, y atendiendo a un criterio exclusivamente electroquímico en cuanto a eficiencia de la carga consumida, es decir, al consumo de carga exclusivamente electrocrómica, la situación óptima será la que enfrente en un mismo dispositivo a dos películas caracterizadas con la misma carga electrocrómica.

En estas condiciones, y atendiendo a las características individuales de cada polímero previamente obtenidas (Sección 3.1.3), se estudió la evolución de las diferentes combinaciones posibles, para el sistema PEDOT/PBEDOT-NMCz, obteniendo la evolución de los contrastes en función de la carga electrocrómica de las películas y de este modo prediciendo las condiciones en las que se obtendría el máximo contraste.

\section{Sistema PEDOT/PBEDOT-NMCz}

Las expresiones matemáticas para las absorbancias de los estados claros y oscuros en función de la carga redox, se obtuvieron en la sección 3.1.3., siendo para películas de PEDOT: $\mathrm{A}=0.09 \mathrm{x} \quad$ (estados claros) y $\mathrm{A}=0.31 \mathrm{x}$ (estados oscuros), $\mathrm{y}$ para PBEDOT-

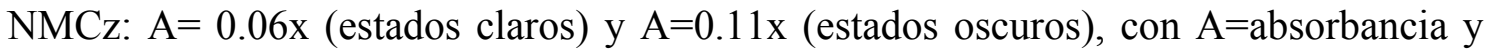
$\mathrm{x}=$ densidad de carga redox expresada en $\mathrm{mCcm}^{-2}$. Se obtuvo el comportamiento de las películas de estos materiales individualmente, en el rango $0-5 \mathrm{mC} / \mathrm{cm}^{-2}$. Las evoluciones en absorbancia obtenidas para cada polímero se muestran en la figura 3.2.2.

En base a estas expresiones matemáticas, y mediante las relaciones de aditividad de la absorbancia demostradas en la sección 3.2.1, se obtuvieron las respuestas ópticas de las combinaciones PEDOT/PBEDOT-NMCz, sumando la contribución de cada material (figura 3.2.5.a), resultando en una expresión para la absorbancia dual 
$\mathrm{A}=0.15 \mathrm{x}($ estados claros $)$

$\mathrm{A}=0.42 \mathrm{x}$ (estados oscuros)

La transformación de esos valores a porcentajes de transmitancia permitió evaluar las condiciones en las que se obtiene el máximo contraste y el valor de éste (figura 3.2.5.b). Estos valores corresponden a películas de $1.66 \mathrm{mCcm}^{-2}$ y un contraste de 36.28 $\%$ (56.4 y $20.16 \%$ en sus estados claro y oscuro, respectivamente)
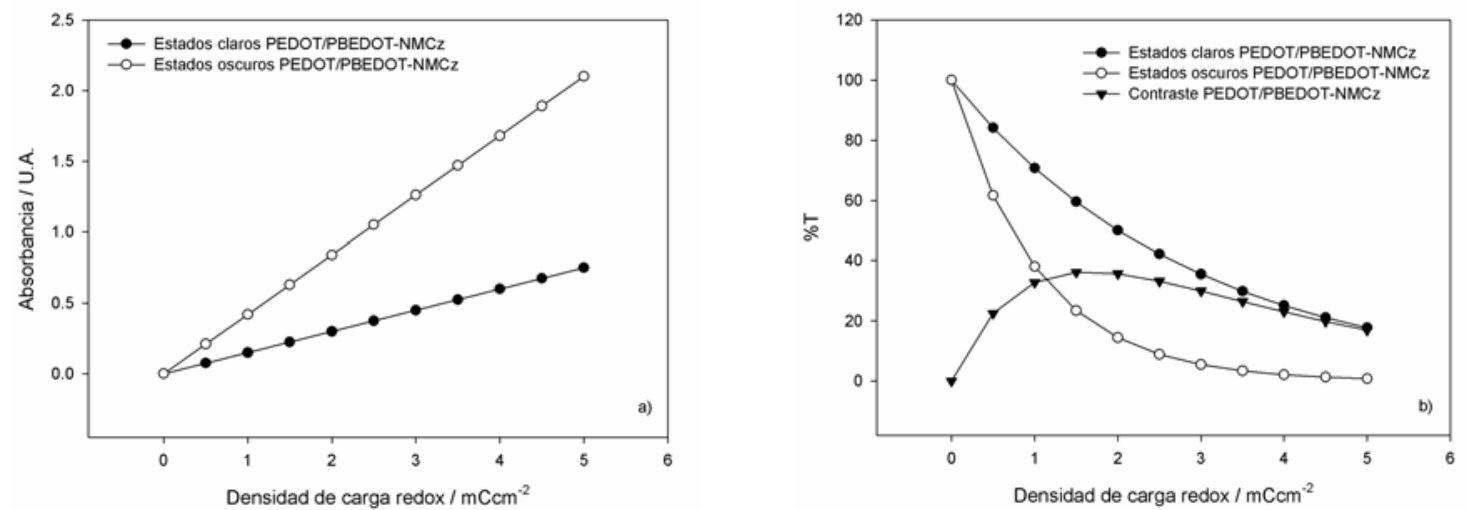

Figura 3.2.5 a) Relaciones de absorbancia en estado claro y oscuro en función de la densidad de carga redox, para un sistema dual PEDOT/PBEDOT-NMCz, supuesto que las dos películas tengan la misma densidad de carga redox b) Conversión de los valores de absorbancia dual a \% transmitancia, obteniendo los valores de contraste por medio de su diferencia

\subsection{Criterio óptico}

Previamente, en la sección 3.1.3, se obtuvieron los comportamientos ópticos de películas de material electrocrómico en función de su carga redox disponible, para los 
dos polímeros estudiados, PBEDOT-NMCz y PEDOT. Para un rango comprendido entre 0 y $5 \mathrm{mCcm}^{-2}$, se halló que las relaciones entre absorbancia y carga disponible mantienen una evolución líneal.

El orden de combinaciones posibles, atendiendo a su densidad de carga redox, entre dos películas de estos materiales para formar un dispositivo dual es del orden de $10^{32}$ (estrictamente serían $\left(3.1 \times 10^{16}\right) \times\left(3.1 \times 10^{16}\right)$ combinaciones, teniendo en cuenta que los valores de carga están cuantizados por el valor de la carga de un electrón, 1.6x10 $0^{-19}$ C). Atendiendo a sus características ópticas, en el siguiente estudio se obtuvieron los contrastes resultantes para cada combinación, determinando las condiciones y valores de máximo contraste.

Los valores de absorbancia, transmitancia y contraste se muestran a continuación. Las evoluciones para valores de uno de los dos ejes de densidades de carga iguales a cero corresponderían con los valores para los polímeros individualmente.

De los resultados obtenidos para el sistema, se pueden extraer dos comportamientos significativos; el primero, que existen combinaciones determinadas para las cuales el contraste resultante de la unión de las dos películas es mayor que el presentado individualmente por cada una de ellas, aunque éstas representan la minoría de los casos. El aumento de contraste debido a una configuración dual sólo ocurre para películas con densidad de carga redox menor de $1 \mathrm{mCcm}^{-2}$, para las cuales las transmitancias del PEDOT son suficientemente altas (mayores de $60 \%$ en el estado oscuro)

El segundo es que el contraste máximo obtenible por medio de una combinación dual es menor que el obtenido para uno de los dos polímeros, en este caso el PEDOT. 


\section{Sistema PEDOT/PBEDOT-NMCz}
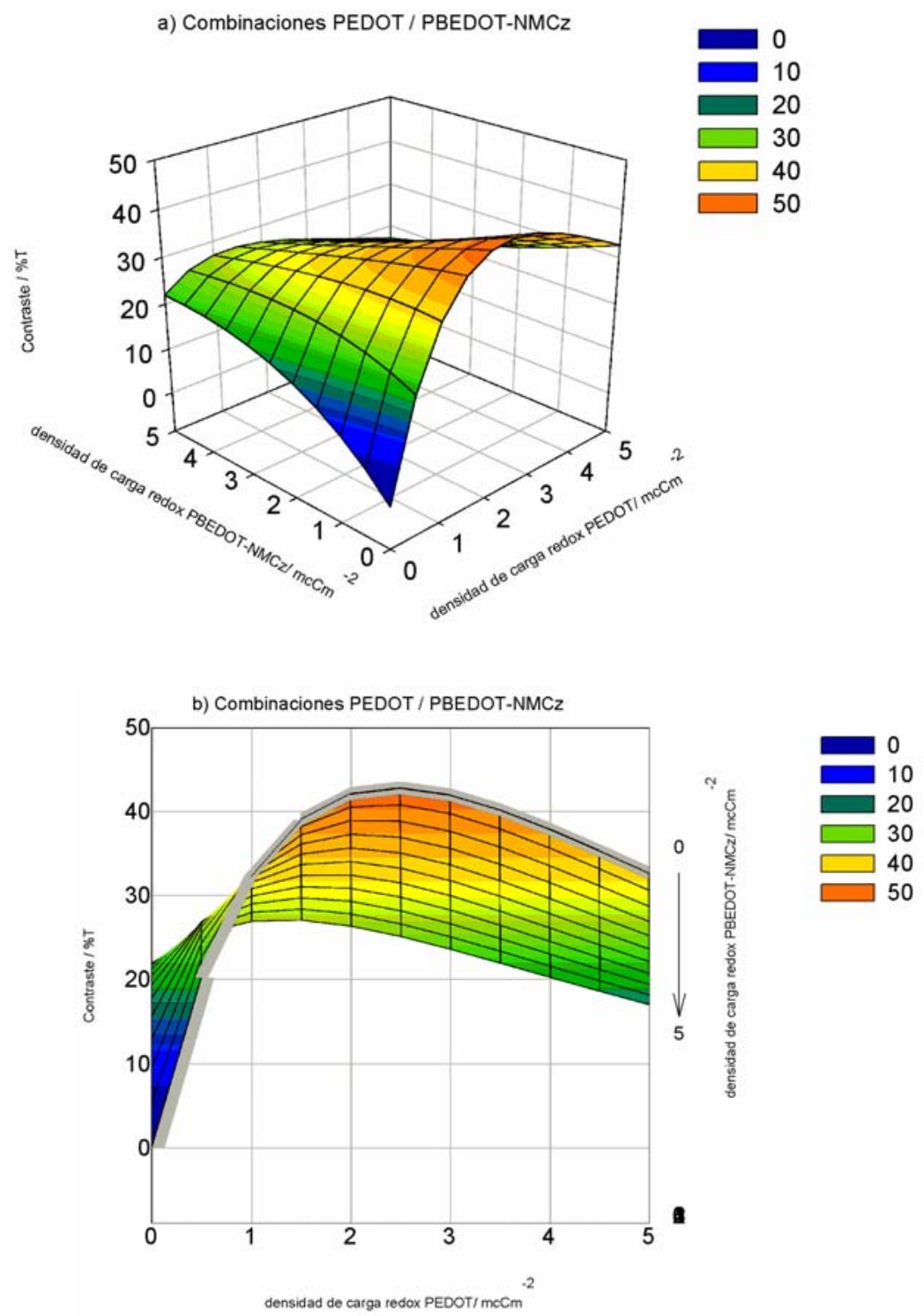

Figura 3.2.6 a) Simulación de los valores de contraste para combinaciones de películas PEDOT/PBEDOT-NMCz, en función de la densidad de carga redox, dentro del rango $0-5 \mathrm{mCcm}^{-2}$ b) Proyección sobre el eje correspondiente a PEDOT. 


\subsubsection{Obtención experimental del máximo contraste en sistemas duales PEDOT/PBEDOT-NMCZ}

Para la comprobación experimental de los resultados obtenidos teóricamente en la sección 3.2.1, se polimerizaron 5 películas de cada polímero sobre láminas de ITO, de densidades de carga redox comprendidas entre los rangos 0-5 $\mathrm{mCcm}^{-2}$ para el PEDOT y 0-8 $\mathrm{mCcm}^{-2}$ para el PBEDOT-NMCz, obteniéndose sus espectros fotópicos. Los valores de caracterización de densidad de carga redox fueron $0.74,1.49,2.24,3.63$ y 5.42 $\mathrm{mCcm}^{-2}$ en el caso del PEDOT y $0.91,2.23,2.41,4.12$ y $7.81 \mathrm{mCcm}^{-2}$ para el PBEDOT-NMCz. Tanto los valores de caracterización electroquímica como óptica fueron obtenidos como en anteriores secciones: el cálculo de la densidad de carga redox de cada película se obtuvo por integración de voltamperogramas llevados a cabo entre 1.15 y $0.05 \mathrm{~V}$ para el PEDOT y -0.75 y $0.75 \mathrm{~V}$ vs. $\mathrm{Ag} / \mathrm{Ag}^{+}$para el PBEDOT-NMCz, a una velocidad de barrido de $100 \mathrm{mVs}^{-1}$ en disoluciones $0.1 \mathrm{M}$ de $\mathrm{LiCF}_{3} \mathrm{SO}_{3}$ en acetonitrilo. La superficie polimerizada fue $2.1 \mathrm{~cm}^{-2}$ en todos los casos. Los espectros de absorción entre 350 y $850 \mathrm{~nm}$ fueron registrados durante la aplicación de $-1.15 \mathrm{~V}$ y 0.05 $\mathrm{V}$ para el PEDOT y -0.75 y $0.75 \mathrm{~V}$ para el PBEDOT-NMCz, y fueron ponderados fotópicamente como se determina en la sección 1.3. Los valores ópticos para cada serie polimérica se muestran en la figura 3.2.7. Se obtuvieron los siguientes ajustes para las absorbancias: 

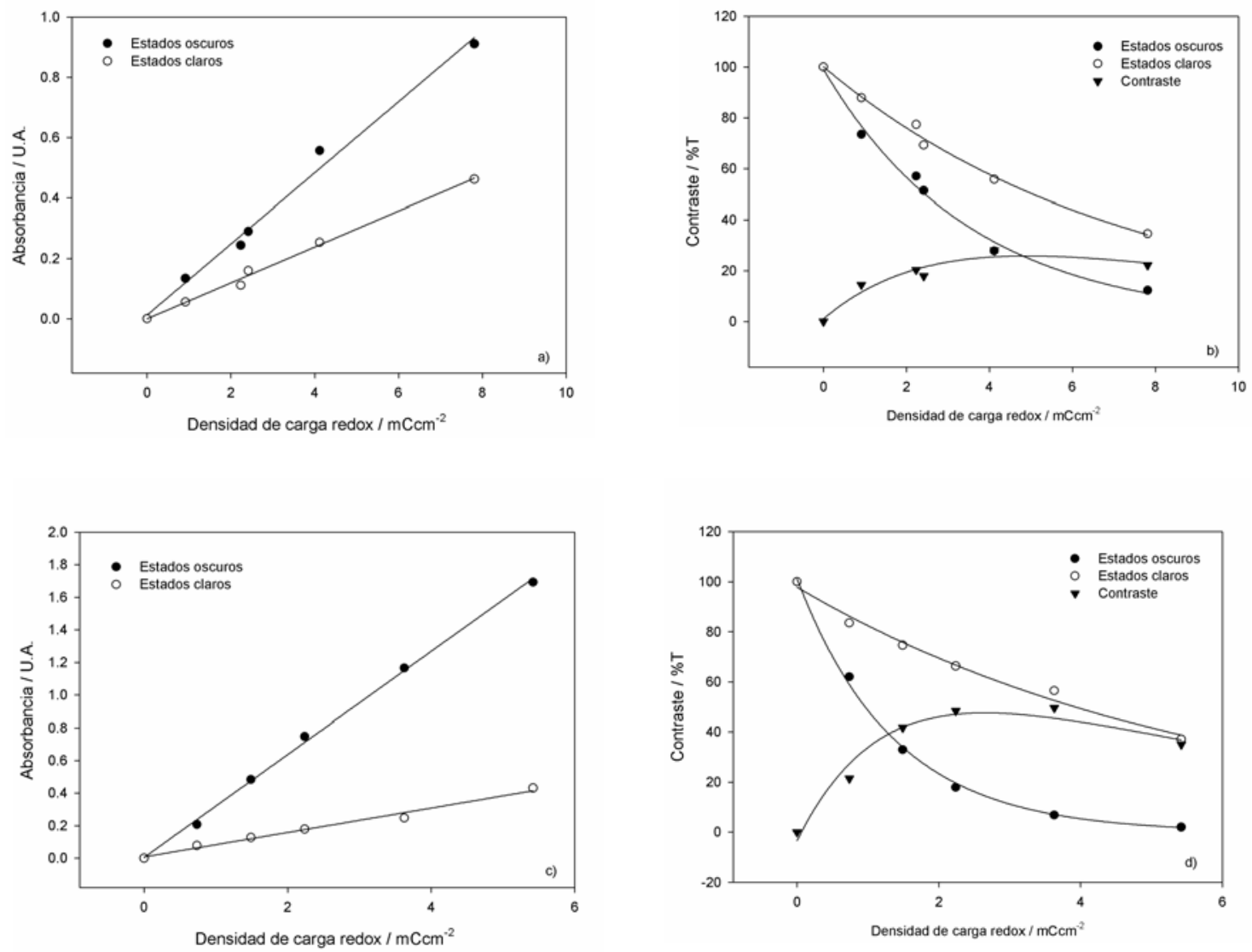

Figura 3.2.7 Valores ópticos fotópicos para películas de PEDOT y PBEDOT-NMCz. a) Valores de absorbancia en los estados claros y oscuros para películas de PEDOT con densidades de carga 0.74, 1.49, 2.24, 3.63 y $5.42 \mathrm{mCcm}^{-2}$ b) Valores convertidos a \% transmitancia, y contraste obtenido por diferencia entre los estados claros y oscuros. c) Valores de absorbancia en los estados claros y oscuros para películas de PBEDOT-NMCz con densidades de carga $0.91,2.23,2.41,4.12$ y $7.81 \mathrm{mCcm}^{-2}$ d) Valores convertidos a $\%$ transmitancia, y contraste obtenido por diferencia entre los estados claros y oscuros. 


\section{PBEDOT-NMCz}

$\mathrm{A}=0.1178 \mathrm{x}$ (estados oscuros) $\quad \mathrm{r}^{2}=0.990$

$\mathrm{A}=0.0595 \mathrm{x}($ estados claros $)$

$r^{2}=0.994$

[ 3.2.16]

\section{PEDOT}

$\mathrm{A}=0.3157 \mathrm{x} \quad$ (estados oscuros $) \quad \mathrm{r}^{2}=0.998$

$\mathrm{A}=0.075 \mathrm{x}$ (estados claros)

En clara concordancia con las relaciones obtenidas en la sección 3.1.3.

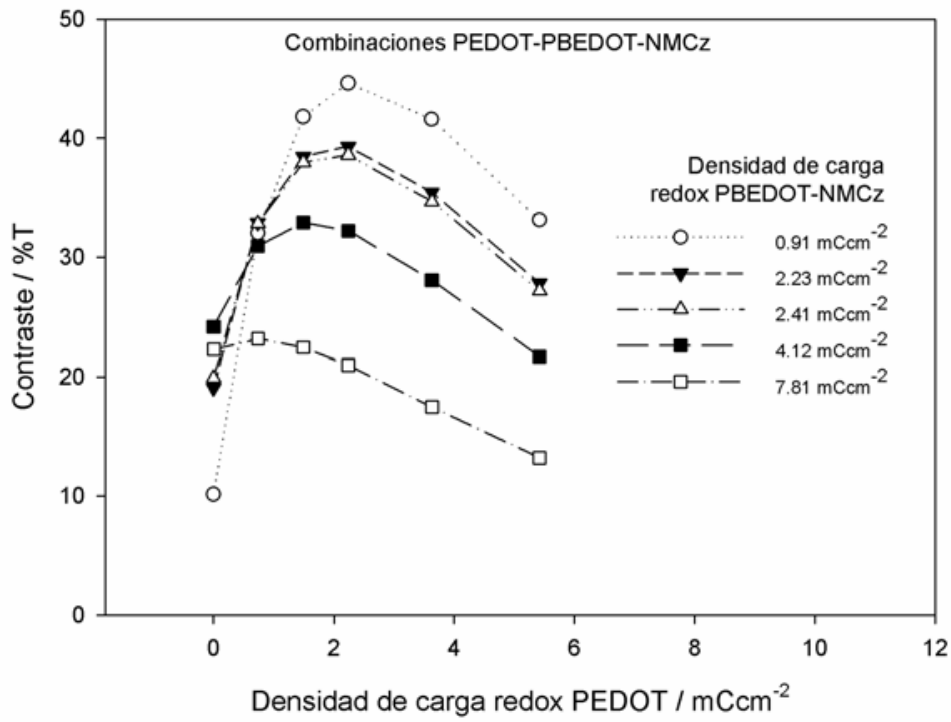

Figura 3.2.8 Valores de contraste fotópico calculados teóricamente para combinaciones duales de películas de PEDOT con densidades de carga redox $0.74,1.49,2.24,3.63$ y $5.42 \mathrm{mCcm}^{-2}$ y películas de PBEDOT-NMCz con $0.91,2.23,2.41,4.12$ y $7.81 \mathrm{mCcm}^{-2}$. 
Las posibles combinaciones entre las 5 películas de cada polímero son un total de 25. Los valores de contraste calculados teóricamente mediante el método propuesto en anteriores puntos se muestran en la figura 3.2.8

Las combinaciones entre películas de PBEDOT-NMCz con $0.91 \mathrm{mCcm}^{-2}$, y los cinco valores de PEDOT (serie de máximo contraste en la figura anterior), así como las combinaciones entre películas de PEDOT de $2.24 \mathrm{mCcm}^{-2}$ y los cinco valores de PBEDOT-NMCz (aproximadamente los puntos de máximo contraste para cada serie de la figura anterior), fueron testadas experimentalmente con el fin de obtener la correlación entre valores obtenidos teórica y experimentalmente.
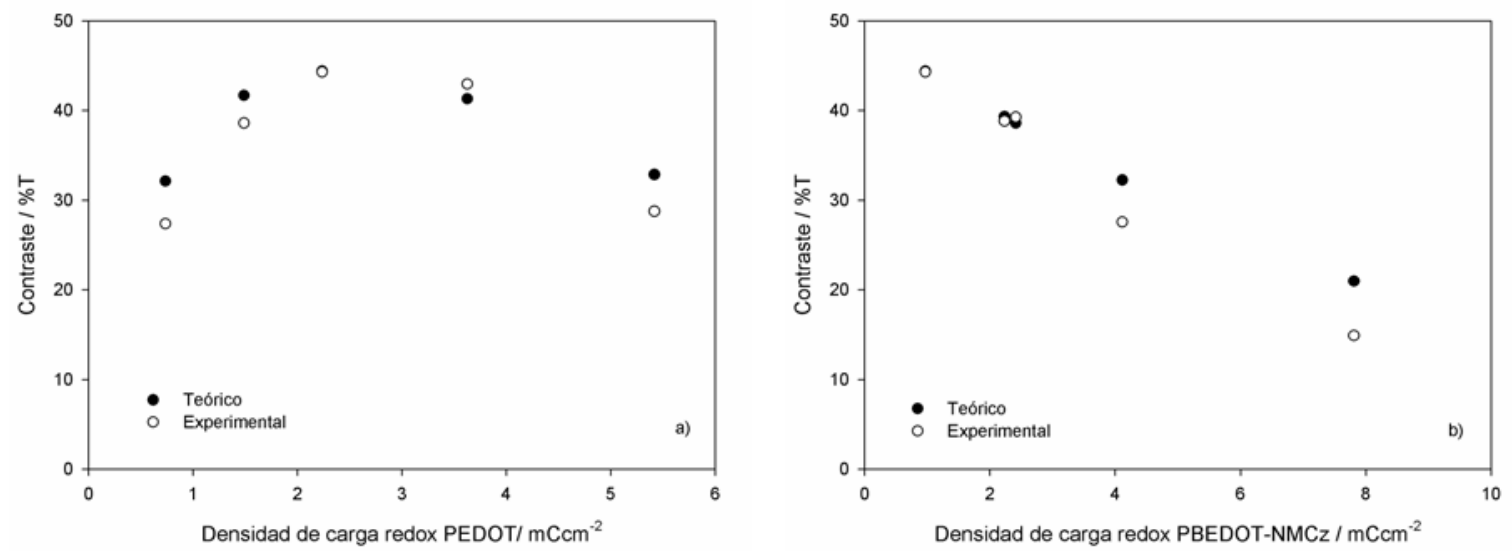

Figura 3.2.9 Comparativa entre los valores de contraste de combinaciones duales PEDOT/PBEDOT$\mathrm{NMCz}$ calculados teórica y experimentalmente, para a) densidad de carga para el PBEDOT-NMCz constante $\left(0.91 \mathrm{mCcm}^{-2}\right)$ y densidades de carga de $0.74,1.49,2.24,3.63$ y $5.42 \mathrm{mCcm}^{-2}$ para el PEDOT y b) densidad de carga para el PEDOT constante $\left(2.24 \mathrm{mCcm}^{-2}\right)$ y densidades de carga de $0.91,2.23,2.41$, 4.12 y $7.81 \mathrm{mCcm}^{-2}$ para el PBEDOT-NMCz.

Los dispositivos formados con dichas combinaciones fueron sometidos a saltos entre 2.2 y $-2.2 \mathrm{~V}$ en disolución de acetonitrilo $0.1 \mathrm{M} \mathrm{LiCF} \mathrm{SO}_{3}$, obteniendo sus respectivos espectros y valores fotópicos. Los valores obtenidos experimentalmente, 
junto con los predichos teóricamente se muestran en la figura 3.2.9, obteniéndose valores coherentes. Por lo tanto, la validez de las predicciones matemáticas desarrolladas fue comprobada experimentalmente. 



\subsection{ESTUDIO ELECTROQUÍMICO DE SISTEMAS DUALES. FACTORES INVOLUCRADOS EN UN FUNCIONAMIENTO CORRECTO}

En las secciones previas se ha demostrado que la funcionalidad de un material electrocrómico está directamente ligada a los procesos redox que ocurren en sus electrodos, encontrándose relaciones lineales entre absorbancia y densidad de carga redox para películas de PEDOT y PBEDOT-NMCz (Sección 3.1.3). Para cada polímero conductor, estos procesos ocurren en un determinado rango de potencial. También se ha discutido el problema de la degradación electroquímica producida por sobrepotenciales. (Sección 3.1.1)

La información relativa a las condiciones de trabajo (estado de oxidación, carga consumida) de cada electrodo polimérico durante el funcionamiento del dispositivo resulta útil para obtener un conocimiento inmediato del estado del material y los riesgos potenciales, así como para la optimización del funcionamiento del dispositivo. Las técnicas habituales como la voltamperometría cíclica o cronoamperometría utilizadas en una configuración de tres electrodos no son capaces de aportar esa información simultáneamente para los dos electrodos, y el potencial del contraelectrodo no se controla. Por el contrario una configuración de dos electrodos, más acorde con el funcionamiento real de un dispositivo, consistente en aplicar una diferencia de potencial conocida entre ambos, sin utilizar un tercero de referencia, no aporta información sobre ninguno de los dos electrodos.

En este estudio proponemos una metodología de dos pasos para estudiar sistemas duales basados en polímeros conductores, consistente en la caracterización individual de los materiales constituyentes antes de su uso en el sistema dual, seguido de la obtención 
de sus parámetros electroquímicos (estado de oxidación, carga consumida) durante el funcionamiento del dispositivo dual. La inclusión de un electrodo de referencia durante el funcionamiento del dispositivo en una configuración de celda de dos electrodos permite el seguimiento del estado de oxidación de cada electrodo. Este seguimiento, junto con la obtención de los porcentajes de carga útil e inútil consumida durante el funcionamiento del dispositivo proporciona una información relevante de cara a optimizar el funcionamiento del dispositivo y maximizar el tiempo de vida de los materiales, por lo que el siguiente estudio se ocupa de la obtención de esta información para distintos sistemas electroquímicos. Se estudiará el sistema electrocrómico dual PEDOT/PBEDOT-NMCz, así como sistemas de un solo polímero. Las estructuras de los monómeros utilizados se muestran en la figura 3.3.1.

BEDOT-NMCZ<smiles>Cc1sc(-c2ccc3c(c2)c2cc(-c4sc(C)c5c4OCCO5)ccc2n3C)c2c1OCCO2</smiles>

Polimero coloreable anódicamente Electrodo de trabajo WE
EDOT<smiles>Cc1sc(C)c2c1OCCO2</smiles>

\section{Polímero coloreable catódicamente Contraelectrodo CE}

Figura 3.3.1 Estructuras químicas y notación de los polímeros utilizados. Para las combinaciones duales, el PBEDOT-NMCz fue usado como electrodo de trabajo y el PEDOT como contraelectrodo.

Siguiendo los procesos electroquímicos de los dos electrodos durante el funcionamiento del dispositivo, se obtendrán las diferencias en la distribución de potenciales entre sistemas de un solo polímero y sistemas duales. 
Asimismo, se estudiará la influencia que las principales variables electroquímicas y físicas como el potencial aplicado, la relación de carga entre los dos electrodos constituyentes y el estado de oxidación inicial de cada electrodo, tienen en el funcionamiento de sistemas duales.

\subsubsection{Metodología propuesta}

\subsubsection{Caracterización individual de los materiales. Ventana de potencial electrocrómica.}

Previamente a su uso en un dispositivo dual, cada película es caracterizada espectroelectroquímicamente, dentro de la ventana de potencial electrocrómica correspondiente. Esta ventana de potencial electrocrómica, es decir, el rango de potenciales para los cuales existe una variación en el espectro óptico del material, fue previamente determinada (Sección 3.1), siendo $-1.15 \mathrm{~V}$ a $0.05 \mathrm{~V}$ para el PEDOT y $0.75 \mathrm{~V}$ a $0.75 \mathrm{~V}$, respecto al electrodo de referencia $\mathrm{Ag} / \mathrm{Ag}^{+}$, para PBEDOT-NMCz.

Cada película es sometida a barridos de potencial cíclicos dentro de su ventana correspondiente, obteniendo de esta manera, por medio de la integración directa del voltamperograma, la carga electrocrómica disponible para dicha película, quedando por lo tanto caracterizada de esta manera.

\subsubsection{Caracterización de sistemas duales. Carga consumida útil y no útil.}

Dos películas de PBEDOT-NMCz, previamente caracterizadas individualmente en configuración de tres electrodos, por medio de voltamperometría cíclica dentro de su 
ventana de potencial electrocrómica, con comportamientos electroquímicos similares (figura 3.3.2.a), fueron utilizadas para componer un sistema dual. La carga electrocrómica de cada película fue obtenida de los voltamperogramas individuales anteriores. El dispositivo polimérico dual fue entonces sometido, en la configuración indicada en la figura 2.2.3, a cinco ciclos de potencial consecutivos entre -1 y $1.2 \mathrm{~V}$, empezando en $0 \mathrm{~V}$. Se obtuvo la respuesta voltamperométrica del dispositivo (insertada en la figura 3.3.2.a) y por medio del multímetro se adquirieron las evoluciones de los potenciales respecto al electrodo de referencia $\mathrm{Ag} / \mathrm{Ag}^{+}$(figura 3.3.2.b).

La carga consumida por el dispositivo se obtuvo por medio de la integración del voltamperograma. Este valor se comparó con los valores de carga electrocrómica de cada película, obteniendo entonces el tanto por ciento de la carga electrocrómica consumida (resultante de dividir la carga consumida por el dispositivo entre la carga electrocrómica disponible para cada película). Este valor porcentual aporta información acerca de la idoneidad de las condiciones de funcionamiento aplicadas, en términos de un consumo resultante de carga superior o inferior al disponible para cada electrodo. Asimismo, cuantifica si el consumo de carga entre los dos electrodos, respecto a la carga electrocrómica disponible, se encuentra compensado. Un dispositivo optimizado debería mostrar valores de $100 \%$ para los dos electrodos. 

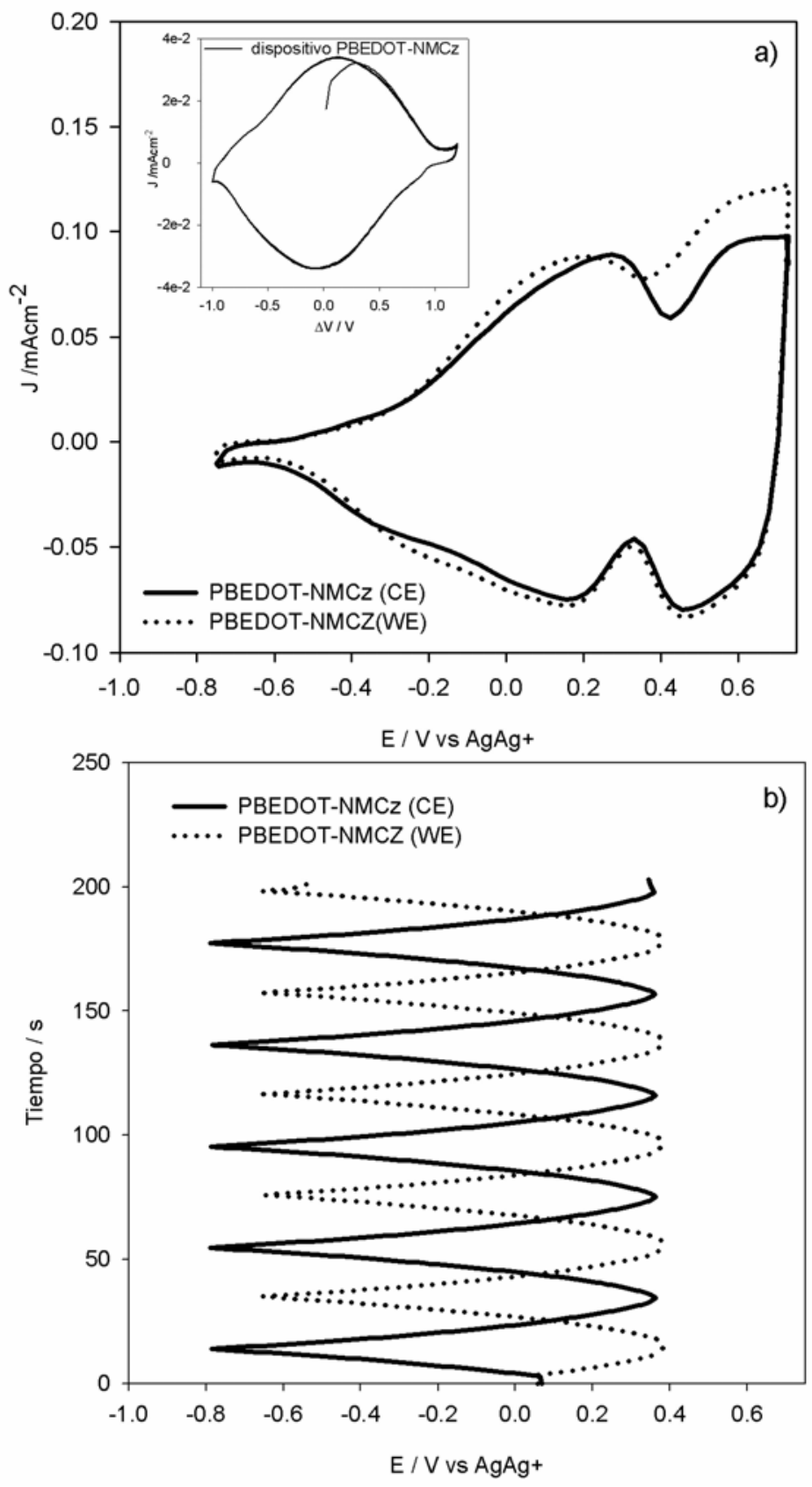

Figura 3.3.2 Caracterización electroquímica de dispositivos PBEDOT-NMCz / PBEDOT-NMCz. a) Voltamperometrías cíclicas de dos películas de PBEDOT-NMCz previas a su utilización como parte de un sistema dual, entre -0.75 and $0.75 \mathrm{~V}$ vs. $\mathrm{Ag} / \mathrm{Ag}^{+}$en disolución de acetonitrilo $0.1 \mathrm{M} \mathrm{LiCF}_{3} \mathrm{SO}_{3}$. Velocidad de barrido $100 \mathrm{mVs}^{-1}$. La figura insertada muestra la respuesta en corriente del dispositivo constituido por esas dos películas, ciclado en la misma disolución. Barrido de potencial aplicado entre -1 y 1.2 V. b) Estados de oxidación simultáneos alcanzados por cada electrodo durante el ciclado del dispositivo entre -1 y $1.2 \mathrm{~V}$. 
Se identificaron los valores de carga consumidos dentro y fuera de la correspondiente ventana de potencial electrocrómica, por medio de la evolución de los estados de oxidación de cada electrodo, y la carga consumida en cada rango. Estos valores fueron comparados con la carga consumida por el dispositivo, obteniendo de esta manera los porcentajes de carga inútil consumida (resultado de dividir la carga consumida fuera de la ventana electrocrómica para cada electrodo por la carga total consumida por el dispositivo). Este valor, junto con el análisis de las evoluciones de los estados de oxidación, aporta información acerca de posibles procesos de degradación. Un dispositivo optimizado debería resultar en valores de $0 \%$ en cada caso* .

\subsubsection{Aplicación de la metodología propuesta}

\subsubsection{Distribución de potenciales en sistemas de un solo polímero}

Usando la metodología anteriormente propuesta, se estudió la distribución del potencial entre los dos electrodos (ITO-polímero e ITO desnudo) para dispositivos de un solo polímero (configuración ITO-polímero/electrolito/ITO). Dispositivos de este tipo, para películas tanto de PEDOT como de PBEDOT-NMCz, fueron estudiados utilizando como contraelectrodo una lámina de ITO desnuda.

La figura 3.3.3 muestra la distribución del potencial entre los dos electrodos, polimérico e ITO desnudo, durante el ciclado en la configuración mostrada en la figura 2.2.3, entre -1 y $1.2 \mathrm{~V}$ : la mayor parte del potencial aplicado ( $90 \%$ de la energía) fue consumida por reacciones electroquímicas en el contraelectrodo de ITO, y sólo un 10 \%

\footnotetext{
* Nota: Los valores concretos para el dispositivo referido en este punto se muestran más adelante, en el punto 3.3.2.2.1, tabla 3.3.1.
} 
para llevar a cabo reacciones electrocrómicas en el polímero. Aunque las reacciones ocurridas en el electrodo de ITO son ineficientes con respecto a cambios de color, consumieron la mayor parte de la energía eléctrica $E_{e}\left(E_{e}=I \eta_{1}+I \eta_{2}\right.$, con $\eta_{1}$ y $\eta_{2}$ representando los sobrepotenciales de cada electrodo, e I la intensidad eléctrica). Con la aplicación de un potencial externo cíclico entre - 1 y $1.2 \mathrm{~V}$, los estados de oxidación de los electrodos poliméricos en cada caso sólo cambiaron aproximadamente $0.2 \mathrm{~V}$, de 0.04 a $0.16 \mathrm{~V}$, vs. $\mathrm{Ag} / \mathrm{Ag}^{+}$, para el PEDOT (figura 3.3.3.a) y de -0.05 a $0.18 \mathrm{~V}$ para el PBEDOT-NMCz (figura 3.3.3.b). Por lo tanto, aunque se aplicó una diferencia de potencial relativamente grande al dispositivo, los polímeros conductores experimentaron pequeñas variaciones electrocrómicas.
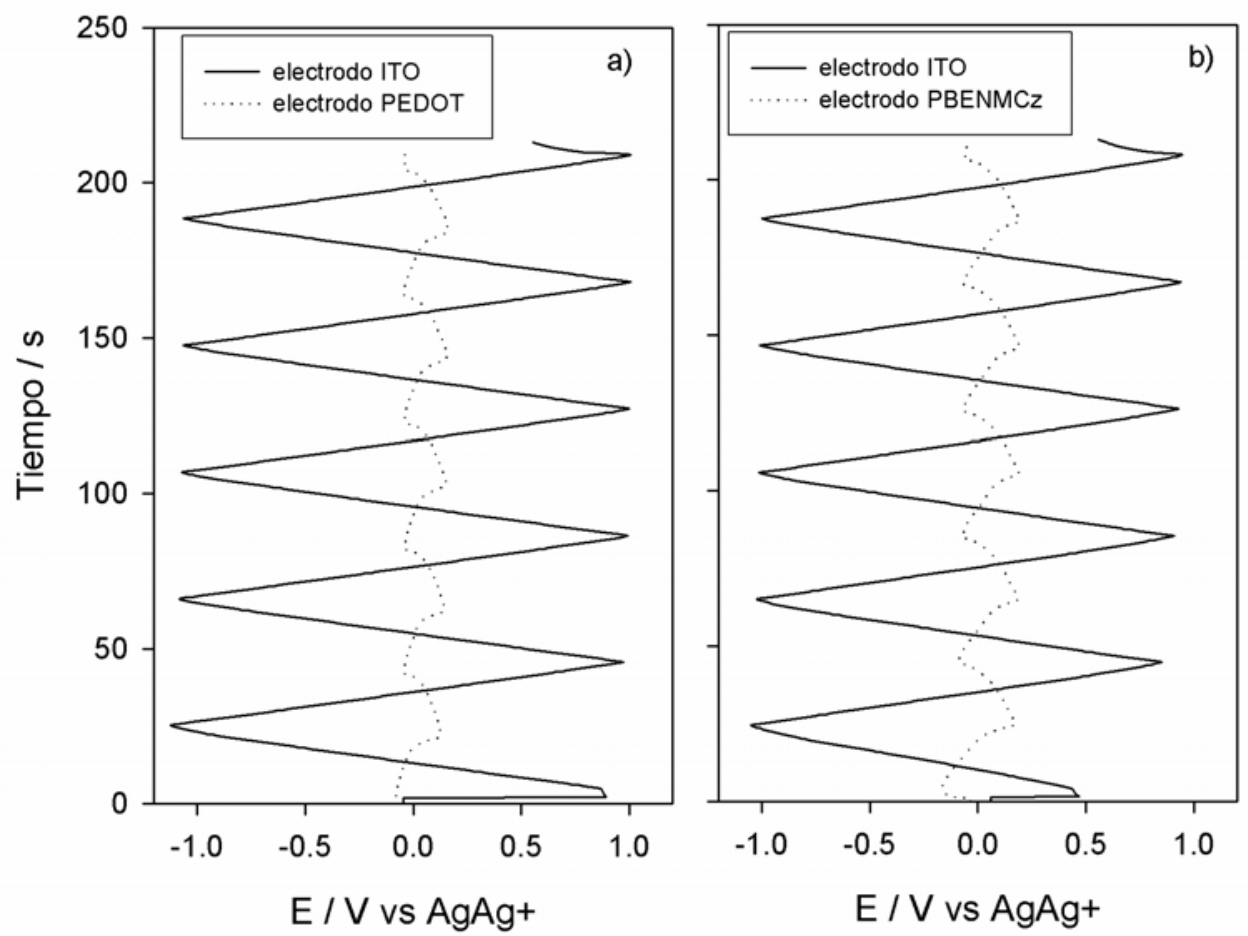

Figura 3.3.3 Distribución de potenciales vs. $\mathrm{Ag} / \mathrm{Ag}^{+}$entre los dos electrodos constituyentes de dos configuraciones electrocrómicas de un solo polímero: a) ITO/ PEDOT/electrolito/ ITO y b) ITO /PBEDOT-NMCZ /electrolito / ITO. El potencial aplicado entre los dos electrodos fue barrido entre -1 y 1.2 V, comenzando en $0 \mathrm{~V}$, en disolución $0.1 \mathrm{M} \mathrm{LiCF}_{3} \mathrm{SO}_{3}(\mathrm{ACN})$. Velocidad de barrido $100 \mathrm{mVs}^{-1}$. 
Para obtener cambios de absorbancia significativos, se necesitan evoluciones de los sobrepotenciales poliméricos más extensas. Sin embargo, cualquiera que sea el potencial aplicado al dispositivo, la mayoría de la energía se consume en procesos electroquímicos ineficientes, en términos electrocrómicos, en el electrodo de ITO. Este resultado reforzó la conveniencia del uso de sistemas duales electrocrómicos.

\subsubsection{Estudio de las variables de funcionamiento de dispositivos poliméricos duales}

Siendo los cambios electrocrómicos función del cambio en la concentración de cromóforos (polarones y bipolarones) dentro de la película, y siendo esta concentración controlada por el consumo de carga redox, cualquier variable que tenga influencia en la velocidad de consumo de carga tendrá consecuencias en el correspondiente cambio electrocrómico. En este punto se estudiaron el rango de potencial aplicado, la relación de carga electrocrómica entre los dos electrodos constituyentes, y el estado de oxidación inicial de cada material. La metodología experimental propuesta se usó para obtener información acerca de la influencia que estos factores tienen en el funcionamiento de los dispositivos poliméricos duales.

\subsection{Efecto de los límites de potencial aplicados}

Los dispositivos electrocrómicos funcionan habitualmente por medio de la aplicación de potenciales o corrientes. Para estudiar el efecto de la aplicación de distintos límites de potencial, un dispositivo constituido por dos películas ITO/PBEDOT-NMCz fue sometido a barridos de potencial consecutivos entre los 
siguientes límites: $-0.75 / 0.75 \mathrm{~V},-1 / 1.2 \mathrm{~V}, \mathrm{y}-1 / 1.5 \mathrm{~V}$, en la configuración mostrada en la figura 2.2.3. Cada polímero se caracterizó previamente por medio de voltamperometría cíclica, usando un contraelectrodo de platino y un electrodo de referencia, definiendo sus densidades de carga electrocrómica dentro de las correspondientes ventanas de potencial electrocrómicas.

Los límites de potencial anódico y catódico (vs. $\mathrm{Ag} / \mathrm{Ag}^{+}$) alcanzados por cada uno de los electrodos de PBEDOT-NMCz durante el ciclado del dispositivo, el porcentaje de carga consumida por el dispositivo comparada con la carga electrocrómica disponible para cada electrodo, y el porcentaje de carga consumida por cada electrodo fuera de su ventana electrocrómica (carga inútil) se calcularon por el procedimiento descrito anteriormente, y se muestran en la tabla 3.3.1.

\begin{tabular}{|c|c|c|c|c|c|c|c|c|c|c|}
\hline \multirow[t]{3}{*}{$\begin{array}{c}\text { Potencial } \\
\text { aplicado } \\
\text { / } \Delta \mathrm{V}\end{array}$} & \multicolumn{6}{|c|}{$\begin{array}{l}\text { *Potenciales } \\
\text { alcanzados } \\
\text { / V vs Ag/Ag+ }\end{array}$} & \multicolumn{2}{|c|}{$\begin{array}{c}\% \text { carga } \\
\text { electrocrómica } \\
\text { consumida }\end{array}$} & \multicolumn{2}{|c|}{$\begin{array}{c}\% \text { carga } \\
\text { consumida } \\
\text { no útil }\end{array}$} \\
\hline & & CE & & & WE & & $\mathrm{CE}$ & WE & CE & WE \\
\hline & $\begin{array}{l}\text { máximo } \\
\text { anódico }\end{array}$ & $\begin{array}{l}\text { máximo } \\
\text { catódico }\end{array}$ & total & $\begin{array}{l}\text { máximo } \\
\text { anódico }\end{array}$ & $\begin{array}{l}\text { máximo } \\
\text { catódico }\end{array}$ & total & & & & \\
\hline-0.75 a $0.75 \mathrm{~V}$ & 0.31 & -0.39 & 0.7 & 0.36 & -0.4 & 0.76 & 52 & 51 & 0.00 & 0.00 \\
\hline-1.0 a $1.2 \mathrm{~V}$ & 0.36 & -0.79 & 1.15 & 0.38 & -0.65 & 1.03 & 59 & 57 & 0.60 & 0.00 \\
\hline-1.0 a $1.5 \mathrm{~V}$ & 0.42 & -1 & 1.42 & 0.48 & -0.58 & 1.06 & 66 & 65 & 3.83 & 0.00 \\
\hline
\end{tabular}

Tabla 3.3.1 Distribución de potenciales entre elctrodo de trabajo y contraelectrrodo para un dispositivo PBEDOT-NMCz/PBEDOT-NMCz, junto con los porcentajes de carga electrocrómica útil y carga no util consumida, para distintos voltajes externos aplicados.

El aumento del potencial aplicado resultó en un aumento de la carga consumida por el dispositivo, aumentando, al mismo tiempo, los rangos de potencial recorridos por cada electrodo. Finalmente, para potenciales aplicados suficientemente altos, los potenciales alcanzados por los materiales fueron empujados fuera de la ventana útil. 


\subsection{Influencia de la relación de carga electrocrómica entre los electrodos consituyentes}

En secciones previas (secciones 3.1 .3 y 3.2) se ha propuesto y utilizado la caracterización de películas electrocrómicas por medio de su carga electrocrómica, definida como la carga redox asociada a cambios electrocrómicos. El objetivo en este punto fue determinar el efecto que la variación del ratio de carga electrocrómica entre los dos electrodos tiene en el rango de potencial alcanzado por cada electrodo, y en la carga útil consumida, para unas condiciones de chequeo del dispositivo concretas.

Se prepararon películas de cada uno de los polímeros estudiados, PEDOT y PBEDOT-NMCz, sobre electrodos de ITO por medio de la aplicación del correspondiente potencial. Después de la polimerización, cada película fue ciclada dentro de su ventana electrocrómica para definir su carga electrocrómica. Se obtuvieron películas de PBEDOT-NMCz con 2.5 y $1.2 \mathrm{mCcm}^{-2}$ y películas de PEDOT de $4.00 \mathrm{y}$ $1.34 \mathrm{mCcm}^{-2}$, respectivamente. Las películas de PBEDOT-NMCz se combinaron con las películas de PEDOT, resultando en cuatro combinaciones duales. Comparando los valores de sus cargas electrocrómicas, los correspondientes ratios fueron: 0.5, 1.1, 1.6 y 3.3 .

Cada dispositivo se sometió a ciclados de potencial consecutivos entre -1 y $1.2 \mathrm{~V}$. Los dispositivos se chequearon usando el PBEDOT-NMCz como WE y el PEDOT como CE. Las respuestas voltamperométricas se obtuvieron a través del potenciostato, mientras que la evolución del estado de oxidación de cada electrodo se adquirió a través del multímetro. La evolución de los rangos de potencial alcanzados para cada electrodo, siendo parte de un dispositivo dual, se muestra en la tabla 3.3.2. 


\begin{tabular}{|c|c|c|c|c|c|c|}
\hline \multirow[t]{3}{*}{ Ratio CE:WE } & \multicolumn{6}{|c|}{ Potenciales alcanzados / V vs $\mathrm{Ag} / \mathrm{Ag}+$} \\
\hline & \multicolumn{3}{|c|}{ CE } & \multicolumn{3}{|c|}{ WE } \\
\hline & $\begin{array}{l}\text { máximo } \\
\text { anódico }\end{array}$ & $\begin{array}{l}\text { máximo } \\
\text { catódico }\end{array}$ & total & $\begin{array}{l}\text { máximo } \\
\text { anódico }\end{array}$ & $\begin{array}{l}\text { máximo } \\
\text { catódico }\end{array}$ & total \\
\hline $\begin{array}{l}\text { Sistema } \\
\text { PEDOT/ } \\
\text { PBEDOT-NMCZ }\end{array}$ & & & & & & \\
\hline 3.3 & -0.07 & -0.37 & 0.30 & 0.82 & -1.09 & 1.91 \\
\hline 1.6 & 0.05 & -0.42 & 0.48 & 0.75 & -0.99 & 1.74 \\
\hline 1.1 & 0.26 & -0.70 & 0.96 & 0.48 & -0.74 & 1.22 \\
\hline 0.5 & 0.49 & -0.80 & 1.29 & 0.42 & -0.42 & 0.84 \\
\hline
\end{tabular}

* El potencial aplicado a los dispositivos fue entre -1 y $1.2 \mathrm{~V}$.

PBEDOT-NMCz actuó como WE y PEDOT como CE en todos los casos.

Tabla 3.3.2 Distribución de los potenciales entre electrodo de trabajo y contraelectrodo en función del ratio de carga electrocrómica entre los dos electrodos.

Se obtuvo la carga consumida por cada dispositivo, y mediante la comparación con la correspondiente carga electrocrómica disponible para cada película, el porcentaje de carga electrocrómica consumida por cada película durante el funcionamiento del dispositivo.

Se obtuvieron las evoluciones de potencial respecto al electrodo de referencia, es decir, de los estados de oxidación, para cada electrodo durante el funcionamiento del dispositivo. Esto permitió la cuantificación de las cargas consumidas dentro y fuera de las ventanas electrocrómicas de cada película, obteniendo los porcentajes de carga inútil consumidos por el dispositivo (tabla 3.3.3). 


\begin{tabular}{lccccccc}
\hline Ratio CE:WE & $\begin{array}{c}\text { Carga } \\
\text { electrocrómica } \\
\text { para cada } \\
\text { película } \\
\text { /mCcm-2 }\end{array}$ & $\begin{array}{c}\text { Carga } \\
\text { consumida } \\
\text { por el } \\
\text { dispositivo } \\
\text { /mCcm-2 }\end{array}$ & $\begin{array}{c}\text { \% carga } \\
\text { electrocrómica } \\
\text { consumida }\end{array}$ & $\begin{array}{c}\text { \% carga } \\
\text { consumida } \\
\text { no útil }\end{array}$ \\
\hline Sistema & CE & WE & & CE & WE & CE & WE \\
\cline { 2 - 9 } & & & & & & & \\
PEDOT/ & & & & & & & \\
PBEDOT-NMCz & & & & & & & \\
1.3 & 4.00 & 1.20 & 1.16 & 29.1 & 96.8 & 0.0 & 23.1 \\
1.6 & 4.00 & 2.48 & 2.13 & 53.4 & 86.2 & 6.5 & 5.0 \\
1.1 & 1.34 & 1.20 & 0.82 & 61.3 & 68.3 & 17.4 & 0.0 \\
0.5 & 1.34 & 2.48 & 1.14 & 85.5 & 46.2 & 30.4 & 0.0 \\
\hline
\end{tabular}

${ }^{*}$ El potencial aplicado a los dispositivos fue de -1 a $1.2 \mathrm{~V}$

** PBEDOT-NMCz actuó como WE en todos los casos

Tabla 3.3.3 Porcentajes de carga útil electrocrómica y carga no útil consumida por dispositivos duales, en función del ratio de carga electrocrómica entre sus electrodos.

A partir de los datos de las tablas 3.3.2 y 3.3.3, se observa que un aumento en los valores de los ratios, correspondiente con un aumento de la carga relativa del $\mathrm{CE}$ (PEDOT) respecto a la del WE (PBEDOT-NMCz), se refleja en un aumento de la ventana de potencial recorrida por el material con menos carga (PBEDOT-NMCz) y un aumento del porcentaje de carga consumida por el dispositivo respecto a la carga electrocrómica disponible para esa película. Se observan tendencias opuestas para el electrodo complementario.

Las combinaciones con ratio próximos a 1 mostraron los porcentajes de carga electrocrómica consumida más compensados entre los dos electrodos, como cabía esperar, pero se observaron porcentajes de carga inútil consumida $(17.4 \%$ para el PEDOT con ratio 1.1).

Las tendencias en los porcentajes de carga inútil consumida no son tan claras. La disminución de la carga relativa de uno de los polímeros respecto al complementario se asocia, atendiendo a los resultados experimentales de las tablas 3.3.2 y 3.3.3, a un aumento en los porcentajes de carga útil consumida y el rango de potenciales alcanzado. 
Como resultado de ese incremento en los rangos de potenciales alcanzados, se aumentó también el porcentaje de cargas inútiles. Para el sistema PEDOT/PBEDOT-NMCz, y para las condiciones experimentales concretas (potencial aplicado entre -1 y $1.2 \mathrm{~V}$ ), los dos electrodos consumieron cargas inútiles en alguno de los casos. Se observó que una diferencia sustancial entre la carga de uno de los dos electrodos respecto al otro se traduce en una ventana de potencial recorrida durante el funcionamiento del dispositivo muy reducida. Por lo tanto, esta es una manera de mantener prácticamente el mismo estado de oxidación, y por lo tanto un color constante, durante el funcionamiento del dispositivo. Estos resultados sugieren la posibilidad de usar estas películas como capas de almacenamiento iónico, funcionando como filtros de color. Esto puede ser usado para obtener combinaciones de colores en dispositivos poliméricos duales.

\subsection{Influencia del estado de oxidación inicial}

El control voltamperométrico de un polímero conductor muestra que la velocidad de consumo de carga cambia a lo largo del voltamperograma con el estado de oxidación del polímero. Esto significa que para unas condiciones experimentales concretas, el rango de potenciales alcanzados, la carga electrocrómica útil y la variación de absorbancia debe ser diferente dependiendo del estado de oxidación inicial de cada polímero en el que comencemos a hacer funcionar el dispositivo.

En este apartado se estudiará el efecto que la modificación del estado inicial de oxidación de los polímeros tiene en la evolución de los potenciales alcanzados durante el ciclado del dispositivo.

Se estudió una combinación PEDOT/PBEDOT-NMCz, con cargas electrocrómicas de $0.45 \mathrm{mCcm}^{-2}$ y $0.39 \mathrm{mCcm}^{-2}$ respectivamente. Después de la caracterización 
voltamperométrica individual, el PBEDOT-NMCz se mantuvo en estado reducido y el PEDOT en estado oxidado, parando los barridos de potencial en los correspondientes límites. La película de PBEDOT-NMCz reducida fue usada como electrodo de trabajo en el dispositivo. El dispositivo fue ciclado, comenzando en $0 \mathrm{~V}$ y en sentido anódico, entre -1 y $1.2 \mathrm{~V}$. Para un potencial aplicado de $0 \mathrm{~V}$, ambos polímeros se situaron en $0.10 \mathrm{~V}$ vs. $\mathrm{Ag} / \mathrm{Ag}^{+}$. Los límites de potencial alcanzados por las películas de PEDOT y PBEDOT-NMCz fueron $+0.15 /-0.50$ y $0.50 /-1.03 \mathrm{~V}$ vs. $\mathrm{Ag} / \mathrm{Ag}^{+}$respectivamente: 15 $\%$ del rango de potencial cubierto por el PEDOT estaba fuera de su ventana electrocrómica, mientras que este porcentaje fue de $17 \%$ para el electrodo de PBEDOTNMCz.

Después de esta experiencia, ambas películas fueron reducidas individualmente, usando un contraelectrodo metálico auxiliar, a $-1.55 \mathrm{~V}$ y $-1.15 \mathrm{~V}$, respectivamente. La configuración dual fue reconstruida con los dos electrodos reducidos, y sometida a $0 \mathrm{~V}$. Los polímeros se situaron en $-0.5 \mathrm{~V}$ vs. $\mathrm{Ag} / \mathrm{Ag}^{+}$. Aplicando el mismo barrido de potencial, los rango de potencial cubiertos fueron en este caso $-0.30 /-0.78 \mathrm{~V}$ para el PEDOT y $0.21 /$-1.50 V para el PBEDOT-NMCz, durante el primer ciclo. Todos los potenciales alcanzados por el PEDOT estuvieron dentro de su ventana electrocrómica, evitando procesos inútiles y posiblemente degradativos, mientras que un $40 \%$ de los potenciales recorridos por el PBEDOT-NMCz estuvieron fuera de su ventana electrocrómica. Sin embargo, los límites de potencial alcanzados por los polímeros durante el ciclado no fueron tan estables como en el experimento previo. Estas variaciones se muestran en la figura 3.3.4. 

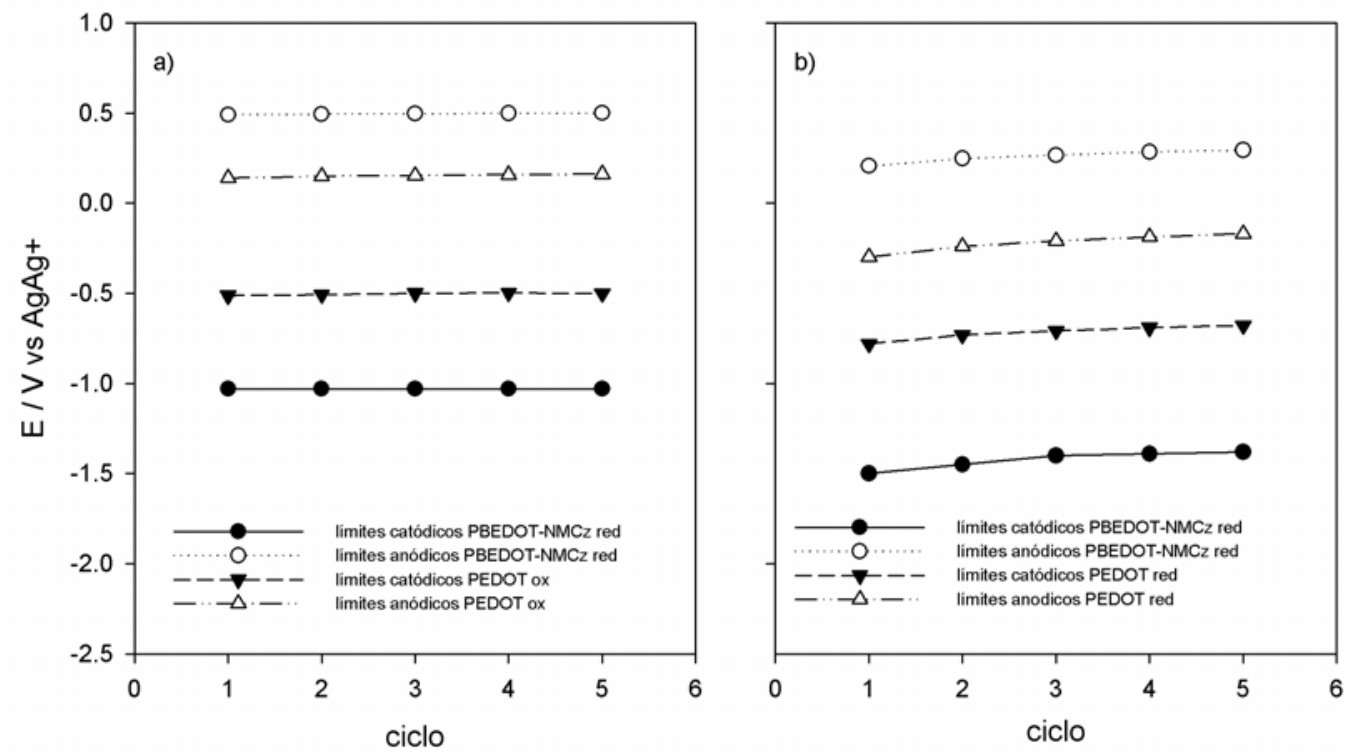

Figura 3.3.4 Evolución del máximo potencial anódico y catódico alcanzado para cada electrodo durante cinco ciclos, para un sistema PEDOT/PBEDOT-NMCz. El potencial aplicado fue barrido entre -1 y 1.2V, en disolución de acetonitrilo $0.1 \mathrm{M} \mathrm{LiCF}_{3} \mathrm{SO}_{3}$ (velocidad de barrido $100 \mathrm{mVs}^{-1}$ ).

a) Evolución de los potenciales para un sistema PEDOT oxidado / PBEDOT-NMCz reducido en el comienzo del experimento. El estado de oxidación inicial de las películas se obtuvo deteniendo el correspondiente voltamperograma individual de caracterización en el potencial adecuado.

b) Evolución de los potenciales para un sistema PEDOT fuertemente reducido / PBEDOT-NMCz fuertemente reducido en el comienzo del experimento. La película de PEDOT se redujo mediante la aplicación de $-1.55 \mathrm{~V}$ vs. $\mathrm{Ag} / \mathrm{Ag}^{+}$por 30 segundos y la película de PBEDOT-NMCz fue reducida mediante la aplicación de $-1.15 \mathrm{~V}$ vs. $\mathrm{Ag} / \mathrm{Ag}^{+}$por 30 segundos, en disolución de acetonitrilo $0.1 \mathrm{M} \mathrm{LiCF}_{3} \mathrm{SO}_{3}$. 
Apéndice. Reconstrucción de los voltamperogramas individuales de los electrodos constituyentes de un dispositivo dual

Mediante la metodología propuesta, un barrido de potencial entre los dos electrodos, $\Delta \mathrm{V}$, es aplicado al dispositivo, a una velocidad constante, $\mathrm{s}=\mathrm{d} \Delta \mathrm{V} / \mathrm{dt}$, mientras se registra la corriente redox del dispositivo, $I_{d}$, por lo tanto obteniendo la respuesta voltamperométrica del dispositivo. La carga consumida por el dispositivo, $\mathrm{Q}_{\mathrm{d}}$, se puede calcular directamente por integración voltamperométrica. Simultáneamente, el potencial de uno de los electrodos, $\mathrm{V}_{\mathrm{WE}}$ ó $\mathrm{V}_{\mathrm{CE}}$, respecto al electrodo de referencia es registrado (y por simple diferencia, el potencial del electrodo opuesto, $\mathrm{V}_{\mathrm{CE}}$ ó $\mathrm{V}_{\mathrm{WE}}$, puesto que $\Delta \mathrm{V}$ es conocido en todo momento).

La consecución de la reacción redox en la celda implica que la corriente que fluye a través de un electrodo sea la misma que la que fluye en el electrodo opuesto (pero con distinto signo), y por lo tanto

$\mathrm{I}_{\mathrm{d}}=\mathrm{I}_{\mathrm{WE}}=-\mathrm{I}_{\mathrm{CE}}$

$\mathrm{Q}_{\mathrm{d}}=\mathrm{Q}_{\mathrm{WE}}=-\mathrm{Q}_{\mathrm{CE}}$

La obtención de la evolución de los estados de oxidación de cada material electródico, y de la intensidad de oxidación-reducción en cada momento, permite reconstruir los voltamperogramas individuales de cada electrodo durante el funcionamiento del dispositivo dual. Esto permite una comparación directa con el voltamperograma de caracterización obtenido previamente para cada película dentro de su ventana electrocrómica, pudiendo cuantificar la carga consumida por la película durante el funcionamiento del dispositivo fuera de la ventana electrocrómica correspondiente, así como la evolución de los potenciales de oxidación. 

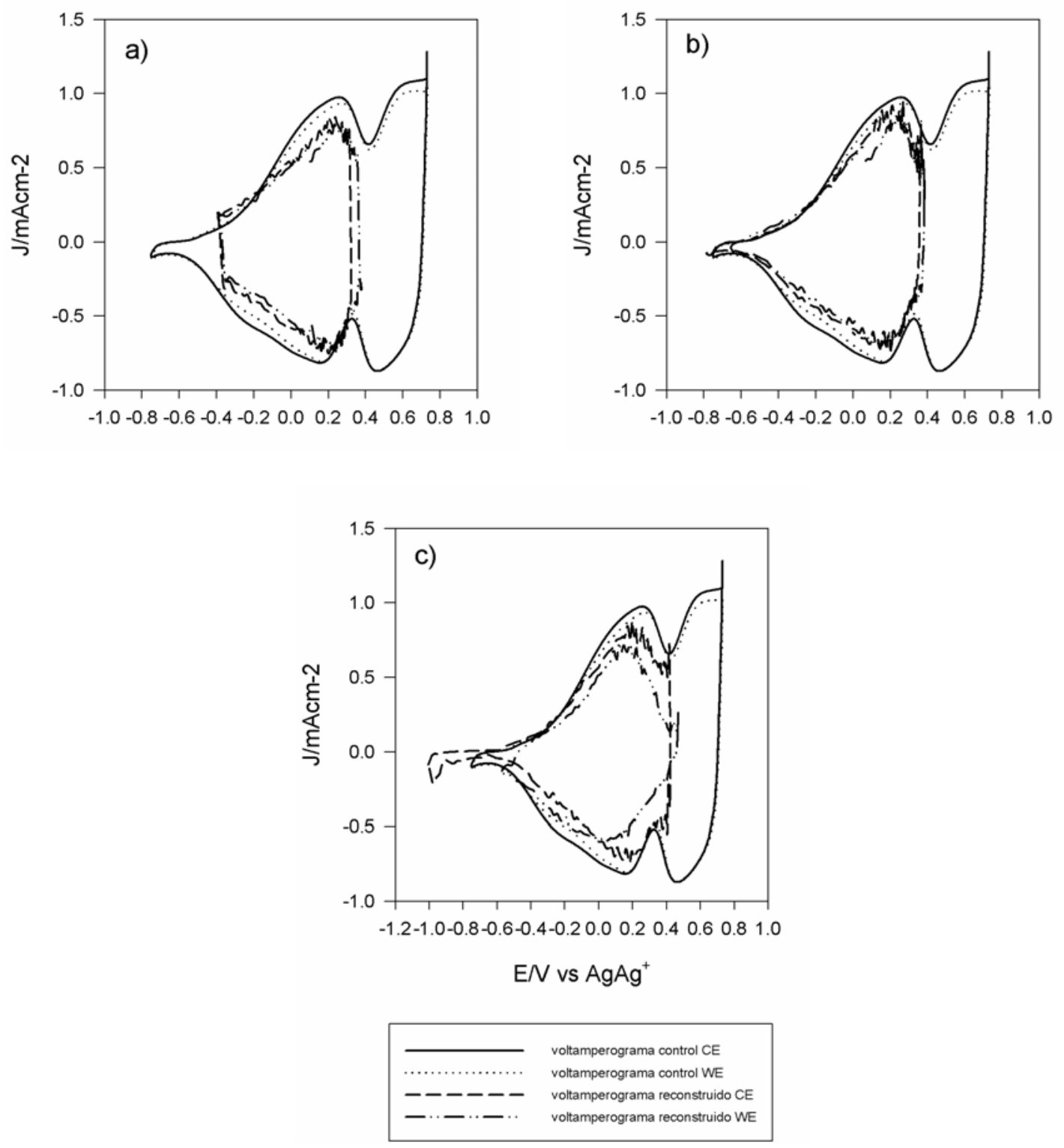

Figura 3.3.5 Voltamperogramas individuales de las películas constituyentes de un dispositivo PBEDOT-NMCz / PBEDOT-NMCz.—— Voltamperograma de control y caracterización de la película usada como CE realizado previamente al uso de la película en el dispositivo. ……... Voltamperograma de control y caracterización de la película usada como WE realizado previamente al uso de la película en el dispositivo. - - - - Voltamperograma de la película usada como $\mathrm{CE}$ reconstruido a través del registro de la evolución de su estado de oxidación durante el ciclado del dispositivo. -" - "- Voltamperograma de la película usada como WE reconstruido a través del registro de la evolución de su estado de oxidación durante el ciclado del dispositivo. La gráfica a) corresponde al dispositivo ciclado entre -0.75 y $0.75 \mathrm{~V}, \mathrm{~b}$ ) entre -1 y $1.2 \mathrm{~V}$ y c) entre -1 y $1.5 \mathrm{~V}$. Todos los experimentos fueron llevados a cabo en disolución $0.1 \mathrm{M} \mathrm{LiCF}_{3} \mathrm{SO}_{3}(\mathrm{ACN})$ y velocidad de barrido $100 \mathrm{mVs}^{-1}$. 

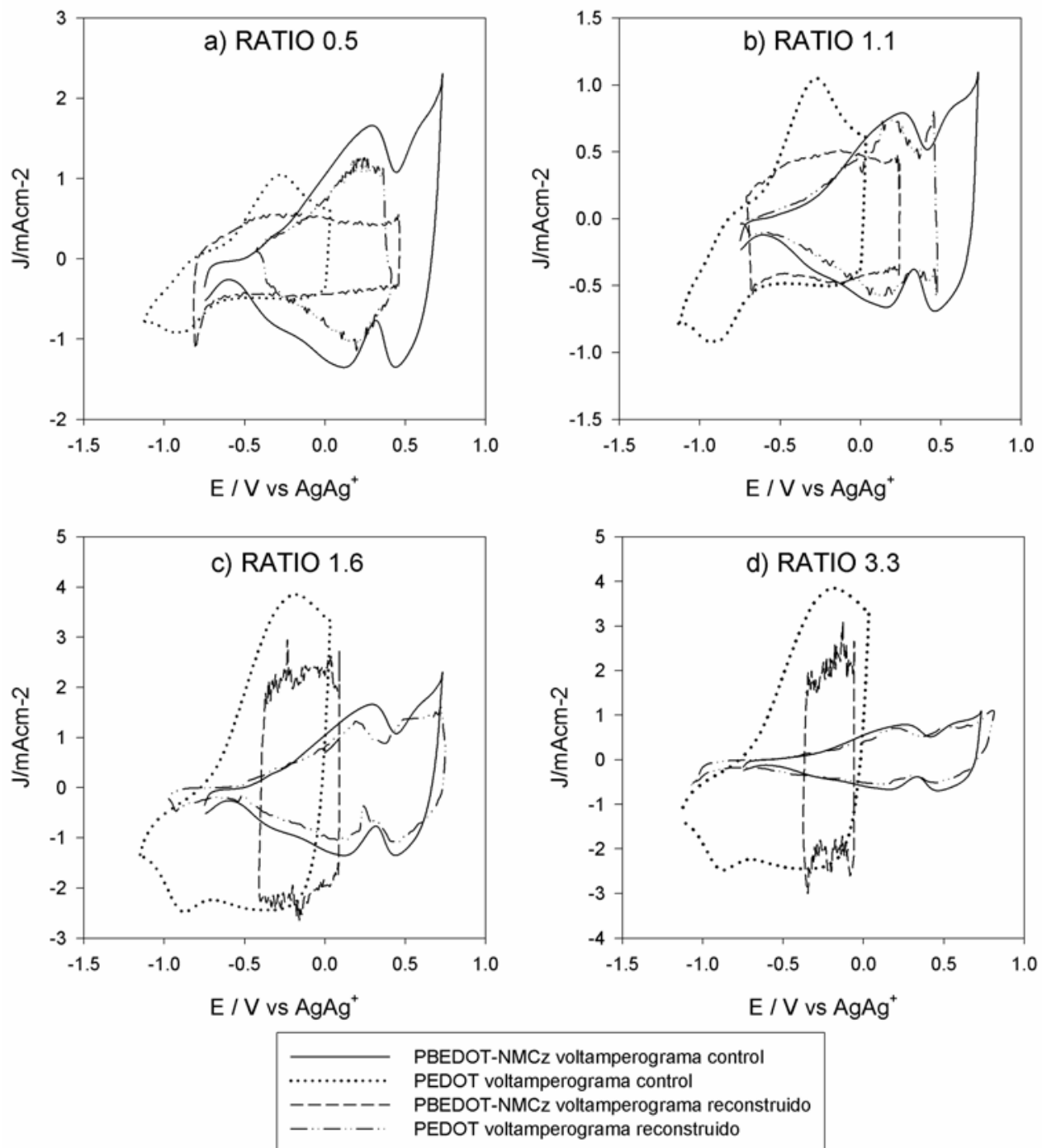

Figura 3.3.6 Voltamperogramas individuales de las películas constituyentes de dispositivos PEDOT / PBEDOT-NMCz. — Voltamperograma de control y caracterización de la película de PBEDOTNMCz realizado previamente al uso de la película en el dispositivo. ……... Voltamperograma de control y caracterización de la película de PEDOT realizado previamente al uso de la película en el dispositivo. - - - - Voltamperograma de la película de PBEDOT-NMCz reconstruido a través del registro de la evolución de su estado de oxidación durante el ciclado del dispositivo. - - - - Voltamperograma de la película de PEDOT reconstruido a través del registro de la evolución de su estado de oxidación durante el ciclado del dispositivo. La gráfica a) corresponde al dispositivo con ratio entre las cargas consumidas durante los voltamperogramas de caracterización, entre las películas constituyentes, igual a 0.5, b) ratio igual a $1.1, \mathrm{c})$ ratio igual a $1.6 \mathrm{y}$ d) ratio igual a 3.3. Todos los experimentos fueron llevados a cabo en disolución $0.1 \mathrm{M} \mathrm{LiCF}_{3} \mathrm{SO}_{3}(\mathrm{ACN})$ y velocidad de barrido $100 \mathrm{mVs}^{-1}$. 
A diferencia de los voltamperogramas habituales, en los que la velocidad de barrido de potencial es impuesta experimentalmente, los voltamperogramas reconstruidos a partir de esta técnica presentan la particularidad de mostrar una velocidad de barrido no constante. La técnica experimental impone una velocidad de barrido constante para la diferencia de potencial aplicada entre los dos electrodos; sin embargo, la manera en la que éste se distribuye entre los dos electrodos respecto al electrodo de referencia, y la evolución particular para cada uno de ellos está condicionada por otros factores que previamente han sido estudiados, como el estado de oxidación inicial, la diferencia de potencial aplicado, el ratio entre la capacidad redox de cada electrodo, o el propio material escogido. Esta particularidad debe ser tenida en cuenta a la hora de comparar los voltamperogramas reconstruidos con los voltamperogramas de caracterización previamente obtenidos para cada película. Dos voltamperogramas obtenidos a distintas velocidades de barrido sólo pueden ser comparados mediante la normalización de sus intensidades,

$\mathrm{I}_{\text {norm, }}=\mathrm{I}_{\mathrm{i}} / \mathrm{s} \quad$ (para cada punto i registrado experimentalmente) $\quad$ con $\mathrm{s}=\delta \mathrm{V} / \delta \mathrm{t}$

siendo $\mathrm{s}$ la velocidad de barrido, y tanto $\delta \mathrm{V}$ como $\delta \mathrm{t}$, constantes e impuestos experimentalmente. En el caso de los voltamperogramas reconstruidos, la normalización se lleva a cabo por el mismo procedimiento,

$\mathrm{I}_{\text {norm, }}=\mathrm{I}_{\mathrm{i}} / \mathrm{s}_{\mathrm{i}}$ (para cada punto i registrado experimentalmente) con $\mathrm{s}_{\mathrm{i}}=\Delta \mathrm{V}_{\mathrm{i}} / \Delta \mathrm{t}$

siendo en este caso, tanto $\mathrm{s}_{\mathrm{i}}$ como $\Delta \mathrm{V}_{\mathrm{i}}$ variables y registrados experimentalmente. 


\subsection{DISPOSITIVOS EN ESTADO SÓLIDO. VENTANAS INTELIGENTES. SISTEMAS PEDOT / PBEDOT-NMCZ}

Habitualmente el desarrollo de dispositivos electrocrómicos se realiza en superficies menores de $5 \mathrm{~cm}^{2}$. En este estudio se describe la fabricación de ventanas electrocrómicas en estado sólido basadas en la configuración dual, con áreas relativamente grandes, $30 \mathrm{~cm}^{2}$, usando electrolitos poliméricos fotopolimerizados. Los polímeros conductores utilizados en estos dispositivos fueron electroquímicamente depositados sobre láminas de vidrio y PET (tereftalato de polietileno) recubiertas de ITO. Se discutirán distintos problemas relativos a la polimerización electroquímica de polímeros conductores sobre estas superficies. Adicionalmente, se estudiará el efecto de la adición de plastificante al gel electrolítico en la velocidad de cambio de color de los dispositivos.

Por último, se abordará un significativo problema presente en dispositivos de gran superficie, frente a los de pequeño tamaño $\left(<5 \mathrm{~cm}^{2}\right)$; éste es la presencia de cortocircuitos entre los dos electrodos. La aparición de estos cortocircuitos disminuirá la capacidad del dispositivo de retener un determinado color en circuito abierto, provocará un aumento en el consumo de energía, y posiblemente comprometerá el tiempo de funcionamiento útil del dispositivo. En este estudio presentamos el uso de la voltamperometría cíclica como herramienta para detectar y evaluar dispositivos electrocrómicos con defectos de este tipo. 


\subsubsection{Procesos de electropolimerización en superficies grandes de ITO}

Para prácticamente todas las ventanas electrocrómicas, los electrodos transparentes ópticamente (OTE) han sido superficies recubiertras de ITO. Recientemente, Reynolds et al. describieron el uso de PEDOT/PSS como OTE [22].

Normalmente el ITO tiene una resistencia significativamente mayor que los metales y por lo tanto la electropolimerización sobre su superficie resulta en películas menos uniformes (en el caso de substratos de gran superficie) debido a la caída de potencial a lo largo de la superficie desde el punto de aplicación del campo eléctrico. Esta falta de uniformidad será más pronunciada para materiales con mayor resistencia que el ITO, como es el caso del PEDOT-PSS.

Para polimerizaciones sobre superficies de ITO de $58 \mathrm{~cm}^{2}$, este problema fue solucionado por medio de la inclusión de contactos metálicos sobre el perímetro de la superficie. Esto se consiguió adhiriendo tiras de cinta de cobre adhesiva sobre los bordes del cristal. Como resultado se obtuvieron películas más uniformes de polímero conductor. Adicionalmente, como se observa en las cronoculometrías mostradas en la figura 3.4.1, se consiguió un aumento en las densidades de carga (es decir, en la velocidad de electropolimerización), con el aumento de la superficie de contacto metálica. En la figura 3.4.1 se compara un contacto metálico puntual, recubriendo un lateral, y el perímetro completo. 


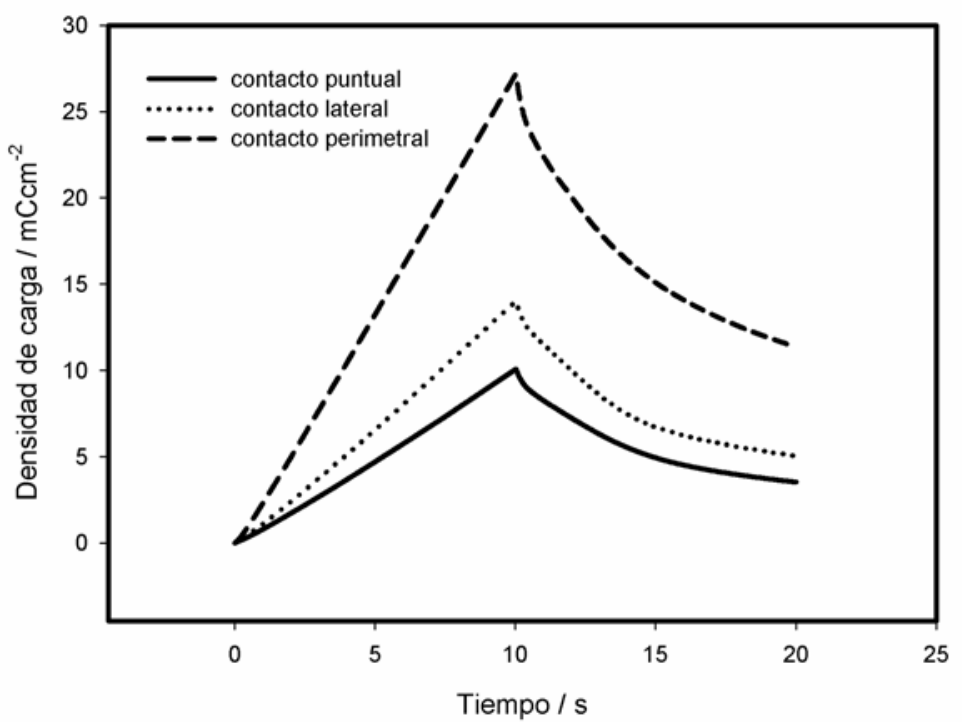

Figura 3.4.1 Cronoculometrías obtenidas durante la electropolimerización de PEDOT usando un punto de contacto metálico (línea continua), un lateral (línea de puntos) y el perímetro completo (línea discontinua).

\subsubsection{Contraste fotópico en los dispositivos EC ensamblados}

Puesto que el usuario final percibe el dispositivo como un todo, es importante que aparte de los propios polímeros electrocrómicos, los demás elementos constituyentes del ensamblado sean suficientemente transparentes en la región del visible. Como se comprobó anteriormente en la sección 3.2.1.1.1, la contribución de estas capas de absorbancia constante disminuirá el valor del contraste máximo obtenible. La tabla 3.4.1 muestra una selección de los valores predichos para las combinaciones de películas PEDOT / PBEDOT-NMCz, en el rango 0-5 $\mathrm{mCcm}^{-2}$, (según ecuaciones 3.2.13 y 3.2.14) y los mismos valores sumando la contribución de las restantes capas de un dispositivo, es decir, cristales de ITO y medio electrolítico. 


\begin{tabular}{|c|c|c|c|c|c|c|}
\hline \multirow{2}{*}{$\begin{array}{c}\text { Densidad de } \\
\text { carga redox/ } \\
\text { mCcm-2 }\end{array}$} & \multicolumn{3}{|c|}{ DUAL (sólo polimeros) } & \multicolumn{3}{|c|}{ DUAL (dispositivo) } \\
\hline & $\%$ T claro & $\% \mathrm{~T}$ oscuro & Contraste & $\% \mathrm{~T}$ claro & $\% \mathrm{~T}$ oscuro & Contraste \\
\hline 0.0 & 100.00 & 100.00 & 0.00 & 93.33 & 93.33 & 0.00 \\
\hline 0.5 & 84.14 & 61.66 & 22.48 & 78.52 & 57.54 & 20.98 \\
\hline 1.0 & 70.79 & 38.02 & 32.78 & 66.07 & 35.48 & 30.59 \\
\hline 1.5 & 59.57 & 23.44 & 36.12 & 55.59 & 21.88 & 33.71 \\
\hline 2.0 & 50.12 & 14.45 & 35.66 & 46.77 & 13.49 & 33.28 \\
\hline 2.5 & 42.17 & 8.91 & 33.26 & 39.36 & 8.32 & 31.04 \\
\hline 3.0 & 35.48 & 5.50 & 29.99 & 33.11 & 5.13 & 27.98 \\
\hline 3.5 & 29.85 & 3.39 & 26.47 & 27.86 & 3.16 & 24.70 \\
\hline 4.0 & 25.12 & 2.09 & 23.03 & 23.44 & 1.95 & 21.49 \\
\hline 4.5 & 21.13 & 1.29 & 19.85 & 19.72 & 1.20 & 18.52 \\
\hline 5.0 & 17.78 & 0.79 & 16.99 & 16.60 & 0.74 & 15.85 \\
\hline
\end{tabular}

Tabla 3.4.1 Valores de transmitancia y contraste para combinaciones duales PEDOT / PBEDOT-NMCz, con densidades de carga iguales para las dos películas, en el rango $0-5 \mathrm{mCcm}^{-2}$. Predicción de la contribución de las capas electrocrómicas únicamente, comparada con los valores del conjunto de un dispositivo, incluyendo la absorbancia debida a las capas de cristal y medio electrolítico.

Se observa efectivamente una disminución en los valores de contraste, siendo el valor de contraste máximo alrededor de $34 \%$, en comparación con el $36 \%$ teniendo en cuenta únicamente la contribución de las capas poliméricas electrocrómicas.

A su vez, se observa que hay un rango amplio de combinaciones cuyo valor está próximo al máximo y es mayor de $30 \%$, entre 1 y $2.5 \mathrm{mCcm}^{-2}$. La diferencia entre estas combinaciones es fundamentalmente la transparencia de sus valores claro y oscuro; un aumento en la densidad de carga viene acompañado de estados menos transparentes. La aplicación final del dispositivo que se quiera construir debe ser tenida en cuenta a la hora de escoger los valores de densidad de carga para las películas constituyentes. Valores con estados más absorbentes pueden ser interesantes para dispositivos cuya finalidad sea prioritariamente el ahorro energético en refrigeración, mientras que para su uso como dispositivos de protección ocular, puede ser más importante el obtener la máxima transparencia posible en el estado claro, manteniendo tanto en para una como 
para otra finalidad un rango de ajuste suficiente de los valores de contraste (en este caso, en torno al $30 \%$ ).

En nuestro caso, se dio prioridad a la obtención de los valores de transmitancia más altos posibles en el estado claro, por lo que se escogieron las combinaciones de 1 $\mathrm{mCcm}^{-2}$. Los valores teóricos de transmitancia correspondientes son 66.07 y $35.48 \%$ (contraste 30.59)

Se polimerizaron películas con esta densidad de carga redox, y fueron ensambladas en dispositivos sólidos. Los dispositivos ensamblados en estas condiciones mostraron un $30 \%$ aprox. de contraste (65 \% transmitancia fotópica en el estado transparente, $34 \%$ en el estado coloreado) cuando fueron ciclados entre -1 y $1.4 \mathrm{~V}$, mostrando un excelente acuerdo con los resultados teóricos. La figura 3.4.2 muestra las fotos de un dispositivo electrocrómico en estado sólido en sus estados transparente y coloreado, con transmitancias fotópicas de 65 y $34 \%$.
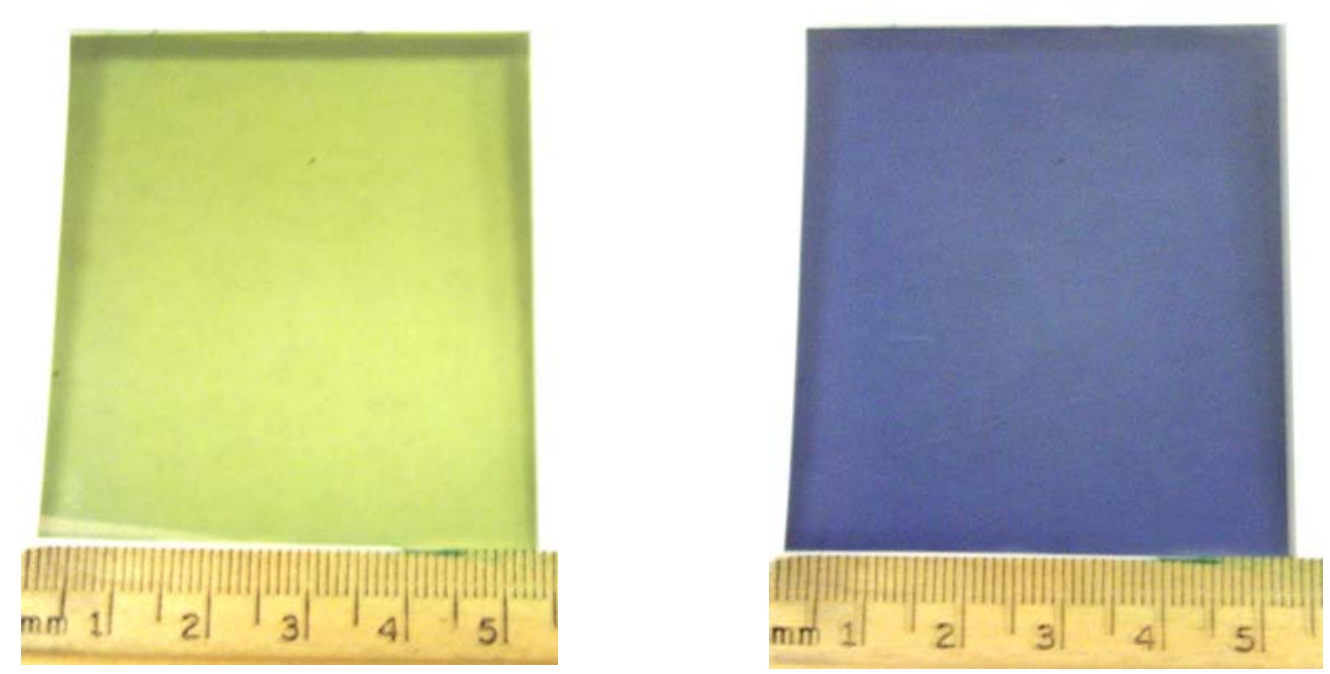

Figura 3.4.2 Dispositivo dual PEDOT//PBEDOT-NMCz en estado sólido con un área electrocrómica de $\sim 30 \mathrm{~cm}^{2}$ en sus estados transparente (65\% transmitancia) y coloreado (34\%) 
Los espectros ponderados de transmisión fotópica de este dispositivo se muestran en la figura 3.4.3.
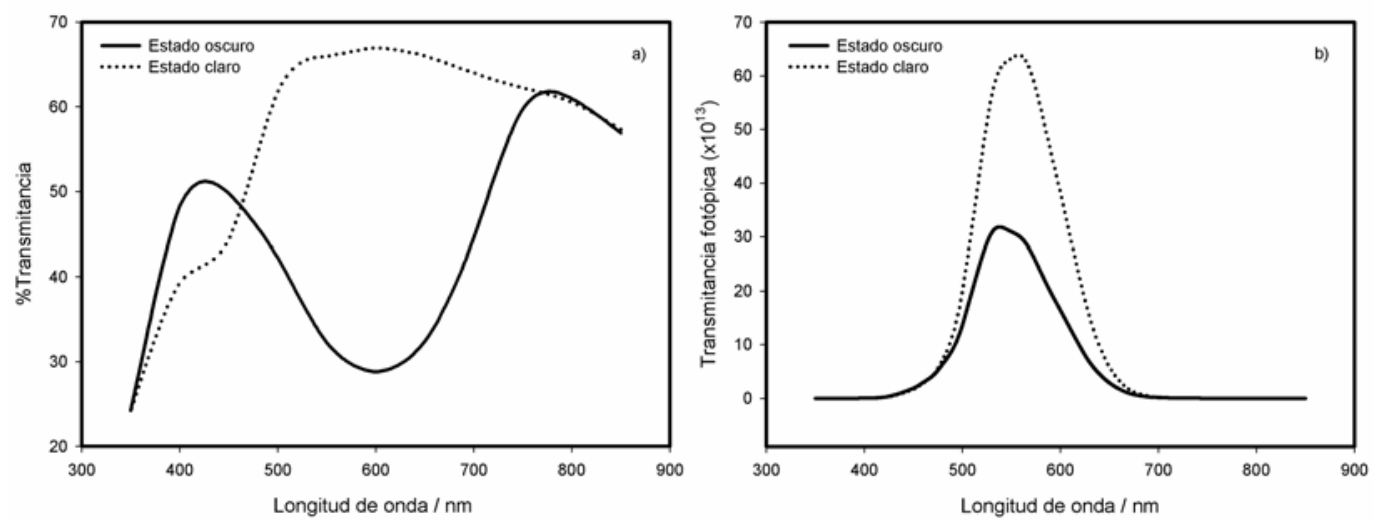

Figura 3.4.3 a) Espectros de transmitancia de un dispositivo en sus estados transparente y coloreado en comparación con los b) espectros fotópicos ponderados.

\subsubsection{Potenciales de funcionamiento de los dispositivos en estado sólido}

Se obtuvieron voltamperometrías cíclicas de los dispositivos en estado sólido usando una configuración de dos electrodos, cortocircuitando los terminales del contraelectrodo y referencia en el potenciostato. Los electrodos recubiertos de PEDOT fueron los utilizados como contraelectrodos/electrodos de referencia. La figura 3.4.4 muestra el voltamperograma cíclico de uno de estos dispositivos duales en estado sólido obtenido a una velocidad de barrido de $100 \mathrm{mVs}^{-1}$, junto con su correspondiente cambio en el porcentaje de transmisión a $555 \mathrm{~nm}$. 

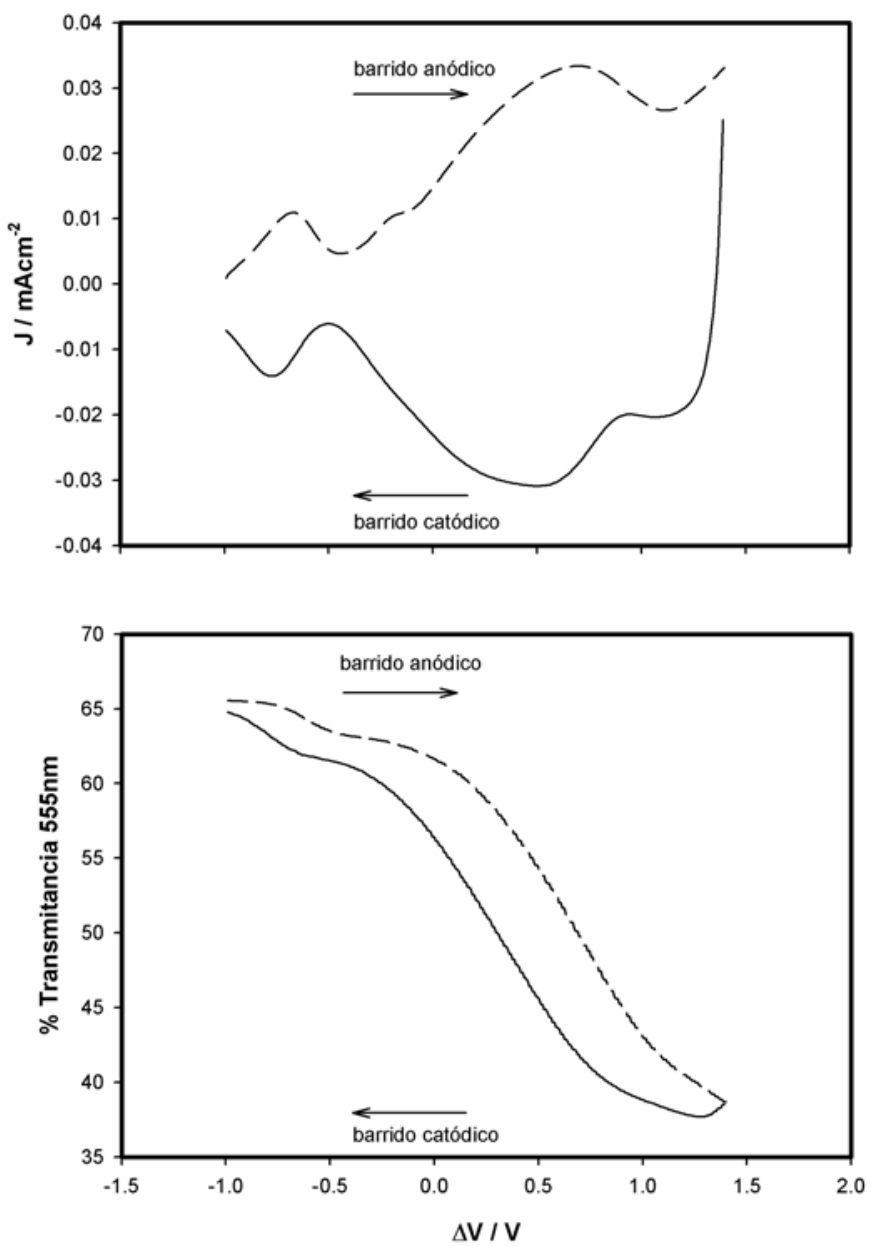

Figura 3.4.4 Voltamperograma (figura superior) y cambios en transmitancia a $555 \mathrm{~nm}$ (figura inferior) de un dispositivo dual PEDOT//PBEDOT-NMCz en estado sólido medidos en función del potencial aplicado (referenciado respecto al electrodo de PEDOT). Velocidad de barrido $100 \mathrm{mVs}^{-1}$

Durante el barrido anódico desde -1 a $1.4 \mathrm{~V}$ el dispositivo cambia desde su estado transparente al coloreado. A -1 V (es decir, estado transparente), el PEDOT está en su estado oxidado mientras que el PBEDOT-NMCz está en su estado neutro, mientras que a $1.4 \mathrm{~V}$, cuando el dispositivo esta coloreado, los correspondientes estados se intercambian. Durante el barrido catódico el cambio en el porcentaje de transmitancia no recorre el mismo camino marcado originalmente durante el barrido anódico, mostrando un proceso de histéresis. Este fenómeno fue observado incluso a velocidades 
de barrido muy lentas de hasta $10 \mathrm{mVs}^{-1}$, para todas las composiciones de geles estudiadas e incluso para dispositivos ensamblados con electrolito líquido ${ }^{*}$.
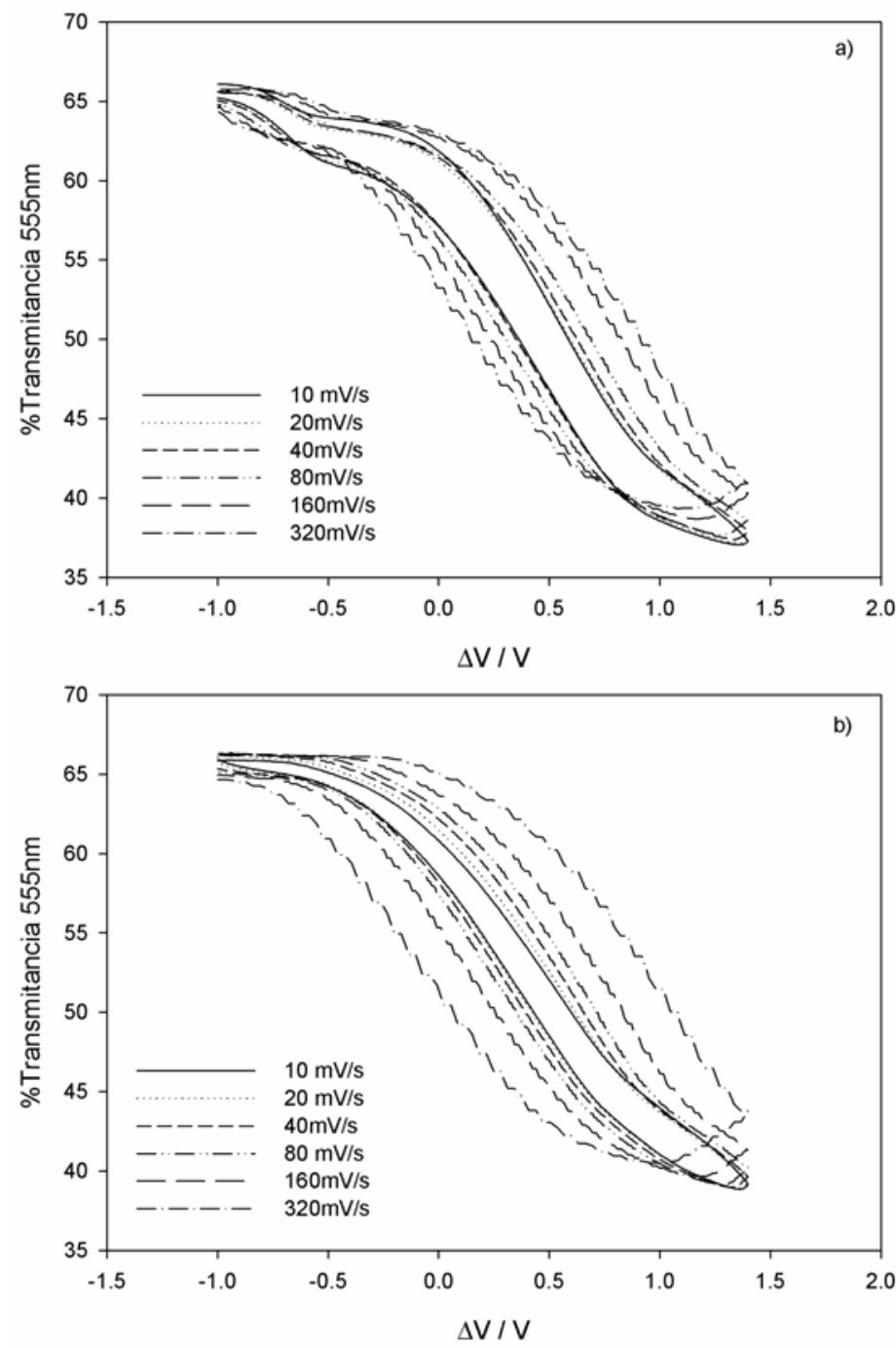

Figura 3.4.5 Evoluciones de la transmitancia a $555 \mathrm{~nm}$ en función del potencial aplicado a distintas velocidades de barrido $\left(10,20,40,80,160\right.$ y $\left.320 \mathrm{mVs}^{-1}\right)$, para a) un dispositivo en estado sólido (composición del gel $70 \% \mathrm{DA} / 30 \% \mathrm{PC}$, ver tabla 2.3.1), y b) un dispositivo con medio electrolítico líquido (10 $\mathrm{mM} \mathrm{LiCF}_{3} \mathrm{SO}_{3}$ en carbonato de propileno).

\footnotetext{
${ }^{*}$ Se construyeron dispositivos con electrolito líquido (10 $\mathrm{mM} \mathrm{LiCF}_{3} \mathrm{SO}_{3}$ en carbonato de propileno), adecuadamente sellados, substituyendo al gel electrolítico.
} 
Por lo tanto esta histéresis parece tener su origen en el comportamiento de los polímeros conductores, y no en la naturaleza del medio electrolítico (sea sólido o líquido). Las evoluciones de la transmitancia a $555 \mathrm{~nm}$ en función del potencial aplicado a distintas velocidades de barrido $\left(10,20,40,80,160\right.$ y $\left.320 \mathrm{mVs}^{-1}\right)$, para un dispositivo en estado sólido (composición del gel 70 \% DA/ 30 \% PC, ver tabla 2.3.1), y otro con medio electrolítico líquido ( $10 \mathrm{mM} \mathrm{LiCF}_{3} \mathrm{SO}_{3}$ en carbonato de propileno), se muestran en la figura 3.4.5. Una asimetría o histéresis inherente a los procesos anódicos y catódicos es un fenómeno observado habitualmente en procesos redox de polímeros conductores. Las diferencias energéticas entre los procesos de dopado y desdopado, relacionados con cambios estructurales asimétricos necesarios para completarlos, se han sugerido como posible explicación [131]. Puesto que el cambio en transmitancia esta directamente relacionado con los procesos redox, con la creación o eliminación de bandas intermedias en el gap de energía del material, la histéresis observada en la respuesta espectral es inherente al polímero conductor.

Se concluyó que el ciclado entre los límites -1 y $1.4 \mathrm{~V}$ era adecuado, al no observarse ninguna pérdida de contraste. En general, los dispositivos resultaron estables en esta ventana de potencial con respecto al contraste y la velocidad de respuesta durante aproximadamente 90000 ciclos [132]. 


\subsubsection{Optimización de la velocidad de respuesta}

Varias disoluciones basadas en polietilenglicoletileter metacrilato (MA) ó polietilenglicol diacrilato (DA), 2,2-dimetoxi-2-fenil-acetofenona 99\% (DMPAP) y $\mathrm{LiCF}_{3} \mathrm{SO}_{3}$, mezcladas con diferentes cantidades de plastificante (carbonato de propileno, PC), se usaron en la preparación de los electrolitos poliméricos, con composiciones mostradas en la tabla 2.3.1. Disoluciones únicamente de MA ó DA, y con porcentajes de plastificante de $10,20,30,40$ y $50 \%$ se usaron para este estudio. Una disolución de $10 \mathrm{mM}$ de $\mathrm{LiCF}_{3} \mathrm{SO}_{3}$ en $\mathrm{PC}$ se usó adicionalmente para estudiar las diferencias entre electrolitos sólidos y líquidos.

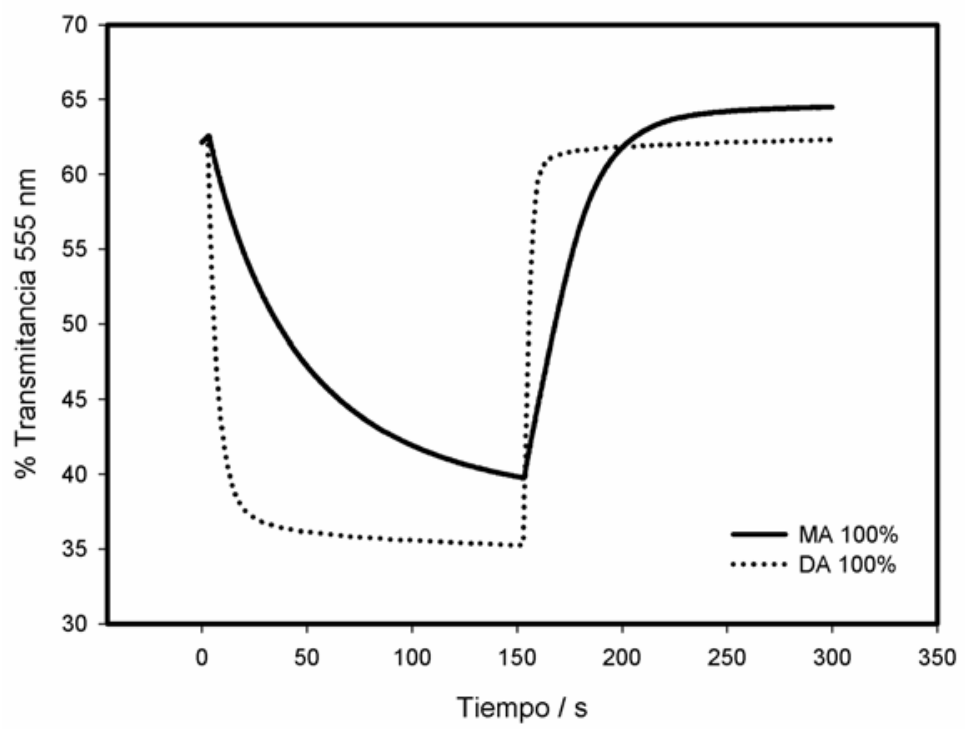

Figura 3.4.6 Cambio en el \% transmitancia a $555 \mathrm{~nm}$ durante la aplicación de saltos de potencial entre -1 y $1.4 \mathrm{~V}$, para dispositivos conteniendo $100 \%$ MA y $100 \%$ DA en la composición de sus electrolitos (ver tabla 2.3.1 para la composición de los geles). 
Se aplicaron saltos de potencial entre -1 y $1.4 \mathrm{~V}$, en la configuración de dos electrodos, a los dispositivos construidos con estos electrolitos, y se obtuvo la respuesta en transmitancia (a $555 \mathrm{~nm}$ ) para determinar su velocidad de respuesta. Definimos la velocidad del dispositivo como el tiempo necesario para alcanzar un $90 \%$ del valor final de transmitancia. Sorprendentemente, sin plastificante, los dispositivos con DA mostraron mayor velocidad que los correspondientes a MA, como se muestra en la figura 3.4.6.

Se hubiese esperado que un sistema polimérico entrecruzado, como el DA, tuviera menos movilidad entre sus cadenas, y que por lo tanto los dispositivos construidos con este material fueran más lentos que los construidos en base a un polímero líneal como el MA. Ambos sistemas mostraron similares velocidades una vez mezcados con plastificador, siendo el MA ligeramente más rápido. Un cambio sustancial en la velocidad se obtuvo incluyendo porcentajes de 0 a $20 \%$ de plastificante. La velocidad en el caso del MA disminuyó de 90 a 2 segundos, mientras que en el caso del DA, la mejora fue desde 10 a 2 segundos. El incremento en el porcentaje de plastificante en 30, 40, o $50 \%$, disminuyó ligeramente la velocidad en ambos casos, hasta llegar aproximadamente a velocidades de $1 \mathrm{~s}$ (figuras 3.4.7.a y b) 

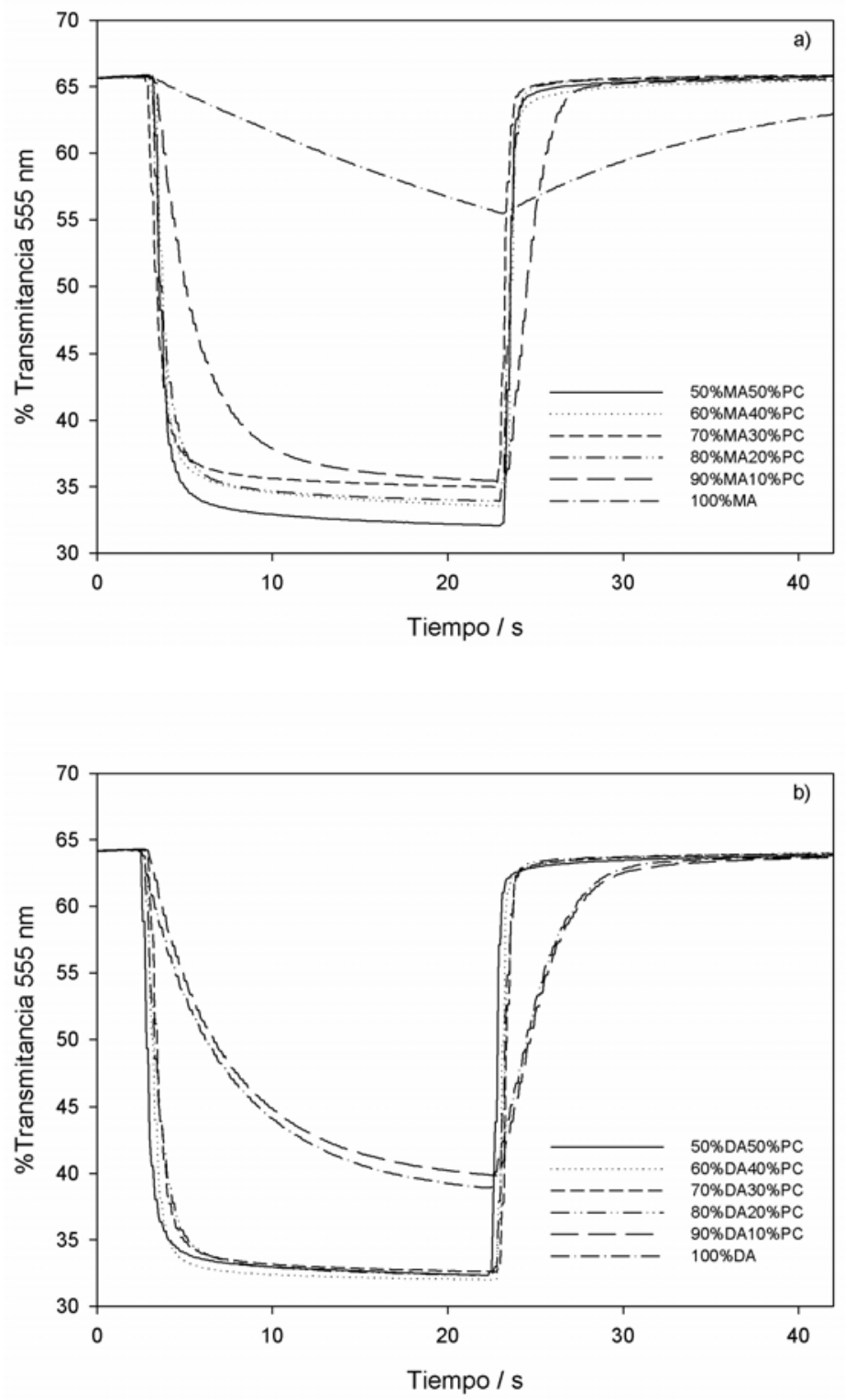

Figura 3.4.7 Cambio en el \% transmitancia a $555 \mathrm{~nm}$ durante la aplicación de saltos de potencial entre -1 y 1.4 V, para dispositivos conteniendo distintas composiciones de geles electrolíticos basados en a) MA y b) DA (ver tabla 2.3.1. para las composiciones de los geles)

El uso de un electrolito líquido, $\mathrm{PC} / \mathrm{LiCF}_{3} \mathrm{SO}_{3}$, sólo disminuyó la velocidad unos 0.3 segundos aproximadamente comparada con los polielectrolitos conteniendo $>20 \%$ en plastificante. La tabla 3.4.2 muestra los valores de velocidad obtenidos en función de la composición del electrolito. 


\begin{tabular}{ccc}
\hline \multirow{2}{*}{$\begin{array}{c}\text { Composición } \\
\text { del gel }\end{array}$} & \multicolumn{2}{c}{ Tiempo / s } \\
\hline & Coloreado & Aclarado \\
\cline { 2 - 3 } 100\% MA & 95.5 & 48.6 \\
100\% DA & 15.9 & 7.8 \\
& & \\
50\%MA/50\%PC & 1.5 & 0.9 \\
60\%MA/40\%PC & 1.8 & 0.9 \\
70\%MA/30\%PC & 2.2 & 1.1 \\
80\%MA/20\%PC & 2.4 & 1.5 \\
90\%MA/10\%PC & 6.3 & 3.1 \\
& & \\
50\%DA/50\%PC & 1.6 & 0.8 \\
60\%DA/40\%PC & 1.5 & 1.1 \\
70\%DA/30\%PC & 2 & 1.2 \\
80\%DA/20\%PC & 2.4 & 1.5 \\
90\%DA/10\%PC & 10.6 & 5.6 \\
& & \\
100\%PC & 1.1 & 0.6 \\
\hline
\end{tabular}

Tabla 3.4.2 Velocidades para el cambio de estado transparente a coloreado y viceversa, para distintas composiciones de geles, en dispositivos PEDOT/PBEDOT-NMCz en estado sólido

Un comportamiento general observado fue que la velocidad de oscurecimiento o coloreado fue mayor que la de aclarado. Esta diferencia en algunos casos llego a ser casi el doble. La configuración dual implica que, yendo desde el estado transparente al coloreado, el PEDOT pasa de su estado oxidado al reducido, mientras que el PBEDOTNMCz pasa de un estado reducido a oxidado.

Aunque las diferencias en las velocidades podrían ser atribuidas a las diferencias en la conductividad de los estados oxidado y reducido, o a procesos de compactaciónrelajación que podrían dificultar el proceso de oxidación del PBEDOT-NMCZ [133, 134], el hecho de que ambos polímeros están incluidos simultanemanete en el proceso hace difícil proponer una única explicación. 


\subsubsection{Corrientes de pérdida y memoria de los dispositivos}

La presencia de corrientes de pérdida tendrá un efecto significativo en la capacidad de retención del color en circuito abierto, y además incrementará el consumo de energía de los dispositivos [135]. Aparte de la capacidad del propio polímero conjugado para retener un estado óptico definido, el diseño del dispositivo juega un papel crucial en la obtención de tiempos de retención de color altos. Los dispositivos en estado sólido basados en polímeros conductores son similares a los condensadores en cuanto que almacenan carga eléctrica cuando se les aplica un potencial y posteriormente se dejan en circuito abierto [136]. En ambos estados, coloreado y transparente, uno de los dos polímeros se encuentra positivamente cargado, y un contacto eléctrico entre los dos electrodos tendrá como consecuencia la pérdida de carga y por lo tanto del estado óptico.

En la configuración de nuestros dispositivos, uno de los electrodos es una lámina delgada de PET recubierta de ITO, con tendencia a doblarse en las esquinas, lo que en algunos casos puede desembocar en la aparición de contactos eléctricos entre los dos electrodos, resultando en una incapacidad del dispositivo para retener su color una vez que el potencial aplicado es detenido. Esto fue experimentalmente confirmado, descargando intencionadamente uno de los polímeros sobre el otro, por medio de un cable conector entre los dos electrodos, observándose una pérdida del estado óptico. La voltamperometría cíclica se usó como herramienta para detectar dispositivos defectuosos cortocircuitados. Se conectaron diferentes resistencias de valor conocido $(25,100,270,1000$ y $2200 \Omega)$, simulando de esta manera la aparición de cortocircuitos que disiparían la corriente, aumentando de esta manera el consumo eléctrico. La figura 
3.4.8 muestra la serie de voltamperogramas cíclicos obtenidos con estas resistencias de valor conocido, dispuestas en paralelo a un dispositivo no defectuoso.

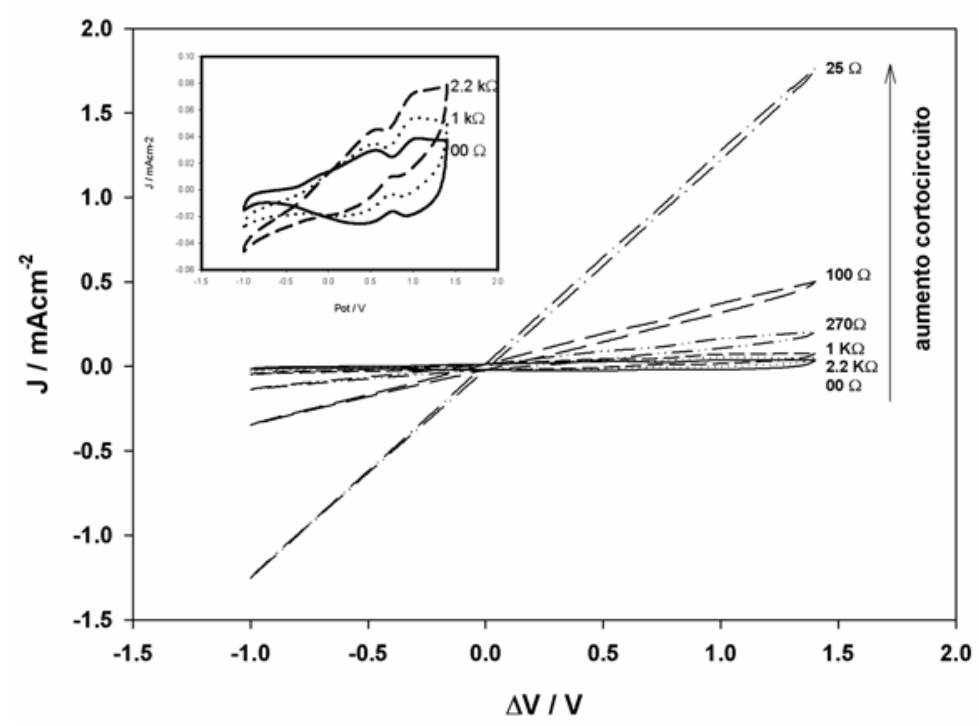

Figura 3.4.8 Voltamperogramas cíclicos de un dispositivo electrocrómico en estado sólido con diferentes resistencias de valor conocido: $\infty \Omega$ (i.e. dispositivo sin resistencia añadida), $2.2 \mathrm{k} \Omega, 1 \mathrm{k} \Omega, 270 \Omega, 100 \Omega$ y $25 \Omega$ dispuestas en paralelo. Las primeras tres se muestran ampliadas por claridad.

Se observó que la corriente que atraviesa a través del conjunto dispositivo + resistencia en paralelo aumenta con valores decrecientes de la resistencia, y la respuesta en los voltamperogramas se acerca a la de una resistencia pura $i=V / R$. La posible aparición de pequeños contactos eléctricos en el dispositivo se identifica con un comportamiento eléctrico similar al que observamos en este experimento con resistencias conocidas. Un aumento de este número de defectos significa un aumento en las corrientes de pérdida del dispositivo, es decir, una menor resistencia al paso de estas corrientes. En este caso, la mayor parte de la corriente consumida sería a través de estos contactos, puesto que presentarían menor resistencia que el conjunto polímeros+electrolito, traduciéndose en un voltamperograma cada vez más semejante al de una resistencia pura. Por lo tanto, se determinó que el uso de la voltamperometría 
cíclica puede ser una buena herramienta para detectar posibles deficiencias en el ensamblado del dispositivo, con la consiguiente aparición de contactos eléctricos entre los dos electrodos, y por lo tanto deducir su comportamiento futuro.

Es importante señalar que la presencia de estos contactos no afecta a la transmitancia obtenida en ninguno de los dos estados, transparente y coloreado. El efecto de estas deficiencias, en forma de contactos eléctricos, es la de ofrecer una menor capacidad para retener sus estados ópticos, y a su vez, incrementar el consumo de energía en su funcionamiento innecesariamente.

Una vez determinado que el dispositivo no era defectuoso, mediante voltamperometría cíclica como se ha descrito en el párrafo anterior, se procedió a estudiar la capacidad de ajuste de color y retención óptica. La figura 3.4.9 muestra la capacidad de ajuste de color y de retención de un estado determinado de un dispositivo no defectuoso en estado sólido a diferentes potenciales. El dispositivo se mantuvo inicialmente a $-1.1 \mathrm{~V}$ y después se aplicaron sucesivos saltos de potencial hasta llegar a $1.4 \mathrm{~V}$, interrumpiendo la aplicación de potencial 10 segundos después del correspondiente salto, mientras que se registraba la transmitancia a $555 \mathrm{~nm}$. Exceptuando el pequeño incremento (entre 1-2\%) en el porcentaje de transmitancia justo despues de la interrupción del potencial, el dispositivo retuvo los diferentes estados de coloración hasta 24 horas. Como se observa en la figura, la evolución en transmitancia desde -1 a $0.2 \mathrm{~V}$ es muy gradual, mientras que una variación más significativa se observa desde -0.2 a $0.8 \mathrm{~V}$, en concordancia con lo observado en la figura 3.4.4.

En general, los dispositivos en su estado transparente retuvieron su estado hasta 4 dias, en condiciones de circuito abierto, indicando la ausencia de procesos de 
fotooxidación. No se observó ningún cambio en el comportamiento óptico en términos de contraste y velocidad de respuesta a la finalización de este experimento.

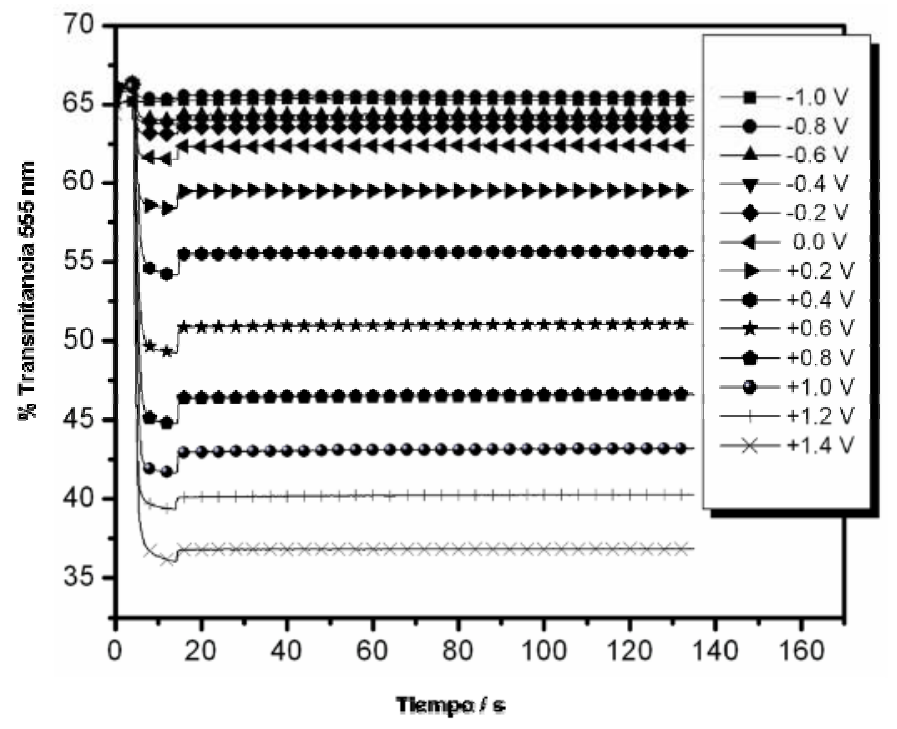

Figura 3.4.9 Capacidad de ajuste óptico de un dispositivo en estado sólido PEDOT/PBEDOT-NMCz a diferentes potenciales, junto con la capacidad de retención de esos estados en condiciones de circuito abierto (La transmitancia fue obtenida a $555 \mathrm{~nm}$ ) 



\subsection{SISTEMAS DUALES DE CONTRASTE AUMENTADO. SISTEMAS PBPMOM-PRODOTI/PBEDOT-NMCZ Y PDIBZ- PRODOT//PBEDOT-NMCZ}

En este estudio se describen las propiedades electroópticas de dos polímeros conjugados coloreables catódicamente basados en ProDOT sustituidos, anteriormente sintetizados por primera vez por Kumar et al [49, 51], y su uso en dispositivos electrocrómicos duales en estado sólido. Se ha descrito que estos polímeros presentan contrastes mayores que el PEDOT, por lo que se comprobará cuales son estos contrastes y si su inclusión en dispositivos duales supone una mejora en el contraste del sistema. Los valores de contraste se ponderarán fotópicamente. Los dispositivos serán construidos utilizando los derivados de poli (ProDOT) como el polímero coloreable catódicamente, mientras que el poli(3,6-bis(2-(3,4-etilenedioxi)tienil)- $N$-metilcarbazol) (PBEDOT-NMCz) será utilizado como polímero coloreable anódicamente, constituyendo una configuración de polímeros complementarios. Los dispositivos tendrán una configuración similar a la utilizada anteriormente para el sistema PEDOT / PBEDOT-NMCz, mostrado en la figura 2.3.3. La figura 3.5.1 muestra las estructuras químicas de los dos derivados del ProDOT utilizados en este estudio, junto con la del BEDOT-NMCz. 
a) DBz-ProDOT

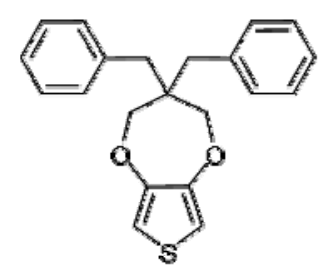

b) BPMOM-ProDOT

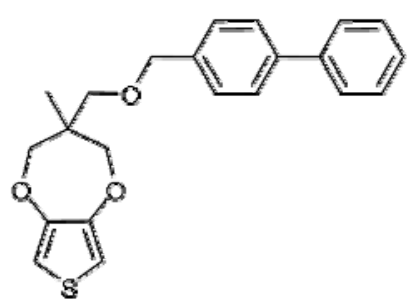

c) BEDOT-NMC2

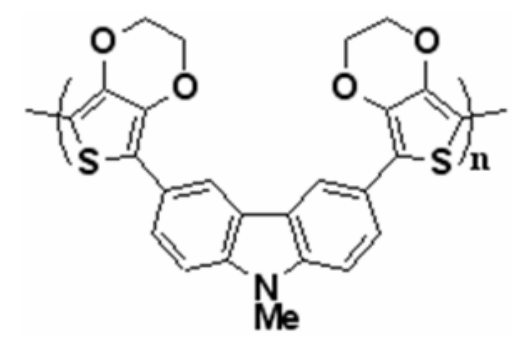

Figura 3.5.1 Estructuras químicas de (a) DiBz-ProDOT (b) BPMOM-ProDOT y (c) BEDOT-NMCz.

Los sistemas PBPMOM-ProDOT//PBEDOT-NMCz y PDiBzProDOT//PBEDOT$\mathrm{NMCz}$ se estudiarán en base a la metodología propuesta, consistente en la caracterización optoelectroquímica individual de cada polímero, parametrización y optimización de la mejor combinación dual en base a la predicción teórica.

\subsubsection{Caracterización optoelectroquímica individual de PBPMOM- ProDOT y PDiBz-ProDOT}

La caracterización espectroelectroquímica de películas de PBPMOM-ProDOT y PDiBz-ProDOT fue llevada a cabo, con la metodología usada en la sección 3.1.1, determinándose una ventana electrocrómica entre -0.8 y $0.4 \mathrm{~V}$ vs. $\mathrm{Ag} / \mathrm{Ag}^{+}$en $\operatorname{los}$ dos casos. Respecto a sus propiedades ópticas, el PBPMOM-ProDOT muestra un pico de absorción, en su estado neutro, a $581 \mathrm{~nm}$, junto con un hombro a $626 \mathrm{~nm}$, mientras que el PDiBz-ProDOT muestra un pico a $634 \mathrm{~nm}$ con un hombro a $578 \mathrm{~nm}$, tal y como se 
ha descrito anteriormente $[49,51,52]$. La figura siguiente muestra los comportamientos voltamperométricos y espectroscópicos de los dos polímeros.
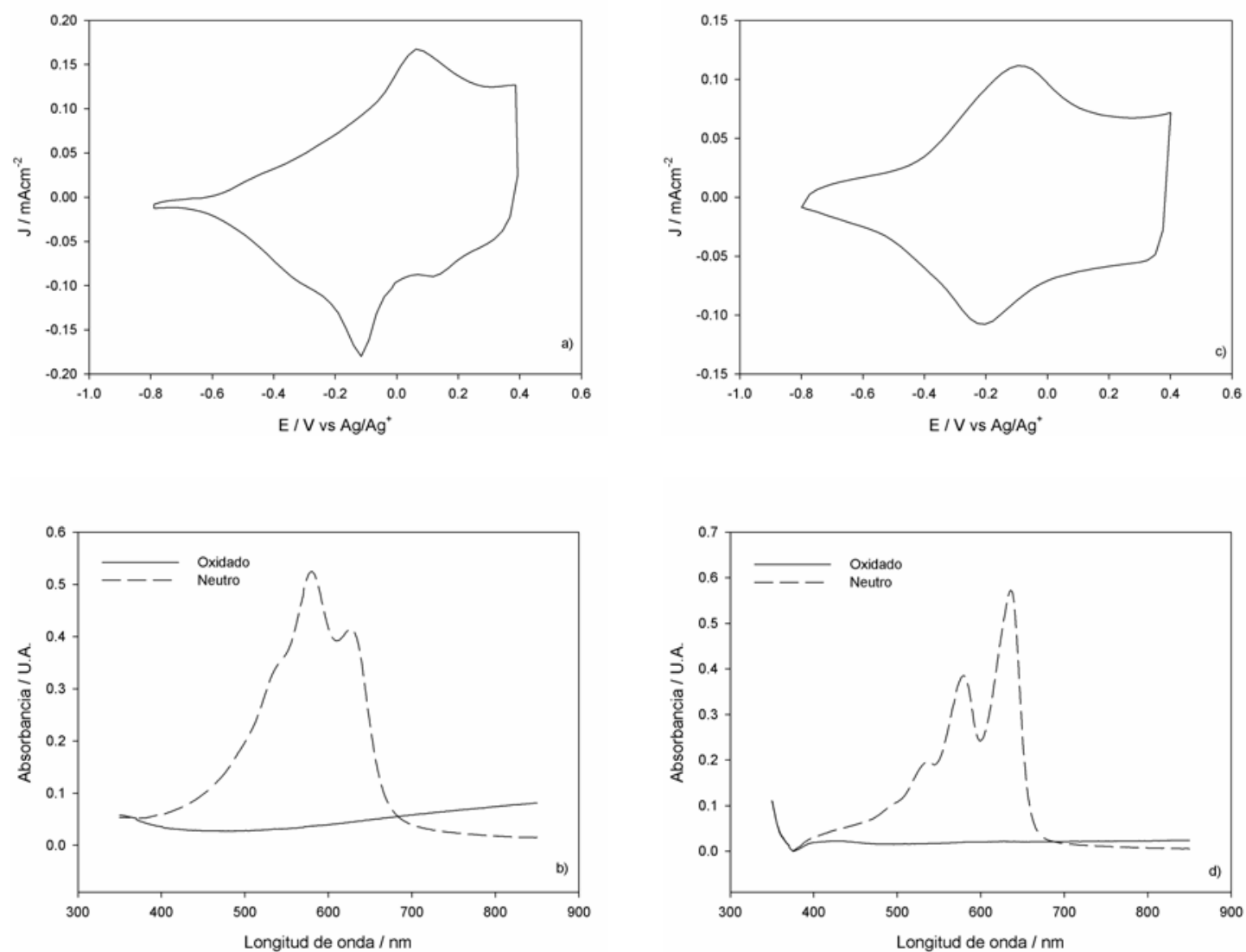

Figura 3.5.2 a) Voltamperograma correspondiente a una película de PBPMOM-ProDOT con una densidad de carga $0.87 \mathrm{mCcm}^{-2}$, ciclada en disolución de acetonitrilo $0.1 \mathrm{M} \mathrm{LiCF}_{3} \mathrm{SO}_{3}$, a $100 \mathrm{mVs}^{-1}$, entre -0.8 y $0.4 \mathrm{~V}$ vs. $\mathrm{Ag} / \mathrm{Ag}^{+}$b) Espectros obtenidos en estado neutro $(-0.8 \mathrm{~V})$ y oxidado $(0.4 \mathrm{~V})$ en el rango del visible c) Voltamperograma correspondiente a una película de PDiBz-ProDOT con una densidad de carga $0.76 \mathrm{mCcm}^{-2}$, ciclada en disolución de acetonitrilo $0.1 \mathrm{M} \mathrm{LiCF}_{3} \mathrm{SO}_{3}$, a $100 \mathrm{mVs}^{-1}$, entre -0.8 y $0.4 \mathrm{~V}$ vs. $\mathrm{Ag} / \mathrm{Ag}^{+}$d) Espectros obtenidos en estado neutro $(-0.8 \mathrm{~V})$ y oxidado $(0.4 \mathrm{~V})$ en el rango del visible.

La evolución de la absorbancia en los estados claro y oscuro en función de la densidad de carga redox fue obtenida para los dos casos, tal y como se describió 
anteriormente para PEDOT y PBEDOT-NMCz (Sección 3.1.3) obteniéndose las relaciones siguientes

\section{PBPMOM-ProDOT}

$\mathrm{A}=0.0529 \mathrm{x} \quad($ estados claros $)$

$\mathrm{r}^{2}=0.989$

$\mathrm{A}=0.282 \mathrm{x} \quad$ (estados oscuros)

$r^{2}=0.991$

$\% \mathrm{~T}($ estados claros $)=101.2 \exp ^{(-0.12 \mathrm{x})}$

$\% \mathrm{~T}($ estados oscuros $)=85.47 \exp ^{(-0.65 x)}$

$\Delta \mathrm{T}($ contraste $)=101.2 \exp ^{(-0.12 \mathrm{x})}-85.47 \exp ^{(-0.65 \mathrm{x})}$

\section{PDiBz-ProDOT}

\begin{tabular}{|c|c|c|}
\hline $\mathrm{A}=0.0413 \mathrm{x} \quad$ (estados claros $)$ & $r^{2}=0.9971$ & [ 3.5.6] \\
\hline $\mathrm{A}=0.3098 \mathrm{x} \quad$ (estados oscuros $)$ & $r^{2}=0.9862$ & [ 3.5.7] \\
\hline \multicolumn{2}{|c|}{$\% \mathrm{~T}($ estados claros $)=100.51 \exp ^{(-0.1 x)}$} & [ 3.5.8] \\
\hline \multicolumn{2}{|c|}{$\% \mathrm{~T}($ estados oscuros $)=88.77 \exp ^{(-0.71 \mathrm{x})}$} & [ 3.5.9] \\
\hline \multicolumn{2}{|c|}{$\Delta \mathrm{T}($ contraste $)=100.51 \exp ^{(-0.1 \mathrm{x})}-88.77 \exp ^{(-0.71 \mathrm{x})}$} & [ 3.5.10 \\
\hline
\end{tabular}

con $\mathrm{x}=$ densidad de carga redox expresada en $\mathrm{mCcm}^{-2}$. Las evoluciones de absorbancia en función de la densidad de carga redox para los dos polímeros se muestran en la figura siguiente. 

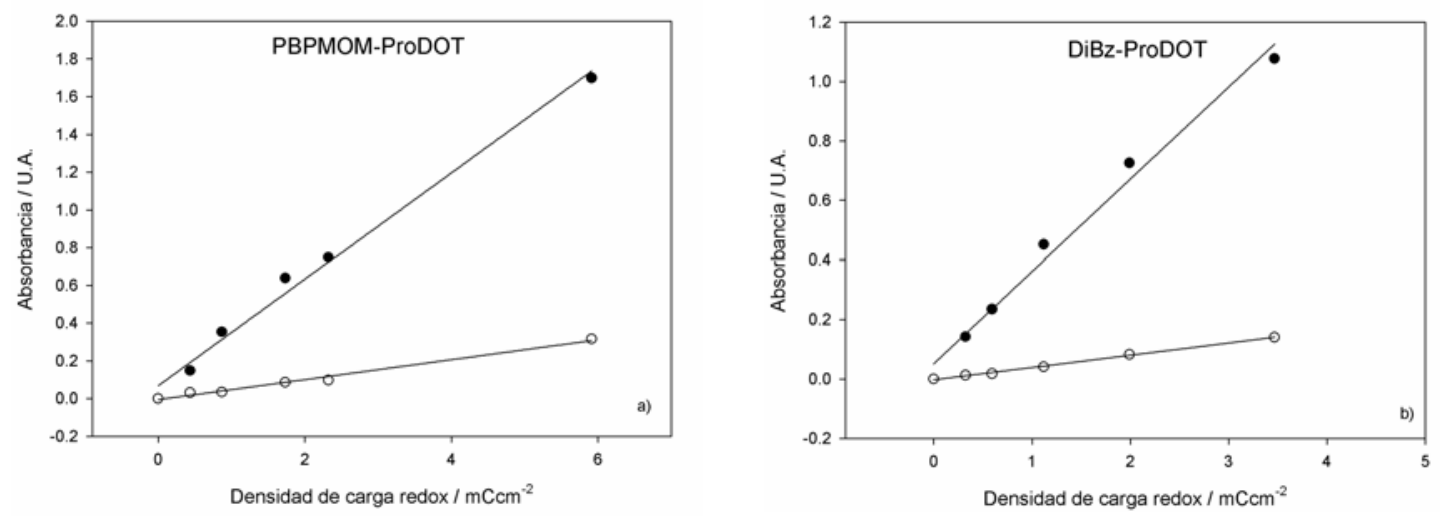

Figura 3.5.3 Relación entre densidad de carga redox y absorbancia fotópica para películas de a) PBPMOM-ProDOT y b) PDiBz-ProDOT depositadas sobre ITO. En los dos casos, las condiciones experimentales fueron: potencial de polimerización $1.3 \mathrm{~V}$ vs. $\mathrm{Ag} / \mathrm{Ag}^{+}$en disolución $5 \mathrm{mM}$ de monómero, $0.1 \mathrm{M} \mathrm{LiCF}_{3} \mathrm{SO}_{3}$ (acetonitrilo). Obtención de valores de carga redox a través de voltamperometría cíclica entre -0.8 y $0.4 \mathrm{~V}$ vs. $\mathrm{Ag} / \mathrm{Ag}^{+}$en la misma disolución en ausencia de monómero, velocidad de barrido $100 \mathrm{mVs}^{-1}$. Valores ópticos obtenidos a través de espectros realizados en $-0.8 \mathrm{~V}$ y $0.4 \mathrm{~V}$ vs. $\mathrm{Ag} / \mathrm{Ag}^{+}$

Aplicando la ecuación 3.1.6 para la obtención del punto de máximo contraste, se obtuvieron unos valores de contraste fotópico máximo para el PBPMOM-ProDOT de $58.09 \%(71.5$ y $13.41 \%$ en sus estados claro y oscuro respectivamente), para una densidad de carga de $2.85 \mathrm{mCcm}^{-2}$, y un contraste fotópico máximo de $65.21 \%(75.23 \mathrm{y}$ 10.02 en sus estados claro y oscuro respectivamente), para una densidad de carga de $3.06 \mathrm{mCcm}^{-2}$, en el caso del PDiBz-ProDOT. La tabla 3.5.1 compara estos valores con los obtenidos anteriormente para el PEDOT y PBEDOT-NMCz. Asimismo, se comparan los diferentes valores obtenidos para todos los polímeros en $555 \mathrm{~nm}$ y en las respectivas $\lambda_{\max }(620 \mathrm{~nm}$ para el PEDOT, $580 \mathrm{~nm}$ para el PBEDOT-NMCz, $581 \mathrm{~nm}$ para el PBPMOM-ProDOT y 634 nm para el PDiBz-ProDOT). 


\begin{tabular}{cccccc}
\hline \multicolumn{5}{c}{ Valores de máximo contraste } \\
\hline Polimero & $\begin{array}{c}\text { Longitud } \\
\text { de onda } \\
\text { I } \mathbf{n m}\end{array}$ & $\begin{array}{c}\text { Densidad de } \\
\text { carga redox } \\
\text { I mCcm-2 }\end{array}$ & $\begin{array}{c}\text { \% } \\
\text { estado } \\
\text { claro }\end{array}$ & $\begin{array}{c}\% \mathrm{~T} \\
\text { estado } \\
\text { oscuro }\end{array}$ & Contraste \\
\hline PEDOT & Fotópico & 2.23 & 62.76 & 19.36 & 43.40 \\
& $555 \mathrm{~nm}$ & 2.15 & 64.24 & 17.72 & 46.52 \\
& $620 \mathrm{~nm}$ & 1.66 & 65.45 & 20.16 & 45.29 \\
\hline PBEDOT-NMCz & Fotópico & 4.77 & 54.18 & 30.82 & 23.36 \\
& $555 \mathrm{~nm}$ & 5.06 & 55.45 & 27.55 & 27.90 \\
& $580 \mathrm{~nm}$ & 4.95 & 54.37 & 27.49 & 26.89 \\
\hline PBPMOM-ProDOT & Fotópico & 2.85 & 71.50 & 13.41 & 58.09 \\
& $555 \mathrm{~nm}$ & 2.52 & 75.25 & 12.90 & 62.36 \\
& $581 \mathrm{~nm}$ & 1.99 & 78.86 & 10.44 & 68.42 \\
\hline PDiBz-ProDoT & Fotópico & 3.06 & 75.23 & 10.02 & 65.21 \\
& $555 \mathrm{~nm}$ & 2.94 & 76.42 & 8.43 & 67.99 \\
& $634 \mathrm{~nm}$ & 1.61 & 85.23 & 4.68 & 80.55 \\
\hline
\end{tabular}

Tabla 3.5.1 Valores de contrastes fotópicos máximos para los polímeros PBEDOT-NMCz, PEDOT, PBPMOM-ProDOT y PDiBz-ProDOT, y densidades de carga redox asociadas.

Se observa como los valores fotópicos máximos para PBPMOM-ProDOT y PDiBzProDOT superan los obtenidos para el PEDOT, y por lo tanto cabría esperar que la sustitución del PEDOT por estos materiales en sistemas duales combinados con PBEDOT-NMCz, representase un aumento en el contraste de los dispositivos. El hecho de que los valores de transmitancia en los estados claros sean más transparentes que los obtenidos para el PEDOT refuerza esta suposición, puesto que, como se determinó en la sección 3.2, la transparencia de los respectivos polímeros es fundamental para conseguir mejores contrastes en una combinación dual.

Los valores presentados muestran las diferencias existentes entre los valores obtenidos a una sóla longitud de onda frente a los valores fotópicos. Mientras que los valores registrados en $555 \mathrm{~nm}$ no difieren sustancialmente de los fotópicos, los valores en $\lambda_{\max }$ pueden ofrecer hasta un $20 \%$ de diferencia (para el PDiBz-ProDOT). 


\subsubsection{Combinaciones duales. Valores teóricos de contraste}

En base a las relaciones lineales obtenidas en la sección anterior, se realizó el cálculo teórico del comportamiento óptico de las combinaciones duales con iguales densidades de carga, es decir, siguiendo el criterio electroquímico adoptado en la sección 3.2.1.2.1, obteniéndose los valores de máximo contraste y las densidades de carga asociadas.

Las evoluciones del comportamiento óptico en función de la densidad de carga redox se muestran en la figura 3.5.4.
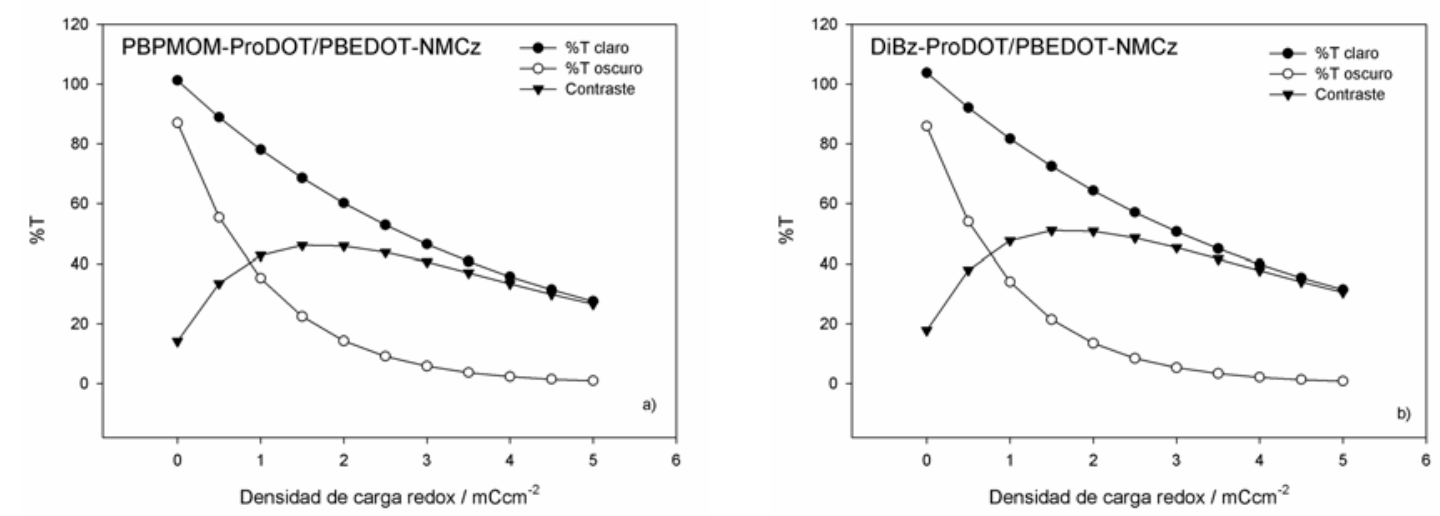

Figura 3.5.4 Relaciones de transmitancia en estado claro y oscuro en función de la densidad de carga redox, supuesto que las dos películas tengan la misma densidad de carga redox, obteniendo los valores de contraste por medio de su diferencia, para los sistemas duales a) PBPMOM-ProDOT/PBEDOT-NMCz, y b) PDiBz-ProDOT/PBEDOT-NMCz.

Los valores de contraste máximos obtenidos para la combinación PBPMOMProDOT/PBEDOT-NMCz fueron $46.29 \%(65.02$ y $18.73 \% \mathrm{~T}$ en el estado claro y oscuro respectivamente), para una densidad de carga redox de $1.70 \mathrm{mCcm}^{-2}$. Para el sistema PDiBz-ProDOT/PBEDOT-NMCz los valores fueron $51.3 \%$ (69.15 y 17.85 \% T) para una densidad de carga de $1.69 \mathrm{mCcm}^{-2}$. 


\subsubsection{Dispositivos en estado sólido}

Se construyeron dispositivos en estado sólido en los que PBPMOM-ProDOT ó PPDiBz-ProDOT fueron usados como los polímeros coloreables catódicamente, y el PBEDOT-NMCz como polímero coloreable anódicamente. En cada caso se utilizaron películas con la misma carga redox para los dos electrodos, y los dispositivos fueron ensamblados con las películas de ProDOT en su estado oxidado y las de PBEDOT$\mathrm{NMCz}$ en su estado reducido, con una configuración semejante a la mostrada en la sección 2.3. La composición del gel utilizada en los dispositivos estudiados fue $50 \%$ MA / $50 \%$ PC, tal y como se describe en la tabla 2.3.1.

\subsubsection{Contraste en los dispositivos}

Para la fabricación de dispositivos sólidos, al igual que para el sistema PEDOT/PBEDOT-NMCz, se escogieron densidades de carga ligeramente inferiores al punto de máximo contraste, con el fin de incrementar la transparencia del dispositivo, sin perder apreciablemente el rango de contraste obtenible (Sección 3.4.2).

Se fabricaron dispositivos con una densidad de carga de $1.5 \mathrm{mCcm}^{-2}$ para el sistema PBPMOM-ProDOT/PBEDOT-NMCz y $1.6 \mathrm{mCcm}^{-2}$ para el sistema PDiBzProDOT/PBEDOT-NMCz, obteniéndose unos valores de contraste de $46.1 \%$ (59.3 y $13.3 \%$ en los estados claro y oscuro respectivamente), para el primer sistema y $52.0 \%$ (63.6 y $11.6 \% \mathrm{~T})$ para el segundo. Estos valores coinciden con los valores teóricos calculados para esos valores de densidad de carga: $46.1 \%$ (68.5 y $22.4 \%$ ) para el 
sistema PBPMOM-ProDOT/PBEDOT-NMCz y $51.2 \%$ (71.4 y $20.25 \%$ ) para el sistema PDiBz-ProDOT/PBEDOT-NMCz.
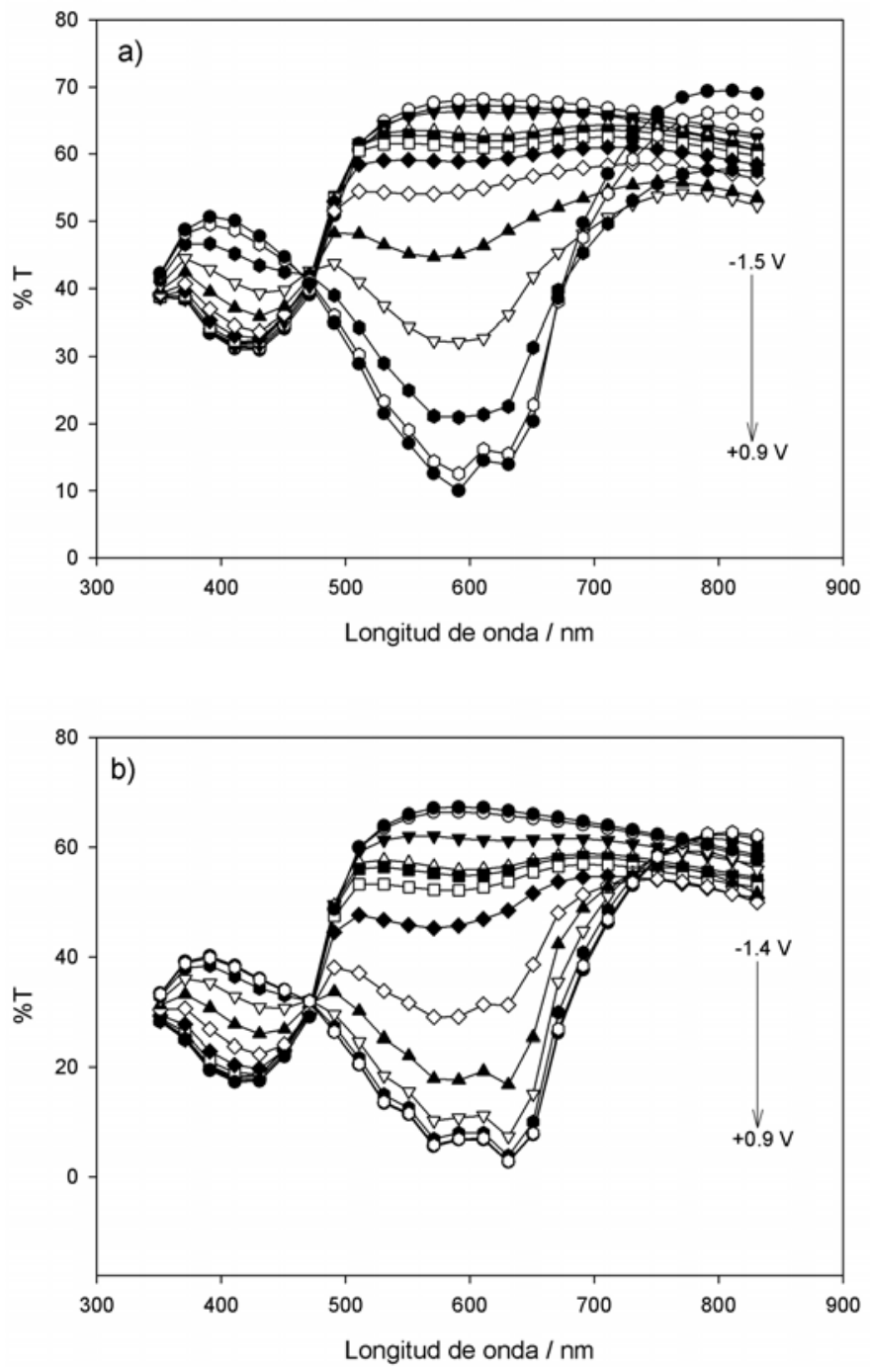

Figura 3.5.5 Espectros de transmitancia de dispositivos basados en a) PBPMOM-ProDOT/PBEDOT$\mathrm{NMCz}$ (densidad de carga redox del dispositivo $=1.50 \mathrm{mC} / \mathrm{cm}^{2}$ ) y b) PDiBz-ProDOT/PBEDOT-NMCz (densidad de carga redox $=1.56 \mathrm{mC} / \mathrm{cm}^{2}$ ) en función del potencial aplicado.

La figura 3.5.5 muestra el cambio en el espectro visible de los dispositivos de alto contraste utilizando PDiBz-ProDOT ó PBPMOM-ProDOT en función del potencial aplicado. Los rangos de potenciales aplicados fueron 0.9 a $-1.5 \mathrm{~V}$ para los dispositivos 
PBPMOM-ProDOT/PBEDOT-NMCz y 0.9 a $\quad-1.4$ V para el sistema PDiBzProDOT/PBEDOT-NMCz.

\subsubsection{Potenciales de funcionamiento de los dispositivos}
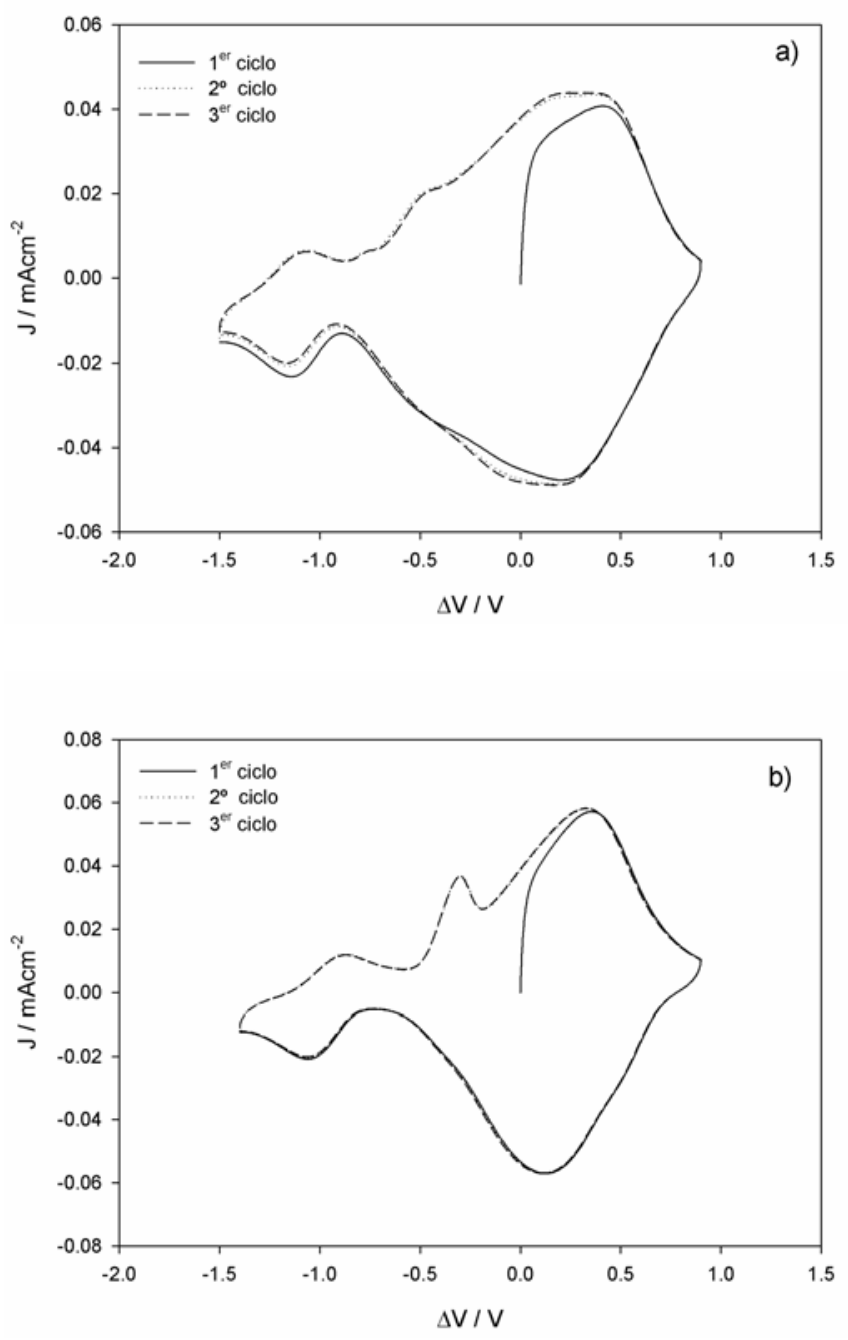

Figura 3.5.6 Voltamperometrías cíclicas de dispositivos electrocrómicos duales con (a) PBPMOMProDOT (densidad de carga redox del dispositivo $=1.50 \mathrm{mC} / \mathrm{cm}^{2}$ ) y (b) PDiBz-ProDOT (densidad de carga redox del dispositivo $=1.56 \mathrm{mC} / \mathrm{cm}^{2}$ ) como polímeros coloreables catódicamente y PBEDOT$\mathrm{NMCz}$ como polímero coloreable anódicamente, a una velocidad de barrido de $100 \mathrm{mVs}^{-1}$. Los potenciales están referidos al electrodo cubierto de ProDOT en cada caso. 
Se obtuvieron voltamperometrías cíclicas, en la configuración de dos electrodos, de los dispositivos PBPMOM-ProDOT/PBEDOT-NMCz y PDiBz-ProDOT/PBEDOTNMCz mediante el ciclado entre -1.5 y $0.9 \mathrm{~V}$, a una velocidad de barrido de $100 \mathrm{mVs}^{-1}$ (figura 3.5.6)

Los dispositivos de PBPMOM-ProDOT/PBEDOT-NMCz mostraban dos picos de oxidación-reducción, respectivamente, centrados en -1.1 y 0.25 V. Los dispositivos de PDiBz-ProDOT/PBEDOT-NMCz exhibían voltamperogramas cíclicos muy parecidos (figura 3.5.6.b).

El pico alrededor de $-0.3 \mathrm{~V}$ en el barrido anódico para los dispositivos de PDiBzProDOT/PBEDOT-NMCz se observó a velocidades de incluso $10 \mathrm{mVs}^{-1}$. La integración de carga de los barridos anódico y catódico demostró que no era un proceso irreversible o degradativo.

Como se observa en los voltamperogramas el proceso sustancial de oxidaciónreducción se inicia a $-0.9 \mathrm{~V}$, lo que concuerda con un cambio en los valores de transmitancia como se muestra en la figura 3.5.7. No se observa un cambio significativo de transmitancia hasta $-1 \mathrm{~V}$, produciéndose el $90 \%$ del cambio total en un reducido rango de potencial, entre -1 y $0.8 \mathrm{~V}$. De manera similar, el $95 \%$ del cambio en transmitancia para el caso de ventanas PDiBz-ProDOT/PBEDOT-NMCz se produce entre -1.2 y $0.6 \mathrm{~V}$. 

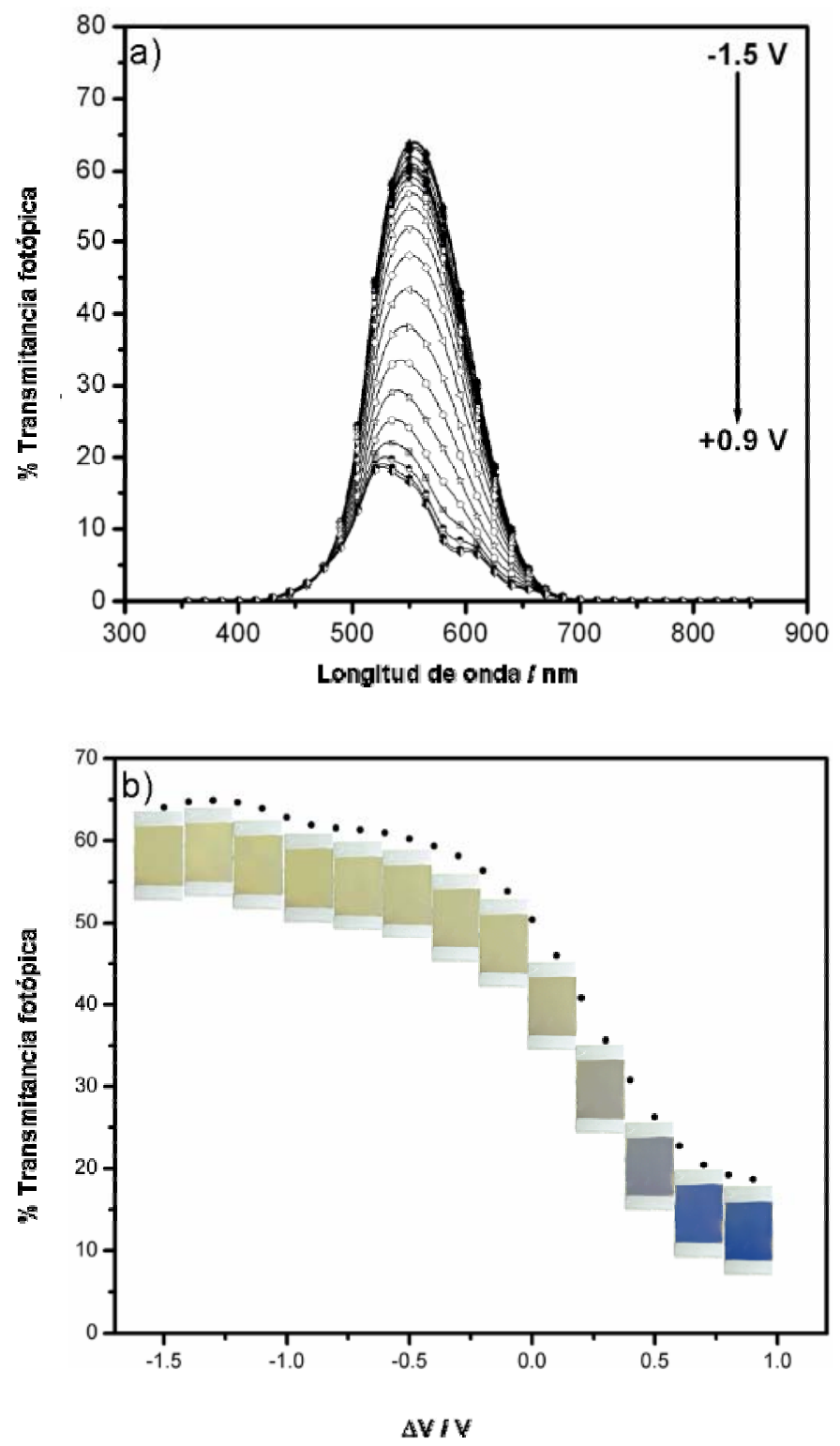

Figura 3.5.7 a) Espectro fotópico en el visible y b) transmitancia fotópica ponderada entre -1.5 y $+0.9 \mathrm{~V}$ para un dispositivo electrocrómico dual en estado sólido. Configuración del dispositivo: Vidrio/ITO/PBPMOM-ProDOT/Gel-electrolítico/PBEDOT-NMCz/ITO/Vidrio (Las fotografías insertadas muestran el dispositivo en sus distintos estados ópticos, con un área activa de $3 \mathrm{~cm}$ x $2.4 \mathrm{~cm}$ ).

Se observó que los dispositivos ciclaban en esta ventana de potencial (-1.5 y $0.9 \mathrm{~V})$ sin pérdidas aparentes de contraste o carga consumida, durante 2000 ciclos de carga y descarga. 


\subsubsection{Velocidad de respuesta y memoria en circuito abierto}

La velocidad de los dispositivos, obtenida mediante la aplicación de saltos de potencial entre -1.5 y $0.9 \mathrm{~V}$, tal y como se describe en la sección 3.4 .4 , fue $1.2 \mathrm{~s}$ en el paso de transparente a coloreado y de $0.7 \mathrm{~s}$ en el inverso.

Los dispositivos mostraron una gran capacidad de retención óptica en circuito abierto. La figura 3.5.8 muestra la transmitancia fotópica de un dispositivo PDiBzProDOT/PBEDOT-NMCz en condiciones de circuito abierto, durante 12 horas.

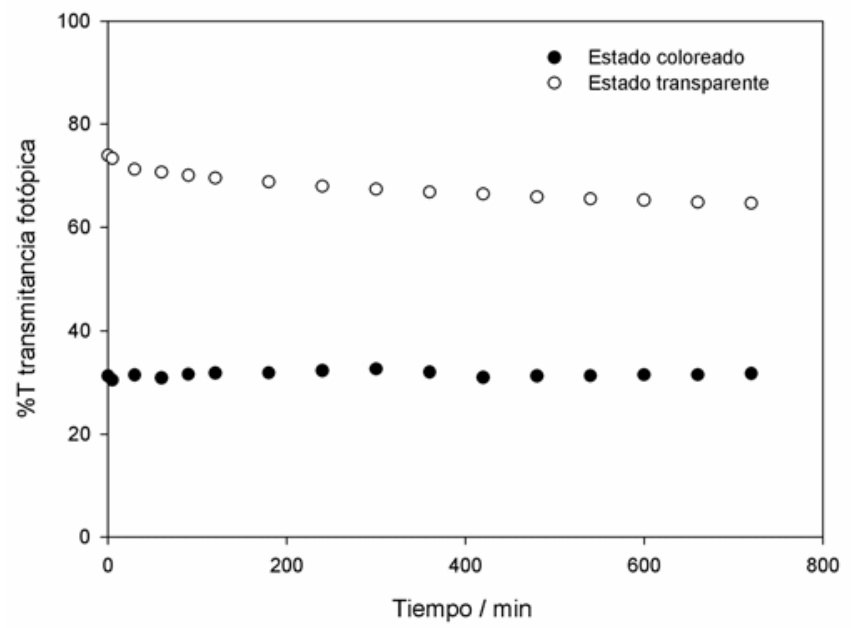

Figura 3.5.8 Memoria en circuito abierto para un dispositivo PDiBz-ProDOT/PBEDOT-NMCz (densidad de carga redox $=0.80 \mathrm{mCcm}^{-2}$ ) en función del tiempo. Los valores de \% fueron fotópicamente ponderados.

El dispositivo fue sometido a -1.5 ó 0.9 V (vs. PDiBz-ProDOT), respectivamente, durante $10 \mathrm{~s}$, momento en el cual el potencial dejó de ser aplicado. Los espectros de los dispositivos (entre 850 y $350 \mathrm{~nm}$ ) fueron obtenidos en intervalos regulares de 30 minutos para las primeras dos horas, y a partir de ahí cada hora durante las 10 horas restantes. Se calcularon los valores fotópicos usando la ecuación anteriormente citada (Sección 1.3). Todos los resultados mostrados corresponden a dispositivos en 
condiciones ambientales normales de luz. Después de 12 horas, el porcentaje de transmitancia del estado transparente decreció un $9.3 \%$, mientras que el estado coloreado se mantuvo estable. Respecto al estado transparente, se registró un primer intervalo de pérdida más rápido, de $0.036 \%$ / minuto, durante las primeras dos horas, seguido de un ritmo de pérdida más suave, $0.0085 \%$ /minuto, durante las siguientes 10 horas. 
Conclusiones 



\section{Conclusiones}

1. Se discutieron las características ópticas necesarias para que un polímero electrocrómico pueda formar parte de un dispositivo de transmisión variable. Uno de sus estados, bien sea reducido u oxidado, debe ser transparente en el rango del visible mientras que el opuesto debe ser fuertemente absorbente dentro de ese rango. Dos grupos de polímeros pueden ser candidatos, en función de su gap energético: polímeros de alto gap de energía (high band-gap) y de bajo (low band-gap). Se escogieron para su estudio el poli-3,6-bis(2-(3,4etilendioxi)tienil)-N-metilcarbazol (PBEDOT-NMCz) y el poli-3,4etilendioxitiofeno (PEDOT) dentro de estos dos grupos, respectivamente. Se estudiaron las respuestas electrocrómicas en función del estado de oxidación, obteniéndose las ventanas de potencial para las que ocurren cambios electroquímicos en ambos polímeros, siendo de $-1.15 \mathrm{~V}$ a $0.05 \mathrm{~V}$ para el PEDOT y -0.75 a $0.75 \mathrm{~V}$ vs. $\mathrm{Ag} / \mathrm{Ag}^{+}$para el PBEDOT-NMCz. Estos polímeros presentan comportamientos electrocrómicos complementarios. Una película de material electrocrómico puede ser caracterizada electroquímicamente por el consumo de carga redox dentro de estos límites de potencial.

2. Se realizó un estudio del efecto del potencial de polimerización en la respuesta electroquímica del material, obteniéndose los valores de eficiencia de polimerización (carga redox del material / carga consumida en la polimerización), así como los intervalos de potencial de polimerización aconsejables, siendo de 1 a $1.3 \mathrm{~V}$ para el PEDOT y de 0.4 a $0.8 \mathrm{~V}$ vs. $\mathrm{Ag} / \mathrm{Ag}^{+}$ para el PBEDOT-NMCz. La polimerización sobre electrodos de ITO, comparada con la polimerización sobre electrodos de platino, resulta en valores 
ligeramente más bajos para la eficiencia de polimerización, probablemente atribuibles a las características conductoras del ITO.

3. La transmitancia de un material está relacionada exponencialmente con la concentración de especies absorbentes. La producción o eliminación de estas especies para un polímero conductor se realiza por medio de los procesos de reducción y oxidación. El contraste de una película se define como la diferencia de transmitancias entre su estado claro y oscuro. La situación de máximo contraste posible para un material debe estar comprendido entre las dos situaciones en que un polímero conductor no presenta electrocromismo apreciable, bien porque sus dos estados límite son muy transparentes o por el contrario muy absorbentes. Se obtuvieron las relaciones de transmitancia en función de la densidad de carga redox del material para los dos polímeros calculándose los puntos que corresponden con esta situación de máximo contraste.

4. En base a la ley de Lambert-Beer, se discutió la contribución de la adición de distintas capas absorbentes en la evolución de las respuestas ópticas de un material electrocrómico. La inclusión de una capa de absorbancia constante resulta en una disminución de los valores máximos de contraste obtenibles; sin embargo, los parámetros electroquímicos correspondientes a ese valor máximo no se ven modificados. La inclusión de una capa de absorbancia variable electrocrómica modifica los valores de contraste máximo así como los parámetros electroquímicos.

5. La obtención del máximo contraste posible en un sistema electrocrómico dual puede ser tratada desde dos criterios distintos, electroquímico y óptico. E1 criterio electroquímico mantiene iguales los parámetros electroquímicos 
(densidad de carga redox electrocrómica) de las películas constituyentes para cualquier combinación, con el fin de garantizar el balance de cargas de oxidación-reducción entre los dos electrodos, evitando de esta manera posibles reacciones paralelas no relacionadas con la oxidación ó reducción de los polímeros constituyentes. El criterio óptico contempla las combinaciones duales atendiendo a las características ópticas de cada una de las dos películas constituyentes, sin estar condicionado a la igualdad de carga redox entre los dos electrodos. Se obtuvieron simulaciones matemáticas de las evoluciones ópticas para un sistema dual, en base a las caracterizaciones óptoelectroquímicas de cada polímero individual. Estas simulaciones se aplicaron al sistema PEDOT / PBEDOT-NMCz en base a los dos criterios anteriormente mencionados. La concordancia entre los valores calculados teórica y experimentalmente fue comprobada. El desarrollo teórico propuesto es aplicable a cualquier sistema dual electrocrómico, constituyendo una herramienta útil para la optimización de las posibles combinaciones entre distintos polímeros.

6. Se propuso y evaluó una nueva metodología para la evaluación de dispositivos duales de polímeros conductores. La inclusión de un electrodo de referencia en dispositivos constituidos por polímeros electroactivos, operados en una configuración de celda de dos electrodos, permite un control permanente del estado de oxidación de cada electrodo constituyente. Se obtuvo información acerca del comportamiento electroquímico de diferentes sistemas por medio de esta metodología, obteniendo por lo tanto confirmación de su validez.

7. La evolución de los estados de oxidación y carga consumida en sistemas de un solo polímero (ITO-polímero/electrolito/ITO) fue seguida por medio de esta metodología, y mostró que la mayor parte de la energía es consumida por 
los procesos electroquímicos no electrocrómicos que ocurren en el electrodo de ITO, reforzando la conveniencia del uso de sistemas poliméricos duales. El sistema polimérico dual PEDOT / PBEDOT-NMCz fue estudiado por medio de la metodología propuesta y caracterizado electroquímicamente en función de varias variables: potencial aplicado, ratio de densidad de carga entre las películas constituyentes y estado de oxidación inicial.

8. El potencial adecuado a aplicar para cada dispositivo debe ser determinado teniendo en cuenta las ventanas de potencial correspondientes para cada polímero, evitando el consumo ineficiente de carga.

9. Se estudió la influencia de la variación del ratio entre las cargas electrocrómicas de las películas constituyentes de un dispositivo. Esta variación constituye una herramienta eficiente para modificar los estados de oxidación alcanzados por cada polímero durante el funcionamiento del dispositivo. Esto puede ser usado para maximizar los cambios electrocrómicos en ambas películas o por el contrario, minimizarlos para una de ellas, manteniendo un estado de oxidación y color prácticamente constante, dependiendo de la funcionalidad deseada para el dispositivo.

10. Se observó que los cambios en los estados de oxidación iniciales de los polímeros pueden desplazar el rango de potenciales cubierto por cada electrodo, siendo una herramienta eficaz para evitar sobrepotenciales que puedan provocar procesos degradativos, aunque son necesarios experimentos de mayor duración para confirmar el efecto de la estabilidad de los cambios producidos.

11. La metodología propuesta permite el seguimiento individual de la evolución del potencial durante el funcionamiento del dispositivo, así como la obtención de la carga útil consumida, y por lo tanto constituye una herramienta 
potencial para obtener la máxima eficiencia en los procesos de dispositivos duales.

12. Se aplicaron los resultados obtenidos para construir dispositivos electrocrómicos en estado sólido. Se construyeron y estudiaron ventanas electrocrómicas con un área activa de funcionamiento de aproximadamente 30 $\mathrm{cm}^{2}$. El sistema dual PEDOT/PBEDOT-NMCz mostró un contraste fotópico máximo de $30 \%$. Se trataron problemas relativos al escalado de ventanas electrocrómicas, incluyendo la deposición uniforme de polímeros conductores por electropolimerización; asimismo se estudió la evaluación del contraste óptico usando unidades fotópicas, el efecto de la modificación en la composición del medio electrolítico en la velocidad del dispositivo, y la capacidad de detectar y evaluar rápidamente posibles contactos eléctricos en el dispositivo, por medio de la voltamperometría cíclica.

13. Se determinó que para la deposición de superficies suficientemente grandes como para su uso en gafas o sistemas ópticos similares, es necesario desarrollar un buen contacto eléctrico a lo largo del perímetro, de cara a obtener películas más uniformes.

14. Se propuso el uso de geles electrolíticos sólidos fotopolimerizables por medio de luz UV. Este sistema de ensamblado representa un método fácil y rápido, para el cual la membrana electrolítica funciona como unión entre los dos electrodos y medio conductor iónico. Se utilizaron dos oxidos de polietileno, polietilenglicoletileter metacrilato (MA) y polietilenglicol diacrilato (DA) en la composición de los geles. Las membranas de oxido de polietileno acabadas en monoacrilato son peores, en términos de velocidad de los dispositivos estudiados, que las terminadas con dos grupos acrilato, cuando se 
trabaja con electrolitos sólidos; sin embargo, el funcionamiento de ambas es semejante con la introducción de plastificante (carbonato de propileno) en porcentajes desde el 20 al 50\%. Utilizando estas membranas, se obtuvieron velocidades considerablemente rápidas para el tamaño de estos dispositivos (aprox. $1 \mathrm{~s})$.

15. Un problema relacionado con la producción de dispositivos de gran tamaño es la tendencia a la aparición de contactos eléctricos entre los electrodos, en comparación con dispositivos de tamaño reducido $\left(<5 \mathrm{~cm}^{2}\right)$. Un dispositivo cortocircuitado de esta manera ofrecerá una menor capacidad de retención del color en circuito abierto, además de aumentar el consumo de energía eléctrica para su funcionamiento inútilmente. Se propuso la inclusión en el gel electrolítico de cuentas de cristal de diámetros entre 50-100 micras para evitar estos contactos. Se demostró que el uso de la voltamperometría ciclica, en conjunción con resistencias en paralelo de valor conocido, puede ser una herramienta para evaluar la extensión de esos defectos.

16. Se construyeron dispositivos electrocrómicos en estado sólido basados en derivados del ProDOT, Dibencil-ProDOT (DiBz-ProDOT) y Bifenilmetiloximetil-ProDOT (BPMOM-ProDOT), utilizando configuraciones duales, y se registraron sus características electroópticas en función de la densidad de carga redox de sus polímeros constituyentes.

17. Los dispositivos basados en derivados del ProDOT mostraron velocidades de cambio de color de aprox $1 \mathrm{~s}$, con contrastes fotópicos de hasta $52 \%$ para el dispositivo completo. De los resultados obtenidos se concluye que los dispositivos con PDiBz-ProDOT muestran un comportamiento superior a los que utilizan PEDOT ó PBPMOM-ProDOT. Por último, los dispositivos 
estudiados exhibieron unas correctas características de estabilidad en circuito abierto, siendo el estado transparente ligeramente más estable que el coloreado.

18. Los resultados obtenidos en esta trabajo refuerzan la conveniencia de usar valores fotópicos ponderados, cuando las condiciones experimentales lo permitan, en vez de utilizar valores en una sola longitud de onda. Normalmente los valores ópticos en la literatura son obtenidos en el punto de absorción máxima, $\lambda_{\max }$, del sistema, o bien a $555 \mathrm{~nm}$. Sin embargo, debe reconocerse que estos valores pueden diferir sustancialmente de la percepción real del dispositivo en funcionamiento por parte del usuario. Los valores obtenidos a $555 \mathrm{~nm}$ son más consistentes con esta percepción, puesto que el ojo es más sensible a esta longitud de onda, y no diferirán excesivamente de los valores fotópicos (los realmente percibidos por el ojo) mientras que la $\lambda_{\max }$ del dispositivo en cuestión no se aleje demasiado de estos $555 \mathrm{~nm}$. Para dispositivos cuya $\lambda_{\max }$ no se encuentre próxima a $555 \mathrm{~nm}$, se recomienda el uso de los valores fotópicos. 

Índice de tablas 



\section{5 ÍNDICE DE TABLAS}

Tabla 2.3.1 Diferentes composiciones de los geles electrolíticos empleados en la construcción de dispositivos electrocrómicos. Las sustancias referidas son polietilenglicoletileter metacrilato (MA), polietilenglicol diacrilato (DA), 2,2dimetoxi-2-fenil-acetofenona (DMPAP) y trifluorometanosulfonato de litio $\left(\mathrm{LiCF}_{3} \mathrm{SO}_{3}\right)$.

Tabla 3.1.1 Eficiencia de polimerización, definida como cociente entre la carga consumida durante la polimerización respecto a la carga redox consumida por cada película durante su caracterización voltamperométrica, en función del potencial de polimerización para PEDOT y PBEDOT-NMCz

Tabla 3.1.2 Valores de densidad de carga de polimerización, densidad de carga redox (obtenida de la integración de la carga consumida durante una voltamperometría cíclica entre -1.15 y $0.05 \mathrm{~V}$ vs. $\mathrm{Ag} / \mathrm{Ag}^{+}$, velocidad de barrido $100 \mathrm{mVs}^{-1}$ ) y valores fotópicos asociados (calculados en base a los espectros de transmisión obtenidos en $-1.15 \mathrm{~V}$ y $0.05 \mathrm{~V}$ vs. $\mathrm{Ag} / \mathrm{Ag}^{+}$), para una serie de películas de PEDOT depositadas sobre ITO.

Tabla 3.1.3 Valores de contraste máximo obtenible y densidad de carga redox asociada para el PEDOT

Tabla 3.1.4 Valores de densidad de carga de polimerización, densidad de carga redox (obtenida de la integración de la carga consumida durante una voltamperometría cíclica entre -0.75 y $0.75 \mathrm{~V}$ vs. $\mathrm{Ag} / \mathrm{Ag}^{+}$, velocidad de barrido $100 \mathrm{mVs}^{-1}$ ) y valores fotópicos asociados (calculados en base a los espectros de transmisión obtenidos en $-0.75 \mathrm{~V}$ y $0.75 \mathrm{~V}$ vs. $\mathrm{Ag} / \mathrm{Ag}^{+}$), para una serie de películas de PBEDOT-NMCz depositadas sobre ITO.

Tabla 3.1.5 Valores de contraste máximo obtenible y densidad de carga redox asociada para el PBEDOT-NMCZ.

Tabla 3.3.1 Distribución de potenciales entre elctrodo de trabajo y contraelectrrodo para un dispositivo PBEDOT-NMCz/PBEDOT-NMCz, junto con los porcentajes de carga electrocrómica útil y carga no util consumida, para distintos voltajes externos aplicados.

Tabla 3.3.2 Distribución de los potenciales entre electrodo de trabajo y contraelectrodo en función del ratio de carga electrocrómica entre los dos electrodos.

Tabla 3.3.3 Porcentajes de carga útil electrocrómica y carga no útil consumida por dispositivos duales, en función del ratio de carga electrocrómica entre sus electrodos

Tabla 3.4.1 Valores de transmitancia y contraste para combinaciones duales PEDOT / PBEDOT-NMCz, con densidades de carga iguales para las dos películas, en el rango $0-5 \mathrm{mCcm}^{-2}$. Predicción de la contribución de las capas electrocrómicas únicamente, comparada con los valores del conjunto de un dispositivo, incluyendo la absorbancia debida a las capas de cristal y medio electrolítico.

Tabla 3.4.2 Velocidades para el cambio de estado transparente a coloreado y viceversa, para distintas composiciones de geles, en dispositivos PEDOT/PBEDOT-NMCz en estado sólido

Tabla 3.5.1 Valores de contrastes fotópicos máximos para los polímeros PBEDOTNMCz, PEDOT, PBPMOM-ProDOT y PDiBz-ProDOT, y densidades de carga redox asociadas. 

Índice de figuras 



\section{6 ÍNDICE DE FIGURAS}

Figura 1.1.1 a) Dispositivo electrocrómico de transmisión variable integrado en un sistema de visión desarrollado por los grupos del Pr. G.A. Sotzing (Institute of Materials Science, UCONN) y Pr. T.F. Otero (Centro de Electroquímica y Materiales Inteligentes, UPCT) b) Ventana inteligente desarrollada por la compañía Smartglass.

Figura 1.1.2 Esquema utilizado para la definición de absorbancia de un material. Una radiación electromagnética de intensidad inicial $\mathrm{I}_{\mathrm{i}}$ incide sobre el material. Una vez atravesado, la intensidad resultante disminuye hasta un valor de $\mathrm{I}_{\mathrm{f}}$. La absorbancia del material, $\mathrm{A}$, se define como $\mathrm{A}=-\log \left(\mathrm{I}_{\mathrm{f}} / \mathrm{I}_{\mathrm{i}}\right)$.

Figura 1.1.3 Estados electrocrómicos de distintos tipos de polímeros conductores: a) polianilina b) polimetilanilina c) polipirrol d) poli-3-metilpirrol e) poli-3metiltiofeno y f) politiofeno. Para cada polímero, la figura izquierda representa el estado neutro, y la derecha el oxidado [21].

Figura 1.1.4 Estructura química de varios polímeros conductores: poliacetileno, polianilina, polipirrol y politiofeno ....

Figura 1.1.5 Estructuras químicas y niveles energéticos en el proceso de oxidaciónreducción del polietilendioxitiofeno (PEDOT). La figura muestra el proceso de creación-eliminación de niveles energéticos en el intervalo entre banda de valencia y banda de conducción, asociados a polarones y bipolarones, junto con las transiciones energéticas permitidas entre estos nuevos niveles y la modificación del espectro de absorbancia correspondiente. Notación utilizada: $E_{\mathrm{g}}$ : gap energético, difererncia de energía entre banda de valencia y banda de conducción. $\mathrm{E}_{\mathrm{p} 1}$ : nivel energético polarónico enlazante. $\mathrm{E}_{\mathrm{p} 2}$ : nivel energético polarónico antienlazante. $\mathrm{E}_{\mathrm{bp} 1}$ : nivel energético bipolarónico enlazante. $\mathrm{E}_{\mathrm{bp} 2}$ : nivel energético bipolarónico antienlazante. $\mathrm{BP}_{\mathrm{i}}$ : banda energética polarónica. $\mathrm{BBP}_{\mathrm{i}}$ : banda energética bipolarónica

Figura 1.1.6 Estructura química del PEDOT ............................................................ 34

Figura 1.1.7 Estructuras químicas del 3,4-propilendioxitiofeno (ProDOT) (a) y dos monómeros derivados de el, mediante la introducción de grupos sustituyentes, dibencil-ProDOT (b) y bifenilmetiloximetil-ProDOT (c).

Figura 1.2.1 Proceso de oxidación-reducción del PEDOT. La extracción o inserción de electrones (oxidación o reducción), está acompañada por un transporte simultáneo de carga iónica. Estos iones se introducen en (o son expulsados de) la estructura del polímero para mantener la electroneutralidad.

Figura 1.2.2 Esquema de un dispositivo electrocrómico dual. El dispositivo está formado por siete capas. Dos de ellas sirven de substrato para los dos electrodos conductores transparentes (ITO: oxido de indio y estaño). Sobre uno de los electrodos se deposita un material electrocrómico (polímero 1), y sobre el opuesto se deposita otro material (polímero 2) con comportamiento óptico complementario al primero. El dispositivo se completa mediante un medio electrolítico (sólido ó líquido) capaz de proporcionar contacto íonico entre los dos electrodos.

Figura 2.1.1 a) Componentes de la celda electroquímica utilizada para medidas espectro electroquímicas individuales b) Mecanizado de la tapa de teflón para la inserción de los electrodos y borboteo de nitrógeno para desoxigenación c) Vistas lateral y frontal de la celda. El contraelectrodo fue diseñado para no interferir en las medidas espectroscopicas. 
Figura 2.2.1 Evolución del potencial aplicado frente al tiempo para la técnica de voltamperometría cíclica, junto con la respuesta registrada (intensidad frente a potencial)

Figura 2.2.2 Evolución del potencial aplicado frente al tiempo para la técnica de cronoamperometría, junto con la respuesta registrada (intensidad frente a tiempo)

Figura 2.2.3 Esquema del dispositivo experimental. El potenciostato fue usado como fuente de potencial. Ambos terminales de contraelectrodo y electrodo de referencia del potenciostato fueron conectados al contraelectrodo en la celda. El terminal negativo del multímetro se conectó al electrodo de referencia, y el terminal positivo alternativamente al electrodo de trabajo o al contraelectrodo.

Figura 2.2.4 Esquema de funcionamiento de un espectrofotómetro de doble haz. La luz emitida por la fuente de luz es recogida en un monocromador que selecciona la longitud de onda deseada. El haz de luz es dividido en dos; uno atraviesa la sustancia que se define como referencia, y el segundo atraviesa la muestra en estudio. Los dos haces son detectados por los sensores, comparando las intensidades resultantes. Los datos son tratados por el correspondiente software. $\mathrm{L}_{\mathrm{i}}$ con $\mathrm{i}=1,4$, hace referencia a las lentes presentes en el aparato..... 58

Figura 2.3.1 Celda electroquímica usada para la polimerización de los polímeros conductores sobre electrodos de $58 \mathrm{~cm}^{2}$. Las juntas estancas (naranjas) son de silicona, la pieza central (blanca) es de teflón, y las dos piezas restantes son de aluminio. En la figura inferior se observa la celda ensamblada, con el electrodo de referencia.

Figura 2.3.2 Estructura de los polímeros usados en la composición del gel electrolítico

Figura 2.3.3 Corte transversal de un dispositivo electrocrómico dual

PEDOT/PBEDOT-NMCz en estado sólido.

Figura 3.1.1 Estructuras químicas del 3,6-bis(2-(3,4-etilendioxi)tienil)-N-metilcarbazol

(BEDOT-NMCz) y 3,4-etilendioxitiofeno (EDOT). 68

Figura 3.1.2 Espectros de absorbancia del PEDOT y PBEDOT-NMCz en la región visible. Los espectros de PBEDOT-NMCz corresponden a un estado de oxidación de $-0.75 \mathrm{~V}$ (estado neutro) y $0.75 \mathrm{~V}$ (estado oxidado) vs. $\mathrm{Ag} / \mathrm{Ag}^{+}$, mientras que los espectros de PEDOT corresponden a -1.15 (estado neutro) y $0.05 \mathrm{~V}$ (estado oxidado) vs. $\mathrm{Ag} / \mathrm{Ag}^{+}$. Experiencias realizadas en disolución $0.1 \mathrm{M} \mathrm{LiCF}_{3} \mathrm{SO}_{3}$ $(\mathrm{ACN})$.

Figura 3.1.3 Espectros de absorbancia en función del estado de oxidación para los polímeros usados, a) PEDOT y b) PBEDOT-NMCz. Los espectros fueron obtenidos a intervalos de potencial de $0.2 \mathrm{~V}$ entre -1.55 y $0.45 \mathrm{~V}$ para el PEDOT y -1.15 a $1.05 \mathrm{~V}$ para el PBEDOT-NMCz (potenciales referidos a $\mathrm{Ag} / \mathrm{Ag}^{+}$), en disolución $0.1 \mathrm{M} \mathrm{LiCF}_{3} \mathrm{SO}_{3}$ en acetonitrilo.

Figura 3.1.4 Voltamperogramas y sus correspondientes respuestas en absorbancia para PEDOT (registrado en $\lambda_{\max }=620 \mathrm{~nm}$ ), PBEDOT-NMCz $\left(\lambda_{\max }=580 \mathrm{~nm}\right)$ ciclados en $0.1 \mathrm{M} \mathrm{LiCF}_{3} \mathrm{SO}_{3}(\mathrm{ACN})$, velocidad de barrido $100 \mathrm{mVs}^{-1}$, durante 20 ciclos, entre: -1.55 y $0.45 \mathrm{~V}$ vs. $\mathrm{Ag} / \mathrm{Ag}^{+}$(PEDOT), -1.15 y 1.15 (PBEDOT-NMCz). Como contraelectrodo se usó un electrodo de ITO. Por claridad en las gráficas de transmitancia del PBEDOT-NMCz, sólo se representan los ciclos pares. 71

Figura 3.1.5 a) Voltamperograma genérico de un polímero conductor, junto con b) su respuesta en transmitancia registrada en $\lambda_{\max }(580 \mathrm{~nm})$ y c) la densidad de carga consumida, para una película de PBPMOM-ProDOT ciclada en disolución $0.1 \mathrm{M}$ $\mathrm{LiCF}_{3} \mathrm{SO}_{3}$ de acetonitrilo (velocidad de barrido $100 \mathrm{mVs}^{-1}$ ) Se definen las 
magnitudes de carga y potencial electrocrómicos útiles y no útiles, en función del rango de potencial en el que se producen cambios de color.....

Figura 3.1.6 Densidad de carga de polimerización consumida en función del tiempo de polimerización, para distintos potenciales. a) PEDOT, potenciales de polimerización 1, 1.3, 1.6 y $1.9 \mathrm{~V}$ vs. $\mathrm{Ag} / \mathrm{Ag}^{+}$b) PBEDOT-NMCz, potenciales de polimerización $0.4,0.8,1.2$ y $1.6 \mathrm{~V}$ vs. $\mathrm{Ag} / \mathrm{Ag}^{+}$. En ambos casos las polimerizaciones fueron llevadas a cabo sobre electrodo de platino como electrodo de trabajo (con contraelectrodo de platino), en disolución de acetonitrilo $0.1 \mathrm{M}$ $\mathrm{LiCF}_{3} \mathrm{SO}_{3}$ (20 mM EDOT ó $1 \mathrm{mM}$ BEDOT-NMCz). 76

Figura 3.1.7 Voltamperogramas de cuatro series de películas de PEDOT depositadas a distintos tiempos de polimerización ( $\mathrm{t}=2,4,6,8,15$ y $20 \mathrm{~s})$. Los potenciales de polimerización fueron a) $1 \mathrm{~V}$, b) $1.3 \mathrm{~V}$, c) $1.6 \mathrm{~V}$ y d) $1.9 \mathrm{~V}$ vs. $\mathrm{Ag} / \mathrm{Ag}^{+}$. Las polimerizaciones fueron llevadas a cabo sobre electrodo de platino como electrodo de trabajo (con contraelectrodo de platino), en disolución de acetonitrilo $0.1 \mathrm{M}$ $\mathrm{LiCF}_{3} \mathrm{SO}_{3}(20 \mathrm{mM}$ EDOT), y las voltamperometrías se llevaron a cabo en la misma disolución en ausencia de monómero, entre -1.15 y $0.05 \mathrm{~V}$ vs. $\mathrm{Ag} / \mathrm{Ag}^{+} \mathrm{a}$ $100 \mathrm{mVs}^{-1}$.

Figura 3.1.8 Voltamperogramas de cuatro series de películas de PBEDOT-NMCz depositadas a distintos tiempos de polimerización ( $\mathrm{t}=2,4,8,10,15$ y $20 \mathrm{~s})$. Los potenciales de polimerización fueron a) $0.4 \mathrm{~V}$, b) $0.8 \mathrm{~V}$, c) $1.2 \mathrm{~V}$ y d) $1.6 \mathrm{~V}$ vs. $\mathrm{Ag} / \mathrm{Ag}^{+}$. Las polimerizaciones fueron llevadas a cabo sobre electrodo de platino como electrodo de trabajo (con contraelectrodo de platino), en disolución de acetonitrilo $0.1 \mathrm{M} \mathrm{LiCF}_{3} \mathrm{SO}_{3}(1 \mathrm{mM}$ BEDOT-NMCz), y las voltamperometrías se llevaron a cabo en la misma disolución en ausencia de monómero, entre $-0.75 \mathrm{~V} \mathrm{y}$ $0.75 \mathrm{~V}$ vs. $\mathrm{Ag} / \mathrm{Ag}^{+}$a $100 \mathrm{mVs}^{-1}$

Figura 3.1.9 Relación entre la densidad de carga de polimerización consumida y la densidad de carga redox, para distintos potenciales de polimerización. a) PEDOT, potenciales de polimerización 1, 1.3, 1.6 y $1.9 \mathrm{~V}$ vs. $\mathrm{Ag} / \mathrm{Ag}^{+}$b) PBEDOT-NMCz, potenciales de polimerización $0.4,0.8,1.2$ y $1.6 \mathrm{~V} \mathrm{vs.} \mathrm{Ag} / \mathrm{Ag}^{+}$. En ambos casos las polimerizaciones fueron llevadas a cabo sobre electrodo de platino como electrodo de trabajo (con contraelectrodo de platino), en disolución de acetonitrilo $0.1 \mathrm{M}$ $\mathrm{LiCF}_{3} \mathrm{SO}_{3}(20 \mathrm{mM}$ EDOT ó $1 \mathrm{mM}$ BEDOT-NMCz).

Figura 3.1.10 Densidad de carga de polimerización consumida en función del tiempo de polimerización a) PEDOT, potencial de polimerización $1.3 \mathrm{~V}$ vs. $\mathrm{Ag} / \mathrm{Ag}^{+}$b) PBEDOT-NMCz, potencial de polimerización $0.65 \mathrm{~V}$ vs. Ag/Ag+. En ambos casos las polimerizaciones fueron llevadas a cabo sobre ITO como electrodo de trabajo (con contraelectrodo de platino), en disolución de acetonitrilo $0.1 \mathrm{M} \mathrm{LiCF}_{3} \mathrm{SO}_{3}(20$ $\mathrm{mM}$ EDOT ó $1 \mathrm{mM}$ BEDOT-NMCz).

Figura 3.1.11 Relación entre la densidad de carga de polimerización consumida y la densidad de carga redox de películas de a) PEDOT, potencial de polimerización $1.3 \mathrm{~V}$ vs. $\mathrm{Ag} / \mathrm{Ag}^{+}$b) PBEDOT-NMCz, potencial de polimerización $0.65 \mathrm{~V}$ vs. $\mathrm{Ag} / \mathrm{Ag}^{+}$. En ambos casos las polimerizaciones fueron llevadas a cabo sobre ITO como electrodo de trabajo (con contraelectrodo de platino), en disolución de acetonitrilo $0.1 \mathrm{M} \mathrm{LiCF}_{3} \mathrm{SO}_{3}$ (20 mM EDOT ó $1 \mathrm{mM}$ BEDOT-NMCz).

Figura 3.1.12 Eficiencia culómbica, definida como el cociente porcentual entre la carga redox anódica y catódica, obtenida a partir de las correspondientes voltamperometrías cíclicas, para películas de PEDOT y PBEDOT-NMCz, polimerizadas a tiempos crecientes. (PEDOT, potencial de polimerización $1.3 \mathrm{~V}$ vs. $\mathrm{Ag} / \mathrm{Ag}^{+}$y PBEDOT-NMCz, potencial de polimerización $0.65 \mathrm{~V}$ vs. $\mathrm{Ag} / \mathrm{Ag}^{+}$) En ambos casos las polimerizaciones fueron llevadas a cabo sobre ITO como 
electrodo de trabajo (con contraelectrodo de platino), en disolución de acetonitrilo $0.1 \mathrm{M} \mathrm{LiCF}_{3} \mathrm{SO}_{3}(20 \mathrm{mM}$ EDOT ó $1 \mathrm{mM}$ BEDOT-NMCz) y las voltamperometrías se llevaron a cabo en la misma disolución en ausencia de monómero. 84

Figura 3.1.13 Densidades de carga anódicas y catódicas, junto con la diferencia entre ambos valores, obtenidas a partir de las voltamperometrías cíclicas (entre -1.15 y $0.05 \mathrm{~V}$ vs. $\mathrm{Ag} / \mathrm{Ag}^{+}$) de películas de PEDOT polimerizadas a distintos tiempos. Las polimerizaciones fueron llevadas a cabo sobre ITO como electrodo de trabajo (con contraelectrodo de platino), en disolución de acetonitrilo $0.1 \mathrm{M} \mathrm{LiCF}_{3} \mathrm{SO}_{3}(20 \mathrm{mM}$ EDOT) y las voltamperometrías se llevaron a cabo en la misma disolución en ausencia de monómero.

Figura 3.1.14 Relación entre densidad de carga redox y transmitancia fotópica para películas de PEDOT depositadas sobre ITO. Potencial de polimerización $1.3 \mathrm{~V}$ vs. $\mathrm{Ag} / \mathrm{Ag}^{+}$en disolución $20 \mathrm{mM}$ EDOT $0.1 \mathrm{M} \mathrm{LiCF}_{3} \mathrm{SO}_{3}$ (acetonitrilo). Obtención de valores de carga redox a través de voltamperometría cíclica entre -1.15 y $0.05 \mathrm{~V}$ vs. $\mathrm{Ag} / \mathrm{Ag}^{+}$en la misma disolución en ausencia de monómero, velocidad de barrido $100 \mathrm{mVs}^{-1}$. Valores ópticos obtenidos a través de espectros realizados en $-1.15 \mathrm{~V} \mathrm{y}$ $0.05 \mathrm{~V}$ vs. $\mathrm{Ag} / \mathrm{Ag}^{+}$. 90

Figura 3.1.15 Relación entre densidad de carga redox y transmitancia fotópica para películas de PBEDOT-NMCz depositadas sobre ITO. Potencial de polimerización $0.65 \mathrm{~V}$ vs. $\mathrm{Ag} / \mathrm{Ag}^{+}$en disolución $1 \mathrm{mM}$ BEDOT-NMCz $0.1 \mathrm{M} \mathrm{LiCF}_{3} \mathrm{SO}_{3}$ (Acetonitrilo). Obtención de valores de carga redox a través de voltamperometría cíclica entre -0.75 y $0.75 \mathrm{~V}$ vs. $\mathrm{Ag} / \mathrm{Ag}^{+}$en la misma disolución en ausencia de monómero, velocidad de barrido $100 \mathrm{mVs}^{-1}$. Valores ópticos obtenidos a través de espectros realizados en $-0.75 \mathrm{~V}$ y $0.75 \mathrm{~V}$ vs. $\mathrm{Ag} / \mathrm{Ag}^{+}$.

Figura 3.2.1 Esquema teórico de intensidades inicial y final para sistemas de capas individuales y sistemas bicapa.

Figura 3.2.2 Relaciones lineales entre absorbancia en los estados transmisivos (claros) y no transmisivos (oscuros) para películas de a) PEDOT y b) PBEDOT-NMCz, en función de la carga redox electrocrómica de la película. Conversión de los valores a transmitancias, para c) PEDOT y d) PBEDOT-NMCz. Los valores de contraste son obtenidos por diferencia entre valores de transmitancia en el estado claro y oscuro.

Figura 3.2.3 Contribución de una capa de absorbancia fija (absorbancia fotópica 0.07) a los valores ópticos fotópicos del PEDOT en función de la densidad de carga redox.

a) Efecto en los valores de absorbancia. b) Efecto en los valores de transmitancia.

c) Efecto en los valores de contraste.

Figura 3.2.4 Contribución de capas de absorbancia variable a los valores ópticos fotópicos del PEDOT en función de la densidad de carga redox para dos supuestos con diferentes valores. Capa 1: Absorbancia en el estado claro 0.03, oscuro 0.075

a) Efecto en los valores de absorbancia. b) Efecto en los valores de transmitancia.

c) Efecto en los valores de contraste. Capa 2: Absorbancia en el estado claro 0.27, oscuro 0.515 d) Efecto en los valores de absorbancia. e) Efecto en los valores de transmitancia. f) Efecto en los valores de contraste.

Figura 3.2.5 a) Relaciones de absorbancia en estado claro y oscuro en función de la densidad de carga redox, para un sistema dual PEDOT/PBEDOT-NMCz, supuesto que las dos películas tengan la misma densidad de carga redox b) Conversión de los valores de absorbancia dual a \% transmitancia, obteniendo los valores de contraste por medio de su diferencia 
Figura 3.2.6 a) Simulación de los valores de contraste para combinaciones de películas PEDOT/PBEDOT-NMCz, en función de la densidad de carga redox, dentro del rango $0-5 \mathrm{mCcm}^{-2}$ b) Proyección sobre el eje correspondiente a PEDOT........... 112

Figura 3.2.7 Valores ópticos fotópicos para películas de PEDOT y PBEDOT-NMCz. a) Valores de absorbancia en los estados claros y oscuros para películas de PEDOT con densidades de carga $0.74,1.49,2.24,3.63$ y $5.42 \mathrm{mCcm}^{-2}$ b) Valores convertidos a \% transmitancia, y contraste obtenido por diferencia entre los estados claros y oscuros. c) Valores de absorbancia en los estados claros y oscuros para películas de PBEDOT-NMCz con densidades de carga 0.91, 2.23, 2.41, 4.12 y 7.81 $\mathrm{mCcm}^{-2} \mathrm{~d}$ ) Valores convertidos a \% transmitancia, y contraste obtenido por diferencia entre los estados claros y oscuros.

Figura 3.2.8 Valores de contraste fotópico calculados teóricamente para combinaciones duales de películas de PEDOT con densidades de carga redox 0.74, 1.49, 2.24, 3.63 y $5.42 \mathrm{mCcm}^{-2}$ y películas de PBEDOT-NMCz con $0.91,2.23,2.41,4.12$ y $7.81 \mathrm{mCcm}^{-2}$.

Figura 3.2.9 Comparativa entre los valores de contraste de combinaciones duales PEDOT/PBEDOT-NMCz calculados teórica y experimentalmente, para a) densidad de carga para el PBEDOT-NMCz constante $\left(0.91 \mathrm{mCcm}^{-2}\right)$ y densidades de carga de $0.74,1.49,2.24,3.63$ y $5.42 \mathrm{mCcm}^{-2}$ para el PEDOT y b) densidad de carga para el PEDOT constante $\left(2.24 \mathrm{mCcm}^{-2}\right)$ y densidades de carga de 0.91 , $2.23,2.41,4.12$ y $7.81 \mathrm{mCcm}^{-2}$ para el PBEDOT-NMCz.

Figura 3.3.1 Estructuras químicas y notación de los polímeros utilizados. Para las combinaciones duales, el PBEDOT-NMCz fue usado como electrodo de trabajo y el PEDOT como contraelectrodo.

Figura 3.3.2 Caracterización electroquímica de dispositivos PBEDOT-NMCz / PBEDOT-NMCz. a) Voltamperometrías cíclicas de dos películas de PBEDOT$\mathrm{NMCz}$ previas a su utilización como parte de un sistema dual, entre -0.75 and 0.75 $\mathrm{V}$ vs. $\mathrm{Ag} / \mathrm{Ag}^{+}$en disolución de acetonitrilo $0.1 \mathrm{M} \mathrm{LiCF}_{3} \mathrm{SO}_{3}$. Velocidad de barrido $100 \mathrm{mVs}^{-1}$. La figura insertada muestra la respuesta en corriente del dispositivo constituido por esas dos películas, ciclado en la misma disolución. Barrido de potencial aplicado entre -1 y $1.2 \mathrm{~V}$. b) Estados de oxidación simultáneos alcanzados por cada electrodo durante el ciclado del dispositivo entre -1 y $1.2 \mathrm{~V}$.

Figura 3.3.3 Distribución de potenciales vs. $\mathrm{Ag} / \mathrm{Ag}^{+}$entre los dos electrodos constituyentes de dos configuraciones electrocrómicas de un solo polímero: a) ITO/ PEDOT/electrolito/ ITO y b) ITO /PBEDOT-NMCZ /electrolito / ITO. El potencial aplicado entre los dos electrodos fue barrido entre -1 y $1.2 \mathrm{~V}$, comenzando en $0 \mathrm{~V}$, en disolución $0.1 \mathrm{M} \mathrm{LiCF}_{3} \mathrm{SO}_{3}(\mathrm{ACN})$. Velocidad de barrido $100 \mathrm{mVs}^{-1}$.

Figura 3.3.4 Evolución del máximo potencial anódico y catódico alcanzado para cada electrodo durante cinco ciclos, para un sistema PEDOT/PBEDOT-NMCz. El potencial aplicado fue barrido entre -1 y $1.2 \mathrm{~V}$, en disolución de acetonitrilo $0.1 \mathrm{M}$ $\mathrm{LiCF}_{3} \mathrm{SO}_{3}$ (velocidad de barrido $100 \mathrm{mVs}^{-1}$ ).

Figura 3.3.5 Voltamperogramas individuales de las películas constituyentes de un dispositivo PBEDOT-NMCz / PBEDOT-NMCz. — Voltamperograma de control y caracterización de la película usada como $\mathrm{CE}$ realizado previamente al uso de la película en el dispositivo. …….. Voltamperograma de control y caracterización de la película usada como WE realizado previamente al uso de la película en el dispositivo. - - - - Voltamperograma de la película usada como CE reconstruido a través del registro de la evolución de su estado de oxidación durante 
el ciclado del dispositivo. - - - - - Voltamperograma de la película usada como WE reconstruido a través del registro de la evolución de su estado de oxidación durante el ciclado del dispositivo. La gráfica a) corresponde al dispositivo ciclado entre -0.75 y $0.75 \mathrm{~V}, \mathrm{~b}$ ) entre -1 y $1.2 \mathrm{~V}$ y c) entre -1 y $1.5 \mathrm{~V}$. Todos los experimentos fueron llevados a cabo en disolución $0.1 \mathrm{M} \mathrm{LiCF}_{3} \mathrm{SO}_{3}(\mathrm{ACN}) \mathrm{y}$ velocidad de barrido $100 \mathrm{mVs}^{-1}$.

Figura 3.3.6 Voltamperogramas individuales de las películas constituyentes de dispositivos PEDOT / PBEDOT-NMCz. —— Voltamperograma de control y caracterización de la película de PBEDOT-NMCz realizado previamente al uso de la película en el dispositivo. ……... Voltamperograma de control y caracterización de la película de PEDOT realizado previamente al uso de la película en el dispositivo. - - - " - Voltamperograma de la película de PBEDOT-NMCz reconstruido a través del registro de la evolución de su estado de oxidación durante el ciclado del dispositivo. - - - - Voltamperograma de la película de PEDOT reconstruido a través del registro de la evolución de su estado de oxidación durante el ciclado del dispositivo. La gráfica a) corresponde al dispositivo con ratio entre las cargas consumidas durante los voltamperogramas de caracterización, entre las películas constituyentes, igual a $0.5, \mathrm{~b}$ ) ratio igual a $1.1, \mathrm{c}$ ) ratio igual a $1.6 \mathrm{y} \mathrm{d}$ ) ratio igual a 3.3. Todos los experimentos fueron llevados a cabo en disolución 0.1 $\mathrm{M} \mathrm{LiCF}_{3} \mathrm{SO}_{3}(\mathrm{ACN})$ y velocidad de barrido $100 \mathrm{mVs}^{-1}$.

Figura 3.4.1 Cronoculometrías obtenidas durante la electropolimerización de PEDOT usando un punto de contacto metálico (línea continua), un lateral (línea de puntos) y el perímetro completo (línea discontinua).

Figura 3.4.2 Dispositivo dual PEDOT//PBEDOT-NMCz en estado sólido con un área electrocrómica de $\sim 30 \mathrm{~cm}^{2}$ en sus estados transparente (65\% transmitancia) y coloreado $(34 \%)$

Figura 3.4.3 a) Espectros de transmitancia de un dispositivo en sus estados transparente y coloreado en comparación con los b) espectros fotópicos ponderados............ 144

Figura 3.4.4 Voltamperograma (figura superior) y cambios en transmitancia a $555 \mathrm{~nm}$ (figura inferior) de un dispositivo dual PEDOT//PBEDOT-NMCz en estado sólido medidos en función del potencial aplicado (referenciado respecto al electrodo de PEDOT). Velocidad de barrido $100 \mathrm{mVs}^{-1}$

Figura 3.4.5 Evoluciones de la transmitancia a $555 \mathrm{~nm}$ en función del potencial aplicado a distintas velocidades de barrido $\left(10,20,40,80,160\right.$ y $\left.320 \mathrm{mVs}^{-1}\right)$, para a) un dispositivo en estado sólido (composición del gel $70 \% \mathrm{DA} / 30 \% \mathrm{PC}$, ver tabla 2.3.1), y b) un dispositivo con medio electrolítico líquido (10 $\mathrm{mM} \mathrm{LiCF}_{3} \mathrm{SO}_{3}$ en carbonato de propileno).

Figura 3.4.6 Cambio en el \% transmitancia a $555 \mathrm{~nm}$ durante la aplicación de saltos de potencial entre -1 y $1.4 \mathrm{~V}$, para dispositivos conteniendo $100 \% \mathrm{MA}$ y $100 \%$ DA en la composición de sus electrolitos (ver tabla 2.3.1 para la composición de los geles)

Figura 3.4.7 Cambio en el \% transmitancia a $555 \mathrm{~nm}$ durante la aplicación de saltos de potencial entre -1 y $1.4 \mathrm{~V}$, para dispositivos conteniendo distintas composiciones de geles electrolíticos basados en a) MA y b) DA (ver tabla 2.3.1. para las composiciones de los geles)

Figura 3.4.8 Voltamperogramas cíclicos de un dispositivo electrocrómico en estado sólido con diferentes resistencias de valor conocido: $\infty \Omega$ ( i.e. dispositivo $\sin$ resistencia añadida), $2.2 \mathrm{k} \Omega, 1 \mathrm{k} \Omega, 270 \Omega, 100 \Omega$ y $25 \Omega$ dispuestas en paralelo. Las primeras tres se muestran ampliadas por claridad. 
Figura 3.4.9 Capacidad de ajuste óptico de un dispositivo en estado sólido PEDOT/PBEDOT-NMCz a diferentes potenciales, junto con la capacidad de retención de esos estados en condiciones de circuito abierto (La transmitancia fue obtenida a $555 \mathrm{~nm}$ )

Figura 3.5.1 Estructuras químicas de (a) DiBz-ProDOT (b) BPMOM-ProDOT y (c) BEDOT-NMCz.....

Figura 3.5.2 a) Voltamperograma correspondiente a una película de PBPMOMProDOT con una densidad de carga $0.87 \mathrm{mCcm}^{-2}$, ciclada en disolución de acetonitrilo $0.1 \mathrm{M} \mathrm{LiCF}_{3} \mathrm{SO}_{3}$, a $100 \mathrm{mVs}^{-1}$, entre -0.8 y $0.4 \mathrm{~V}$ vs. $\mathrm{Ag} / \mathrm{Ag}^{+}$b) Espectros obtenidos en estado neutro $(-0.8 \mathrm{~V})$ y oxidado $(0.4 \mathrm{~V})$ en el rango del visible c) Voltamperograma correspondiente a una película de PDiBz-ProDOT con una densidad de carga $0.76 \mathrm{mCcm}^{-2}$, ciclada en disolución de acetonitrilo $0.1 \mathrm{M}$ $\mathrm{LiCF}_{3} \mathrm{SO}_{3}$, a $100 \mathrm{mVs}^{-1}$, entre -0.8 y $0.4 \mathrm{~V}$ vs. $\mathrm{Ag} / \mathrm{Ag}^{+}$d) Espectros obtenidos en estado neutro $(-0.8 \mathrm{~V})$ y oxidado $(0.4 \mathrm{~V})$ en el rango del visible.

Figura 3.5.3 Relación entre densidad de carga redox y absorbancia fotópica para películas de a) PBPMOM-ProDOT y b) PDiBz-ProDOT depositadas sobre ITO. En los dos casos, las condiciones experimentales fueron: potencial de polimerización $1.3 \mathrm{~V}$ vs. $\mathrm{Ag} / \mathrm{Ag}^{+}$en disolución $5 \mathrm{mM}$ de monómero, $0.1 \mathrm{M}$ $\mathrm{LiCF}_{3} \mathrm{SO}_{3}$ (acetonitrilo). Obtención de valores de carga redox a través de voltamperometría cíclica entre -0.8 y $0.4 \mathrm{~V}$ vs. $\mathrm{Ag} / \mathrm{Ag}^{+}$en la misma disolución en ausencia de monómero, velocidad de barrido $100 \mathrm{mVs}^{-1}$. Valores ópticos obtenidos a través de espectros realizados en $-0.8 \mathrm{~V}$ y $0.4 \mathrm{~V}$ vs. $\mathrm{Ag} / \mathrm{Ag}^{+}$.... 161

Figura 3.5.4 Relaciones de transmitancia en estado claro y oscuro en función de la densidad de carga redox, supuesto que las dos películas tengan la misma densidad de carga redox, obteniendo los valores de contraste por medio de su diferencia, para los sistemas duales a) PBPMOM-ProDOT/PBEDOT-NMCz, y b) PDiBzProDOT/PBEDOT-NMCZ.

Figura 3.5.5 Espectros de transmitancia de dispositivos basados en a) PBPMOM-

ProDOT/PBEDOT-NMCz (densidad de carga redox del dispositivo $=1.50$

$\mathrm{mC} / \mathrm{cm}^{2}$ ) y b) PDiBz-ProDOT/PBEDOT-NMCz (densidad de carga redox $=1.56$

$\mathrm{mC} / \mathrm{cm}^{2}$ ) en función del potencial aplicado.

Figura 3.5.6 Voltamperometrías cíclicas de dispositivos electrocrómicos duales con (a) PBPMOM-ProDOT (densidad de carga redox del dispositivo $=1.50 \mathrm{mC} / \mathrm{cm}^{2}$ )y (b) PDiBz-ProDOT (densidad de carga redox del dispositivo $=1.56 \mathrm{mC} / \mathrm{cm}^{2}$ ) como polímeros coloreables catódicamente y PBEDOT-NMCz como polímero coloreable anódicamente, a una velocidad de barrido de $100 \mathrm{mVs}^{-1}$. Los potenciales están referidos al electrodo cubierto de ProDOT en cada caso.

Figura 3.5.7 a) Espectro fotópico en el visible y b) transmitancia fotópica ponderada entre $-1.5 \mathrm{y}+0.9 \mathrm{~V}$ para un dispositivo electrocrómico dual en estado sólido. Configuración del dispositivo: Vidrio/ITO/PBPMOM-ProDOT/Gelelectrolítico/PBEDOT-NMCz/ITO/Vidrio (Las fotografías insertadas muestran el dispositivo en sus distintos estados ópticos, con un área activa de $3 \mathrm{~cm} \times 2.4 \mathrm{~cm}$ ).

Figura 3.5.8 Memoria en circuito abierto para un dispositivo PDiBz-

ProDOT/PBEDOT-NMCz (densidad de carga redox $=0.80 \mathrm{mCcm}^{-2}$ ) en función del tiempo. Los valores de $\% \mathrm{~T}$ fueron fotópicamente ponderados. 



\section{$\underline{\text { Referencias }}$}





\section{Referencias}

1. Monk P.M.S, Mortimer R.J., Rosseinsky D.R., Electrochromism: Fundamentals and applications, VCH, Weinheim, 1995.

2. A. A. Argun, P. H. Aubert, B. C. Thompson, I. Schwendeman, C. L. Gaupp, J. Hwang, N. J. Pinto, D. B. Tanner, A. G. Macdiarmid, J. R. Reynolds, Chemistry of Materials, 16 (2004) 4401-4412.

3. C. G. Granqvist, Solar Energy Materials and Solar Cells, 60 (2000) 201-262.

4. K. Hyodo, Electrochimica Acta, 39 (1994) 265-272.

5. R. J. Mortimer, Electrochimica Acta, 44 (1999) 2971-2981.

6. D. R. Rosseinsky, R. J. Mortimer, Advanced Materials, 13 (2001) 783-793.

7. P. R. Somani, S. Radhakrishnan, Materials Chemistry and Physics, 77 (2003) 117-133.

8. J. C. Gustafssoncarlberg, O. Inganas, M. R. Andersson, C. Booth, A. Azens, C. G. Granqvist, Electrochimica Acta, 40 (1995) 2233-2235.

9. R. D. Rauh, Electrochimica Acta, 44 (1999) 3165-3176.

10. A. L. Larsson, G. A. Niklasson, Materials Letters, 58 (2004) 2517-2520.

11. P. Chandrasekhar, B. J. Zay, T. McQueeney, G. C. Birur, V. Sitaram, R. Menon, M. Coviello, R. L. Elsenbaumer, Synthetic Metals, 155 (2005) 623-627.

12. H. Pages, P. Topart, D. Lemordant, Electrochimica Acta, 46 (2001) 2137-2143.

13. I. Schwendeman, J. Hwang, D. M. Welsh, D. B. Tanner, J. R. Reynolds, Advanced Materials, 13 (2001) 634-637.

14. A. Azens, C. G. Granqvist, Journal of Solid State Electrochemistry, 7 (2003) 6468.

15. C. G. Granqvist, E. Avendano, A. Azens, Thin Solid Films, 442 (2003) 201-211.

16. B. W. Faughnan, R. S. Crandall, Topics in Applied Physics, 40 (1980) 181-211.

17. S. F. Cogan, N. M. Nguyen, S. J. Perrotti, R. D. Rauh, Journal of Applied Physics, 66 (1989) 1333-1337.

18. A. Talledo, C. G. Granqvist, Journal of Applied Physics, 77 (1995) 4655-4666.

19. N. Ozer, Thin Solid Films, 305 (1997) 80-87.

20. J. Livage, Chemistry of Materials, 3 (1991) 578-593. 
21. T. F. Otero, I. Boyano, Chemphyschem, 4 (2003) 868-872.

22. A. A. Argun, A. Cirpan, J. R. Reynolds, Advanced Materials, 15 (2003) 13381341.

23. Hadziioannou G., Van Hutten P.F., Semiconducting polymers: Chemistry, physics and engineering, Wiley-VCH, Weinheim, 2000.

24. B. Scrosati, Applications of electroactive polymers, Chapman \& Hall, London, 1993.

25. E. M. Genies, J. M. Pernaut, Journal of Electroanalytical Chemistry, 191 (1985) 111-126.

26. F. Genoud, M. Guglielmi, M. Nechtschein, E. Genies, M. Salmon, Physical Review Letters, 55 (1985) 118-121.

27. C. Carlberg, X. W. Chen, O. Inganas, Solid State Ionics, 85 (1996) 73-78.

28. J. Hwang, D. B. Tanner, I. Schwendeman, J. R. Reynolds, Physical Review B, $67(2003)$

29. R. C. D. Peres, V. F. Juliano, M. A. DePaoli, S. Panero, B. Scrosati, Electrochimica Acta, 38 (1993) 869-876.

30. R. H. Baughman, Makromolekulare Chemie-Macromolecular Symposia, 51 (1991) 193-215.

31. S. Kuwabata, H. Yoneyama, H. Tamura, Bulletin of the Chemical Society of Japan, 57 (1984) 2247-2253.

32. T. Kobayashi, H. Yoneyama, H. Tamura, Journal of Electroanalytical Chemistry, 161 (1984) 419-423.

33. T. Kobayashi, H. Yoneyama, H. Tamura, Journal of Electroanalytical Chemistry, 177 (1984) 281-291.

34. J. C. Lacroix, K. K. Kanazawa, A. Diaz, Journal of the Electrochemical Society, 136 (1989) 1308-1313.

35. G. Heywang, F. Jonas, Advanced Materials, 4 (1992) 116-118.

36. S. Kirchmeyer, K. Reuter, Journal of Materials Chemistry, 15 (2005) 20772088.

37. Y. H. Ha, N. Nikolov, S. K. Pollack, J. Mastrangelo, B. D. Martin, R. Shashidhar, Advanced Functional Materials, 14 (2004) 615-622.

38. K. Gurunathan, A. V. Murugan, R. Marimuthu, U. P. Mulik, D. P. Amalnerkar, Materials Chemistry and Physics, 61 (1999) 173-191.

39. Q. B. Pei, G. Zuccarello, M. Ahlskog, O. Inganas, Polymer, 35 (1994) 13471351. 
40. G. A. Sotzing, J. R. Reynolds, P. J. Steel, Chemistry of Materials, 8 (1996) 882889.

41. B. L. Groenendaal, F. Jonas, D. Freitag, H. Pielartzik, J. R. Reynolds, Advanced Materials, 12 (2000) 481-494.

42. B. Bingol, P. Camurlu, L. Toppare, Journal of Applied Polymer Science, 100 (2006) 1988-1994.

43. E. Sahin, P. Camurlu, L. Toppare, V. M. Mercore, L. Cianga, Y. Yagci, Journal of Electroanalytical Chemistry, 579 (2005) 189-197.

44. E. Sahin, P. Camurlu, L. Toppare, V. M. Mercore, I. Cianga, Y. Yagci, Polymer International, 54 (2005) 1599-1605.

45. O. Turkarslan, A. Erden, E. Sahin, L. Toppare, Journal of Macromolecular Science-Pure and Applied Chemistry, A43 (2006) 115-128.

46. U. H. Yildiz, E. Sahin, I. M. Akhmedov, C. Tanyeli, L. Toppare, Journal of Polymer Science Part A-Polymer Chemistry, 44 (2006) 2215-2225.

47. B. Sankaran, J. R. Reynolds, Macromolecules, 30 (1997) 2582-2588.

48. M. Dietrich, J. Heinze, G. Heywang, F. Jonas, Journal of Electroanalytical Chemistry, 369 (1994) 87-92.

49. K. Krishnamoorthy, A. V. Ambade, M. Kanungo, A. Q. Contractor, A. Kumar, Journal of Materials Chemistry, 11 (2001) 2909-2911.

50. A. Kumar, D. M. Welsh, M. C. Morvant, F. Piroux, K. A. Abboud, J. R. Reynolds, Chemistry of Materials, 10 (1998) 896-902.

51. S. P. Mishra, R. Sahoo, A. V. Ambade, A. Q. Contractor, A. Kumar, Journal of Materials Chemistry, 14 (2004) 1896-1900.

52. S. P. Mishra, K. Krishnamoorthy, R. Sahoo, A. Kumar, Journal of Polymer Science Part A-Polymer Chemistry, 43 (2005) 419-428.

53. E. Smela, Advanced Materials, 15 (2003) 481-494.

54. K. Kaneto, M. Kaneko, Y. Min, A. G. Macdiarmid, Synthetic Metals, 71 (1995) 2211-2212.

55. L. Bay, K. West, P. Sommer-Larsen, S. Skaarup, M. Benslimane, Advanced Materials, 15 (2003) 310-313.

56. R. H. Baughman, Synthetic Metals, 78 (1996) 339-353.

57. T. F. Otero, E. Angulo, J. Rodriguez, C. Santamaria, Journal of Electroanalytical Chemistry, 341 (1992) 369-375.

58. I. Schwendeman, R. Hickman, G. Sonmez, P. Schottland, K. Zong, D. M. Welsh, J. R. Reynolds, Chemistry of Materials, 14 (2002) 3118-3122. 
59. S. A. Sapp, G. A. Sotzing, J. L. Reddinger, J. R. Reynolds, Advanced Materials, 8 (1996) 808-\&.

60. S. A. Sapp, G. A. Sotzing, J. R. Reynolds, Chemistry of Materials, 10 (1998) 2101-2108.

61. M. A. De Paoli, A. F. Nogueira, D. A. Machado, C. Longo, Electrochimica Acta, 46 (2001) 4243-4249.

62. W. E. Price, C. O. Too, G. G. Wallace, D. Zhou, Synthetic Metals, 102 (1999) 1338-1341.

63. A. C. Partridge, Electrochimica Acta, 40 (1995) 1199-1202.

64. T. F. Otero, M. J. Ariza, Journal of Physical Chemistry B, 107 (2003) 1395413961.

65. C. Ehrenbeck, K. Juttner, Electrochimica Acta, 41 (1996) 1815-1823.

66. C. Ehrenbeck, K. Juttner, Electrochimica Acta, 41 (1996) 511-518.

67. Y. Gofer, H. Sarker, J. G. Killian, T. O. Poehler, P. C. Searson, Applied Physics Letters, 71 (1997) 1582-1584.

68. K. H. An, K. K. Jeon, J. K. Heo, S. C. Lim, D. J. Bae, Y. H. Lee, Journal of the Electrochemical Society, 149 (2002) A1058-A1062.

69. T. F. Otero, M. T. Cortes, Advanced Materials, 15 (2003) 279-282.

70. T. W. Lewis, L. A. P. Kane-Maguire, A. S. Hutchison, G. M. Spinks, G. G. Wallace, Synthetic Metals, 102 (1999) 1317-1318.

71. T. W. Lewis, G. M. Spinks, G. G. Wallace, A. Mazzoldi, D. De Rossi, Synthetic Metals, 122 (2001) 379-385.

72. G. A. Sotzing, J. L. Reddinger, A. R. Katritzky, J. Soloducho, R. Musgrave, J. R. Reynolds, Chemistry of Materials, 9 (1997) 1578-1587.

73. A. Kumar, J. R. Reynolds, Macromolecules, 29 (1996) 7629-7630.

74. R. D. Rauh, F. Wang, J. R. Reynolds, D. L. Meeker, Electrochimica Acta, 46 (2001) 2023-2029.

75. B. D. Reeves, B. C. Thompson, K. A. Abboud, B. E. Smart, J. R. Reynolds, Advanced Materials, 14 (2002) 717-+.

76. I. Schwendeman, C. L. Gaupp, J. M. Hancock, L. Groenendaal, J. R. Reynolds, Advanced Functional Materials, 13 (2003) 541-547.

77. G. A. Sotzing, C. A. Thomas, J. R. Reynolds, P. J. Steel, Macromolecules, 31 (1998) 3750-3752. 
78. G. A. Sotzing, J. R. Reynolds, A. R. Katritzky, J. Soloducho, S. Belyakov, R. Musgrave, Macromolecules, 29 (1996) 1679-1684.

79. A. M. Rocco, M. A. DePaoli, A. Zanelli, M. Mastragostino, Electrochimica Acta, 41 (1996) 2805-2816.

80. M. A. DePaoli, A. Zanelli, M. Mastragostino, A. M. Rocco, Journal of Electroanalytical Chemistry, 435 (1997) 217-224.

81. C. Arbizzani, M. Mastragostino, A. Zanelli, Solar Energy Materials and Solar Cells, 39 (1995) 213-222.

82. U. Bulut, A. Cirpan, Synthetic Metals, 148 (2005) 65-69.

83. P. Camurlu, A. Cirpan, L. Toppare, Journal of Electroanalytical Chemistry, 572 (2004) 61-65.

84. D. DeLongchamp, P. T. Hammond, Advanced Materials, 13 (2001) 1455-1459.

85. H. C. Ko, S. A. Park, H. S. Lee, Synthetic Metals, 143 (2004) 31-35.

86. T. H. Lin, K. C. Ho, Solar Energy Materials and Solar Cells, 90 (2006) 506-520.

87. A. Pennisi, F. Simone, G. Barletta, G. Di Marco, M. Lanza, Electrochimica Acta, 44 (1999) 3237-3243.

88. I. L. Skryabin, G. Evans, D. Frost, G. Vogelman, J. M. Bell, Electrochimica Acta, 44 (1999) 3203-3209.

89. S. A. Agnihotry, Pradeep, S. S. Sekhon, Electrochimica Acta, 44 (1999) 31213126.

90. H. J. Byker, Electrochimica Acta, 46 (2001) 2015-2022.

91. P. Georen, G. Lindbergh, Electrochimica Acta, 49 (2004) 3497-3505.

92. D. B. Judd, G. Wyszecki, Color in Business, Science and Industry, John Wiley\& Sons, New york, 1967.

93. S. S. Sekhon, Deepa, S. A. Agnihotry, Solid State Ionics, 136 (2000) 1189-1192.

94. G. Wyszecki, W. S. Stiles, Color Science: Concepts and methods, quantitative data and formulae, John Wiley \& Sons, New York, 1982.

95. F. B. Dias, L. Plomp, J. B. J. Veldhuis, Journal of Power Sources, 88 (2000) 169-191.

96. W. A. Gazotti, M. A. S. Spinace, E. M. Girotto, M. A. De Paoli, Solid State Ionics, 130 (2000) 281-291.

97. W. H. Meyer, Advanced Materials, 10 (1998) 439-448. 
98. H. W. Heuer, R. Wehrmann, S. Kirchmeyer, Advanced Functional Materials, 12 (2002) 89-94.

99. M. K. Song, J. Y. Cho, B. W. Cho, H. W. Rhee, Journal of Power Sources, 110 (2002) 209-215.

100. L. Pigani, A. Heras, A. Colina, R. Seeber, J. Lopez-Palacios, Electrochemistry Communications, 6 (2004) 1192-1198.

101. U. Barsch, F. Beck, Electrochimica Acta, 41 (1996) 1761-1771.

102. J. B. Schlenoff, H. Xu, Journal of the Electrochemical Society, 139 (1992) 23972401.

103. P. A. Christensen, A. Hamnett, Electrochimica Acta, 36 (1991) 1263-1286.

104. X. B. Wan, L. Li, J. B. He, D. S. Zhou, G. Xue, T. W. Wang, Journal of Applied Polymer Science, 86 (2002) 3160-3165.

105. C. C. Chen, K. Rajeshwar, Journal of the Electrochemical Society, 141 (1994) 2942-2946.

106. O. Gunaydin, L. Toppare, Y. Yagci, V. Harabagiu, M. Pintela, B. C. Simionescu, Polymer Bulletin, 47 (2002) 501-508.

107. E. Kalaycioglu, L. Toppare, Y. Yagci, Synthetic Metals, 108 (2000) 1-7.

108. G. A. Sotzing, K. H. Lee, Macromolecules, 35 (2002) 7281-7286.

109. J. Y. Lim, H. C. Ko, H. Lee, Synthetic Metals, 155 (2005) 595-598.

110. L. C. Chen, K. C. Ho, Electrochimica Acta, 46 (2001) 2151-2158.

111. L. C. Chen, K. C. Ho, Electrochimica Acta, 46 (2001) 2159-2166.

112. K. C. Ho, Electrochimica Acta, 44 (1999) 3227-3235.

113. K. C. Ho, Solar Energy Materials and Solar Cells, 56 (1999) 271-280.

114. R. D. Rauh, S. F. Cogan, Journal of the Electrochemical Society, 140 (1993) 378-386.

115. R. K. Gupta, H. Y. Jung, C. M. Whang, Journal of Materials Chemistry, 12 (2002) 3779-3782.

116. P. Damlin, C. Kvarnstrom, A. Ivaska, Journal of Electroanalytical Chemistry, 570 (2004) 113-122.

117. L. M. Abrantes, J. P. Correia, M. Savic, G. Jin, Electrochimica Acta, 46 (2001) 3181-3187.

118. R. C. D. Peres, V. F. Juliano, M. A. DePaoli, S. Panero, B. Scrosati, Electrochimica Acta, 38 (1993) 869-876. 
119. S. Sadki, P. Schottland, N. Brodie, G. Sabouraud, Chemical Society Reviews, 29 (2000) 283-293.

120. A. S. Sarac, G. Sonmez, F. C. Cebeci, Journal of Applied Electrochemistry, 33 (2003) 295-301.

121. U. Barsch, F. Beck, Electrochimica Acta, 41 (1996) 1761-1771.

122. C. C. Chen, K. Rajeshwar, Journal of the Electrochemical Society, 141 (1994) 2942-2946.

123. D. S. Park, Y. B. Shim, S. M. Park, Journal of the Electrochemical Society, 140 (1993) 2749-2752.

124. I. Rodriguez, B. R. Scharifker, J. Mostany, Journal of Electroanalytical Chemistry, 491 (2000) 117-125.

125. J. B. Schlenoff, H. Xu, Journal of the Electrochemical Society, 139 (1992) 23972401.

126. S. Sunde, G. Hagen, R. Odegard, Journal of the Electrochemical Society, 138 (1991) 2561-2566.

127. T. F. Otero, V. Olazabal, Electrochimica Acta, 41 (1996) 213-220.

128. T. F. Otero, M. Marquez, I. J. Suarez, Journal of Physical Chemistry B, 108 (2004) 15429-15433.

129. K.Izutsu, Electrochemistry in nonaqueous solutions, Wiley-VCH, Weinheim, 2002.

130. P.W. Atkins "Química-física" Oxford university press 1978

131. H. Grande, T. F. Otero, Journal of Physical Chemistry B, 102 (1998) 7535-7540.

132. R. S. Draper, M. V. Wood, B. Radmard, K. Mahmud, P. Schuler, G. A. Sotzing, V. Seshadri, W. Mino, J. Padilla, T. F. Otero, Electrochromic variable transmission optical combiner, 2005.

133. T. F. Otero, H. J. Grande, J. Rodriguez, Journal of Physical Chemistry B, 101 (1997) 3688-3697.

134. T. F. Otero, M. Bengoechea, Langmuir, 15 (1999) 1323-1327.

135. N. A. O'Brien, J. Gordon, H. Mathew, B. P. Hichwa, Thin Solid Films, 345 (1999) 312-318.

136. K. H. Heckner, A. Kraft, Solid State Ionics, 152 (2002) 899-905. 